\title{
DIGITALCOMMONS
}

@WAYNESTATE-

Wayne State University

Wayne State University Dissertations

$1-1-2014$

\section{Influence Of Dissolved Hydrogen On The Fatigue Crack Growth Behaviour Of Aisi 4140 Steel}

Varun Ramasagara Nagarajan

Wayne State University,

Follow this and additional works at: http://digitalcommons.wayne.edu/oa_dissertations

\section{Recommended Citation}

Ramasagara Nagarajan, Varun, "Influence Of Dissolved Hydrogen On The Fatigue Crack Growth Behaviour Of Aisi 4140 Steel" (2014). Wayne State University Dissertations. Paper 973. 


\title{
INFLUENCE OF DISSOLVED HYDROGEN ON THE FATIGUE CRACK GROWTH BEHAVIOUR OF AISI 4140 STEEL
}

by

\author{
VARUN RAMASAGARA NAGARAJAN \\ DISSERTATION \\ Submitted to the Graduate School \\ of Wayne State University, \\ Detroit, Michigan \\ in partial fulfillment of the requirements \\ for the degree of \\ DOCTOR OF PHILOSOPHY
}

2014

MAJOR: MATERIALS SCIENCE AND

ENGINEERING

Approved by: 


\section{DEDICATION}

This dissertation work is dedicated to my beloved wife, my lovely mother, my inspiring father, my sweet sister and all my family members and my friends. 


\section{ACKNOWLEDGEMENTS}

This investigation was carried out under a grant from Office of Naval Research (ONR) - ONR grant No: N 00014-09-1-0535. I would like to express my sincere thanks and gratitude to Dr. Asuri K. Vasudevan, Program Manager at ONR for the financial support of this research. I am deeply indebted to my mentor, teacher and advisor Prof. Susil K. Putatunda for his continuous financial and technical support in bringing this work to its current state. This work would have remained only as a research proposal had it not for his efforts to apply, struggle and secure funding for this research. In addition, after advising my Master's degree thesis, I would like to thank him again for the having confidence, faith and patience to assign this project to me.

I want to thank Mr. Eugene Snowden and Mr. Marvin Santure, the technicians at the engineering workshop for their work in preparing all the test samples. I am very thankful to Dr. James M. Boileau and Mr. John Kelly from Ford Motor Company, Dearborn, MI for all their support to allow me to complete part of my work at Ford Research Labs for sharing of knowledge and also for the machining support to make the test samples. I am immensely thankful to Prof. Eswarahalli Sundararajan Dwarakadasa, retired professor at Indian Institute of Science (IISc), Bangalore, India for his advice on my fatigue experiments. I want to express my appreciation to

Dr. Srinivasan Venkatesan who was a part time faculty at Wayne State for his inputs on electrochemical aspects of my studies. I am grateful to my committee members, Prof. Howard W. Matthew, Prof. Golam M. Newaz, Prof. Gavin Lawes and Dr. James M. Boileau for their suggestions, feedback, taking time to review my work and for serving on my graduate defence committee. 
My sincere thanks to my father, G.V. Nagarajan, who initiated and advised me to pursue my Ph.D. degree. This endeavor was possible only due to his belief in my ability and strength. My Ph.D. journey was achievable due to encouragement and emotional support from my mother, R. Vagadevi, whose words helped me a lot during difficult times. I would have given up my degree if not for my mother's strong words of encouragement. The final dissertation report was largely possible, in this final form, only due pressing support from my dear wife Archana Nagarajan. She was instrumental in supporting me throughout my degree and I appreciate her efforts in bearing down on me to complete this report as quickly as possible. The list is not complete without appreciating my sweet sister, Varsha Ramasagara Nagarajan, for her encouragement and support. I want to say thanks to my mother in law, M.S. Sharadamma, and father in law, Prof. K. Nagarajan, for their prayers and blessings. In addition, I am grateful to my grandparents for being very supportive of my career.

This dissertation reached completion only due to the assistance, support and advice from my dear lab mates, Codrick J. Martis and Saranya Panneerselvam. I appreciate their efforts to assist in my experiments, to assist me with my paperwork in my absence and for assistance in organizing the prospectus and final defence meetings. 


\section{FOREWORD}

A lot of work has been done on understanding the influence of hydrogen on the fatigue behaviour of high and low strength steels. Though many studies tend to develop a theoretical equation based mechanism to explain the experimental observations, these equation tend to give unsatisfactory trends when the process conditions are slightly modified than the initial conditions even after accounting for the expected change due to modification of process conditions. Therefore, it is my sincere effort, through this study, to explain my experimental observations and correlate them to any observable evidence which might throw light on the mechanistic process involved. In addition, an honest attempt has been made to explore austempering as a possible route to obtaining high strength steel and verify its susceptibility to hydrogen in a cyclic loading condition. 


\section{TABLE OF CONTENTS}

Dedication

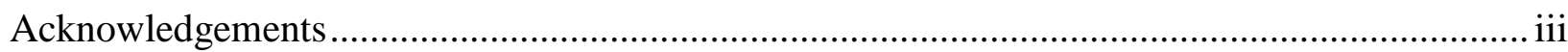

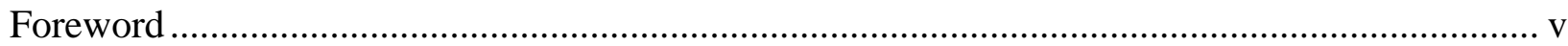

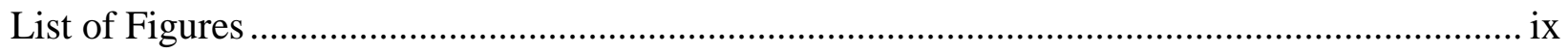

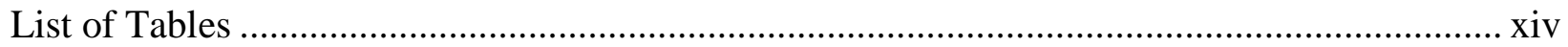

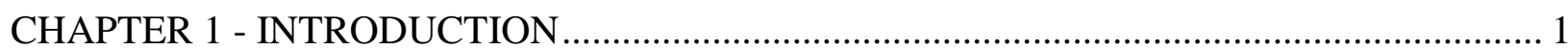

Fatigue Behaviour and Corrosion Fatigue ……………................................................... 1

Stress Corrosion Cracking …………………………................................................... 3

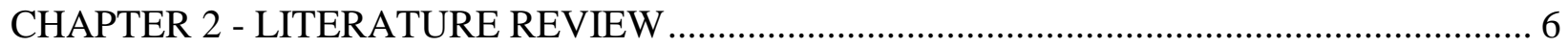

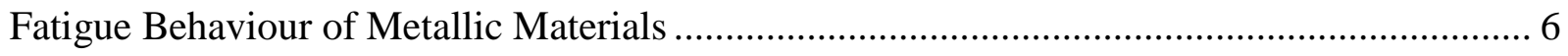

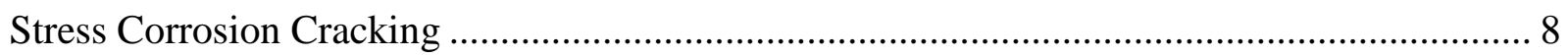

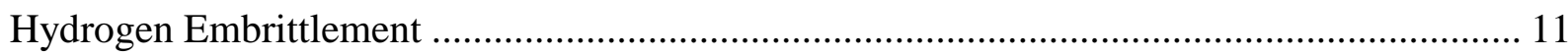

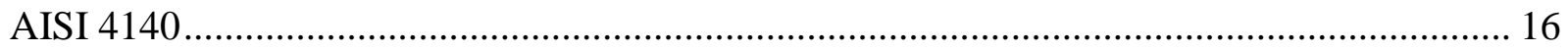

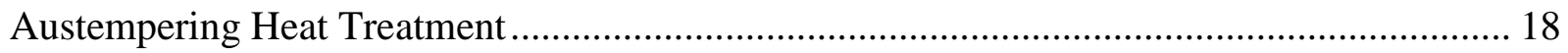

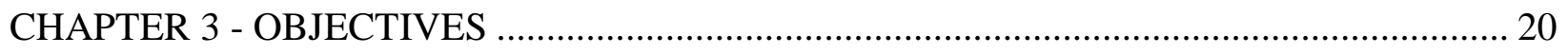

CHAPTER 4 - EXPERIMENTAL MATERIALS AND METHODS ........................................... 21

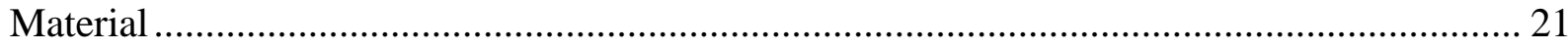

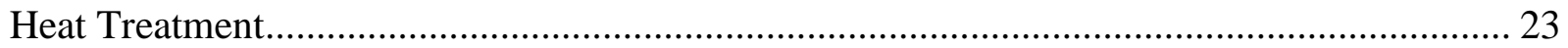

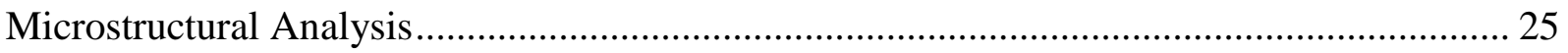


X-Ray Diffraction (XRD) Analysis

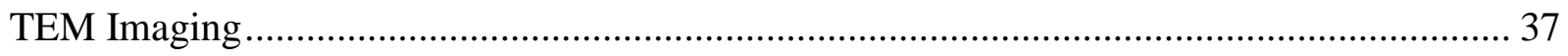

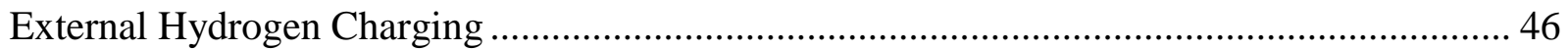

Hydrogen Concentration Analysis (Vacuum Hot Extraction) ........................................... 47

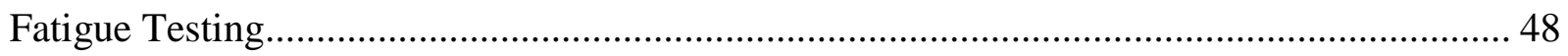

Stress Corrosion Cracking Testing ............................................................................. 49

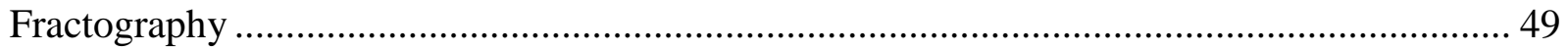

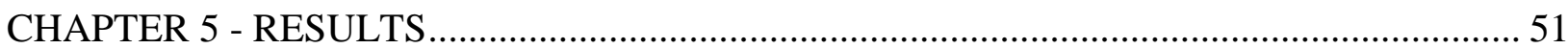

Influence of Time on dissolved hydrogen concentration............................................... 51

Fatigue crack growth behaviour of the material in Annealed (as-received) condition............ 54

Fatigue crack growth behaviour of the material in Austempered Batch - 1 (AB1) condition.. 63

Fatigue crack growth behaviour of the material in Austempered Batch 2 (AB2) condition .... 71

Comparison of Fatigue Crack Growth Behaviour among different heat treatment conditions 80

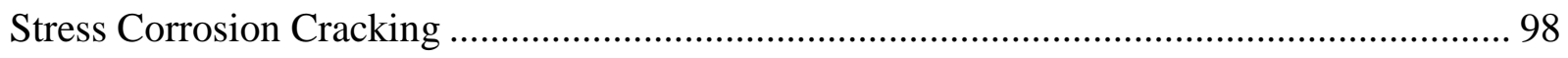

Qualitative mechanism to explain the FCGRs in the Intermediate growth rate $\left(10^{-8} \sim 10^{-7}\right.$

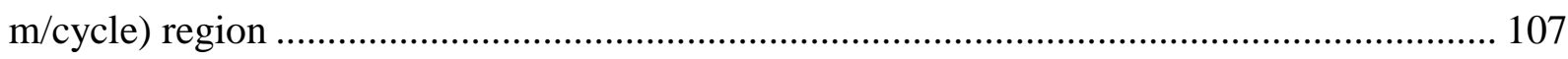

Mechanistic explanation of Fatigue Threshold Stress Intensity Factor $\left(\Delta \mathrm{K}_{\mathrm{th}}\right)$ and Near Threshold Fatigue Crack Growth Rates ..................................................................... 121

Mechanistic explanation of Linear Region Fatigue Crack Growth Rates ........................... 149

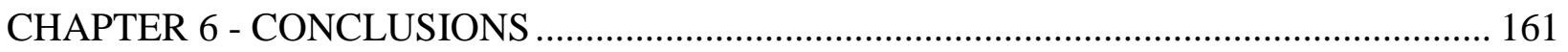




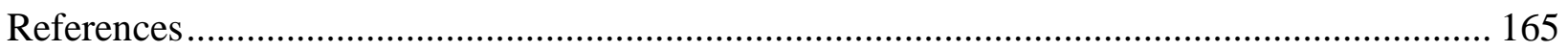

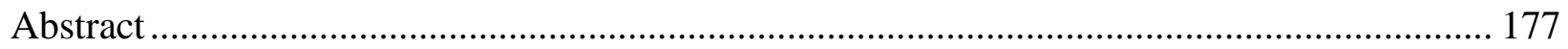

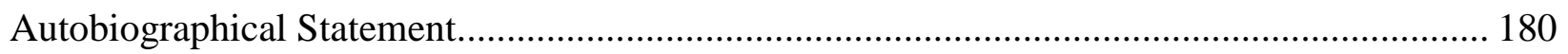




\section{LIST OF FIGURES}

Figure 1: Schematic representation of fatigue crack growth rate vs. stress intensity factor 2

Figure 2: Schematic representation of SCC curve of crack growth rate vs. stress intensity factor[4]

Figure 3: Dimensions of the CT specimen used for fracture toughness $\left(\mathrm{K}_{\mathrm{IC}}\right)$ testing (all dimensions are in inches)

Figure 4: Dimensions of the tensile specimen (all dimensions are in inches)

Figure 5: Microstructure of the annealed sample (Magnification: 1000X)

Figure 6: Microstructure (SEM) and X-ray map of inclusions of the annealed sample (a, b: SEM image - 1000X and 5000X respectively; c, d and e: X-ray map of Fe, $\mathrm{Al}$ and $\mathrm{O}$ respectively at the void location in a).....

Figure 7: Microstructure of the AB1 sample (Magnification: 1000X) 30

Figure 8: Microstructure (SEM) and X-ray maps of the AB1 sample (Magnification: a, b 1000X, 5000X respectively; c - inclusion; d - Fe (Red); e - Mn (Purple); f - S (Yellow); g - Al (Blue) and h - O (green)

Figure 9: Microstructure of the AB2 sample (Magnification: 1000X)

Figure 10: Microstructure (SEM and X-ray maps) of the AB2 sample (Magnification: a, b 1000X, 5000X respectively; c - inclusion; d - Fe (Red); e - Mn (Blue); f - S (Green); $\mathrm{g}$ - $\mathrm{Al}$ (Green dot) and $\mathrm{h}$ - $\mathrm{O}$ (orange dot)

Figure 11: XRD peak identification for the 4140 steel samples: Annealed - AI-10 (Blue), Austempered AB1 $\left(349^{\circ} \mathrm{C}\right)$ - HT -2 (Red) and Austempered AB2 $\left(332^{\circ} \mathrm{C}\right)$ - AU 1 (Black)

Figure 12: (a): Bright field image of AB1 material; (b): dark field image of spot $1-\alpha(011)$ reflection; (c): dark field image of spot 2 - $\alpha(121)$ reflection; and (d): dark field image of spot $6-\alpha(110)_{\mathrm{II}}$ [Magnification: $\left.25000 \mathrm{X}\right]$. 
Figure 13: (a): Bright field image of AB2 material; (b): Dark field image of Spot 1 $\alpha(110)$; (c): Dark field image of Spot 4 - $\alpha(200)$ II; and (d): dark field image of Spot 6 - Fe3C(130) [Magnification: 25000X].

Figure 14: Experimental setup of external hydrogen charging..... .47

Figure 15: Comparison of fatigue crack growth rate in the linear region for annealed samples

Figure 16: Fatigue surface images of annealed material in linear region $(\Delta K(\mathrm{SIF})$ are in $\mathrm{MPa} \sqrt{\mathrm{m}}$ ) [Note: Crack propagation from right to left in all images; Magnification: $1000 \mathrm{X}]$.

Figure 17: Comparison of fatigue crack growth rate in the near threshold region for annealed samples

Figure 18: Fatigue surface images of annealed material in threshold region $(\Delta K(\mathrm{SIF})$ are in $\mathrm{MPa} \sqrt{\mathrm{m}}[$ Note: crack propagation from right to left in all images; Magnification: $1000 \mathrm{X}]$

Figure 19: Comparison of fatigue crack growth rates in the linear region for AB1 samples .

Figure 20: Fatigue surface images of $A B 1$ material in linear region $(\Delta K$ (SIF) are in $\mathrm{MPa} \sqrt{\mathrm{m}}$ [Note: Crack propagation from right to left in all images; Magnification: 1000X]

Figure 21: Comparison of fatigue crack growth rate in the near threshold region for AB1 samples

Figure 22: Fatigue surface images of $A B 1$ material in threshold region $(\Delta K$ (SIF) are in $\mathrm{MPa} \sqrt{\mathrm{m}})$ [Note: crack propagation from right to left in all image; Magnification: $1000 \mathrm{X}]$

Figure 23: Comparison of fatigue crack growth rate in the linear region for AB2 samples.

Figure 24: Fatigue surface images of $A B 2$ material in linear region $(\Delta K$ (SIF) are in $\mathrm{MPa} \sqrt{\mathrm{m}})[$ Note: crack propagation from right to left in all images; Magnification: $1000 \mathrm{X}]$ 
Figure 25: Comparison of fatigue crack growth rate in the near threshold region for AB2 samples

Figure 26: Fatigue surface images of $\mathrm{AB} 2$ material ( $\triangle \mathrm{K}$ (SIF) are in $\mathrm{MPa} \sqrt{\mathrm{m}}$ ) [Note: crack propagation from right to left in all images; Magnification: $1000 \mathrm{X}] . . . . . .78$

Figure 27: Near threshold fatigue crack growth behavior of the material with no exposure to hydrogen charging.....

Figure 28: Near threshold fatigue crack growth behavior of the material with $150 \mathrm{hrs}$ of exposure to hydrogen

Figure 29: Near threshold fatigue crack growth behavior of the material with $200 \mathrm{hrs}$ exposure to hydrogen

Figure 30: Near threshold fatigue crack growth behavior of the material with $250 \mathrm{hrs}$ exposure to hydrogen

Figure 31: Comparison of the fatigue crack growth behavior of the annealed and austempered samples with no exposure to hydrogen charging

Figure 32: Comparison of the fatigue crack growth behavior of the annealed and austempered samples with $150 \mathrm{hrs}$ of exposure to hydrogen

Figure 33: Comparison of the fatigue crack growth behavior of the annealed and austempered samples with $200 \mathrm{hrs}$ of exposure to hydrogen

Figure 34: Comparison of the fatigue crack growth behavior of the annealed and austempered samples with $250 \mathrm{hrs}$ of exposure to hydrogen

Figure 35: SCC behaviour of annealed material at different charging times of dissolved hydrogen (150 hrs - red; 200 hrs - green; 250 hrs - black).....

Figure 36: SCC behaviour of AB1 material at different charging times of dissolved hydrogen (150 hrs - red; 200 hrs - green; 250 hrs - black)....

Figure 37: Influence of Hydrogen Concentration on Incubation period at different stress intensity levels in AB1 material 
Figure 38: Influence of hydrogen concentration (Co) on KISCC (blue - AB1 material (heat treated - HT; red - annealed)

Figure 39: Influence of hydrogen concentration (Co) on da/dt in Region 2 (blue - AB1 material (heat treated - HT); red - annealed)

Figure 40: Classification of plateau region by McEvily and Wei [97, 98]

Figure 41: Comparison of FCGRs in Annealed material in Intermediate region $(10-8 \sim 10-7 \mathrm{~m} /$ cycle $)$.

Figure 42: Fatigue surface images of annealed material ( $\Delta \mathrm{K}$ (SIF) are in MPa $\sqrt{\mathrm{m}}$ ) [Note: Crack propagation from right to left in all images; Magnification: 1000X]

Figure 43: Comparison of FCGRs in $\mathrm{AB} 1$ material in Intermediate region $(10-8 \sim 10-7 \mathrm{~m} /$ cycle $)$.

Figure 44: Fatigue surface images of $\mathrm{AB} 1$ material $(\Delta \mathrm{K}$ (SIF) are in $\mathrm{MPa} \sqrt{\mathrm{m}})$ [Note: Crack propagation from right to left in all images; Magnification: $1000 \mathrm{X}]$....117

Figure 45: Comparison of FCGRs in AB2 material in Intermediate region (10-8 10-7 $\mathrm{m} /$ cycle).

Figure 46: Fatigue surface images of $A B 2$ material ( $\triangle \mathrm{K}$ (SIF) are in MPa $\sqrt{\mathrm{m}}$ ) [Note: Crack propagation from right to left in all images; Magnification: $1500 \mathrm{X}]$

Figure 47: Fatigue surface images of annealed material in threshold region ( $\Delta \mathrm{K}$ (SIF) are in $\mathrm{MPa} \sqrt{\mathrm{m}}$ ) [Note: Crack propagation from right to left in all images; Magnification: 1000X].

Figure 48: Macro photograph of the near threshold region to check for oxide products in annealed material; (a) No hydrogen, (b) $150 \mathrm{hrs,} \mathrm{(c)} 200 \mathrm{hrs}$ and (d) $250 \mathrm{hrs}$ [Note: Crack propagation from right to left in all images; Magnifications: (a) $25 \mathrm{X}$, (b) - (d) 23X]

Figure 49: Fatigue surface images of $A B 1$ material in threshold region ( $\triangle \mathrm{K}$ (SIF) are in $\mathrm{MPa} \sqrt{\mathrm{m}}$ [Note: Crack propagation from right to left in all images; Magnification: $1000 \mathrm{X}]$ 
Figure 50: Banded microstructure of the $\mathrm{AB} 1$ material with $\mathrm{MnS}$ inclusion (bright white elongated feature at lower left section; Magnification: 500X)

Figure 51: EDS map of the banded feature from the fracture surface showing MnS inclusions in $\mathrm{AB} 1$ material

Figure 52: Macro photograph of the near threshold region to check for oxide products in AB1 material; (a) No hydrogen, (b) 150 hrs, (c) 200 hrs and (d) 250 hrs [Note: Crack propagation from right to left in all images; Magnification: 25X]

Figure 53: Fractographs of $\mathrm{AB} 1$ material showing the peak in IG facets at the start of the near threshold region; $\Delta \mathrm{K} \approx 19 \mathrm{MPa} \sqrt{\mathrm{m}}$ [Note: Crack propagation from right to left in all images; Magnification: $1000 \mathrm{X}]$

Figure 54: Crack propagation plane in AB2 material of the sample charged with hydrogen for $200 \mathrm{hrs}$ showing the appearance of shear lips near the crack starter notch (Magnification: 27X)

Figure 55: Fatigue surface images of AB2 material $(\Delta \mathrm{K}$ (SIF) are in $\mathrm{MPa} \sqrt{\mathrm{m}})$ [Note: Crack propagation from right to left in all images; Magnification: $1000 \mathrm{X}] . . .145$

Figure 56: SEM image (Magnification: 1500X) and EDS spectrum of Iron Oxide found in the threshold region of the AB2 sample charged with hydrogen for $250 \mathrm{hrs}$ 146

Figure 57: Fatigue surface images of annealed material in linear region ( $\Delta \mathrm{K}$ (SIF) are in $\mathrm{MPa} \sqrt{\mathrm{m}}$ ) [Note: Crack propagation from right to left in all images; Magnification: 600X: $(\mathrm{k})$ and $1000 \mathrm{X}$ : rest of the images]

Figure 58: Fatigue surface images of $\mathrm{AB} 1$ material in linear region $(\Delta \mathrm{K}$ (SIF) are in $\mathrm{MPa} \sqrt{\mathrm{m}}$ ) [Note: Crack propagation from right to left in all images; Magnification: $1000 \mathrm{X}]$.

Figure 59: Fatigue surface images of $\mathrm{AB} 2$ material in linear region $(\Delta \mathrm{K}(\mathrm{SIF})$ are in $\mathrm{MPa} \sqrt{\mathrm{m}}$ ) [Note: Crack propagation from right to left in all images; Magnification: (c) - 500X, all other images - 1000X] 


\section{LIST OF TABLES}

Table 1: Chemical composition of the material (in wt \%) ....................................................21

Table 2: Mechanical properties of AISI 4140 alloy after heat treatment .................................24

Table 3: Volume fraction of phases (in \%) present in the Annealed condition ............................34

Table 4: Volume fraction of phases present in the Austempered condition ................................35

Table 5: Diffraction indices of AB1 material .....................................................................40

Table 6: Diffraction indexing of AB2 material....................................................................44

Table 7: Influence of charging time on hydrogen concentration ............................................53

Table 8: $\Delta \mathrm{K}_{\mathrm{th}}$ for annealed and heat treated samples without any dissolved hydrogen ..............83

Table 9: $\Delta$ Kth for annealed and heat treated samples for different hydrogen exposure times ......89

Table 10: Comparison of Paris Constants for annealed and austempered samples .....................92

Table 11: Paris constants for different hydrogen exposure time .............................................97

Table 12: KISCC parameter of the annealed material for different hydrogen charging time .....101

Table 13: Values of Monotonic and Cyclic Plastic Zone Size at corresponding SIFs where Maximum Transgranular (TG) features (brittle or ductile) takes place with or without dissolved hydrogen in Annealed Material at Near Threshold FCGRs

Table 14: Values of Monotonic and Cyclic Plastic Zone Size at corresponding SIFs where Maximum Intergranular or Transgranular features (brittle or ductile) takes place with or without dissolved hydrogen in AB1 Material at Near Threshold FCGRs

Table 15: Length of shear lip observed in the transition region (end of intermediate - start of threshold region) in the $\mathrm{AB} 2$ material 
Table 16: Values of Monotonic and Cyclic Plastic Zone Size at corresponding SIFs where Maximum Intergranular or Transgranular features (brittle or ductile) takes place with or without dissolved hydrogen in AB2 Material at Near Threshold FCGRs

Table 17: Paris constants ( $\mathrm{C}$ and $\mathrm{m}$ ) in the annealed material at different hydrogen charging conditions

Table 18: Paris constants $(\mathrm{C}$ and $\mathrm{m})$ in the $\mathrm{AB} 1$ material at different hydrogen charging conditions

Table 19: Paris constants $(\mathrm{C}$ and $\mathrm{m})$ in the $\mathrm{AB} 2$ material at different hydrogen charging conditions 


\section{CHAPTER 1 - INTRODUCTION}

The primary focus of this investigation was to examine the influence of dissolved hydrogen on the stress corrosion cracking and fatigue crack growth behavior on the alloy steel (AISI 4140). The secondary objective was to examine the influence of microstructure on the fatigue crack growth and stress corrosion cracking behaviour of this material.

\section{Fatigue Behaviour and Corrosion Fatigue}

Damage caused due to repetitive or cyclic loading in materials is known as Fatigue. Materials with preexisting flaws or cracks can fail under the influence of cyclic loads often with catastrophic consequence. Under cyclic loading, preexisting flaws present in the structural components can grow and lead ultimately to failure in service. The fatigue crack growth rate (FCGR), (da/dN), has been related to the stress intensity factor (SIF), $(\Delta \mathrm{K})$, and Paris equation [1] has been found very useful to characterize the fatigue crack growth behaviour. The Paris equation relates the fatigue crack growth rate $(\mathrm{da} / \mathrm{dN})$ with the stress intensity range $(\Delta \mathrm{K})$ in the form of a power law:

$$
\frac{d a}{d N}=C(\Delta K)^{m}
$$

Here $\mathrm{C}$ and $\mathrm{m}$ are material constants and $\Delta \mathrm{K}=\mathrm{K}_{\max }-\mathrm{K}_{\min }$, the difference between the maximum $\left(\mathrm{K}_{\max }\right)$ and the minimum $\left(\mathrm{K}_{\min }\right)$ stress intensity factor in a fatigue cycle.

However, when the crack growth rate is plotted against $\Delta \mathrm{K}$ in a log scale it shows three distinct regions. In region $\mathrm{I}$, or the threshold region, the crack growth rate is low and deviates from the Paris equation. In the linear region or region II, the Paris equation is generally obeyed by most materials whereas in the region III or the fast fracture region, the crack growth rate accelerates 
and again deviates from the Paris equation. In addition to all these regions, there is a threshold stress intensity factor $\left(\Delta \mathrm{K}_{\mathrm{th}}\right)$ below which the crack growth rate approaches a zero value. This is illustrated in Figure 1.

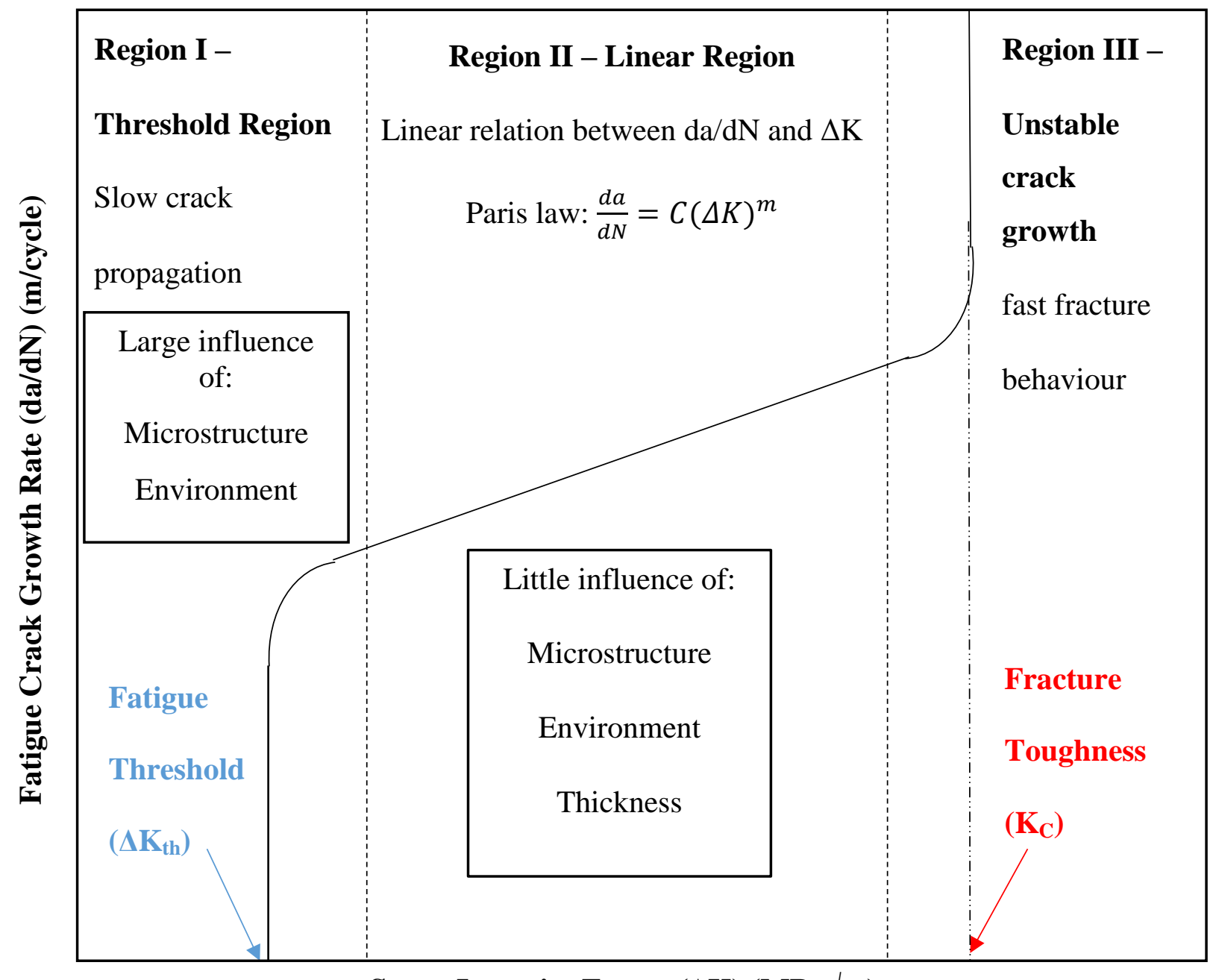

Stress Intensity Factor $(\Delta K)(\mathrm{MPa} \sqrt{ } \mathrm{m})$

Figure 1: Schematic representation of fatigue crack growth rate vs. stress intensity factor

Fatigue threshold is a very important parameter for structural design since structural components designed on the basis of fatigue threshold are expected to survive in service without undergoing any catastrophic failure. This process of crack initiation and crack growth is accelerated in the 
presence of chemically reactive medium or corrosive environment. Corrosion fatigue is thus the material failure mechanism under the combined influence of cyclic loading in service as well as that of a chemically reactive medium or species present in the vicinity or surrounding environment of the material. One of the most commonly encountered and widely studied corrosion fatigue phenomena is that of hydrogen embrittlement (HE) or hydrogen induced cracking (HIC). Understanding how dissolved hydrogen affects the fatigue life of the structural components is crucial for safe life prediction and prevention of fatigue failure in the materials. In addition to this, microstructure can significantly affect the fatigue crack growth rate and fatigue threshold. This is especially important for structural components used in marine or offshore transport industries [2-3] where the dissolved hydrogen can significantly affect the fatigue life of these structural components often leading to unexpected failures in service.

\section{Stress Corrosion Cracking}

Stress corrosion cracking is a very serious problem which drastically reduces the life of the structural components. Under combined actions of stress and corrosion, crack growth rate often accelerates and this can lead to failure of structures, often with catastrophic consequences.

In recent years, the linear elastic fracture mechanics parameter stress intensity factor, $\mathrm{K}$, has been found to be useful in characterizing stress corrosion crack growth behavior of materials. Specifically, the stress intensity factor $(\mathrm{K})$ can be used to describe the crack tip stress-strain field and thus the mechanical driving force necessary for the growth of cracks in stress corrosion cracking situations. 
The stress corrosion crack growth rate $(\mathrm{da} / \mathrm{dt})$ when plotted in terms of $\log (\mathrm{da} / \mathrm{dt})$ versus $\mathrm{K}$ (stress intensity factor) shows three distinct regions as shown in figure 2 . In region I or the linear region, the crack growth rate increases with increase in $\mathrm{K}$, whereas in region II, the steady state crack growth region, the crack growth rate is usually independent of stress intensity factor. In region III, the fast fracture region, the crack growth rate again increases rapidly with increase in stress intensity level. Besides the above three regions, there are two other important parameters in stress corrosion cracking: (a) The incubation period, $t_{i n c}$, defined as the period necessary for the start of crack growth at a fixed value of stress intensity factor in a specific materialenvironment system and (b) the critical stress intensity factor for the onset of crack growth, $\mathrm{K}_{\mathrm{ISCC}}$. This parameter is defined as the value of stress intensity factor below which the crack growth rate will approach a zero value and is considered a material property for a particular material-environment system. All of these parameters have practical significance. Once the appropriate values of these parameters have been determined, they can be used for structural design to establish the critical combination of applied stress and defect size below which stress corrosion cracking will not occur in a given material-environment system. 


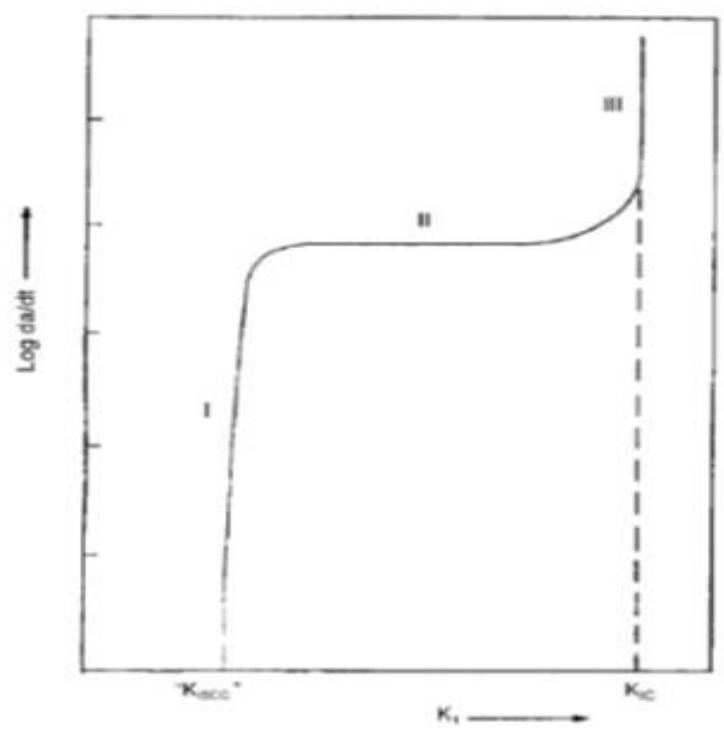

Figure 2: Schematic representation of SCC curve of crack growth rate vs. stress intensity factor [4]

AISI 4140 is used in many naval structural and offshore applications where they are subjected to cyclic and static loading in presence of hydrogen bearing environment. Therefore corrosion fatigue and stress corrosion crack growth behavior of this material is important and needed for safe life prediction and maintaining structural integrity of these components. 


\section{CHAPTER 2 - LITERATURE REVIEW}

\section{Fatigue Behaviour of Metallic Materials}

Fatigue is defined as a term which "applies to changes in properties which can occur in a metallic material due to the repeated application of stresses or strains, although usually this term applies specially to those changes which lead to cracking or failure" as per the report "General Principles for Fatigue Testing of Metals' published in 1964 by the International Organization for Standardization in Geneva [5].

\section{Overview of Fatigue Failures}

In the past one and half century, since the first instance of research on fatigue behaviour of iron hoist chains used in mines by W.A.J. Albert in the 1830s and the first comprehensive railway accident investigation in France in the 1840s which claimed countless lives, there has been a lot of research focused on fatigue behaviour (or influence of cyclic loading) on structural materials [5]. Due to countless number of such research and accidental failure investigations, we have to come to realize the nature and severity of fatigue failures and its impact on human lives. Failure of components in service due to fatigue or failure due to repetitive loading is a very serious problem and can be disastrous when it involves materials used in critical applications up on which human life depends. Under the cyclic loading conditions, preexisting flaws in the material can grow and lead ultimately to service failures. In fatigue loading, there is minimum load $\left(\sigma_{\min }\right)$ or stress intensity $\left(\mathrm{K}_{\min }\right)$ and a maximum load $\left(\sigma_{\max }\right)$ or stress intensity $\left(\mathrm{K}_{\max }\right)$. This difference of maximum and minimum stress $\left(\sigma_{\max }-\sigma_{\min }\right)$ is termed as stress range $(\Delta \sigma)$ whereas stress amplitude $\left(\sigma_{\mathrm{a}}\right)$ is based on $\Delta \sigma / 2$. 
With the advancement in steel technologies and the increased use of alloy steels such as AISI 4140 as a structural member, due to their economic viability and ease of tailoring their material properties with a variety of heat treatment processes, it becomes extremely important to characterize their fatigue properties. A damage tolerant based approach to characterizing fatigue behaviour involves characterizing the fatigue threshold and consequently the fatigue crack growth rate of this material for a given material - environment system. This information is critical in design of structural parts of the material to survive in service without undergoing catastrophic failure.

\section{Types of Fatigue Failures}

1. Mechanical Fatigue are due to fluctuations purely in the externally applied stresses and strains.

2. Creep Fatigue are associated cyclic loads at high temperatures.

3. When the temperature as well as the load fluctuates, it is termed as Thermomechanical Fatigue.

4. Load cycling in the presence of chemically aggressive environment are called as Corrosion Fatigue.

5. Repetitive application of loads along with sliding or rolling contact between materials are called as Sliding and Rolling Contact Fatigue while frictional contact between surfaces gives rise to Fretting Fatigue. 


\section{Approaches to Fatigue Life Predictions [5]}

1. Cyclic loads involving low stress cycles where the material deforms plastically and takes high number of cycles to failure is characterized as High Cycle Fatigue which is based on stress range.

2. Cyclic loads involving high stress cycles with the material undergoing appreciable plastic deformation is termed as Low Cycle Fatigue and the fatigue life is calculated based on strain range.

3. Fatigue life predictions based on useful fatigue life is defined as the number of fatigue cycles to propagate the dominant crack from its initial size to a critical dimension. The critical crack size is usually based on the fracture toughness of the material. This approach is called as Fault Tolerance or Defect Tolerance Approach or Fracture Mechanics based Approach. The underlying requirements, for the applicability of this method to satisfy the linear elastic fracture mechanics criteria, are that the conditions of small scale yielding are met where the plastic zone size at the crack tip or notch is small compared to characteristic dimension of the component.

\section{Stress Corrosion Cracking}

Stress Corrosion Cracking (SCC) is a phenomenon associated with the combination of sustained tensile stress and aggressive (corrosive) environment. The material subjected to static tensile loads in chemically reactive environments fail below the yield strength of the material. These tensile loads may occur in the form of external forces [6], thermal stresses [7-8] and also residual 
stresses [9-10]. The greater the stress occurring at or near the crack tip, the lesser the time required to initiate $\mathrm{SCC}$ (incubation period - $\mathrm{T}_{\text {inc }}$ ).

The kinetics of SCC also depends on the chemical and metallurgical state of the material (i.e. chemical composition, thermal condition, grain size, presence of secondary phases [11-16] and precipitates, etc [17-19]); on environmental conditions (e.g. environment composition, temperature, pressure, $\mathrm{pH}$, electrochemical potential, solution viscosity and mixing, etc.); and on crack geometry and stress state (i.e. uniaxial, triaxial, etc.) [20-21].

Hydrogen Embrittlement (HE) and SCC may be distinguished from each other by consideration of the background information; the extent, nature, and distribution of corrosion; the sites of crack initiation; and other factors. Factors which favor SCC as a failure mechanism include: (1) an inservice environment capable of producing SCC, and conversely, an absence of pre-treatments which could introduce hydrogen into the steel prior to service; (2) multiple cracks initiated from corrosion pits; and (3) corrosion products on the fracture surface, which become thicker closer to the origin. Factors which favor HE include: (1) inadequate baking following coating, or the use of other treatments that could introduce hydrogen into the steel; and (2) exposure of a component to low-humidity air in service [22].

Fractures produced by HE could become corroded after cracking, but such corrosion is generally manifested by patches of rust on both intergranular (IG) and dimpled overload areas rather than by the more uniform, often black, corrosion film found on SCC fractures. HE failures sometimes initiate from subsurface inclusions, but it is often not possible to distinguish between surface initiation sites and initiation sites at small inclusions close to the surface. Moreover, SCC often exhibits more crack branching and less pronounced, partially-formed, dimples than cracking produced by HE. However, the extent of crack branching and dimples also depends on the stress 
intensity at the crack tip, on hydrogen concentration or environment, and on the composition and thermal condition of the steel. Because some of this information is often not known for in-service failures, these features cannot be reliably used to distinguish between HE and SCC [22].Hence the SCC term is often used to describe environmental assisted cracking or hydrogen embrittlement.

An essential step in failure analysis is the determination of the failure mechanism. Identifying whether failure occurred by over load, metallurgical embrittlement or environmental assisted cracking allows the determination of underlining cause of failure and recommendation on proper action to prevent failure recurrence.

The growth of crack during SCC can be either intergranular (IG) [23-24] or trans-granular (TG) [25-27], depending on the alloy, its microstructure, and the environment. However, the crack follows a general macroscopic path that is always normal to the tensile component of stress. While TG failures are less common than the IG ones, both can exist in the same system or even in the same failed part, depending on external conditions. The IG failure mode suggests some inhomogeneity at the grain-boundaries. For example, segregation of $\mathrm{S}$ and $\mathrm{P}$ at grain-boundaries has been observed as the cause of IG SCC of low alloy steels [20].

There are several mechanisms by which SCC can occur in metals and alloys. Among these mechanisms the hydrogen embrittlement [6], adsorption-induced cleavage [28], atomic surface mobility [8-10], film rupture [12], stress-accelerated dissolution [13], film-induced cleavage [14], tunnel pitting [15] and tearing and localized surface plasticity mechanisms [16] are most prominent. There has been some evidence that the solution within the micro volume of the crack becomes acidified, due to hydrolysis reactions similar to those which occur in pits. In case of high strength steels the presence of hydrogen in the crack and the brittle cleavage characteristics 
of TG cracks indicate hydrogen embrittlement (HE) as the mechanism for crack growth during SCC in most cases.

In the case of high strength steels, the mechanisms for SCC is not yet clear. The general classification under two categories of mechanisms (anodic dissolution on one hand and hydrogen effects on the other) is not sufficient. Available models such as the slip dissolution model cannot completely characterize the SCC behaviour of these materials. Recently new models of corrosion-deformation interactions have been proposed. They take into account the interactions between dislocations at the stress corrosion crack tip and corrosion products, such as vacancies injected by dissolution and/or absorbed hydrogen.

\section{Hydrogen Embrittlement}

Structural components during the manufacturing processes and forming operations are often exposed to hydrogen rich environments. This can result in absorption of hydrogen, especially in low alloy steel such as AISI 4140, and can have a marked influence over the fatigue life of the alloy often leading to unexpected failures in service. Hydrogen enters the material, lodges at interstitial locations in the crystal lattice causing localized stress gradients and cause failure in the material at stresses well below the design stress for a particular application. A typical example of hydrogen uptake is during hot stamping operations of automotive body parts or in the case of marine or offshore industry. Understanding how dissolved hydrogen affects the fatigue life of these structural components is crucial for safe life prediction and prevention of fatigue failure in service for these materials. 
Even though hydrogen embrittlement has been known to cause damage to metallic materials since more than $60-70$ years, very little progress has been made to understand and explain clearly the mechanism of hydrogen induced failures. Till date, there is no single mechanism to fully explain the hydrogen degradation applicable to all structural materials due to the complexity of hydrogen embrittlement problem.

Hydrogen embrittlement, as defined by Nelson [17] and other investigator [29], is the material degradation caused by the presence of hydrogen under load. The load may be in form of a static, cyclic or shear loads. The degradation may manifest itself in the material on the various mechanical properties such as loss of ductility, reduction in area, loss of strength (tensile and yield), increase in stress corrosion crack growth rate or decrease $\mathrm{m}$ - the Paris equation slope parameter, fatigue threshold and fracture toughness, increase in fatigue crack propagation rate, fatigue life reduction etc. This degradation causes failure in the material prematurely. Also, the degradation has been reported quite strongly influenced by microstructure [30] and also by the other metallurgical factors of the material or alloy such as chemical composition, grain size and heat treatment methods [31].

Hydrogen embrittlement is a broad term used to describe degradation of material property. This phenomenon can be broadly classified into the following categories [32-33]:

1. Hydrogen Induced Cracking: This is also referred as Internal Hydrogen embrittlement. Hydrogen enters the metal surface, in a variety of ways as explained above, lodges itself as an interstitial solute only in the atomic form [33-34]. This reduces the load bearing capacity of the material. Even ductile materials fail by this method at stresses below their nominal design stresses. This is the most severe form of embrittlement and there is an incubation time after which the material fractures unexpectedly. 
2. Hydrogen Environment Embrittlement: This form of degradation and failure occurs in the steels which are exposed to hydrogen rich environments. The hydrogen absorbed from the surroundings cause deformation in the alloy leading to reduction in the functional life of the material.

3. Hydride formation: The hydrogen absorbed in metals like $\mathrm{Nb}, \mathrm{Ti}, \mathrm{V}$ and their alloys undergoes a chemical reaction with the host metal forming hydrides. These hydrides are extremely brittle, reduces the ability of the material to undergo plastic deformation and thus decrease the fracture toughness causing catastrophic failures in the material.

4. Hydrogen attack: This type of failure occurs in low alloy steels used in chemical and petrochemical industries where it is subjected to high temperatures. The dissolved hydrogen in the material attacks the carbides in the iron alloy matrix which provide strength to the alloy. The hydrogen causes decomposition of these carbides like Iron carbide $\left(\mathrm{Fe}_{3} \mathrm{C}\right)$ or Cementite to iron and methane gas.

$$
2 \mathrm{Fe}_{3} \mathrm{C}+3 \mathrm{H}_{2} \rightarrow 6 \mathrm{Fe}+2 \mathrm{C}_{2} \mathrm{H}_{4} \quad-(2)
$$

Alloy deterioration occurs due to the disappearance of strengthening carbides particles leading to very low ductility and causing failures in the material.

5. Hydrogen blistering: In high strength alloys, the solute hydrogen resides as hydrogen atoms. However, when the concentration of this nascent hydrogen increases in the alloy matrix due to continuous contact of the metal in a solution, the hydrogen migrates into the inner lattice from the metal surface. When this lattice activity of the hydrogen gas phase becomes sufficiently high and equals to the hydrogen ion activity in the vicinity of the solution, this atomic hydrogen can recombine to form more stable molecular hydrogen giving rising to bubbling and cracking at the surface. This occurs due to the fact 
that the molecular hydrogen in sufficiently large in size to accommodate in the metal lattice. The same phenomenon can be initiated at internal surface (grain boundaries, inclusions, dislocations and voids in the material) within the metallic matrix. This gives rise to internal and surface cracks or fissures which act the initiation center for brittle failures.

\section{Hydrogen embrittlement mechanisms}

Though the exact nature of hydrogen embrittlement is still unclear and subject to a lot of controversy, some of the mechanisms explained below are generally applied while investigating or studying hydrogen embrittlement. One or more of these theories may be applicable while analyzing a particular material and none of these theories are applicable to all metallic systems in general.

1. Hydrogen Enhanced Localized Plasticity (HELP) [35]: Hydrogen related failures are often termed as "brittle in nature" due to loss in macroscopic ductility or reduction in flow stress. By fractographic examination, Beachem [23] proposed that embrittlement of steels is linked to locally enhanced plasticity at the crack tip. This concept, over the years, has been accepted as a possible mechanism for fracture in ductile materials. The HELP mechanism can be applied to metal systems with hydrogen in solid solution (dissolved hydrogen), as in our case, and also for gaseous hydrogen bearing environments. According to this model, the application of a stress field at the crack tip results in a highly non-uniform distribution of hydrogen in the material. The chemical potential of hydrogen at the crack tip is reduced and thereby attracting the neighboring hydrogen atoms from the bulk of the material due to concentration gradients. The high hydrogen concentration at the crack tip causes an elastic singularity at the crack tip 
causing reduction in dislocation motion and hence reducing the local yield stress in the material. Slip localization occurs in the material at the vicinity of the crack tip leading to crack tip plasticity at stresses well below the critical stress needed for plastic deformation. Hence, the fracture process proceeds by a highly localized ductile process which manifest as a brittle fracture macroscopically.

2. Hydrogen Enhanced DEcohesion (HEDE): This model was proposed by Troiano [6] and later modified by Oriani [36]. The model states that the high concentration of dissolved hydrogen in the crack tip vicinity reduces the cohesive force between the interatomic bonds and thereby causing decohesion at the crack tip. This model has inherent problems in correlating the cohesive energy to the critical hydrogen concentration needed to cause decohesion between the atoms. There is also lack of experimental evidence to support this mechanism.

3. Internal pressure theory: This theory was developed by Zapffe and Sims [37]. Large concentration of dissolved hydrogen in the material results in precipitation of hydrogen molecules at internal defects such as cracks, fissures and inclusions. Hydrogen bubbles form inside these defects raising the internal pressure and adding on to the applied stress lowering the fracture stress in the material. However, failures have occurred at very low concentration of dissolved hydrogen. Hence, this theory is not widely accepted.

4. Surface energy (adsorption) model: Modification of surface energy concept for crack propagation was introduced by Petch [38-39]. This model states the hydrogen migration to a crack tip lowers the surface energy needed to create new surface for crack propagation and thus alters the fracture stress in the material. Lack of experimental observations coupled with paucity of equations to calculate the reduction of surface 
energy projects this model to be insufficient to explain the phenomenological characteristics of hydrogen embrittlement.

\section{Existence of hydrogen traps}

Diffused or dissolved hydrogen are known to exist in the metal lattice sites known as Normal Lattice Interstitial Sites (NILS) as well as in imperfections such as dislocations, vacancies, grain boundaries, inclusions or second phase particles [40]. These imperfections in the material are known as traps. These traps are distinguished as reversible traps (low binding energy $<60$ $\mathrm{kJ} / \mathrm{mol}$ ) in which $\mathrm{H}$ atom can diffuse in and out and irreversible strong traps (high binding energy $>60 \mathrm{kj} / \mathrm{mol}$ ) in which the $\mathrm{H}$ atom degasses out only at high temperatures [41-43]. Reversible traps are defects such as vacancy [44], grain boundaries, dislocations and substitutional elements. Irreversible traps are secondary phases like carbide precipitates, oxides and inclusion sites etc.

\section{AISI 4140}

AISI 4140 is one of the most commonly used and available low alloy steel ( $<8 \%$ alloying elements). AISI 4140 is a medium carbon steel containing chromium, molybdenum and manganese as the principal alloying elements having high hardenability with good fatigue resistance. Owing to their strength and toughness properties, this steel has many applications in mission critical structural components such as naval structural components and other defense applications [45-46]. A close variety of AISI 4140 steel is being sought in Japan as a candidate material for hydrogen storage tanks and cylinder to fuel the next generation Hydrogen economy [47]. These steels can easily be nitrided to maximize the wear and abrasion resistance. It can also by hardened by a variety of heat treatment processes to high 
hardness offering good tensile strength and impact strength. Therefore they are used to manufacture small gears, pinions, high strength studs and bolts, head screws which are employed in severe service applications. They are commercially available in the hot and cold rolled conditions in the form of sheets, strips, plates and bars along with some aircraft quality grade bars and tubes [45].

While in service in many critical structural applications i.e., naval structural components and other defence applications, this alloy can be exposed to hydrogen bearing environments. Hydrogen induced fatigue crack growth data of this material is very important and is needed for safe life prediction and design of these components. Although a significant number of studies have been carried out on fatigue and corrosion behaviour of high strength steels, most of these studies were carried out in $3.5 \% \mathrm{NaCl}$ solutions [46, 48-53] in boiling sodium hydroxide [54], in gaseous hydrogen [55]. Fatigue behaviour of 4140 has also been investigated on the effect of magnetic treatment [56] and on the effect of ion nitriding [57]. However, not much information is available in literature on the influence of dissolved hydrogen (ex situ hydrogen charging) on the fatigue crack growth behaviour of AISI 4140 steel. It is quite common, in a practical scenario, that this steel is exposed to hydrogen bearing environment while processing or in service. The time of exposure to hydrogen environment may be continuous such as in aqueous solutions or might be temporary when exposed to air after processing. Thus, it is very important to examine the fatigue behaviour and SCC of this alloy when charged via ex situ hydrogen charging which closely mimics the real world scenario than a controlled atmosphere such as aqueous solution (in situ charging) or via gaseous hydrogen contained in a closed chamber. 
In order to examine the influence of microstructure on the SCC and FCG behaviour, the material was tested with different microstructures such as ferritic - pearlitic and tempered martensitic bainitic structures. The latter was produced by austempering process.

\section{Austempering Heat Treatment}

In recent years, austempering has generated a lot of interest as an alternate heat treatment process than the traditional austenitize, quench and tempering process. This type of heat treatment is generally preferred over quench and tempering process due to its reduced distortion and quench cracking [58] in steels with sufficiently high carbon (in excess of $0.40 \%$ ). This heat treatment process can result in similar strength like quenched and tempered steel but with better fracture toughness [59-60]. The typical microstructure expected in the austempering process is bainite with little or no martensite. The process involves heating the steel to austenitizing temperature and then quenching in a molten salt bath to a temperature above or very close to the martensite start temperature (Ms) to isothermally transform the austenite into bainite with little or no martensite depending on the isothermal transformation temperature. The absence of sudden quench cycle to form martensite before tempering, as in the traditional quench and tempering process, results in removal of thermal gradients in the material. This reduces the distortion and minimizes the appearance of quench cracks, especially in small parts like gears, bolts and clips which are extensively used in the automotive industry and in naval applications. In addition, the austempered material does not need a tempering step during the heat treatment process being an inexpensive and shorter duration process. In a study involving a similar type low alloy steel (4340), it was found that the austempered material had better high cycle fatigue compared to the quenched and tempered material at the same hardness level of $45 \mathrm{HRc}$ [60]. Another study [61] 
revealed that the austempered 4340 material had better resistance to hydrogen embrittlement (in terms of mechanical properties) when compared to quench and tempered material at the same strength level.

\section{Rationale behind this research}

Not much information is available in literature $[55,62]$ on the structure - property relationship for AISI 4140 steel in the austempered condition, especially for the fatigue crack growth (FCG) behaviour and SCC behaviour. The paucity of information available on the FCG and SCC behaviour of 4140 in presence of dissolved hydrogen and how austempering can affect the FCG behaviour, with or without dissolved hydrogen in the alloy matrix is of great interest and provided the rationale and thrust toward this investigation. It was shown by Tomita and others [63-65] that heat treatment very close to the martensitic start (Ms) temperature or in the borderline between the lower bainite and Ms temperature region for 4340 yielded a dual phase microstructure consisting of lower bainite and tempered martensite with high strength, fracture toughness and good fatigue properties. It was our understanding that in a similar way, by austempering 4140 by changing the austempering time and temperature, a dual matrix structure could be obtained and its SCC and FCG resistance could possibly be improved. In this way, the fatigue behaviour and SCC behaviour of 4140 due to dissolved hydrogen in the annealed (asreceived) and austempered condition could be compared. This would pave a way to tailor the right microstructure in this alloy having the best hydrogen embrittlement resistance in both static as well as dynamic loading condition. 


\section{CHAPTER 3 - OBJECTIVES}

The following were the objectives of this investigation -

1. The primary objectives of this investigation were:

a. to examine the influence of dissolved hydrogen on the fatigue crack growth behaviour of AISI 4140 steel.

b. to examine the influence of microstructure on the fatigue crack growth behavior of this steel and to investigate whether austempering can improve the fatigue crack growth behaviour.

c. microstructure has significant influence on the static as well as dynamic loading of materials and the interaction of microstructural features with hydrogen is of great interest. Therefore, one of the objective was to determine the crack growth mechanism in this steel during cyclic loading condition.

2. The secondary objective of this investigation was to determine the role of inclusions and their influence in affecting the fatigue crack growth rate of this material. 


\section{CHAPTER 4 - EXPERIMENTAL MATERIALS AND METHODS}

\section{Material}

The material used in this investigation is a low alloy steel AISI 4140. The material was available in the form of cold rolled and annealed plate with identifiable rolling direction. The chemical composition of the material is reported in Table 1. From this steel plate, compact tension (CT) samples and tensile specimens were prepared as per ASTM E-647 and E-8 [66-68] respectively with TL orientation. The aspect ratio $(\mathrm{a} / \mathrm{W})$ was kept about 0.3 whereas the width of the specimens (W) were about $50.8 \mathrm{~mm}$. The thickness of the specimens (B) was kept about $3-4$ mm.

Table 1: Chemical composition of the material (in wt \%)

\begin{tabular}{|c|c|c|c|c|c|c|}
\hline C - & 0.40 & Mn - & 0.93 & P - & 0.025 & $\mathrm{Fe}-$ \\
\hline $\mathrm{Cr}-$ & 1.12 & $\mathrm{Si}$ - & 0.33 & $\mathrm{Cu}-$ & 0.02 & \\
\hline Mo - & 0.18 & S - & 0.031 & $\mathrm{Ni}$ - & 0.17 & \\
\hline
\end{tabular}

Figure 3 shows the dimensions of the CT specimen used for fracture toughness testing. The aspect ratio $(\mathrm{a} / \mathrm{W})$ was kept about 0.4 whereas the width of the specimens $(\mathrm{W})$ were about 37.6 $\mathrm{mm}$. The thickness of the specimens (B) was kept about $19-20 \mathrm{~mm}$ for the plane strain fracture toughness $\left(\mathrm{K}_{\mathrm{IC}}\right)$ specimen. 
A similar type of specimen was used for SCC and corrosion fatigue crack growth testing. The aspect ratio $(\mathrm{a} / \mathrm{W})$ in the fatigue $\mathrm{CT}$ specimen was kept about 0.3 with the width $(\mathrm{W})$ being about $50 \mathrm{~mm}$. A thinner specimen having a thickness of about $4 \mathrm{~mm}$ was utilized for this study.

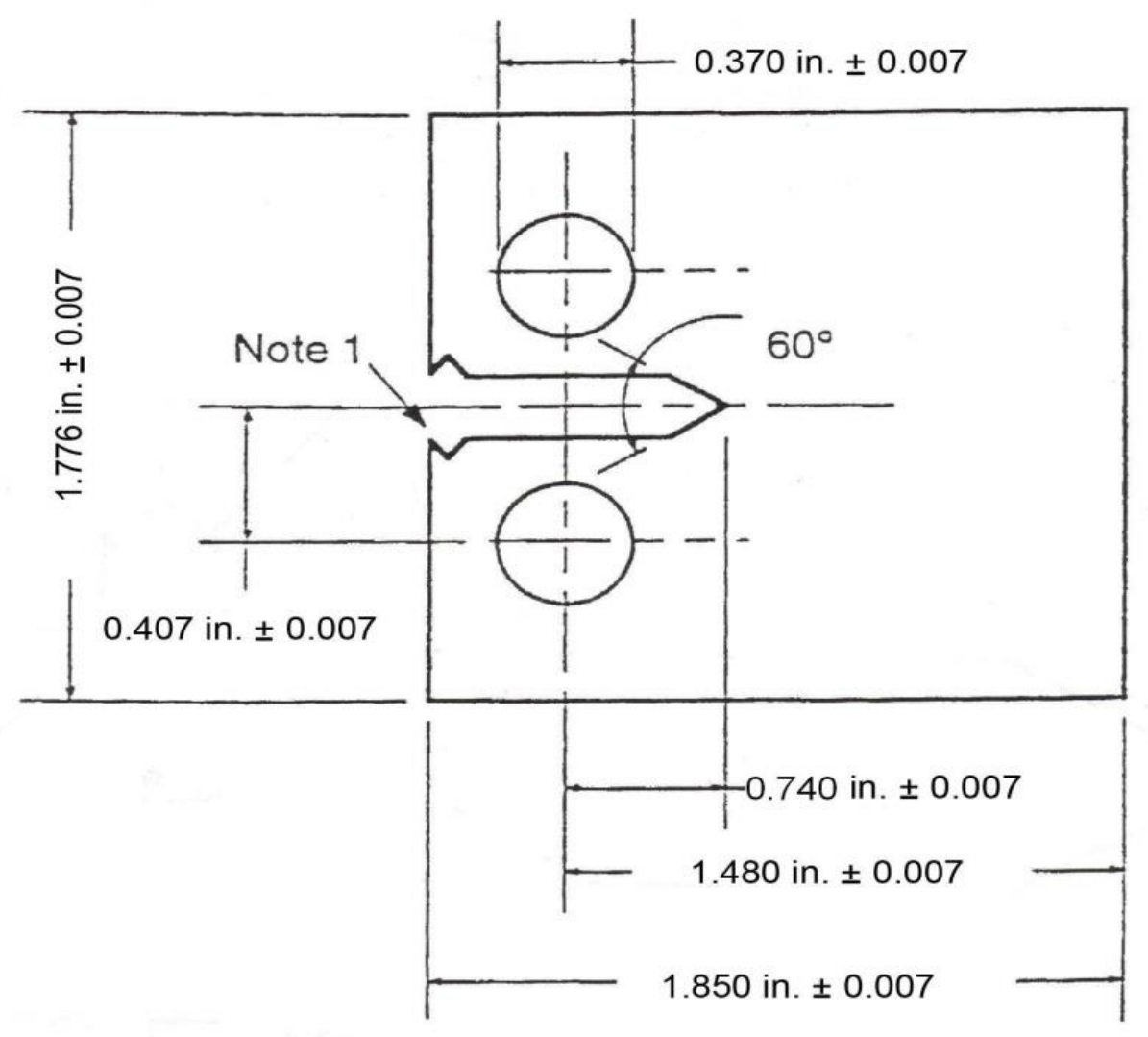

Figure 3: Dimensions of the CT specimen used for fracture toughness $\left(\mathrm{K}_{\mathrm{IC}}\right)$ testing (all dimensions are in inches)

Figure 4 shows the tensile specimen used in this study. The diameter (d) in the thin middle section was kept at $6.35 \mathrm{~mm}$ and the length (L) of this section was $32.13 \mathrm{~mm}$ giving the aspect ratio (L/d) of about 5 . 


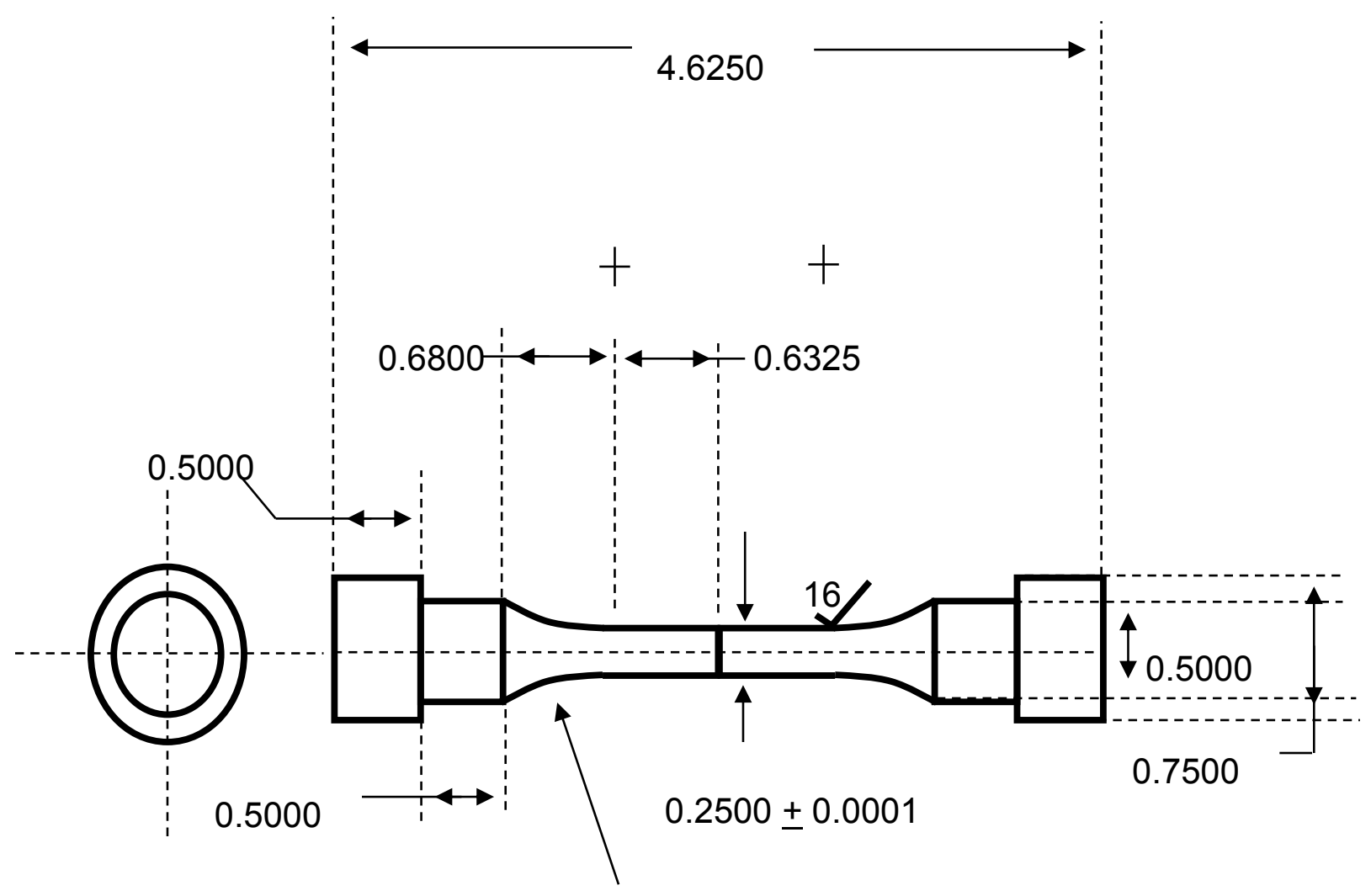

R1.9150

Figure 4: Dimensions of the tensile specimen (all dimensions are in inches)

\section{Heat Treatment}

The material was used in three different heat treated conditions: the first batch of samples were used in the as received cold rolled and annealed condition and while the second and the third batch of samples were used in austempered conditions (heat treated). The specimens were austempered in two different austempering temperatures. For the first batch of heat treated samples (here after referred as $\mathbf{A B 1}$ ), the specimens were initially austenitized at $885^{\circ} \mathrm{C}$ for 1 hour then austempered at $349^{\circ} \mathrm{C}$ for 1 hour in a molten salt bath. The second batch of heat treated samples (here after referred as $\mathbf{A B 2}$ ) was done by austenitizing at $882^{\circ} \mathrm{C}$ for $45 \mathrm{~min}$ and then austempered at $332^{\circ} \mathrm{C}$ for $60 \mathrm{~min}$. The austempering temperatures chosen for the heat treatment 
are close to each other. However, these temperatures were chosen such that they were slightly above and below the martensitic start (Ms) temperature of 4140 alloy. More specific details about the Ms temperature of 4140 alloy is discussed in the TEM analysis section. After austempering, the specimens were air cooled to room temperature. The specimens were then ground on both surfaces and polished with 600 grit emery paper. Finally, they were cleaned and degreased in acetone. Table 2 reports the mechanical properties of the material in annealed and austempered condition.

Table 2: Mechanical properties of AISI 4140 alloy after heat treatment

\begin{tabular}{|c|c|c|c|c|c|}
\hline $\begin{array}{l}\text { Material } \\
\text { Condition }\end{array}$ & $\begin{array}{c}\text { Yield } \\
\text { strength } \\
\text { (MPa) }\end{array}$ & $\begin{array}{c}\text { Ultimate Tensile } \\
\text { Strength* } \\
\text { (MPa) }\end{array}$ & $\begin{array}{c}\% \\
\text { Elongation }\end{array}$ & $\begin{array}{c}\text { Hardness } \\
\text { (HRc) }\end{array}$ & $\begin{array}{c}\text { Fracture } \\
\text { Toughness } \\
(\mathrm{MPa} \sqrt{ } \mathbf{m})\end{array}$ \\
\hline Annealed & $757 \pm 20$ & $1031 \pm 5$ & 5.63 & $28 \pm 3$ & $65 \pm 2.2$ \\
\hline $\begin{array}{l}\text { Austempered - } \\
\text { AB1 }\left(349^{\circ} \mathrm{C}\right)\end{array}$ & $1368.5 \pm 4$ & $1526.6 \pm 9$ & 5.92 & $41 \pm 3$ & $78 \pm 2.3$ \\
\hline $\begin{array}{l}\text { Austempered - } \\
\text { AB2 }\left(332^{\circ} \mathrm{C}\right)\end{array}$ & $1481 \pm 12$ & $1646 \pm 8.62$ & 5.5 & $45 \pm 1$ & $72 \pm 5.8$ \\
\hline
\end{tabular}




\section{Microstructural Analysis}

A through microstructural analysis was carried out to reveal and characterize the microstructural features in each of the three heat treatment conditions. From the fabricated fatigue CT specimen, a sample about 1-2 $\mathrm{cm}$ in length and width was cut from the annealed, AB1 and AB2 specimens. These samples were then mounted on Copper impregnated phenolic powder based mounts. The samples underwent a series of grinding steps starting from 180 to 2400 Grit emery paper to prepare a smooth surfaces which followed by series of polishing steps using Alumina powder having the grain size of $5,3,1$ and 0.5 microns respectively in that order. At the end of the polishing step, each of the these samples were visually examined under an optical microscope to make sure a uniformly flat smooth shiny surface with a mirror like appearance was obtained and ready for etching.

\section{Annealed Microstructure}

The microstructure of the annealed sample after polishing was etched with $3 \%$ Nital solution for about 8-10 s. The microstructure was then examined using a Nikon Epiphot optical microscope and a JEOL JSM - 6610LV scanning electron microscope fitted with an Oxford Instruments XMax 80 energy dispersive X-ray analysis (EDAX) gun to get X-ray mapping information. Since the dissolved hydrogen can lodge at inclusions and voids in the material, X-Ray mapping was done around any void or inclusion areas found on the polished and etched surface to analyze the chemical makeup in and around void areas to characterize any possible impurities, inclusions and/or secondary phase particles which may affect the hydrogen uptake in the material and thereby influence the FCG and SCC behaviour of the material. 
The microstructure of the annealed samples is reported in Figure 5. The coarse pearlitic lamellae can be found as dark areas in the matrix with the surrounding light area (fully dark area being Cementite $-\mathrm{Fe}_{3} \mathrm{C}$ and the surrounding light phase being $\alpha$ phase). The ferrite phase appears as the complete white area Figure 6a shows the SEM microstructure of the annealed (as-received) sample has coarse pearlitic (white broken dendritic phase) microstructure in a predominantly ferritic background matrix (grey background). Figure $6 \mathrm{~b}$ is a higher magnification of the observed area to indicate the coarse nature of the pearlitic lamellae. There were some voids observed on the etched sample which are seen in Figure 6a as holes on the surface. X-ray mapping revealed these voids to be composed of Aluminum Oxide. Figures $6 \mathrm{c}$, d, and e shows the X-ray maps obtained for $\mathrm{Fe}$ (red), $\mathrm{Al}$ (green) and $\mathrm{O}$ (yellow) respectively at the void area. However, the presence of voids in the material shows that it is possible for dissolved hydrogen to be trapped at one of these locations. It is also important to note that though the pearlitic lamellae are not very distinct even at high magnification, the grain size distribution of the alloy in the annealed condition was estimated to be between $8-12$ microns from the microstructure (grain boundaries very faintly visible in Figure 6a) and also from some of the facets observed in the fractographs discussed later. 


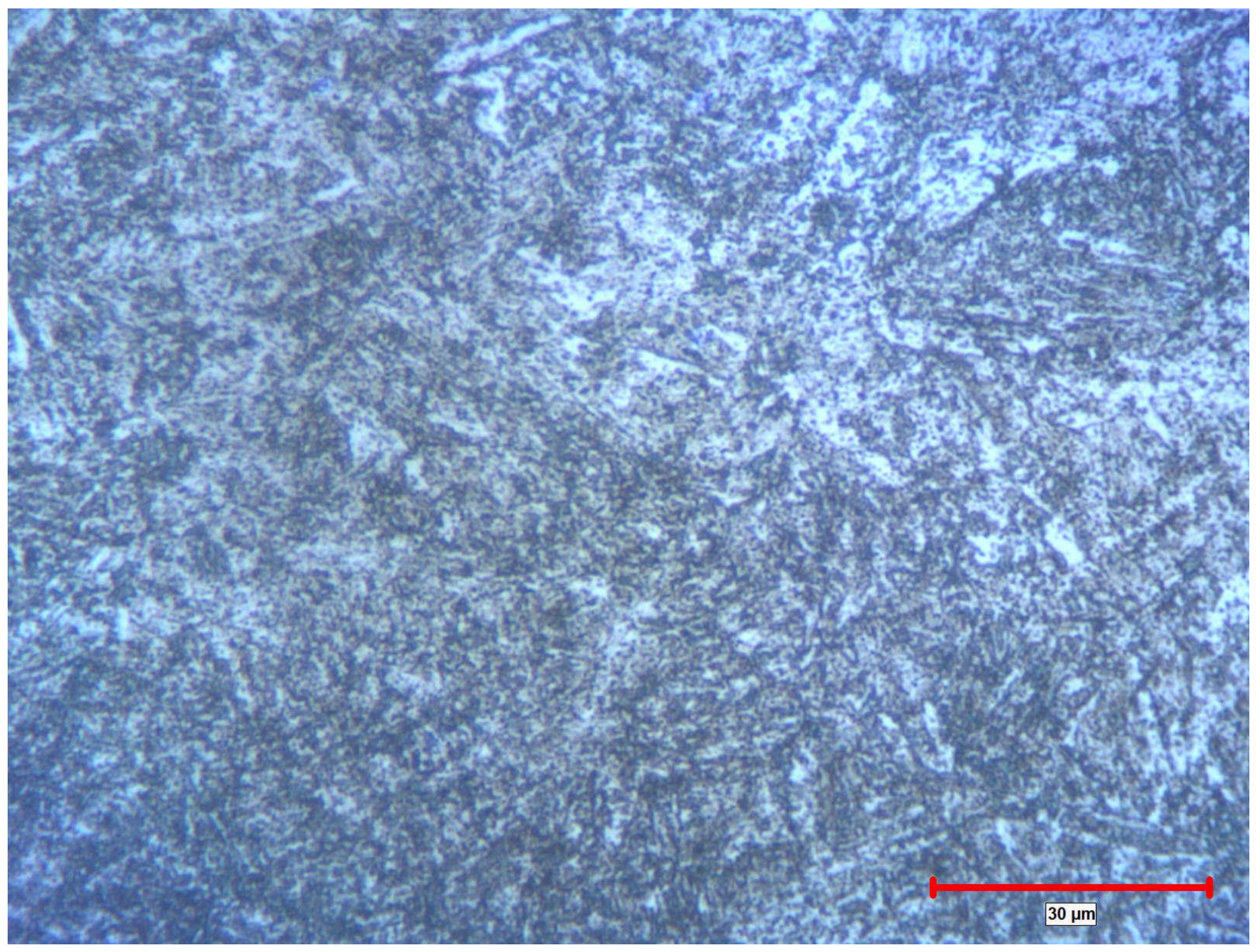

Figure 5: Microstructure of the annealed sample (Magnification: 1000X) 

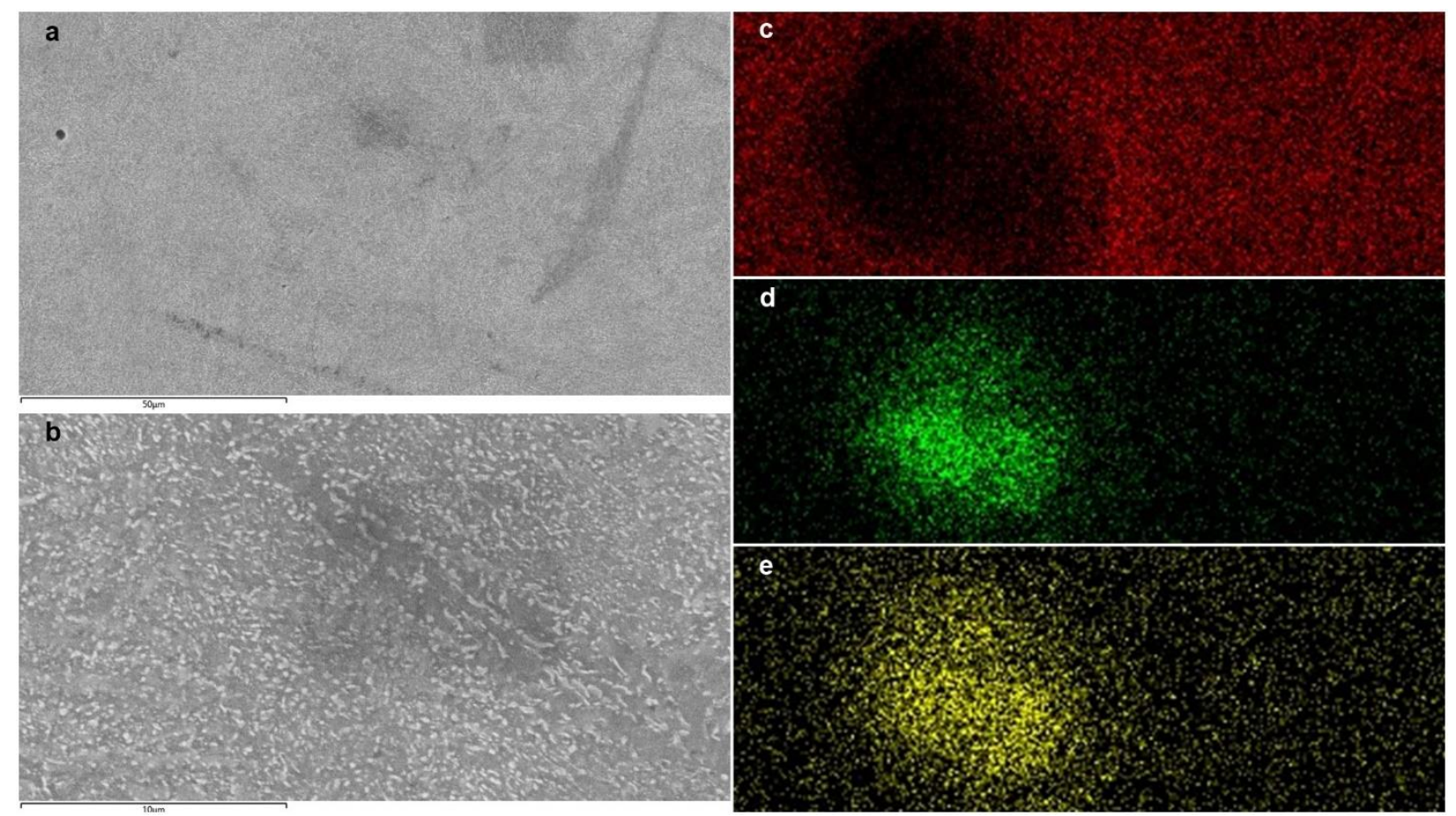

Figure 6: Microstructure (SEM) and X-ray map of inclusions of the annealed sample (a, b: SEM image - 1000X and 5000X respectively; c, d and e: X-ray map of Fe, Al and O respectively at the void location in a)

\section{Austempered Batch -1 (AB1) microstructure}

As discussed earlier, the austempering heat treatment resulted in a microstructure consisting of predominantly bainite with a small amount of tempered martensite and retained austenite. Since the grain size as observed in the annealed condition was very small in nature and also the bainite and martensite formed during the austempering process occurs by shear mechanism, it was expected that the differentiating between these two phases in the material would be very difficult.

In order to resolve this issue, tint etching process was used with a $15 \%$ Sodium Metabisulphite (SMB) solution. This tint etch characteristically gives a bluish tint for Bainite (B), dark brown 
and straw yellow tint for Martensite (M) and leaving the Retained Austenite (RA) as white phase. Both the $\mathrm{AB} 1$ and $\mathrm{AB} 2$ samples were etched with this solution for about 40-50 s to get a distinguishable tint checking periodically under an optical microscope. After the tint etch, both the samples were washed in water and then cleaned with a small amount of alcohol and immediately dried under compressed air. A $200 \mathrm{~g}$ microindent was made at the center and on one edge of the specimen using LECO Microhardness Tester - LM 248 AT. This indent mark was used as a reference marker so that the voids and the microstructure around this indent could be obtained by optical and SEM imaging. These then could be compared in order to help identify the microstructural features at around the same point. After this procedure, the micrographs and X-ray maps were obtained in the same manner as explained earlier.

The optical micrographs showing the tint obtained at 1000X magnification for the AB1 sample is shown in Figure 7. From the Figure 7, it is evident that all the three expected phases $-\mathrm{B}, \mathrm{M}$ and RA are present based on the tint characteristics explained earlier. It is also noted from the Figure 7 that the $\mathrm{B}$ islets and the $\mathrm{M}$ laths or plates, which are predominantly expected, cannot be differentiated clearly owing to the very fine scale microstructure of the material and also due to their formation by the shear mechanism explained earlier. By initial examination of Figure 7, it may be concluded that the AB1 material has predominantly the B phase due to bluish tint visible in larger area with little M (dark brown to brick red) phase and very little RA present (white phase). 


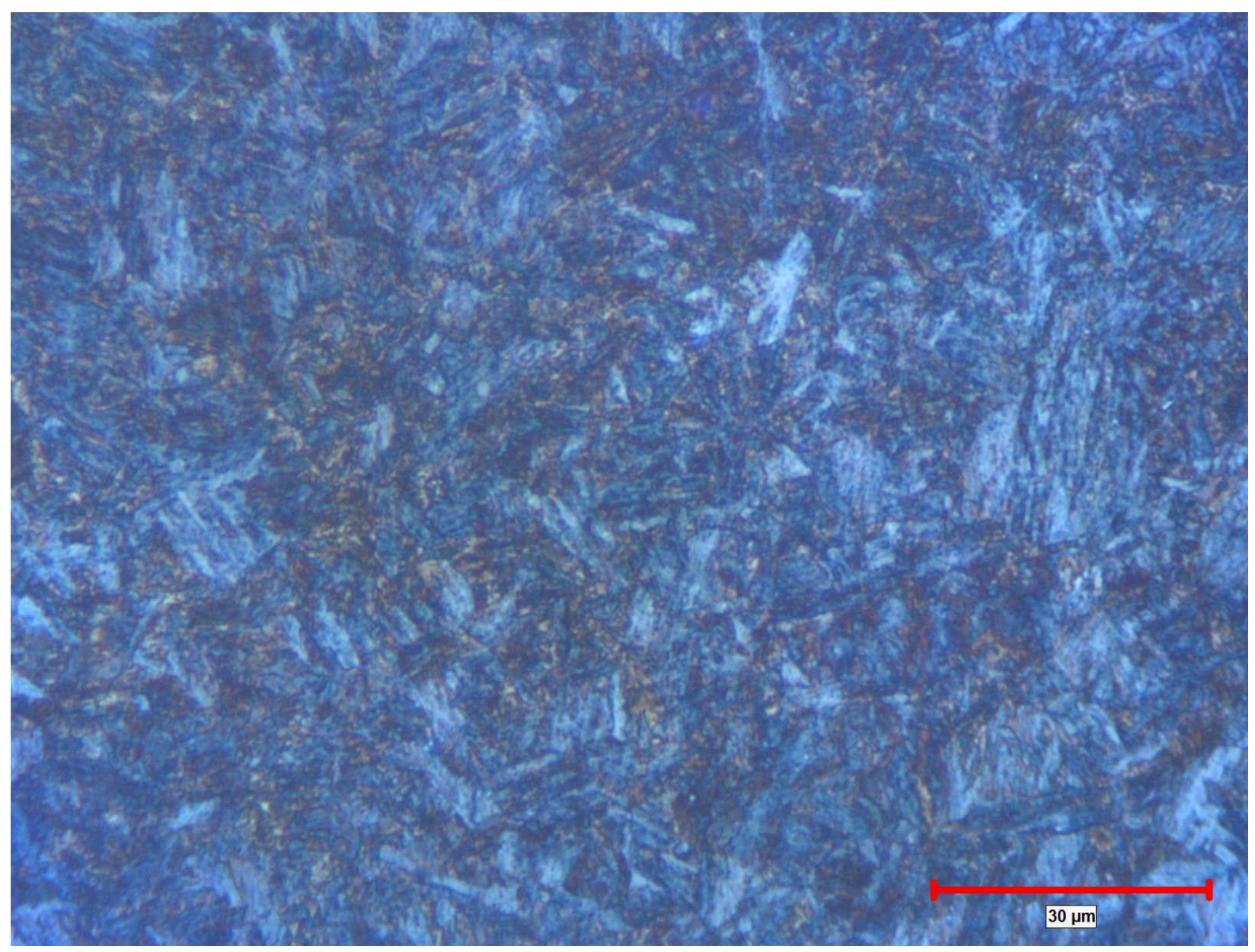

Figure 7: Microstructure of the AB1 sample (Magnification: 1000X)

The SEM micrographs and X-ray maps of AB1 are shown in the Figure 8. Figure 8a and 8b show the bainitic and martensitic structures although they look similar even a very high magnification. Figure 8c shows an inclusion visible in the Figure 8a (top left corner). In the AB1 sample, the inclusion was found to be Manganese Sulphide (MnS) in the Figures 8e and 8f. 


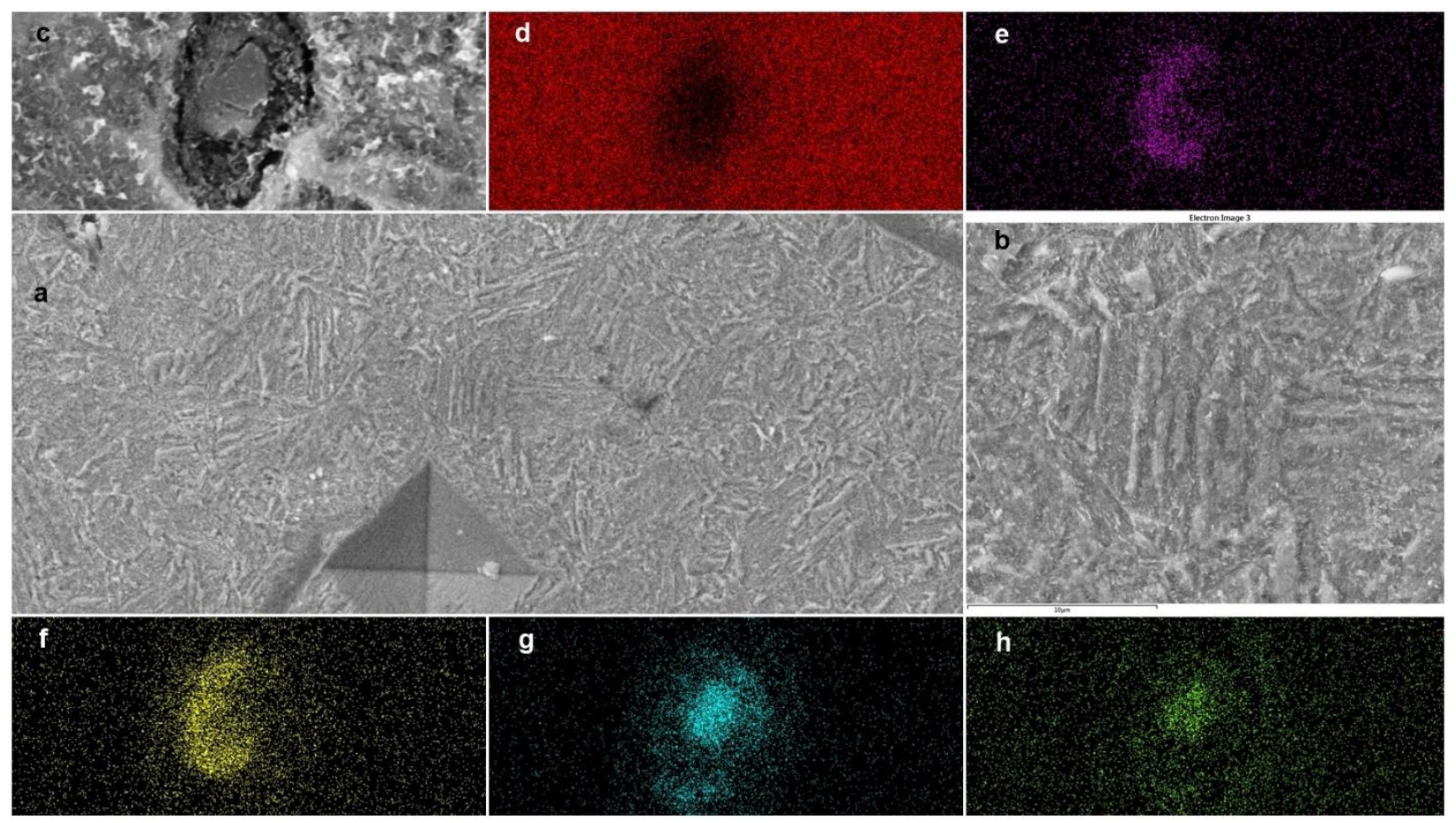

Figure 8: Microstructure (SEM) and X-ray maps of the AB1 sample (Magnification: a, b 1000X, 5000X respectively; c - inclusion; d - Fe (Red); e - Mn (Purple); f - S (Yellow); g - Al (Blue) and h - O (green)

\section{Austempered Batch -2 (AB2) microstructure}

Figure 9 shows the optical micrographs of the AB2 sample. A similar microstructure consisting of $\mathrm{B}, \mathrm{M}$ and RA phases are seen in the micrographs. However, since the austempering temperature is less than $\mathrm{AB} 1$ sample, a higher fraction of brown/reddish brown $\mathrm{M}$ phase is together with the RA phase as very small white phase in the micrograph. 


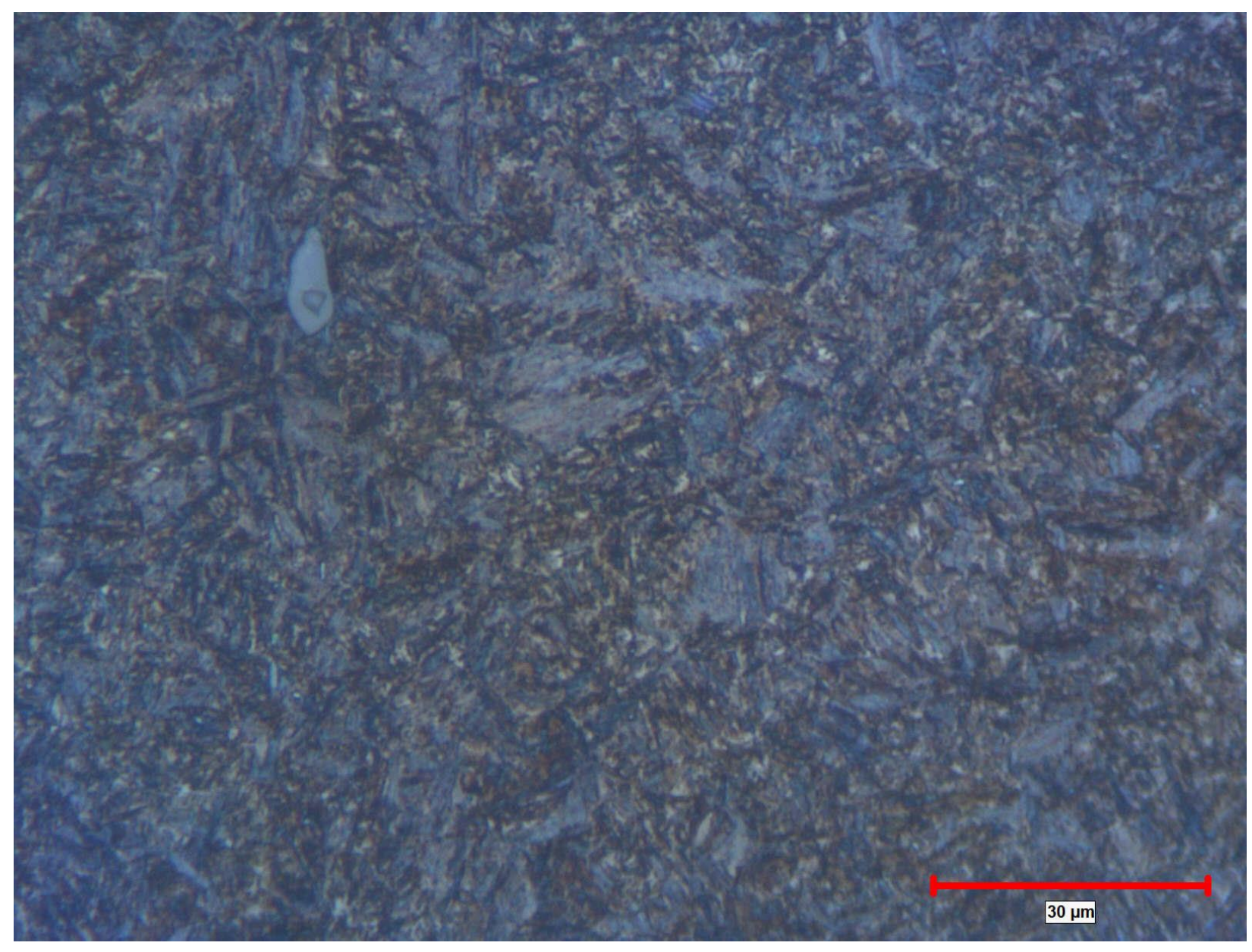

Figure 9: Microstructure of the AB2 sample (Magnification: 1000X)

Figure 10 shows the SEM and X-ray micrographs of the AB2 sample. The AB2 sample has $\mathrm{B}$ and $\mathrm{M}$ phase (Figure 10a and 10b), but a clear distinction could not be made like in the $\mathrm{AB} 1$ sample. AB2 also had MnS inclusions as seen in Figure 10e and 10f.

It is clear that there are inclusions present in the matrix in all the three batches of samples used for the fatigue crack growth rate tests and SCC tests. The main inclusion present in this steel is $\mathrm{MnS}$ as seen from the X-ray maps and very small amount of Aluminum Oxide $\left(\mathrm{Al}_{2} \mathrm{O}_{3}\right)$. 


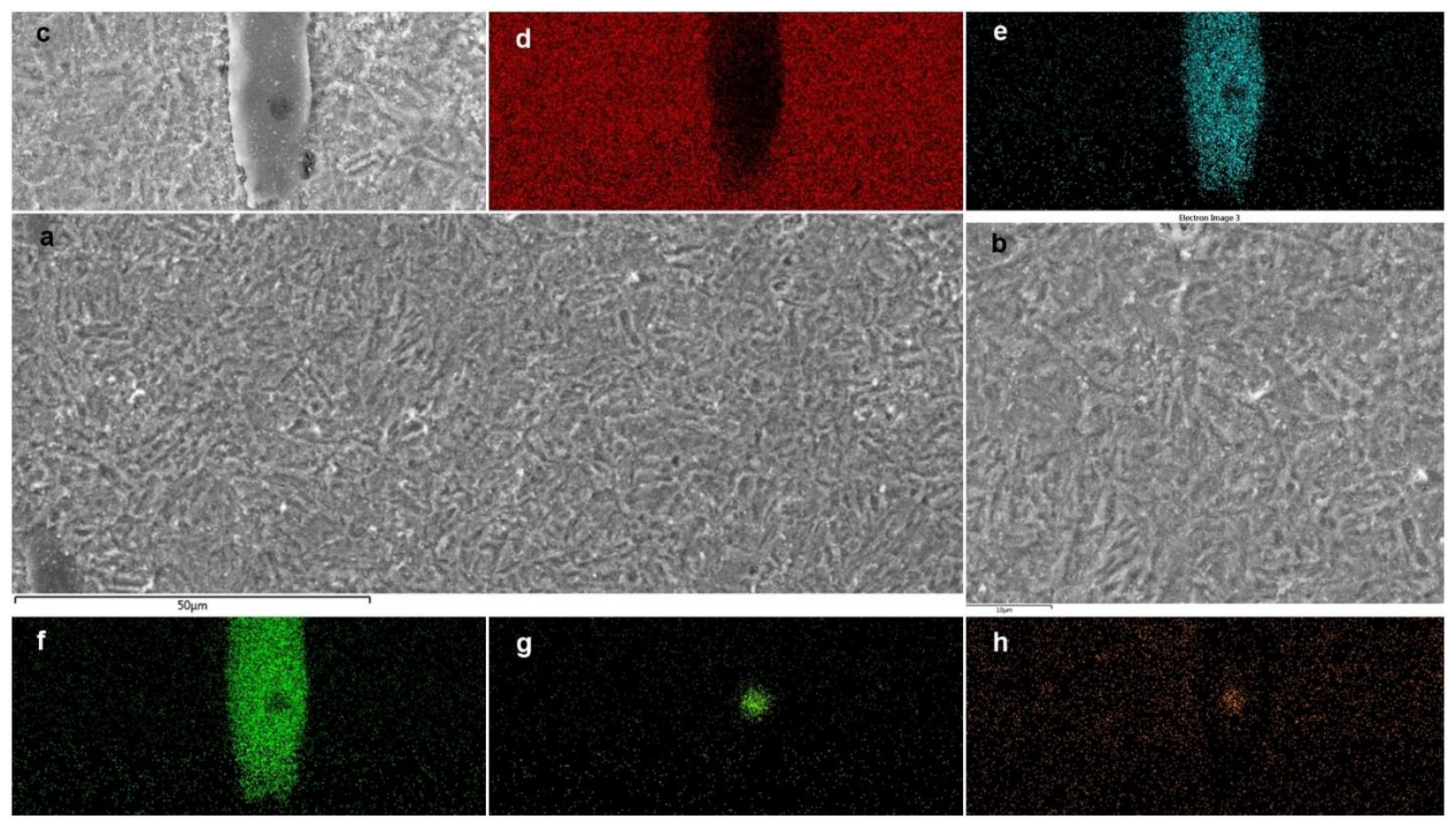

Figure 10: Microstructure (SEM and X-ray maps) of the AB2 sample (Magnification: a, b 1000X, 5000X respectively; c - inclusion; d - Fe (Red); e - Mn (Blue); f - S (Green); g - Al

(Green dot) and h - O (orange dot)

\section{Volume fraction analyses}

It was clear from the microstructural analysis that the annealed microstructure had a coarse pearlitic microstructure surrounded by a minor component of ferrite and that the austempered materials (AB1 and $\mathrm{AB} 2$ ) had a duplex microstructure composed of lower bainite and tempered martensite with very small amount of retained austenite (RA) phase. As seen from the figure 7 and 9, these $\mathrm{B}$ and $\mathrm{M}$ phases varied from $\mathrm{AB} 1$ to $\mathrm{AB} 2$ materials in relative amounts due to the difference in austempering temperatures. This could have a bearing on the resulting FCGRs and SCC behaviour with or without hydrogen. 
Using the previously obtained metallographs, at a constant magnification, the relative volume fraction of each component was obtained using Image Pro 6.0 image analyzer. A set of five images was taken for each material at a constant magnification - $400 \mathrm{X}$ for the annealed and 200X for the austempered material. These images were processed by the image analyzer to get the volume fraction based on morphology and color in the case of annealed material and based on color in the case of austempered material. The average of the relative amounts obtained from the five images was taken as the final volume fraction for each phase. This method also gave the volume fraction of inclusions in each of these materials.

Table 3 shows the volume fraction of ferrite as well as of pearlite (ferrite $+\mathrm{Fe}_{3} \mathrm{C}$ ). As evident from the microstructure in figure 1 , the ferritic $(\alpha)$ phase is only about $7 \%$ in volume and the matrix is composed of pearlitic phase (about 92\%) with a minor fraction of inclusion of about $1 \%$.

Table 3: Volume fraction of phases (in \%) present in the Annealed condition

\begin{tabular}{|c|c|c|c|}
\hline Material & $\begin{array}{c}\text { Volume fraction of } \\
\text { Ferrite (\%) }\end{array}$ & $\begin{array}{c}\text { Volume fraction of } \\
\text { Pearlite (\%) }\end{array}$ & $\begin{array}{c}\text { Volume fraction of } \\
\text { Inclusions (\%) }\end{array}$ \\
\hline Annealed & 7.2 & 91.9 & 0.9 \\
\hline
\end{tabular}

Table 4 lists the volume fraction of the $\mathrm{B}$ and $\mathrm{M}$ phases along with the percentage of inclusions present. It was noted that the B phase was more in volume in both the austempered conditions with the $\mathrm{M}$ phase in increasing with decrease in austempering temperature. All the three batches had nearly the equal amount of inclusions since it was from the same batch of steel and with the same orientation of rolling direction. The RA phase does not appear in appreciable amounts (less 
than about $0.5 \%$ ) in both austempered conditions and hence has not been calculated in the final analysis. This is validated by XRD and TEM analysis discussed later.

Table 4: Volume fraction of phases present in the Austempered condition

\begin{tabular}{|c|c|c|c|}
\hline Material & $\begin{array}{c}\text { Volume fraction of } \\
\text { Tempered }\end{array}$ & $\begin{array}{c}\text { Volume fraction of } \\
\text { Martensite }(\%)\end{array}$ & $\begin{array}{c}\text { Volume fraction of } \\
\end{array}$ \\
\hline $\mathrm{AB}-1\left(349^{\circ} \mathrm{C}\right)$ & 20.5 & 77.8 & 1.7 \\
\hline $\mathrm{AB}-2\left(332^{\circ} \mathrm{C}\right)$ & 38.6 & 60.2 & 1.2 \\
\hline
\end{tabular}

\section{X-Ray Diffraction (XRD) Analysis}

In order to reveal the phases present in the annealed (as-received) and the austempered material in the 4140 steel, a detailed XRD analysis was performed. The samples were sectioned from the CT specimens, one in each heat treated condition, about $15 \mathrm{~mm} * 15 \mathrm{~mm}$ in size having a thickness of about $4 \mathrm{~mm}$. The samples were labeled in annealed and in austempered condition (AB1 and AB2) as AI-10, HT-2 and AU-1 respectively in that order. These specimens were ground and polished in the same manner as explained in the microstructural analysis and then mounted in a sample holder using putty recessed below the focal plan of X-ray beam. For the XRD, a Miniflex diffractometer using $\mathrm{Cu} \mathrm{K \alpha}$ radiation was utilized. The scan rate for each specimen was held constant at $1^{\circ} / \mathrm{min}$ between the $2 \theta$ range of $2-90^{\circ}$. The obtained data was plotted and analyzed using PDXL software. The scan intensity was normalized using the strongest peak. In order to 
improve the clarity of the figures, the peaks were smoothed using an extended Gaussian convolution algorithm.

The scans taken from AI-10, HT-2 and AU-1 are shown in Figure 11. The XRD peaks show that all the peaks correspond only to the $\alpha$ phase of iron (ferrite) (ICDD \#04-016-4758) with no evidence of $\gamma$ phase (austenite). It about $40.1^{\circ} 2 \theta$, there is weak peak corresponding to a very small amount of $\mathrm{Fe}_{4} \mathrm{C}$ (ICDD \#04-007-9963). However, the peak intensity is not strong enough to perform a solid identification. Figure 11 also shows an overlay (faint green line) that shows where the minor radiation peak should diffract based on the observed (110) peak. The faint line (that of $110 \mathrm{~K} \beta$ peak) coincides with the position of the small peaks of $\mathrm{Fe}_{4} \mathrm{C}$. Though the small presence of $\mathrm{Fe}_{4} \mathrm{C}$ cannot be ruled out, it might also be due to non-monochromatic radiation source. The peaks associated the $\gamma$ - Austenite phase were not detected by XRD possibly due to very low volume fraction of Retained Austenite phase in the alloy in all three heat treated conditions. 


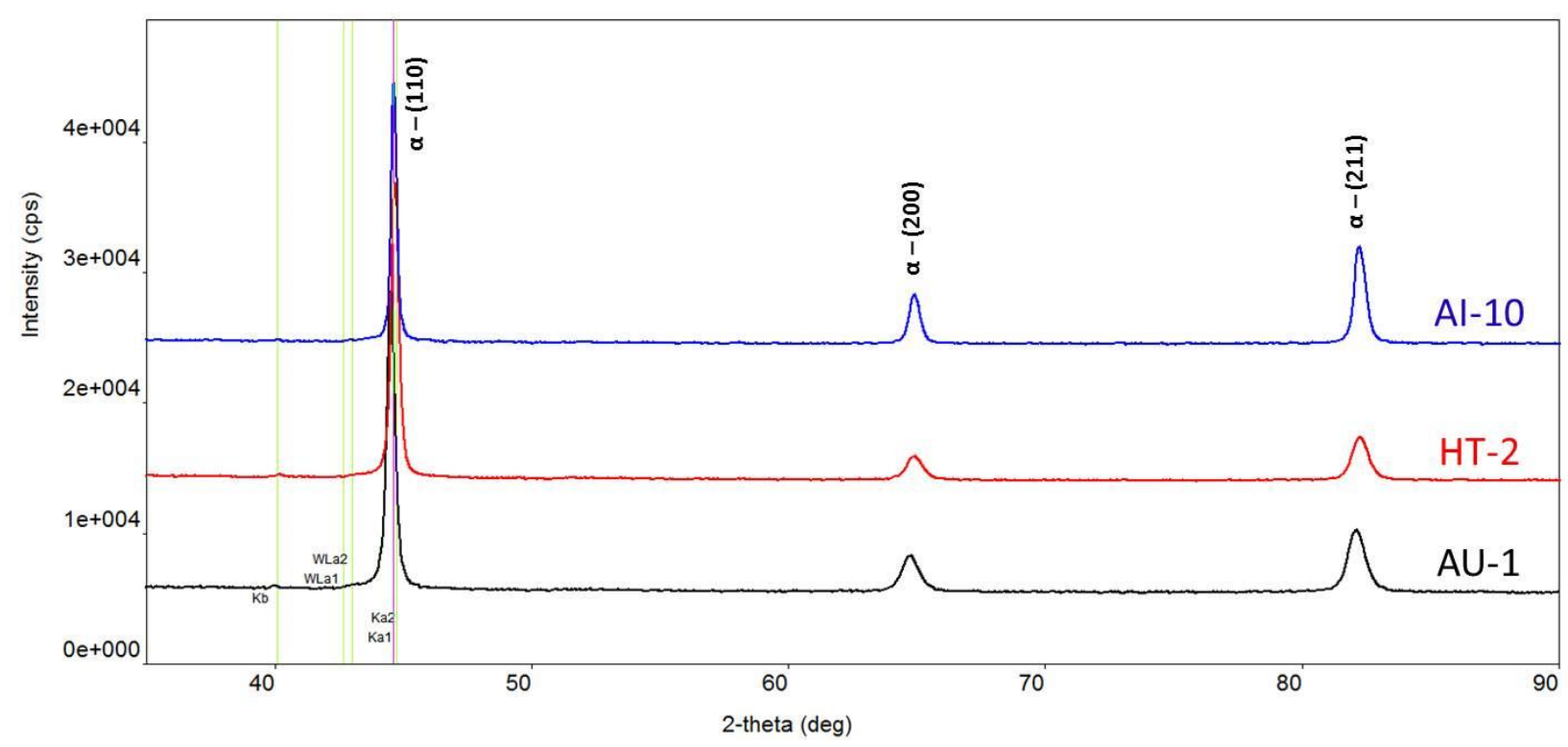

Figure 11: XRD peak identification for the 4140 steel samples: Annealed - AI-10 (Blue), Austempered AB1 $\left(349^{\circ} \mathrm{C}\right)$ - HT -2 (Red) and Austempered AB2 (332 $\left.{ }^{\circ} \mathrm{C}\right)$ - AU - 1 (Black)

\section{TEM Imaging}

Transmission Electron Microscopy (TEM) was performed to identify and confirm the phases present in the AISI 4140 material in the two austempered conditions. This was done as a secondary as well as confirmatory step to identify the phases (Martensite and Bainite) observed in the metallographic analysis via Tint Etching technique using Optical Microscope (OM) and confirm the absence of the Austenite $(\gamma)$ phase with the FCC crystal structure observed in the XRay Diffraction (XRD) analysis.

To prepare the TEM grids for imaging, a $15 \mathrm{~mm}$ x $15 \mathrm{~mm}$ sample was cut out of the CT specimen used for the fatigue crack growth rate testing from each of the austempered material (AB-1 and AB-2) using a Struers abrasive cutter. From the $4 \mathrm{~mm}$ thick sample obtained, one each from the AB-1 and AB-2 material, a thin sample about $0.5 \mathrm{~mm}$ was sectioned using a 
Buehler low speed cutting saw. These thin samples were then ground to about $90-100 \mu \mathrm{m}$ thickness by grinding with Silicon Carbide (SiC) emery paper from Grit 60 to 2400 to obtain a smooth surface and then polished to obtain a mirror finish, having a final thickness of about 50 $75 \mu \mathrm{m}$ foils, using a series of alumina polishing powders with a particle size from $5-0.05 \mu \mathrm{m}$. A $3 \mathrm{~mm}$ diameter discs are cut out from the thin foils (about 10 - 15 discs from each of AB-1 and AB-2 thin foils) slightly varying in thickness from $50-75 \mu \mathrm{m}$ using a TEM disc punch. The foils were then subjected to electro polishing using $10 \%$ perchloric acid solution as electrolyte maintained at $-30^{\circ} \mathrm{C}$ in a Fischione Instruments Model -110 Twin Jet electropolisher wired to Fischione Instruments Model - 120 Automatic Power Control to supply a steady voltage of 27+/1 VDC for a time period of $30-35 \mathrm{sec}$ to obtain a small perforation in the center of the $3 \mathrm{~mm}$ discs. Finally, the perforated discs are used for TEM imaging using a JEOL - 2010 TEM at a voltage of $200 \mathrm{kV}$. 


\section{Austempered Batch - 1 (AB1) TEM imaging}

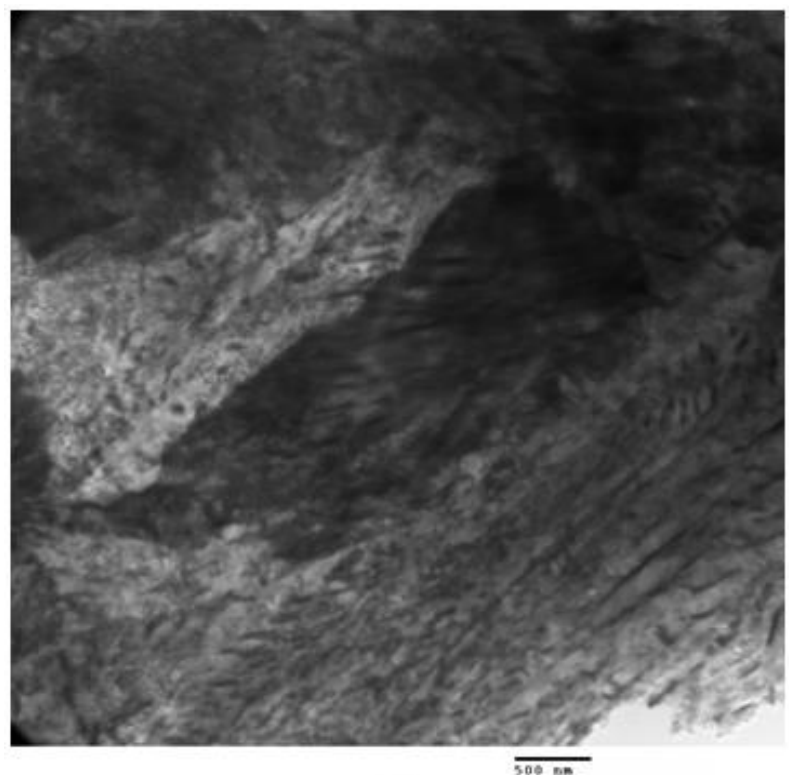

(a)

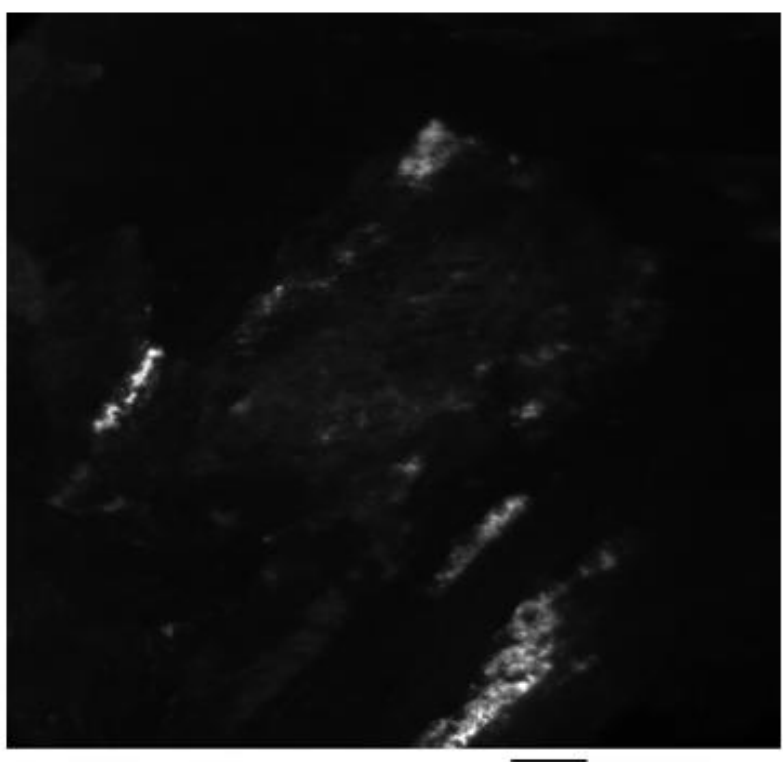

(c)

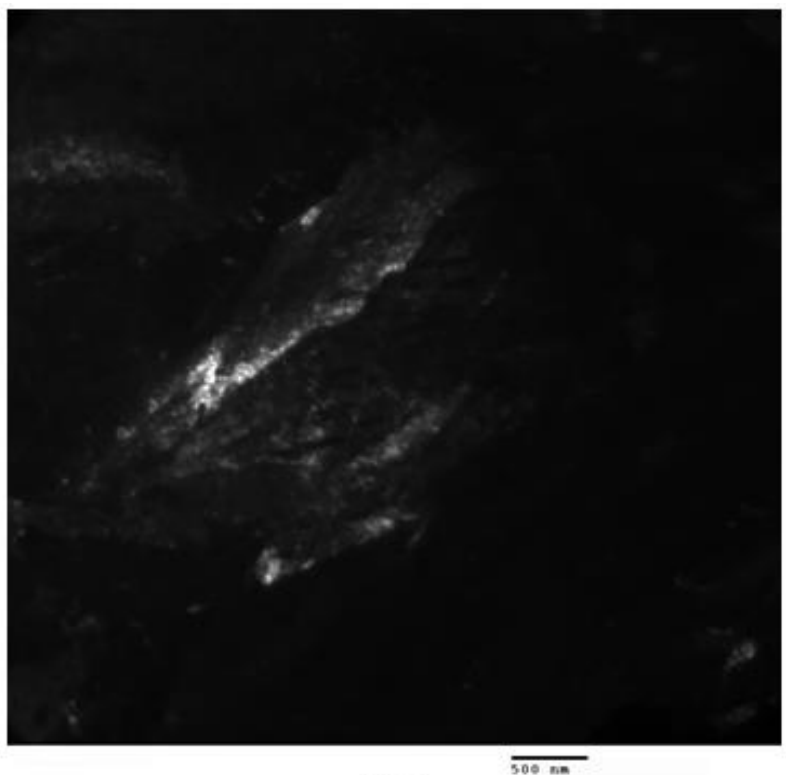

(b)

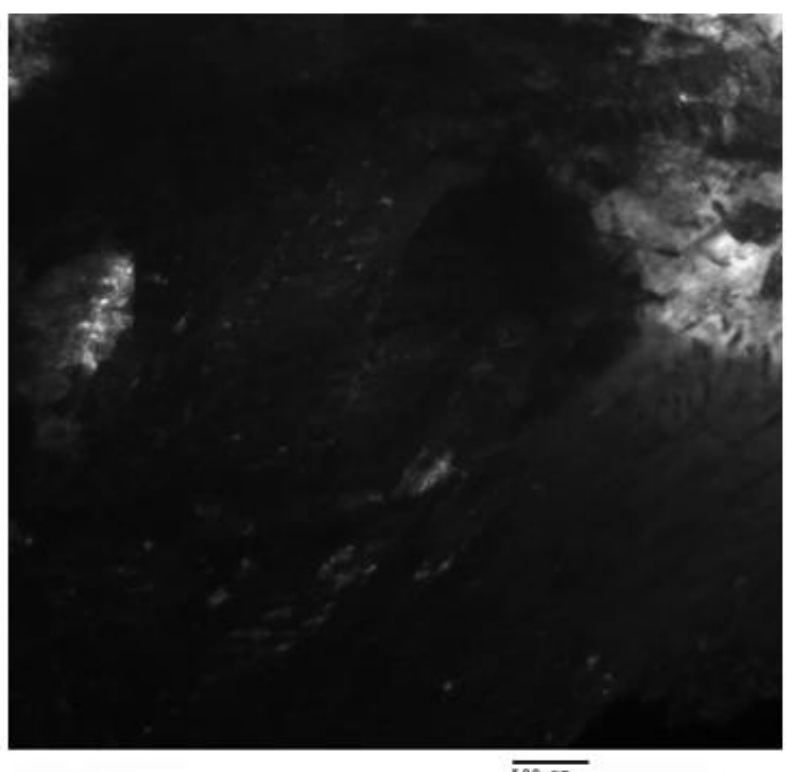

(d)

Figure 12: (a): Bright field image of AB1 material; (b): dark field image of spot 1 - $\alpha(011)$ reflection; (c): dark field image of spot 2 - $\alpha(121)$ reflection; and (d): dark field image of spot 6 - $\alpha(110)_{\text {II }}$ [Magnification: 25000X] 


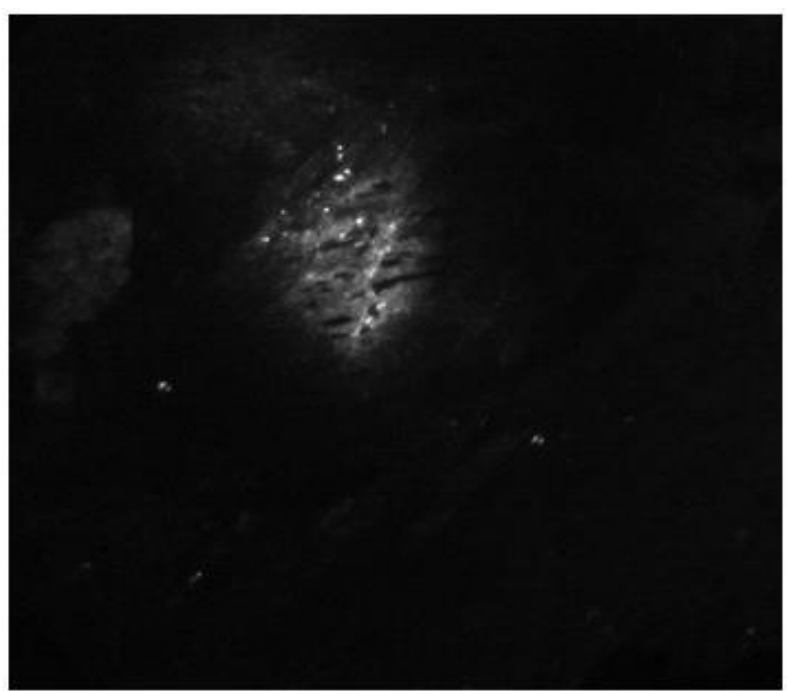

(e)

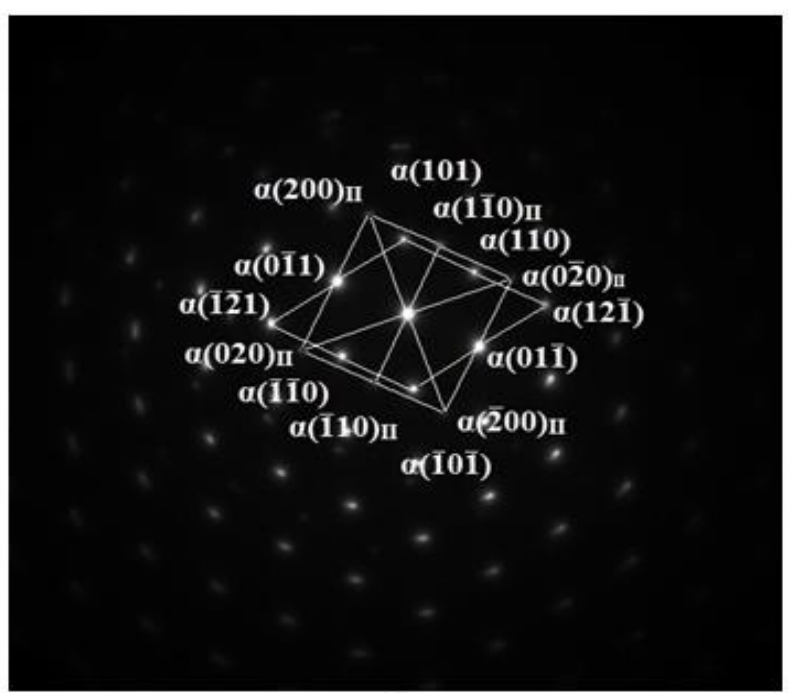

(f)

Figure 12: (e): Dark field image of spot 5 - $\alpha(020)_{\text {II }}$ [Magnification: $\left.25000 X\right]$; (f): SAD pattern of AB1 material from bright field image (figure 12 (a))

Table 5: Diffraction indices of AB1 material

\begin{tabular}{|c|c|c|c|}
\hline Spot & $\begin{array}{c}\text { Measured d spacing } \\
(\AA)\end{array}$ & $(\mathbf{h k l})$ & Calculated d \\
& 2.0827 & $\alpha(01 \overline{1})$ & 2.0293 \\
\hline 1 & 1.2027 & $\alpha(12 \overline{1})$ & 1.1717 \\
\hline 2 & 2.0938 & $\alpha(110)$ & 2.0293 \\
\hline 3 & 2.0957 & $\alpha(101)$ & 2.0293 \\
\hline 4 & 1.4733 & $\alpha(0 \overline{2} 0)_{\text {II }}$ & 1.4350 \\
\hline 5 & 2.0920 & $\alpha(1 \overline{1} 0)_{\text {II }}$ & 2.0293 \\
\hline 6 & 1.4807 & $\alpha(200)_{\text {II }}$ & 1.4350 \\
\hline 7 & & & \\
\hline
\end{tabular}

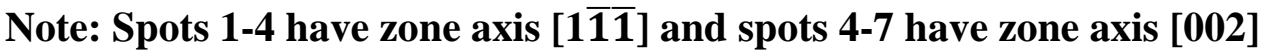


Figure 12 (a) - (f) shows the bright field, dark field and the SAD pattern of the austempered 4140 material at $349^{\circ} \mathrm{C}(\mathrm{AB} 1)$. Table 1 lists the indices of the SAD pattern in Figure 12 (f). It is evident from the figure 12 and table 5 that the material has predominantly $\alpha$ phase as seen in the XRD analysis. All the diffraction spots obtained were linked to $\alpha$ phase having BCC crystal structure. Since Austenite $(\gamma)$ phase could not be resolved in the obtained SAD patterns, the $\alpha$ phase could not be characterized into Tempered Martensite ( $\left.\alpha^{\prime}\right)$ and Bainite $(\alpha)$ distinctly which have the BCT and BCC crystal structure respectively. The $\gamma$ phase shares specific orientation relationship with the $\alpha^{\prime}$ and $\alpha$ phases in order to effectively characterize them separately [69]. Due to lack of $\gamma$ phase (almost less than $1 \%$ in volume fraction), the diffraction patterns of $\alpha$ phase were not able to be differentiated into $\alpha$ ' and $\alpha$ phases distinctly. However, going by the single orientation of carbides within the lath (Figure 12(a) and (d)), it could said they are from the lower Bainite $(\alpha)$ phase [55] and considering the fact the austempering temperature was very close to the Ms temperature, both theoretical [70,71] and from the CCT diagram [72]. From the table 5, the spots from 1 to 4 were found to be parallel to the electron beam having a zone axis of [11̄1] and the other spots from 5 to 7 were oriented parallel to the zone axis [002]. The calculated d spacing for all the spots were based on considering that $\alpha^{\prime}$ and $\alpha$ phases both had BCC crystal structure. Even though tempered martensite ( $\left.\alpha^{\prime}\right)$ has a BCT crystal structure, the calculated c/a ratio for 4140 steel was found to be $1.0213(\approx 1)$ from the martensite parameter equations [73]. Hence, it was considered to have a BCC crystal structure and the measured d spacing values are in agreement with the calculated d spacing values. This proves that it is a valid assumption. Although the Austenite $(\gamma)$ phase could not be resolved in the TEM analysis due to extremely small volume fraction, the relative closeness of the austempering temperature to the Ms temperature of this steel, the existence of only $\alpha$ diffraction spots in the SAD pattern 
predominantly; and the single orientation of carbides particles could be satisfactorily used as evidence for the presence of tempered martensite and lower bainite phases in this material AB1 austempered at $349^{\circ} \mathrm{C}$. 


\section{Austempered Batch - 2 (AB2) TEM imaging}

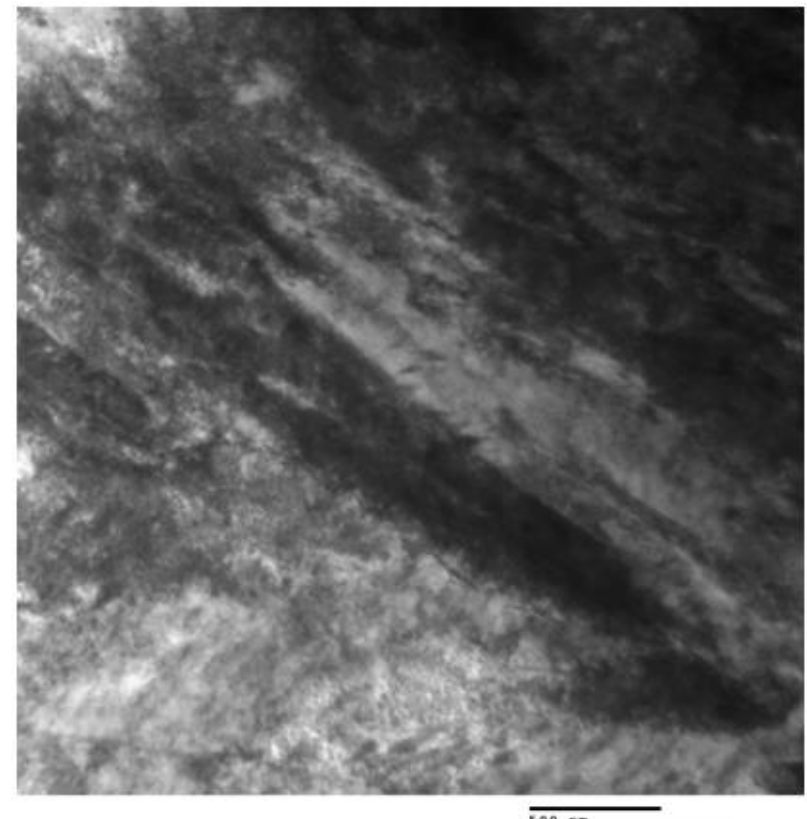

(a)

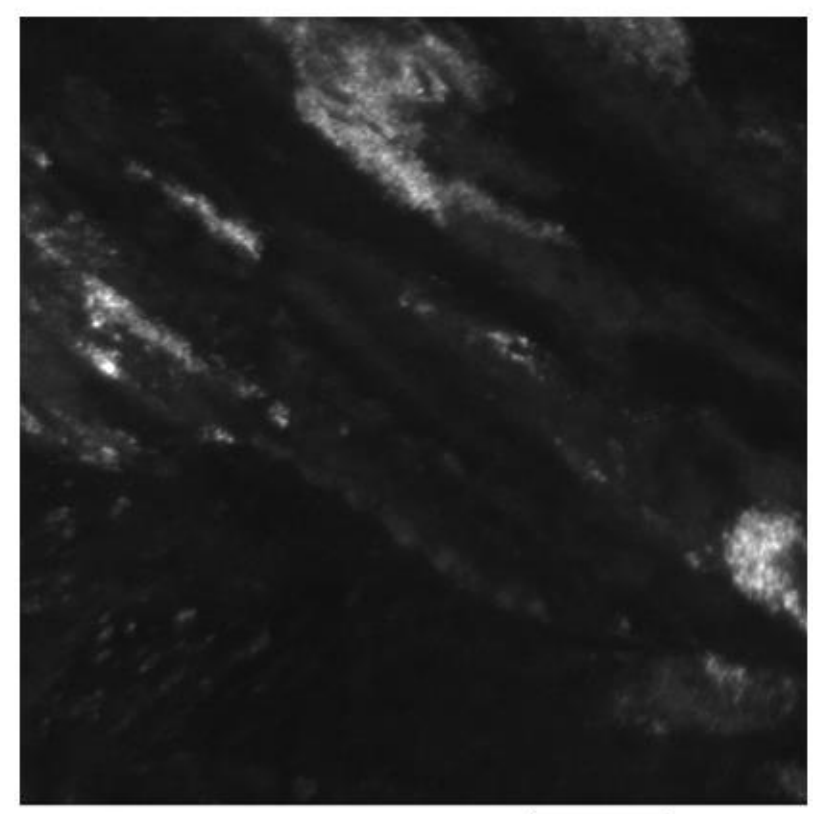

(c)

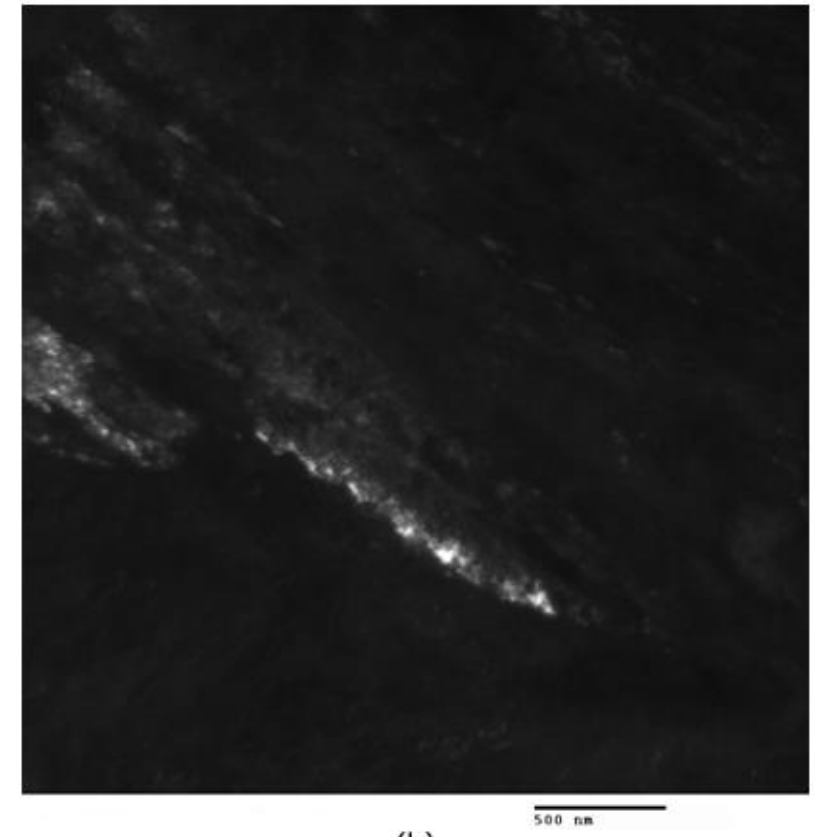

(b)

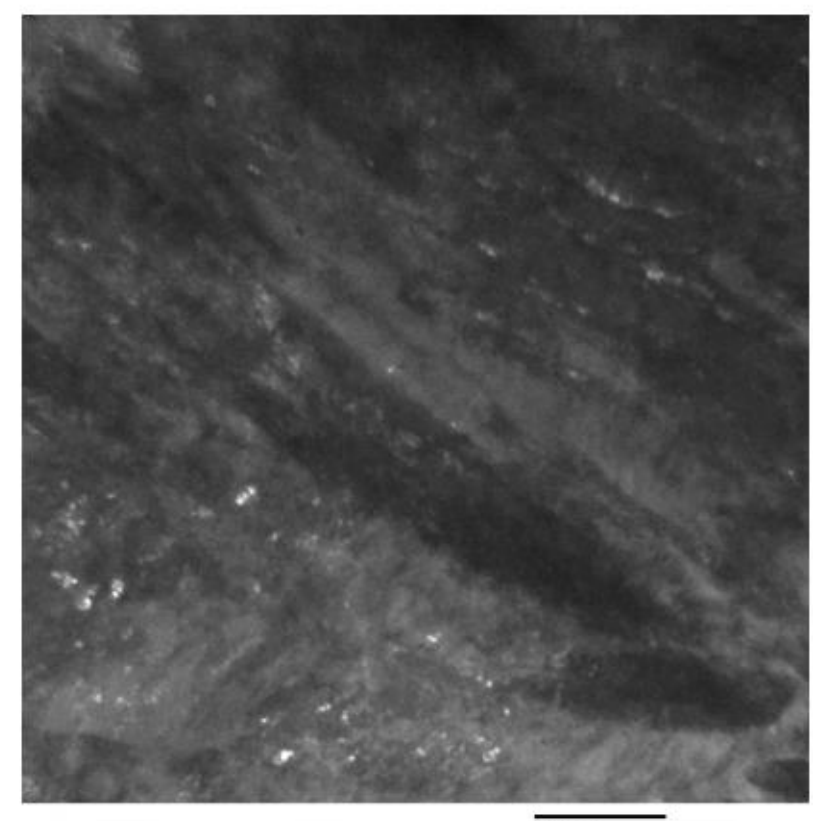

(d)

Figure 13: (a): Bright field image of AB2 material; (b): Dark field image of Spot 1 - $\alpha(110)$;

(c): Dark field image of Spot 4 - $\alpha(200) I I$; and (d): dark field image of Spot 6 - Fe3C(130)

[Magnification: 25000X] 


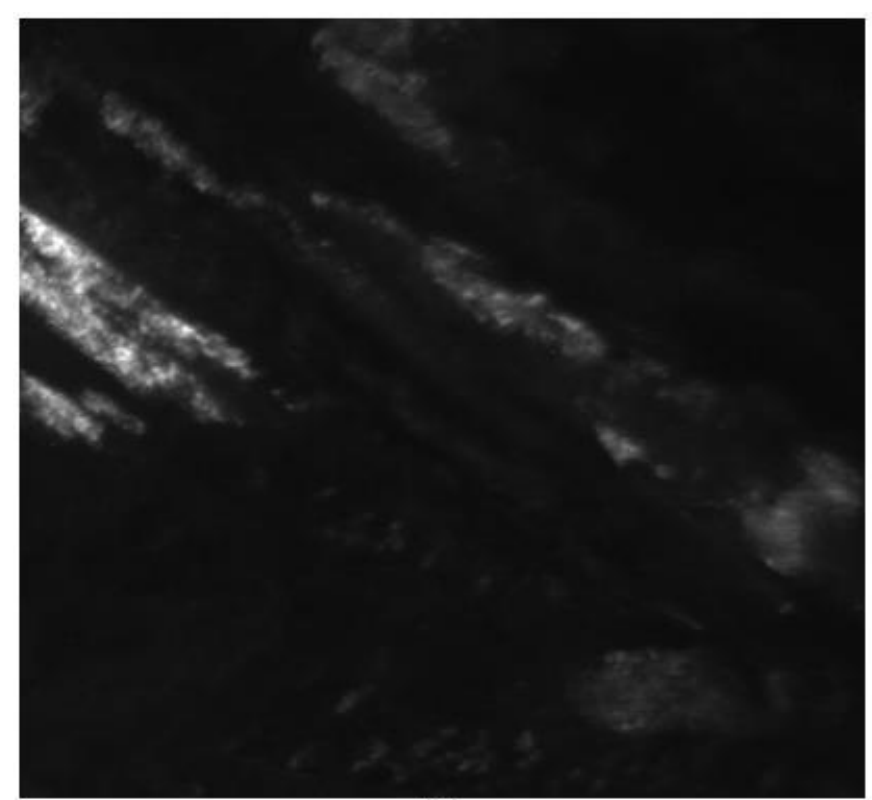

(e)

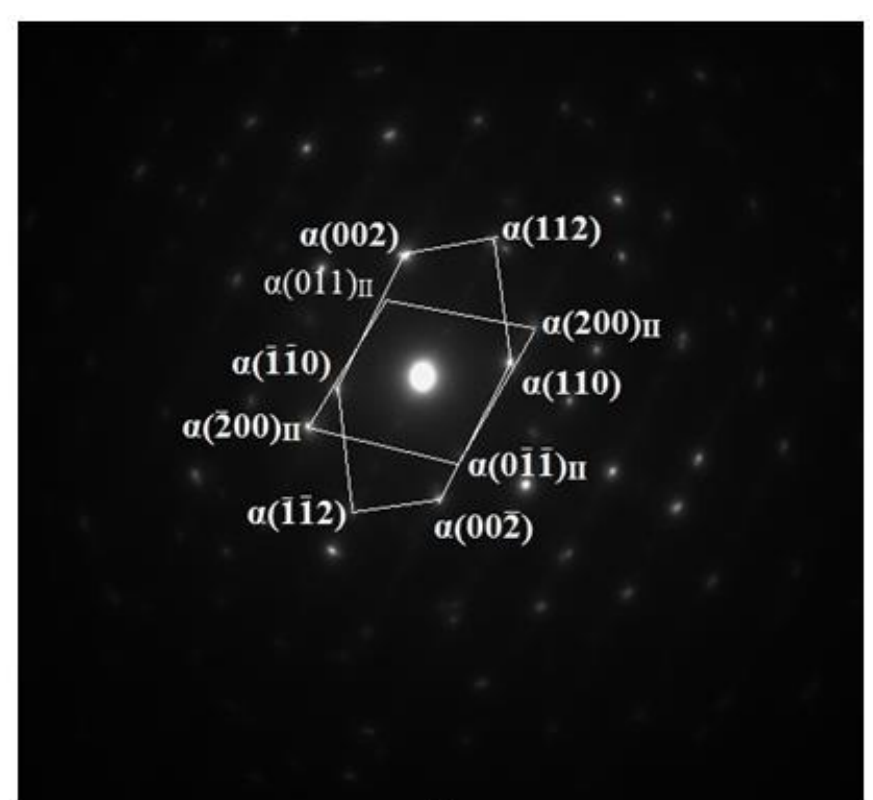

(f)

Figure 13: (e): Dark field image of Spot 4 - $\alpha(200)_{\text {II }}$ reflection [Magnification: 25000X];

(f): SAD pattern of AB2 material from bright field image (figure 13(a))

Table 6: Diffraction indexing of AB2 material

\begin{tabular}{|c|c|c|c||}
\hline Spot & $\begin{array}{c}\text { Measured d spacing } \\
(\mathbf{A})\end{array}$ & Calculated d \\
& 2.0882 & $\alpha(110)$ & 2.0293 \\
\hline 1 & 1.1954 & $\alpha(112)$ & 1.1716 \\
\hline 2 & 1.4632 & $\alpha(002)$ & 1.4350 \\
\hline 3 & 1.4623 & $\alpha(200)_{\text {II }}$ & 1.4350 \\
\hline 4 & 2.0919 & $\alpha(011)_{\text {II }}$ & 2.0293 \\
\hline 5 & 1.5834 & $\mathrm{Fe}_{3} \mathrm{C}(130)$ & 1.5878 \\
\hline 6 & & & \\
\hline
\end{tabular}

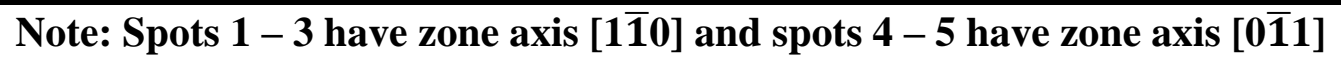


Figure 13 (a) - (f) shows the bright and dark field TEM images of the AB2 material austempered at $332^{\circ} \mathrm{C}\left(630^{\circ} \mathrm{F}\right)$. It is seen from the figure $13(\mathrm{a})$ that the material has a lath structure corresponding to that of tempered martensite and bainite with the small carbides suspended in the matrix. The SAD pattern in figure 13(f) showed mainly $\alpha$ and $\alpha$ ' peaks as listed in the table 6 in a similar fashion as in the $\mathrm{AB} 1$ material. The indexed patterns are parallel to two different zone axes. The spots $1-3$ have the electron beam parallel to the zone axis [11̄0] and the other spots $4-5$ have the zone axis [0111]. The dark field images of spots 1 and 4 are shown in figure 13 (b), (c) and (e). In addition, to the $\alpha$ ' and $\alpha$ phase having a $\mathrm{BCC}$ crystal structure, a $\mathrm{Fe}_{3} \mathrm{C}$ carbide having an orthorhombic crystal structure [74] was indexed from the SAD pattern in figure 13(f) having a direction of (130) from a faint diffraction spot in between spot 3 and 5 and its reflections (not shown in figure 13(f)). The zone axis for the $\mathrm{Fe}_{3} \mathrm{C}$ could not be found as carbides oriented in the other directions were not resolved for the obtained SAD pattern. However, the presence of $\mathrm{Fe}_{3} \mathrm{C}$ in the lath structure proves that the lower bainite phase is present in this material [69]. A similar argument from the $\mathrm{AB} 1$ material can be used for the $\mathrm{AB} 2$ material with reference to identifying the tempered martensite and bainite phases due to relatively very low volume fraction of Austenite phase $(\gamma)$ which was not resolved in the analysis. Since the austempering temperature $\left(332^{\circ} \mathrm{C}\right)$ is much closer to the calculated Ms temperature [70-71] of $322{ }^{\circ} \mathrm{C}$ and slightly below the Ms temperature from the CCT diagram of $4140\left(\approx\right.$ about $\left.350^{\circ} \mathrm{C}\right)$, a higher volume fraction percentage of tempered martensite $\left(\alpha^{\prime}\right)$ would be expected in the AB2 material.

In this analysis, in the $\mathrm{AB} 1$ and $\mathrm{AB} 2$ materials, based on the evidence of the lath structure observed from the bright field image (figure 12(a) and 13(a) and the single orientation of carbides within the lath structure, it may be concluded that both the tempered martensite and 
lower bainite are the phases present with relative differences in the volume fraction of these phases with the austempering temperature.

\section{External Hydrogen Charging}

After machining and cleaning, all these batches of samples (annealed as well as austempered) were then externally charged with hydrogen before conducting the fatigue crack growth tests. The experimental setup consisted of two DC power supplies: Agilent E3616A and Sorensen XPL-30-2D capable of providing a steady source of electric current of about 1-1.5 A, a Pyrex glass dish for the electrolyte and a stainless steel bar of about $4 \mathrm{~mm}$ thickness acting as the anode. The samples (annealed and austempered) to be charged with Hydrogen was used as a cathode. Sodium Hydroxide with a concentration of $1 \mathrm{~N}$ was used as the electrolyte for charging hydrogen into the samples. Deionized water obtained from Barnstead Nanopure Diamond D11911 having a resistivity of about $16.5+/-0.5 \mathrm{M} \Omega-\mathrm{cm}$ was used to dissolve the electrolyte. This was done to avoid the uptake of deleterious ions interfering with the fatigue crack growth rate test during the external hydrogen charging. The current density was maintained steady at $300 \mathrm{~A} / \mathrm{m}^{2}$ or $0.03 \mathrm{~A} / \mathrm{cm}^{2}$ and the samples were charged with hydrogen for different time periods ranging from 150-250 hours. A minimum of three samples were charged from each batch for each exposure time. A photograph of the experimental setup is shown in Figure 14. 


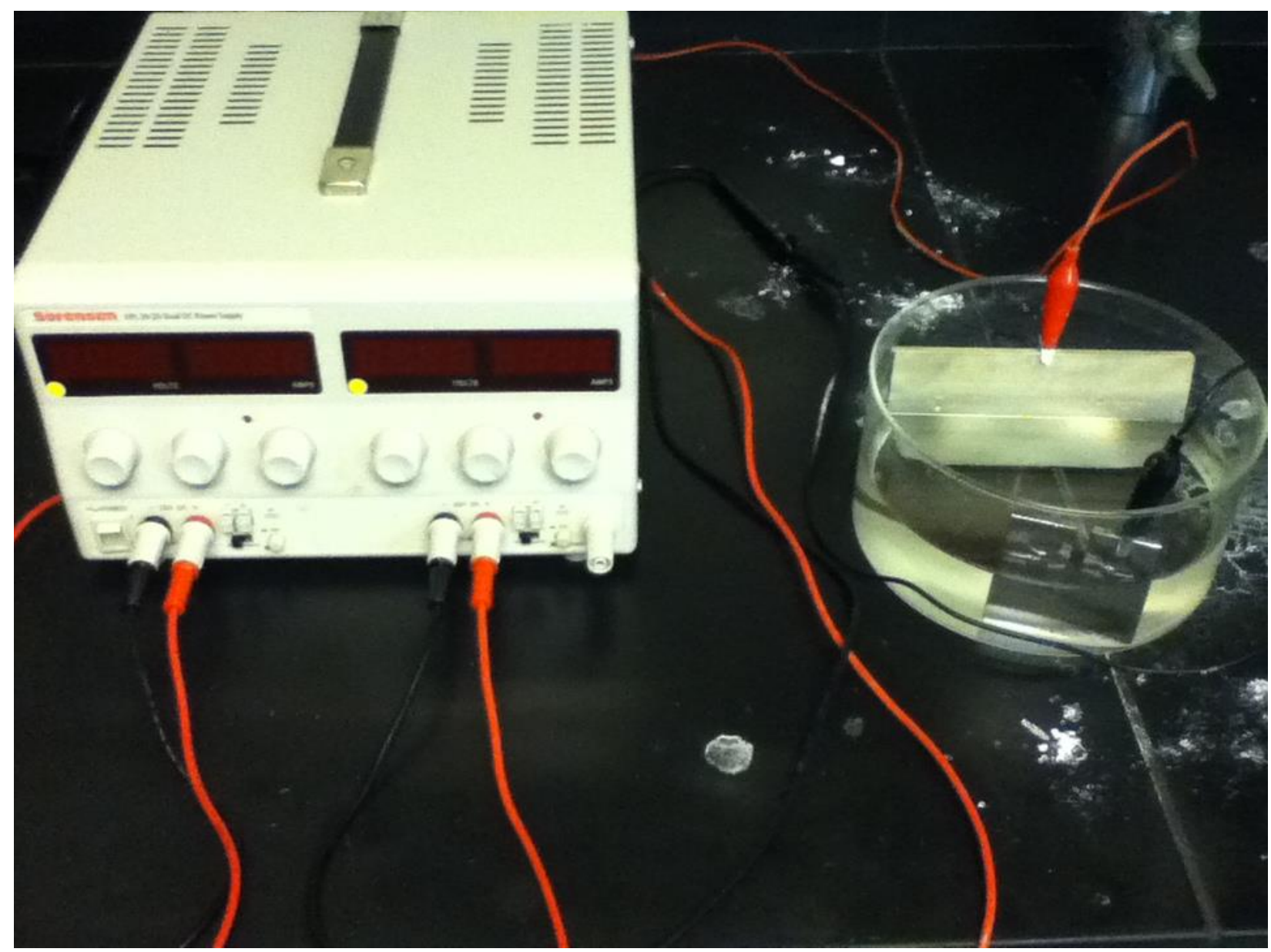

Figure 14: Experimental setup of external hydrogen charging

\section{Hydrogen Concentration Analysis (Vacuum Hot Extraction)}

The precharged samples with hydrogen were analyzed for the hydrogen concentration via a Vacuum Hot Extraction (VHE) method using NRC model 917. The precharged sample was first weighed out, cleaned with ether to remove surface contaminants and then introduced into an evacuated chamber surrounded by induction heating coil. The sample was then heated to a point just below the melting point of the sample to degas hydrogen from the sample which is collected in a separate chamber in the system. The amount of hydrogen is then measured by McLeod gauge. All the measurements were accurate to within $0.1 \mathrm{ppm}$. 


\section{Fatigue Testing}

After precharging with hydrogen, the specimens were precracked in fatigue to produce a $2 \mathrm{~mm}$ sharp crack front in accordance with ASTM standard E-647 [66]. Fatigue testing of these samples was carried out in a servo hydraulic Material Test System (MTS 810) test machine under load control mode in room temperature and ambient atmosphere. All fatigue testing was carried out at a cyclic loading frequency of 5 cycles per second. A constant amplitude sinusoidal waveform was applied and the tests were carried out at a load ratio $\mathrm{R}=\mathrm{K}_{\max } / \mathrm{K}_{\min }=0.10$.

Crack lengths were measured on the specimen surface using an optical microscope. At the same time, the number of fatigue cycles was also recorded. The crack growth rate, da/dN, was determined as per ASTM standard E-647 [66].

The threshold was obtained using a load shedding decreasing $\Delta \mathrm{K}$ procedure of ASTM E-647 standard [66]. The load was periodically decreased until the crack growth rate reached a level of $10^{-10} \mathrm{~m} /$ cycle. The reduction of load at any $\Delta \mathrm{K}$ level was done in such a way that no more than $10 \%$ of the load was reduced at any $\Delta \mathrm{K}$ level. This load shedding was also done after the crack has grown at least $0.5 \mathrm{~mm}$ at any $\Delta \mathrm{K}$ level. In this way any retardation effect due to previous higher $\Delta \mathrm{K}$ level was avoided.

The fatigue crack growth rate data in the linear region was obtained using the increasing $\Delta \mathrm{K}$ procedure of ASTM E-647 standard [66]. The cyclic load was estimated initially at a given $\Delta \mathrm{K}$ level at the start of the test. It was cycled and held constantly at the same initial value as test progressed. As the crack propagated with time, the $\Delta \mathrm{K}$ at the notch increased with the increase in crack length. The test was continued until the specimen fractured. 
Three specimens were tested from each condition in identical manner in the threshold region and three specimens were tested in the linear region for each hydrogen concentration and the average values from three test specimens were taken as the representative of the crack growth rate at any $\Delta \mathrm{K}$ level. These average data from three test samples were plotted on the log-log scale for the threshold region and the linear region. A best fit line was drawn in the linear region through these data points.

\section{Stress Corrosion Cracking Testing}

The samples (annealed and austempered) were initially precracked in fatigue for $2 \mathrm{~mm}$ in a servo-hydraulic MTS test machine to produce a sharp crack front. After precracking, the samples were charged internally with hydrogen using the method mentioned earlier. After hydrogen charging the samples were tested at a constant load at various initial stress intensity levels.

The crack extensions on the surface of specimens were monitored constantly by an optical travelling microscope and a timer was used to record the corresponding time intervals for the crack growth rate. The incubation time period for the crack growth was also determined and crack extensions were recorded periodically. Crack length versus time was plotted and a polynomial was fitted through these data. Crack growth rates were henceforth determined by differentiating these polynomials.

\section{Fractography}

The fracture surfaces obtained after the fatigue crack growth testing were analyzed using the JEOL JSM - 6510 LV SEM. In addition to this, some images were also obtained using JEOL 
JSM - 6610 LV SEM and JEOL JSM - 7600 FESEM. The fracture images obtained were then used to analyze the fracture surface morphology and crack growth mechanism in annealed and the two batches of austempered specimens to characterize the corrosion fatigue behaviour. 


\section{CHAPTER 5 - RESULTS}

\section{Influence of Time on dissolved hydrogen concentration}

Both the annealed and austempered (AB1 and AB2) specimens were charged with hydrogen for same periods of time namely 150, 200, and 250 hrs respectively. Table 3 shows the effect of charging times on the hydrogen concentration. It is evident from the table that both annealed and AB1 had similar concentration of dissolved of hydrogen. Both the microstructure had predominantly body centered cubic structure as X-ray showed. While there was some difference in microstructure of the samples; the annealed material had ferritic pearlite and austempered samples at $349^{\circ} \mathrm{C}$ and $332^{\circ} \mathrm{C}$ had tempered martensite and bainite structure. But, all of the samples had BCC structure. Since the diffusion of hydrogen in low alloy ferritic steels is relatively the same and occurs at fast rates [42, 75-76], this small microstructural difference did not affect significantly the dissolved hydrogen content in the annealed and the austempered AB1 sample. However, in the case of AB2 sample, it was found to have significantly higher amounts

of dissolved hydrogen. The thickness of the AB2 were slightly thinner than those of annealed as well as the AB1sample. The following equations [77] describe the concentration of hydrogen in exposed specimens:

$$
\begin{aligned}
& J_{\infty}=\frac{I_{\infty}}{F A} \quad-(3) \\
& D_{e f f}=\frac{d^{2}}{6 t_{L}} \quad-(4) \\
& C_{0}=\frac{J_{\infty} d}{D_{e f f}} \quad-(5)
\end{aligned}
$$


Where, $\mathrm{J}_{\infty}=$ Hydrogen permeation flux

$$
\begin{aligned}
& I_{\infty}=\text { Saturation current density } \\
& A=\text { Area of specimen through which diffusion occurs } \\
& F=\text { Faraday constant } \\
& D_{\text {eff }}=\text { Effective hydrogen diffusivity } \\
& d=\text { specimen thickness } \\
& t_{L}=\text { time-lag in seconds for } 0.63 \text { saturation extrapolated from the permeation curve } \\
& C_{0}=\text { Hydrogen concentration on the cathodic side }
\end{aligned}
$$

All other things being constant or almost same due to similar nature of microstructure, except for thickness which is slightly lower in austempered samples at $332^{\circ} \mathrm{C}(\mathrm{AB} 2)$, it would be expected that this samples must have lower $\mathrm{C}_{0}$ based on equations (3) and (4) for the same charging time. However, a contrasting behaviour is observed in this study. A threefold explanation could be offered for such behaviour. Firstly, the martensitic start $\left(\mathrm{M}_{\mathrm{s}}\right)$ temperature for this alloy, as calculated from the following theoretical equation [71] below yields $322^{\circ} \mathrm{C}$ which is comparable to the published value of $345^{\circ} \mathrm{C}$ for AISI 4140 [45]:

$$
\begin{gathered}
\mathrm{M}_{\mathrm{S}}=512-(453 \times \% \mathrm{C})-(16.9 \times \% \mathrm{Ni})+(15 \times \% \mathrm{Cr})-(9.5 \times \% \mathrm{Mo})+\left(217 \times(\% \mathrm{C})^{2}-(71.5 \times\right. \\
\% \mathrm{C} \times \% \mathrm{Mn})-(67.6 \times \% \mathrm{C} \times \% \mathrm{Cr})-(4)
\end{gathered}
$$

Since the austempering temperature for this sample (AB2) is $332^{\circ} \mathrm{C}$, very close to the $\mathrm{M}_{\mathrm{s}}$ temperature, it is expected that this batch of austempered samples have a higher fraction of tempered martensite along with the bainite. 
Secondly, martensitic structures have a higher dislocation density than the bainitic structure [42]. Henceforth, these dislocations act as hydrogen traps in the material. The presence of the traps reduce the diffusivity of hydrogen to lower value than estimated by equation (3). Evidence in literature [78] also points that diffusivity of hydrogen in steel cannot be determined by application of Fick's law (as in equation (3)) in the presence of traps in the material. In this case, it is reasonable to state that sufficiently large number of traps are present in the material austempered at $332^{\circ} \mathrm{C}(\mathrm{AB} 2)$ purely based on the higher concentration values of hydrogen obtained in this material. In addition, in other Cr-Mo steels [42], the diffusion coefficient of martensite was found to be marginally lower than bainite and also the diffusion coefficient reduces with the increased strength of the alloy [76]. Owing to all these reasons, the samples austempered at $332^{\circ} \mathrm{C}(\mathrm{AB} 2)$ had almost a two fold increase in the hydrogen concentration for the same charging time compared to the other two batches.

Table 7: Influence of charging time on hydrogen concentration

\begin{tabular}{|c|c|c|}
\hline Material Condition & Charging time (hrs) & $\begin{array}{c}\text { Hydrogen Concentration } \\
\text { (ppm) }\end{array}$ \\
\hline \multirow{3}{*}{ Annealed } & 150 & 0.7 \\
\hline & 200 & 1.5 \\
\hline & 250 & 2.9 \\
\hline \multirow{3}{*}{$\begin{array}{c}\text { Austempered } \\
\left.\text { (Batch } 1-349^{\circ} \mathrm{C}\right)-\mathrm{AB} 1\end{array}$} & 150 & 0.7 \\
\hline & 200 & 1.5 \\
\hline & 250 & 2.9 \\
\hline \multirow{3}{*}{$\begin{array}{c}\text { Austempered } \\
\left(\text { Batch } 2-3^{\circ}{ }^{\circ} \mathrm{C}\right)-\mathrm{AB} 2\end{array}$} & 150 & 1.6 \\
\hline & 200 & 3.6 \\
\hline & 250 & 8.1 \\
\hline
\end{tabular}




\section{Fatigue crack growth behaviour of the material in Annealed (as-received)} condition

\section{Linear region}

Figure 15 compares the fatigue crack growth rates in the linear region of annealed specimens with different dissolved hydrogen concentration. All the data for the fatigue crack growth behaviour is shown on a log-log scale. It is evident that the dissolved hydrogen causes increase in the crack propagation rates in the linear region. It is seen that as the dissolved hydrogen concentration increases the slope $(\mathrm{m})$ of the Fatigue Crack Growth Rate (FCGR) curves increases indicating the degradation effects of hydrogen at higher concentration in the annealed condition. However, the effect is not as significant as in the threshold region (explained in the next section). This is indicated by the closeness of the fitted curves to one another at various increasing levels of dissolved hydrogen. In the annealed material treated for $250 \mathrm{hrs}$, it is seen from the graph that the FCGRs are very high until about $40 \mathrm{MPa} \sqrt{\mathrm{m}}$ compared to all other hydrogen charging condition and then begins to marginally decline to lower crack growth rate than the $150 \mathrm{hrs}$ samples. Also, it is worthwhile to note that in the case of $250 \mathrm{hrs}$ exposure to hydrogen, the value of $\mathrm{C}$ and $\mathrm{m}$ in annealed specimen is lower than those exposed to hydrogen for $200 \mathrm{hrs}$ (shown later in Tables 10 and 11). This effect can be attributed to the diminished influence of diffused hydrogen to the crack tip on fatigue crack growth rates at high $\Delta \mathrm{K}$ levels. It must be pointed out that the higher fatigue threshold and lower near threshold crack growth rate in $250 \mathrm{hrs}$ exposed annealed specimen can be attributed to the similar effect. Above $1.5 \mathrm{ppm}$ hydrogen concentration, hydrogen does not appear to significantly affect the fatigue crack growth rate in the lower strength (annealed) material as observed in the linear region. Above this 
value for the annealed specimen, the effect of hydrogen may be beneficial in the alloy with very minimal degradation effects. Further investigations are necessary to verify this behaviour.

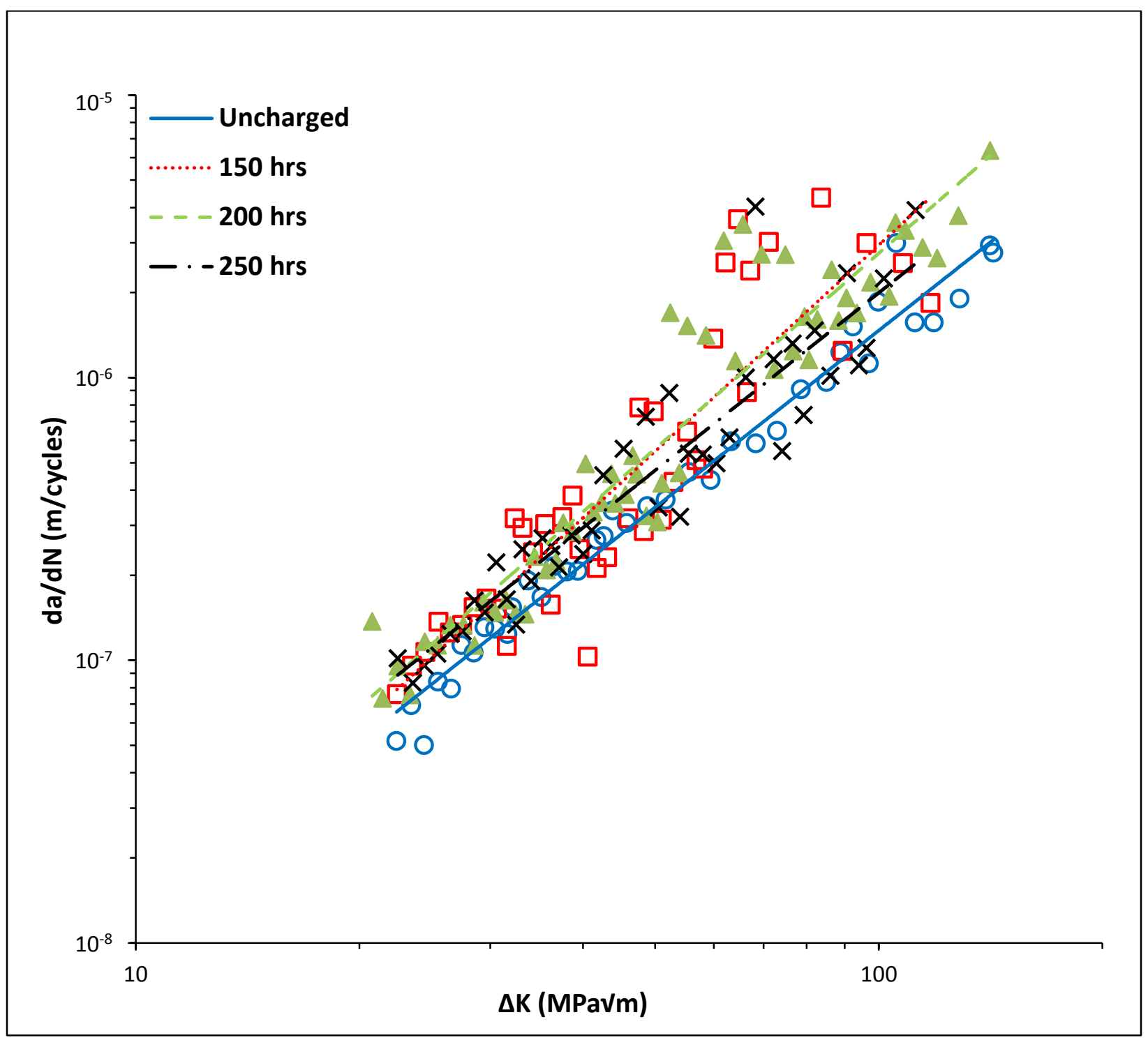

Figure 15: Comparison of fatigue crack growth rate in the linear region for annealed samples 


\section{Linear Region Fractographs}

The fracture surface of the annealed specimen is shown in Figure 16. The annealed specimens show crystallographic failure. However, the annealed specimen show increasingly brittle features with increasing hydrogen concentration with crack branching visible at $250 \mathrm{hrs}$ exposure with some transgranular (TG) facets. 


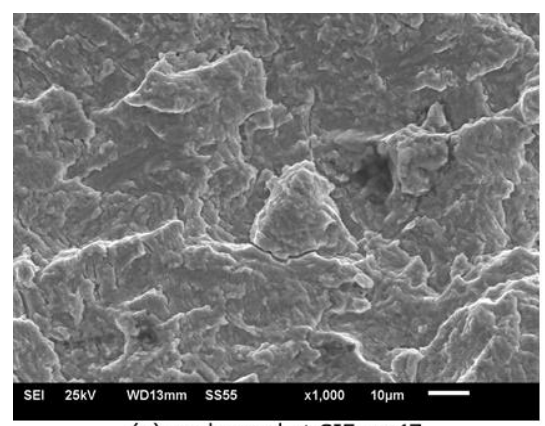

(a) uncharged at SIF 47

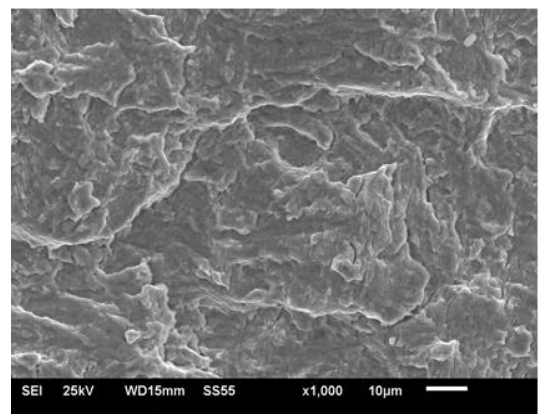

(d) 150 hrs at SIF 47

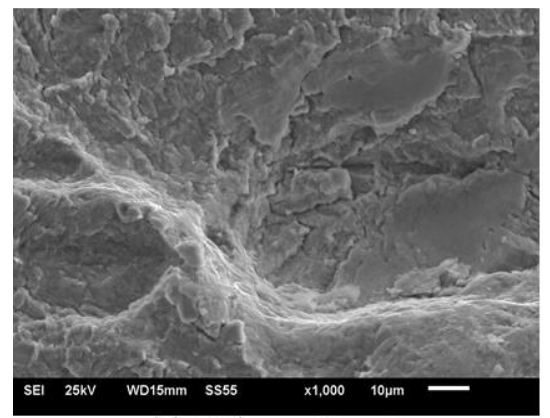

(g) 200 hrs at SIF 45

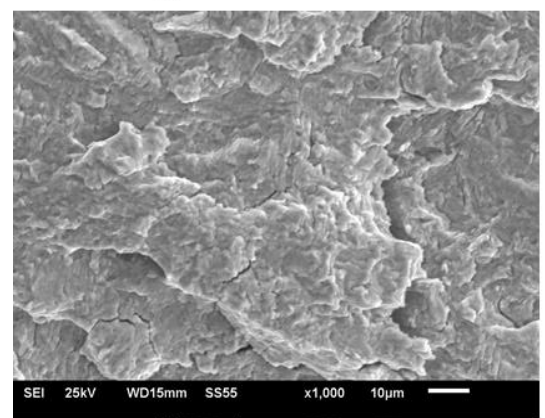

(j) 250 hrs at SIF 45

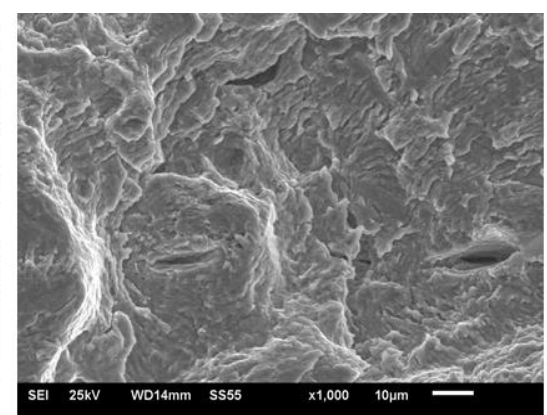

(b) uncharged at SIF 123

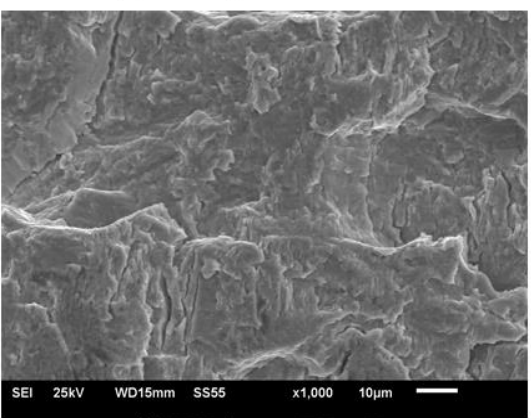

(e) 150 hrs at SIF 62

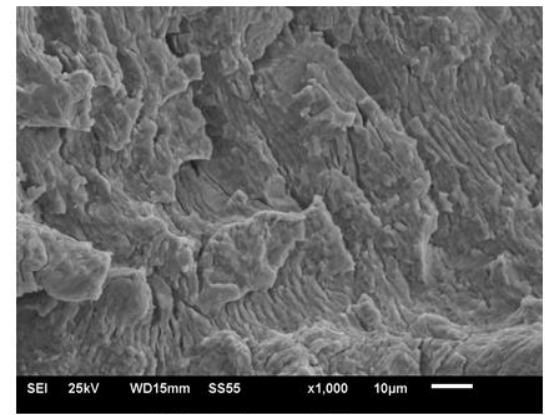

(h) 200 hrs at SIF 64

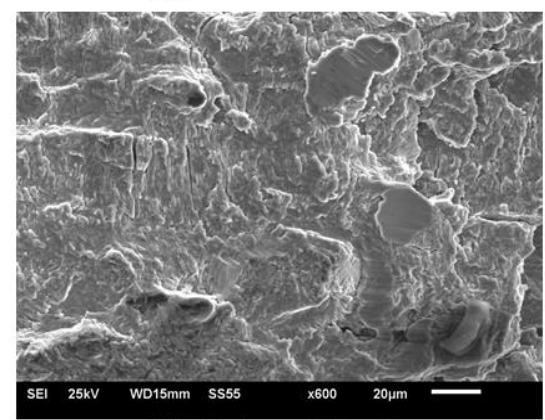

(k) 250 hrs at SIF $~ 60$

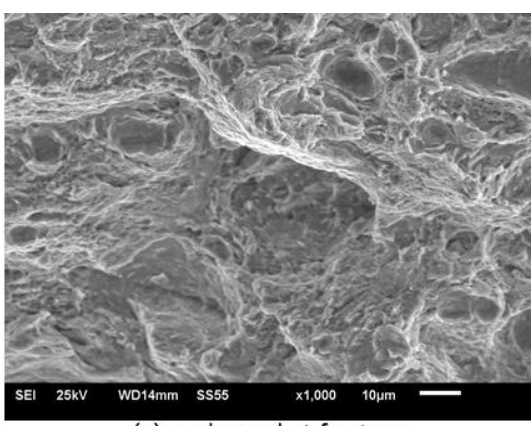

(c) uncharged at fracture

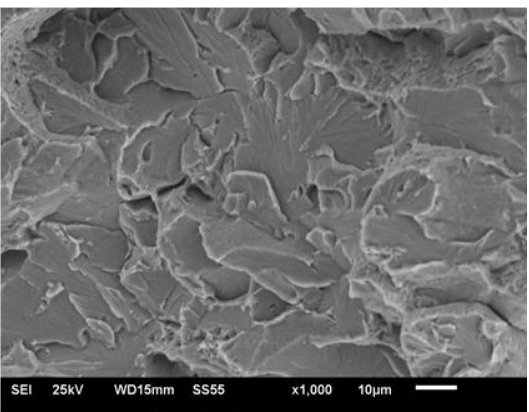

(f) $150 \mathrm{hrs}$ at fracture

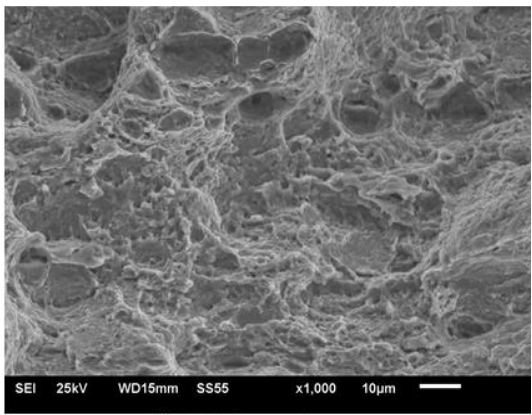

(i) $200 \mathrm{hrs}$ at fracture

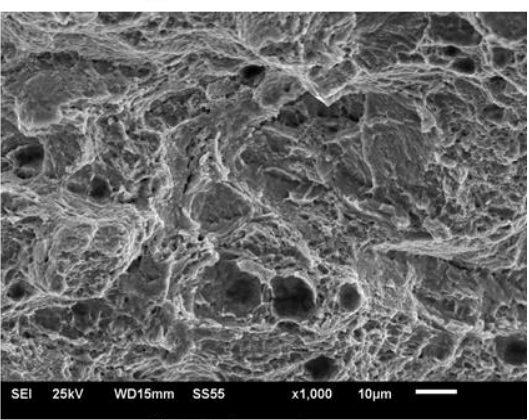

(i) $250 \mathrm{hrs}$ at fracture

Figure 16: Fatigue surface images of annealed material in linear region ( $\Delta K$ (SIF) are in

$\mathrm{MPa} \sqrt{ } \mathrm{m})$ [Note: Crack propagation from right to left in all images; Magnification: 1000X] 


\section{Threshold Region}

Figure 17 shows the effect of dissolved hydrogen on the near threshold fatigue crack growth behaviour of annealed samples. Owing to the lower strength in the annealed specimens, the difference in the fatigue crack growth rate between the samples having no hydrogen and samples with dissolved hydrogen was not very significant. In Table 8, the fatigue threshold values for the annealed samples with different hydrogen exposure times are compared. Figure 17 and Tables 8 and 9 show that the crack growth rate and the fatigue threshold in annealed specimens are not significantly affected by dissolved hydrogen content.

In case of annealed specimens, the $250 \mathrm{hrs}$ charged samples shows an interesting behaviour. The crack growth rate in 250 hrs charged samples are lower than the samples without any hydrogen. It is very interesting to note that the annealed specimens charged with hydrogen for $250 \mathrm{hrs}$ had a higher threshold than the annealed specimens without any dissolved hydrogen content. This behavior is quite interesting as hydrogen is well known to degrade the fatigue life of the alloy steels [79]. The reason for this unusual behaviour is not yet clear. However, it appears that there is a threshold limit for dissolved hydrogen in a material and beyond that limit, it could be beneficial. This limit in the annealed samples appears to be $1.5 \mathrm{ppm}$ as seen in the linear and as well as threshold region.

A possible explanation for this kind of behaviour is based on the combined influence of strength of the alloy in annealed condition and the influence of hydrogen in the lower $\Delta \mathrm{K}$ region. Other investigators [80] have also reported that hydrogen does not play a significant role in the fatigue crack propagation in low yield strength materials. They have reported that [80] the fatigue threshold stress intensity factor is higher in hydrogen than in air in low strength steels. In addition, it is also reported [81] that the fatigue crack growth rate is lower in hydrogen 
environment than in air in some low strength materials upto a $\Delta \mathrm{K}$ of about $12 \mathrm{MPa} \sqrt{\mathrm{m}}$. Hence, a combined effect of the lower strength of the 4140 alloy in the annealed condition and a diminished effect of hydrogen in the lower $\Delta \mathrm{K}$ of about $12 \mathrm{MPa} \sqrt{\mathrm{m}}$ is the reason why the fatigue threshold is higher and the fatigue crack growth rate is lower for the 250 hrs hydrogen exposed specimen than in air as seen from the Figure 17 and Table 9. A similar behaviour has been reported elsewhere for 4140 steel (SCM 440) [82] for the annealed condition. It was reported that there was no reduction in area during a tensile test in hydrogen environment upto a pressure of $10 \mathrm{MPa}$. Since ductility is not reduced, fatigue threshold will not be affected. The fatigue threshold depends on the cyclic plasticity of the material which in turn depends on the ductility of the material. Therefore, this is a preliminary supportive evidence that hydrogen may be beneficial in 4140 steel in the annealed condition upto a threshold limit wherein the fatigue and tensile properties may be enhanced due to the presence of small amounts of hydrogen in the material. 


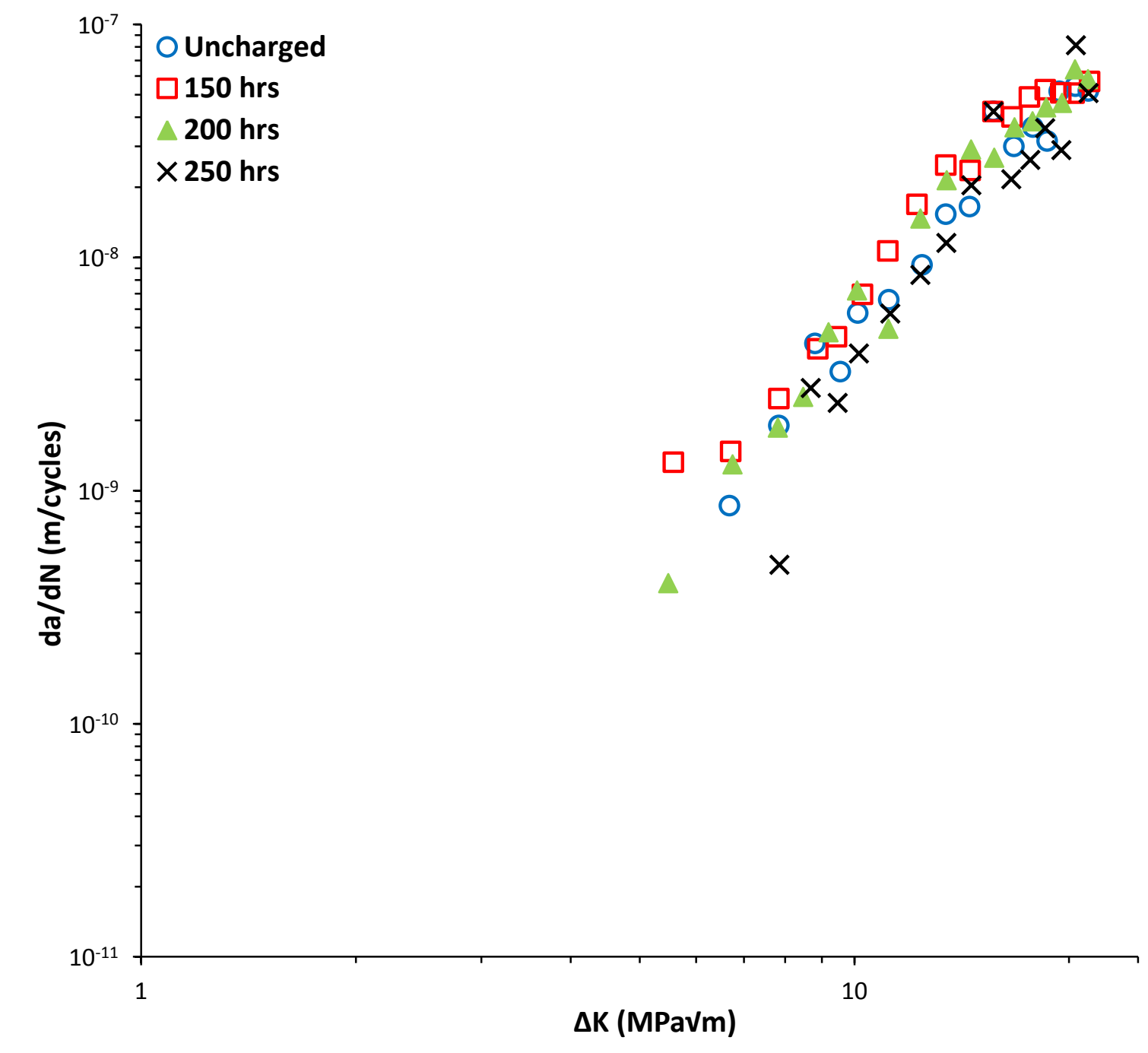

Figure 17: Comparison of fatigue crack growth rate in the near threshold region for annealed samples

\section{Threshold region fractographs}

Fractographs of the annealed specimens (Figure 18) without any dissolved hydrogen show typical crystallographic striation like crack growth surfaces with some TG features in the middle, while the specimens with dissolved hydrogen show the presence of quasi cleavage fracture (150 hrs) with micro cracks, crack branching (200 hrs) and TG features (250 hrs). 


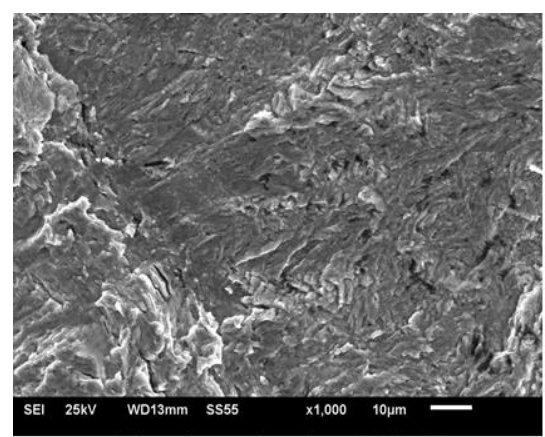

(a) uncharged at threshold SIF

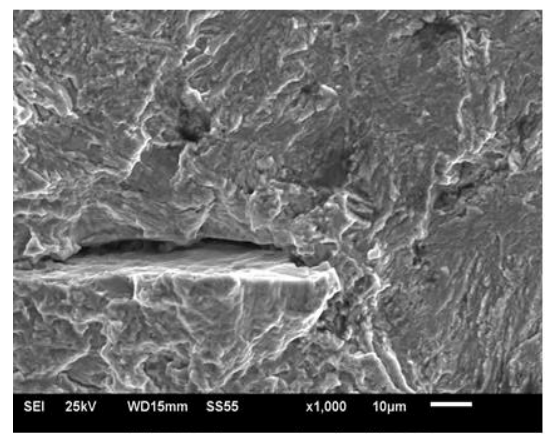

(d) $150 \mathrm{hrs}$ at threshold SIF

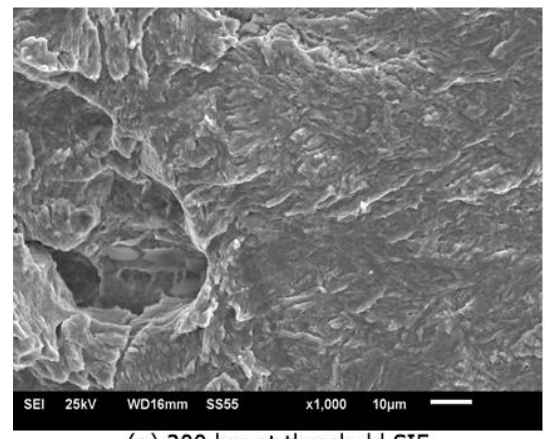

(g) $200 \mathrm{hrs}$ at threshold SIF

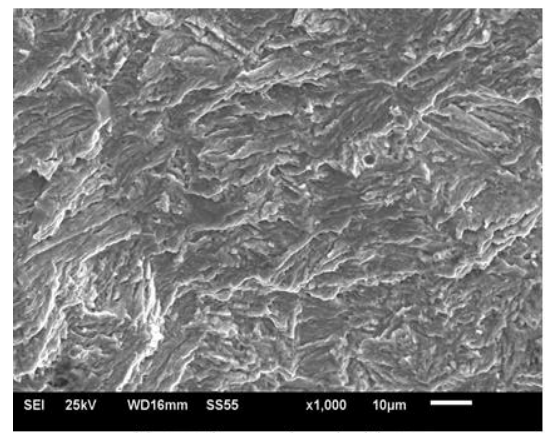

(j) $250 \mathrm{hrs}$ at threshold SIF

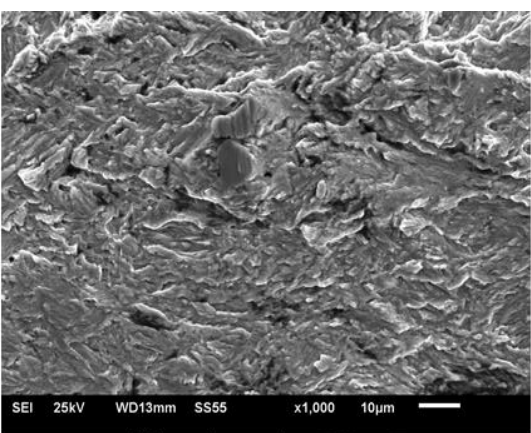

(b) uncharged at SIF 9

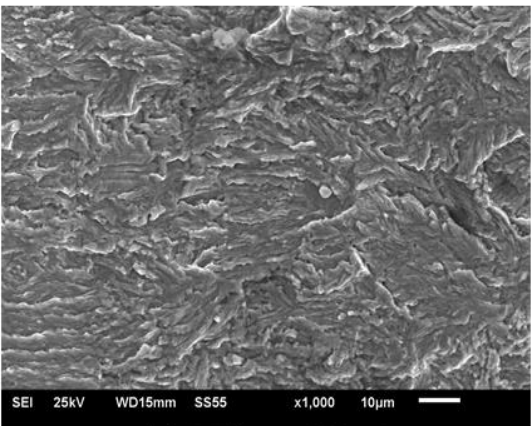

(e) 150 hrs at SIF 9

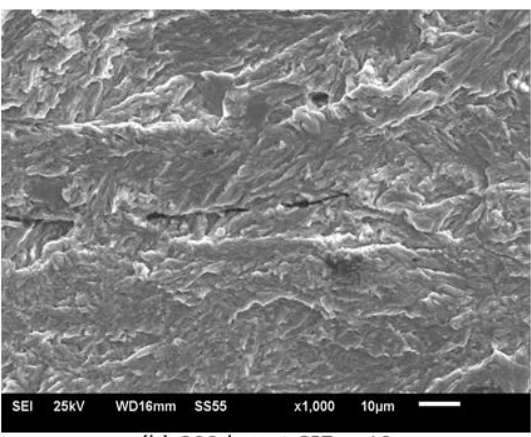

(h) 200 hrs at SIF 10

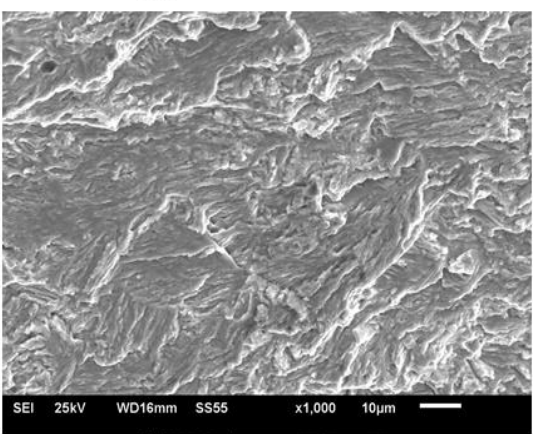

(k) 250 hrs at SIF 12

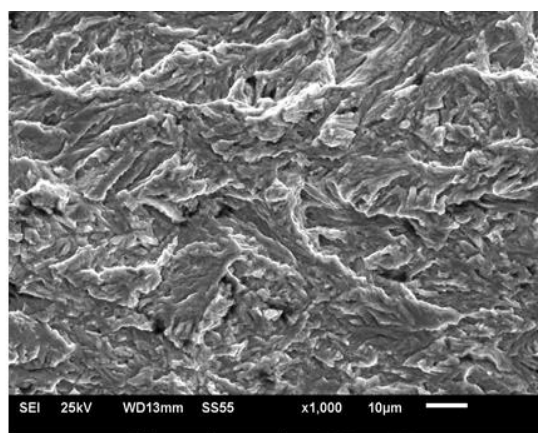

(c) uncharged at SIF 12

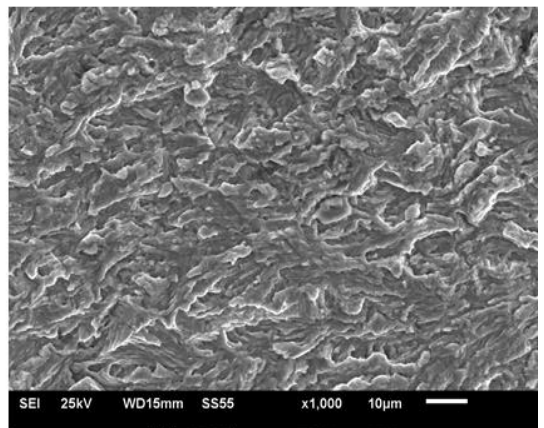

(f) 150 hrs at SIF 12

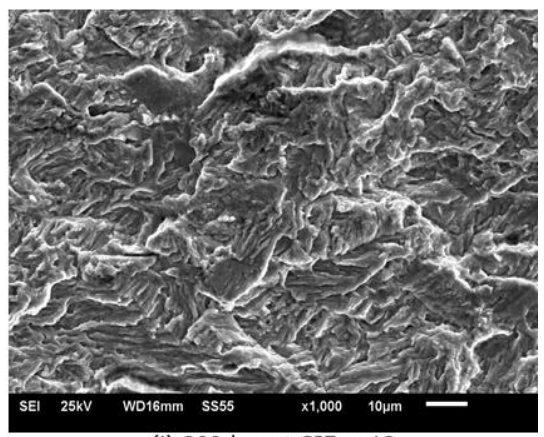

(i) 200 hrs at SIF 13

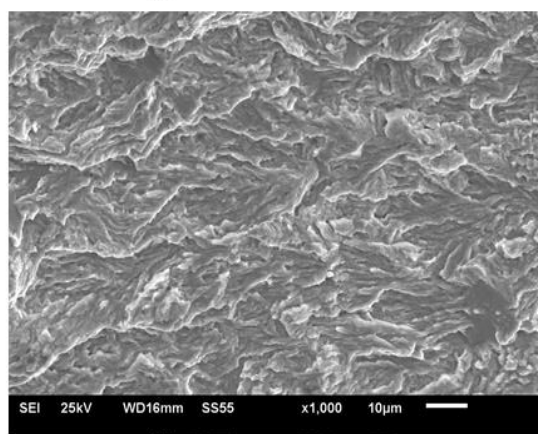

(I) $250 \mathrm{hrs}$ at SIF 15

Figure 18: Fatigue surface images of annealed material in threshold region $(\Delta K(\mathrm{SIF})$ are

in MPa $\sqrt{ } \mathrm{m}$ [Note: crack propagation from right to left in all images; Magnification: 1000X] 


\section{Summary of observations for Annealed material:}

1. The FCGRs in the linear region are accelerated in presence of hydrogen compared to the specimens without any dissolved hydrogen. The FCGRs in the linear region are increased with increasing hydrogen concentration until about $1.5 \mathrm{ppm}$ concentration above which there is little effect of hydrogen. The fractographs show increasing brittle features with crack branching with the increase in hydrogen concentration.

2. The near threshold FCGRs are also accelerated and the fatigue thresholds decrease with increasing hydrogen concentration upto $200 \mathrm{hrs}$ of charging time. At $250 \mathrm{hrs,} \mathrm{the} \mathrm{fatigue}$ threshold had unusually high value greater than the uncharged specimen. This again indicates that above $1.5 \mathrm{ppm}$ of hydrogen in the material it may be beneficial in the material. The fractographs show signs of quasi cleavage fracture on increasing the dissolved hydrogen concentration. 


\section{Fatigue crack growth behaviour of the material in Austempered Batch - 1}

\section{(AB1) condition}

\section{Linear region}

Figure 19 shows the linear FCGRs for the austempered AB1 specimens. It is evident that the dissolved hydrogen affects the crack propagation rates at high $\Delta \mathrm{K}$ region until the final fracture

in the AB1 specimens. It is apparent that the hydrogen influences the fatigue crack growth rate much more significantly in the austempered (AB1) samples based on the steep curves (higher slopes) obtained in the linear region. Also, it is worthwhile to note that in the case of $250 \mathrm{hrs}$ exposure to hydrogen, the value of $\mathrm{C}$ and $\mathrm{m}$ in austempered (AB1) (explained in the comparison of different heat treatments - Tables 10 and 11) is lower than those exposed to hydrogen for 200 hrs. This effect can be attributed to the diminished influence of diffused hydrogen to the crack tip on fatigue crack growth rates at high $\Delta \mathrm{K}$ levels.

Generally, the higher strength (AB1) specimens are affected more by the diffused hydrogen than the annealed samples. Previous investigators [81] have reported that an increase in the strength of steel causes intense stress gradients at the cyclic plastic zone ahead of the crack tip region. During cyclic loading, a cyclic plastic zone forms ahead of the crack tip. In higher strength material, there is intense stress gradients in the vicinity of the crack tip in this plastic zone. This intense stress gradient also affects the crack growth rate in the higher strength materials. The steep crack growth rate curve of the austempered samples over annealed specimen is therefore attributable to combined effect of two reactions: 1) due to degradation effect of hydrogen and 2) due to intense stress gradients at the crack tip. 


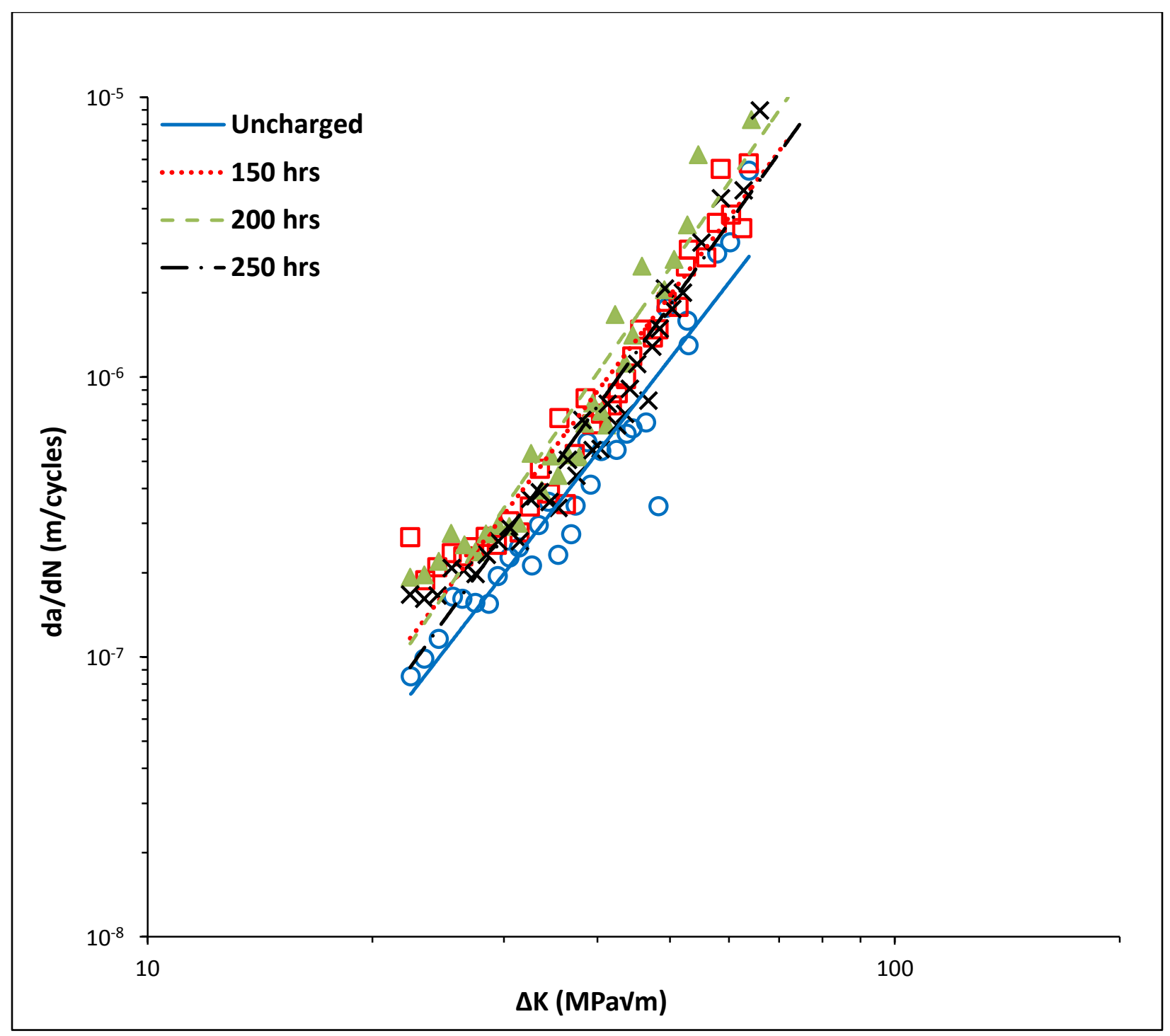

Figure 19: Comparison of fatigue crack growth rates in the linear region for $\mathrm{AB} 1$ samples

\section{Linear region fractographs}

The AB1 specimens show extensive crack branching with increasing the hydrogen concentration and brittle mode of failure (Figure 20). It is evident that at 150, 200 and $250 \mathrm{hrs}$ exposure time, the formation of transgranular facets with quasi cleavage is clear from the fractographs in the case of austempered specimens (AB1). This again points to the high strength of the alloy along 
with the degradation effects of hydrogen in high strength materials which is responsible for this kind of fracture behaviour.

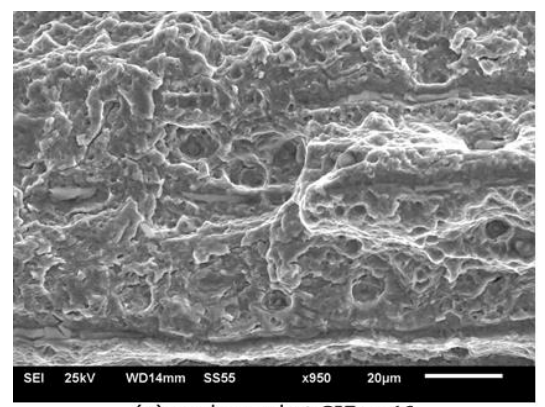

(a) uncharged at SIF 46

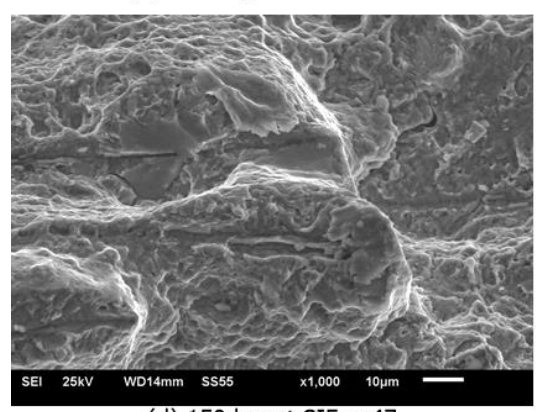

(d) 150 hrs at SIF 47

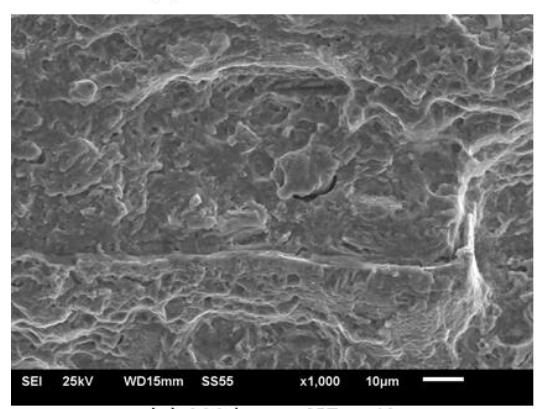

(g) 200 hrs at SIF 48

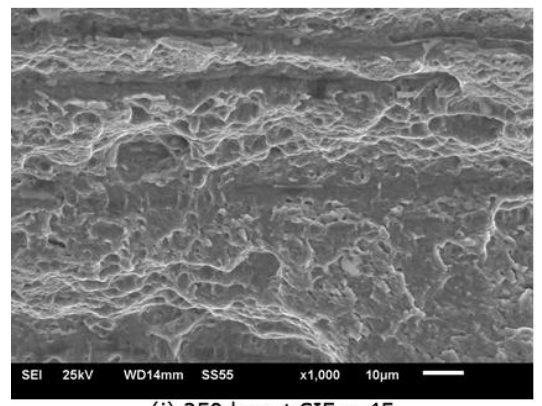

(j) 250 hrs at SIF 45

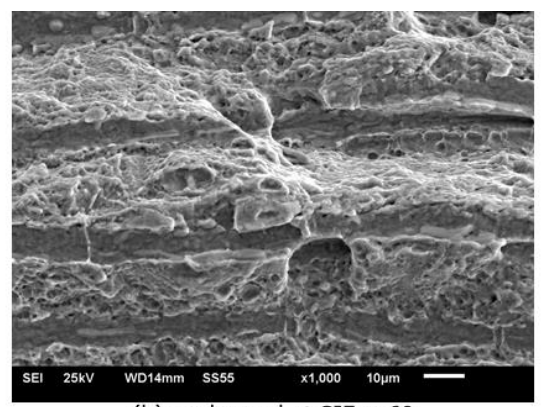

(b) uncharged at SIF 60

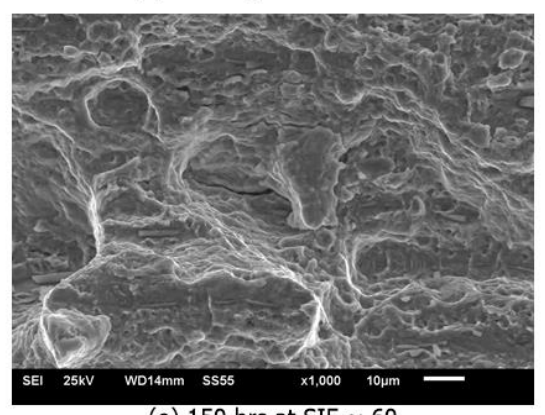

(e) 150 hrs at SIF 60

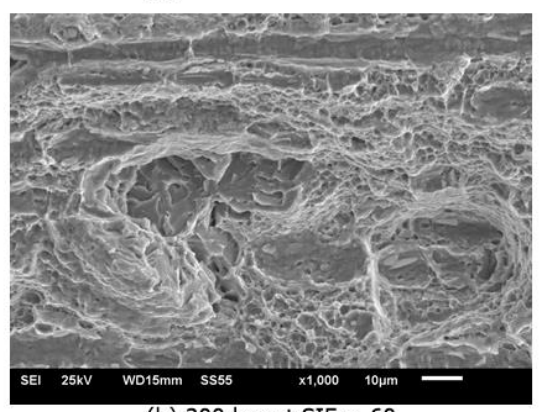

(h) 200 hrs at SIF $~ 60$

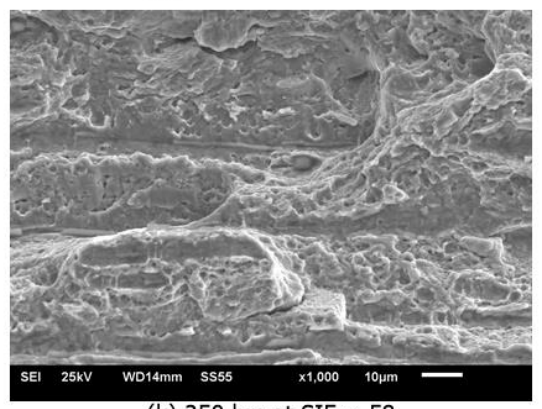

(k) 250 hrs at SIF 58

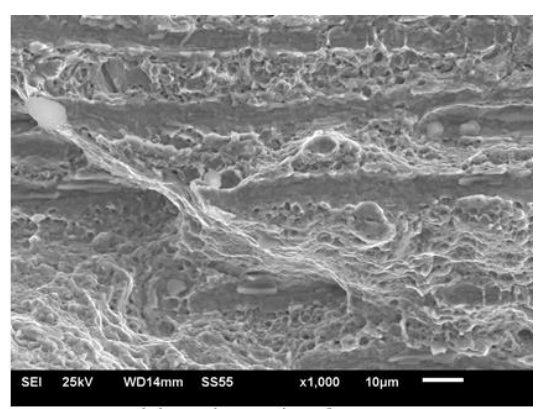

(c) uncharged at fracture

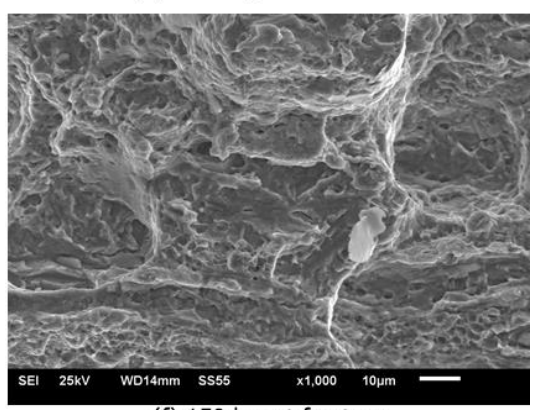

(f) $150 \mathrm{hrs}$ at fracture

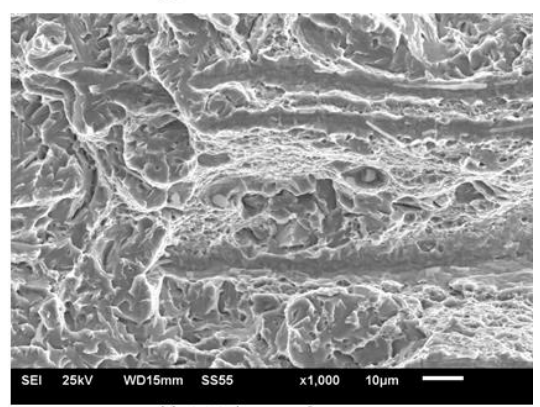

(i) $200 \mathrm{hrs}$ at fracture

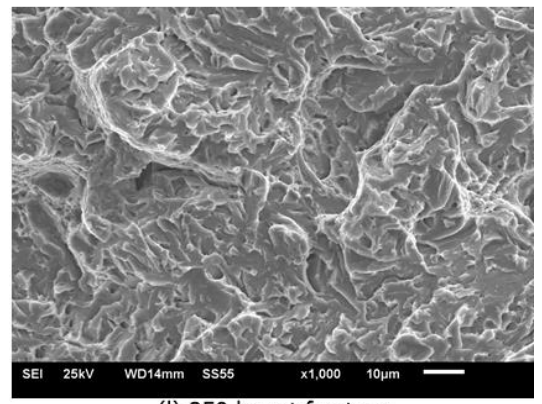

(I) $250 \mathrm{hrs}$ at fracture

Figure 20: Fatigue surface images of $A B 1$ material in linear region $(\Delta K$ (SIF) are in

MPa $\sqrt{ }$ m) [Note: Crack propagation from right to left in all images; Magnification: 1000X] 


\section{Threshold region}

Figure 21 reports the near threshold fatigue crack growth behaviour of the austempered (AB1) samples with different hydrogen concentration. It is apparent that the near threshold fatigue crack growth increases with increase in hydrogen concentration in the heat treated samples. It is evident also from this plot that the fatigue threshold stress intensity is reduced quite significantly as the dissolved hydrogen concentration increases in the AB1 specimens. This behaviour is seen through the threshold region. However, the effect of dissolved hydrogen is more clearly evident in the near threshold region $\left(\mathrm{da} / \mathrm{dN}-10^{-9}-10^{-11} \mathrm{~m} / \mathrm{cycle}\right)$ with the significant increase in FCGRs and drastic drop in $\Delta \mathrm{K}_{\mathrm{th}}$. The transition region (da/dN $-10^{-7}-10^{-9} \mathrm{~m} /$ cycle) shows the embrittlement effect of hydrogen though the concentration effects of hydrogen is diminished compared to the near threshold region.

The embrittlement effect of hydrogen is very significant in the lower $\Delta \mathrm{K}$ or the threshold region. Several investigators [79-80] have reported that the embrittlement effect of hydrogen is more prominent in the threshold region than the linear or fast fracture region. Moreover, this effect increases with the hydrogen concentration [83]. An accumulation of hydrogen causes lattice dilation in the steel resulting in the generation of strain fields that increase the internal energy. The dissolved hydrogen can migrate to the crack tip during cyclic loading or fatigue easily due to low loads encountered in the threshold region. Sufficient time is available for hydrogen to diffuse from the bulk of the specimen to the vicinity of the crack tip between the low stress cycles which is common in this region. This hydrogen accumulation ahead of the crack tip will increase energy and consequently will increase the crack driving force for crack propagation [79] since crack can now propagate at lower applied stress. This has resulted in higher near threshold crack growth rate in the heat treated samples (AB1) with increased hydrogen concentration. 


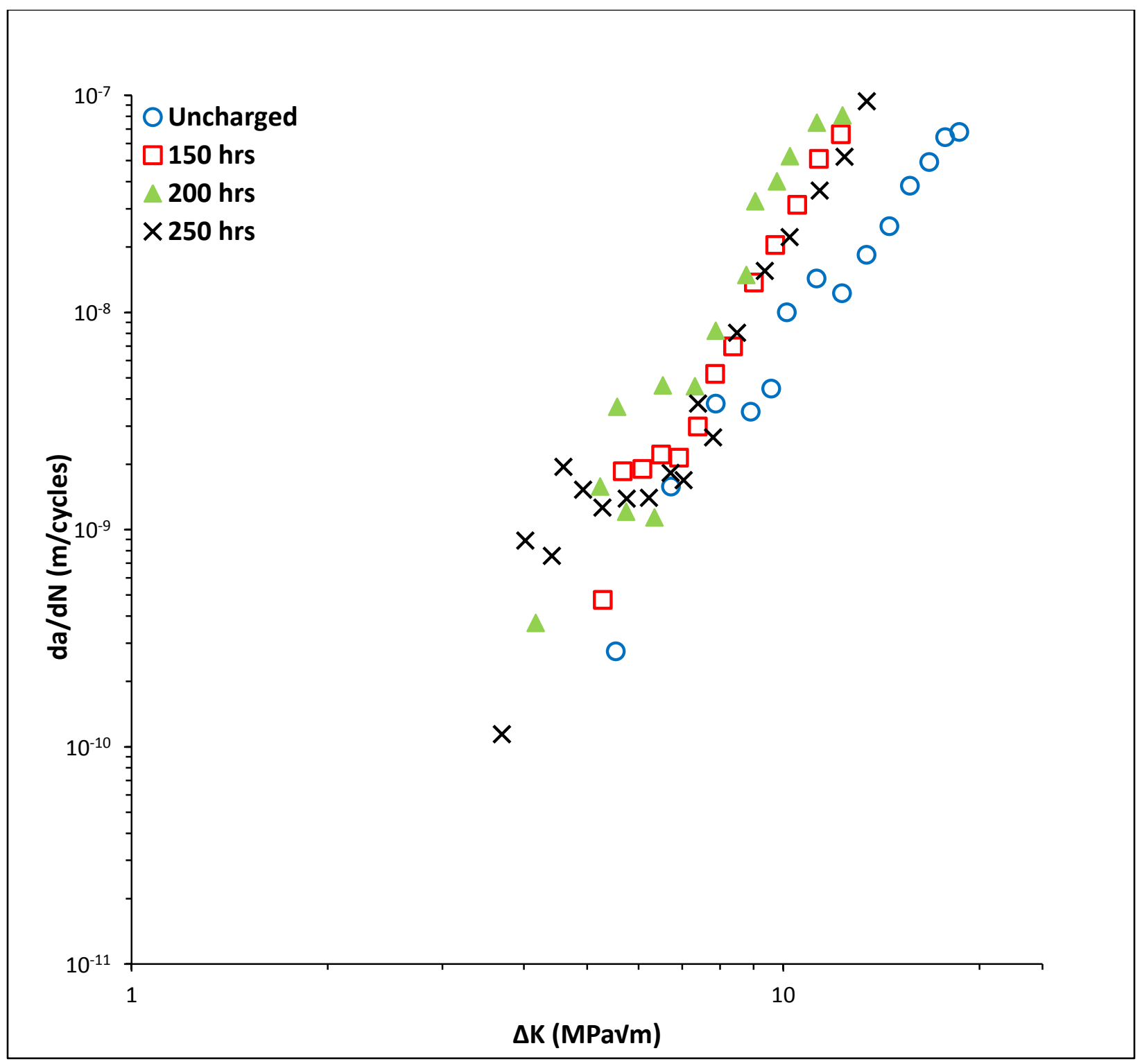

Figure 21: Comparison of fatigue crack growth rate in the near threshold region for AB1 samples

\section{Threshold region fractographs}

Figure 22 shows the fractographs of the AB1 samples at different dissolved hydrogen concentrations in the threshold region. The uncharged AB1 specimens show typical ductile mode striation like crystallographic failure but the samples with dissolved hydrogen had presence of 
intergranular fracture which is characteristic of hydrogen embrittlement. Some crack branching was also observed in austempered specimens. The number of IG facets increased with hydrogen concentration upto 200 hrs. At 250 hrs, a mixed mode having many IG facets, some transgranular (TG) and cleavage like features with crack branching was observed. 


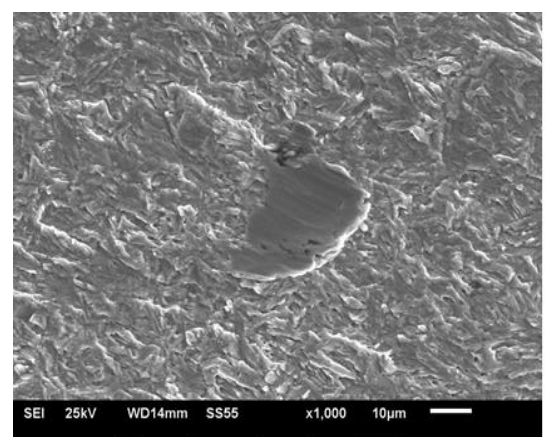

(a) uncharged at threshold SIF

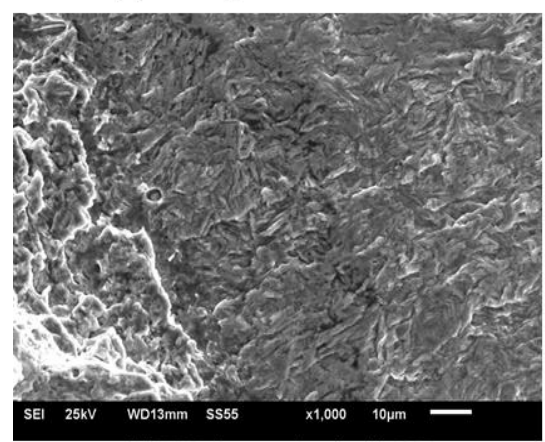

(d) $150 \mathrm{hrs}$ at threshold SIF

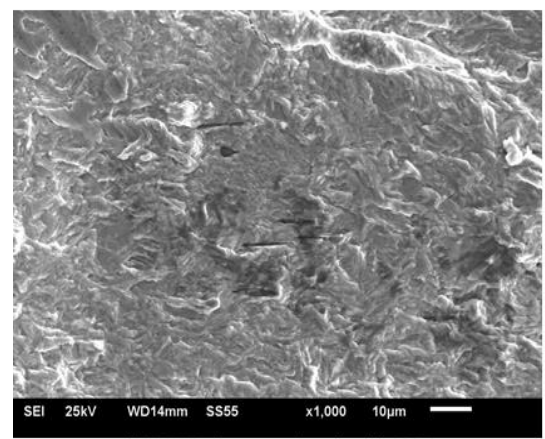

(g) $200 \mathrm{hrs}$ at threshold SIF

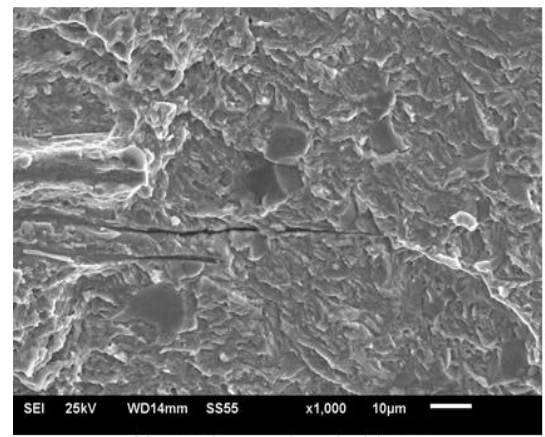

(j) $250 \mathrm{hrs}$ at threshold SIF

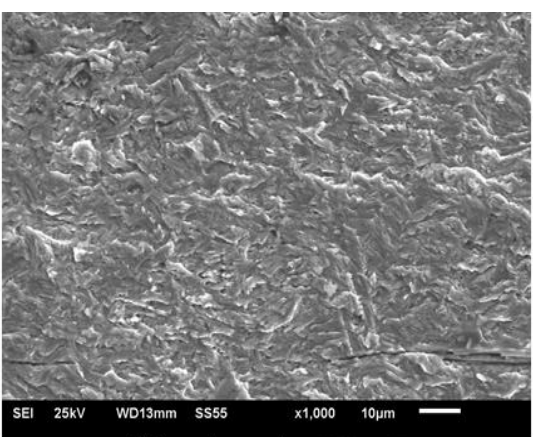

(b) uncharged at SIF 9

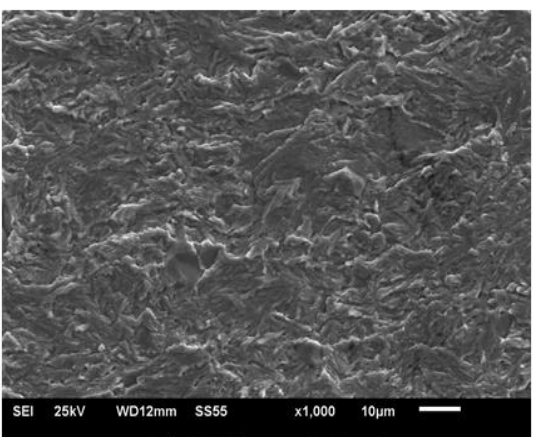

(e) 150 hrs at SIF 9

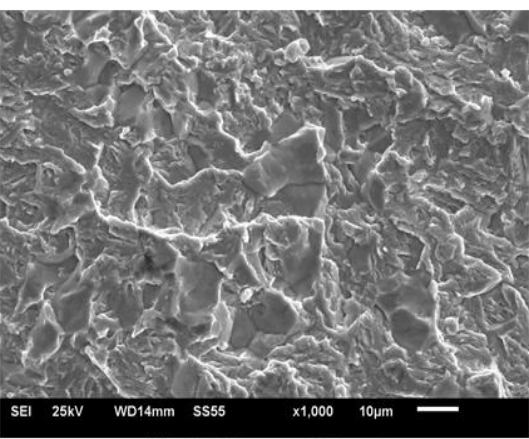

(h) 200 hrs at SIF 9

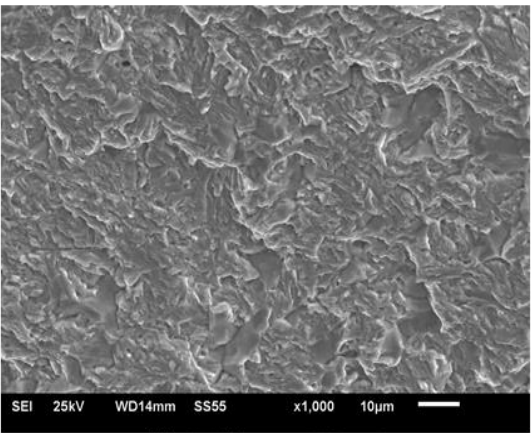

(k) 250 hrs at SIF 9

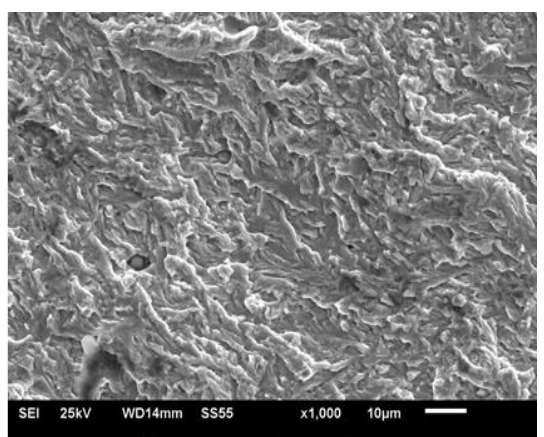

(c) uncharged at SIF 12

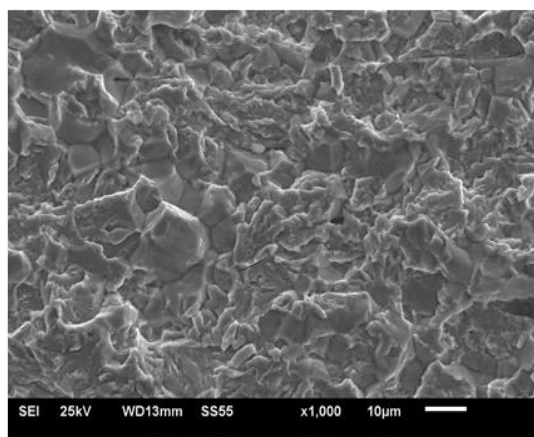

(f) 150 hrs at SIF 13

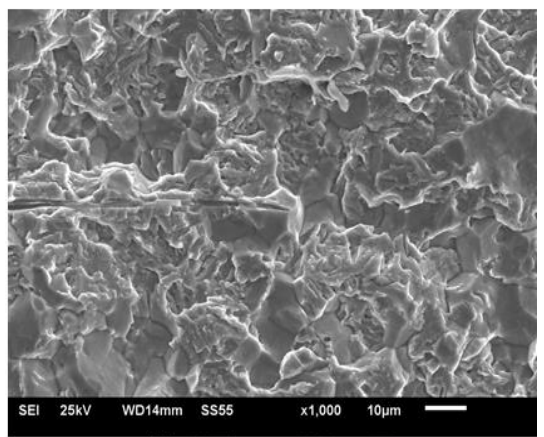

(i) 200 hrs at SIF 12

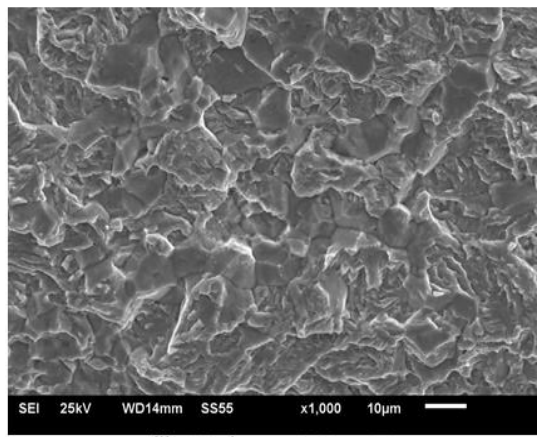

(I) 250 hrs at SIF 12

Figure 22: Fatigue surface images of $A B 1$ material in threshold region $(\Delta K$ (SIF) are in

$\mathrm{MPa} \sqrt{ } \mathrm{m})$ [Note: crack propagation from right to left in all image; Magnification: 1000X] 


\section{Summary of observations for Austempered Batch 1 (AB1) material:}

1. On increasing the dissolved hydrogen concentration in the AB1 material, the linear FCGRs are greatly affected and increases with the hydrogen charging time. The $250 \mathrm{hrs}$ charged specimen had a lower FCGR than the 200 hrs charged specimen. However, the charged FCGRs at all times were significantly higher than the uncharged specimen. The fractographs showed signs of embrittlement with brittle like features on the fracture surface.

2. The near threshold FCGRs are increased and the fatigue thresholds reduce in the AB1 material upon increasing the dissolved hydrogen concentration and to a greater extent than the annealed material. The $\Delta \mathrm{K}_{\mathrm{th}}$ at all charged conditions is lower than the uncharged condition. The higher strength might be responsible for this behaviour. The embrittlement effects are much severe in the threshold condition as indicated by the highly faceted fracture surface. 


\section{Fatigue crack growth behaviour of the material in Austempered Batch 2}

\section{(AB2) condition}

\section{Linear region}

The linear FCGRs for AB2 material is shown in Figure 23. Higher FCGRs are seen in the specimens charged with hydrogen than the uncharged specimens. The higher the dissolved hydrogen concentration the faster the crack growth rate at the low $\Delta \mathrm{K}$ region. The effect of hydrogen on the linear FCGRs is diminished at higher $\Delta \mathrm{K}$ region. The slope of fatigue curves does not change significantly up on increasing the hydrogen concentration unlike the previous other two conditions (annealed and AB1) indicating the AB1 material, though degraded by hydrogen, plays a minimal role on the fatigue crack propagation at high $\Delta \mathrm{K}$. It is observed that the fatigue growth rate curves converge to a single point just before the fracture occurs. Several investigators $[2,80,84]$ in the past have studied the influence of hydrogen on the fatigue behaviour of high strength alloys in the fast fatigue crack propagation region and has indicated that the curves converge to the same value of crack growth rate irrespective of concentration of dissolved hydrogen in the matrix or has less influence at high $\Delta \mathrm{K}$. However in the present investigation, we find that the curves do not converge to a single point in the case of annealed and $\mathrm{AB} 1$. All the fatigue curves converge to a single point in the austempered AB2 specimen. It is evident that the curves with different hydrogen concentrations are very close. The reason for this is that it takes sufficient time for hydrogen to diffuse from the bulk of the sample into the crack tip region, where it causes decohesion at the crack tip leading to fast fracture. At high $\Delta \mathrm{K}$ levels, the crack growth is faster and diffusion rate of hydrogen is not fast enough to keep in pace with the crack growth or in other words, there is not enough time for hydrogen to accumulate and cause decohesion to break the lattice bonds. Hence, the degradation effect of hydrogen is 
diminished in the linear region causing the crack growth rate curves to vary minimally at all dissolved hydrogen concentrations. Hence, it can be concluded that the FCGRs and the degradation caused by hydrogen are mutually coupled.

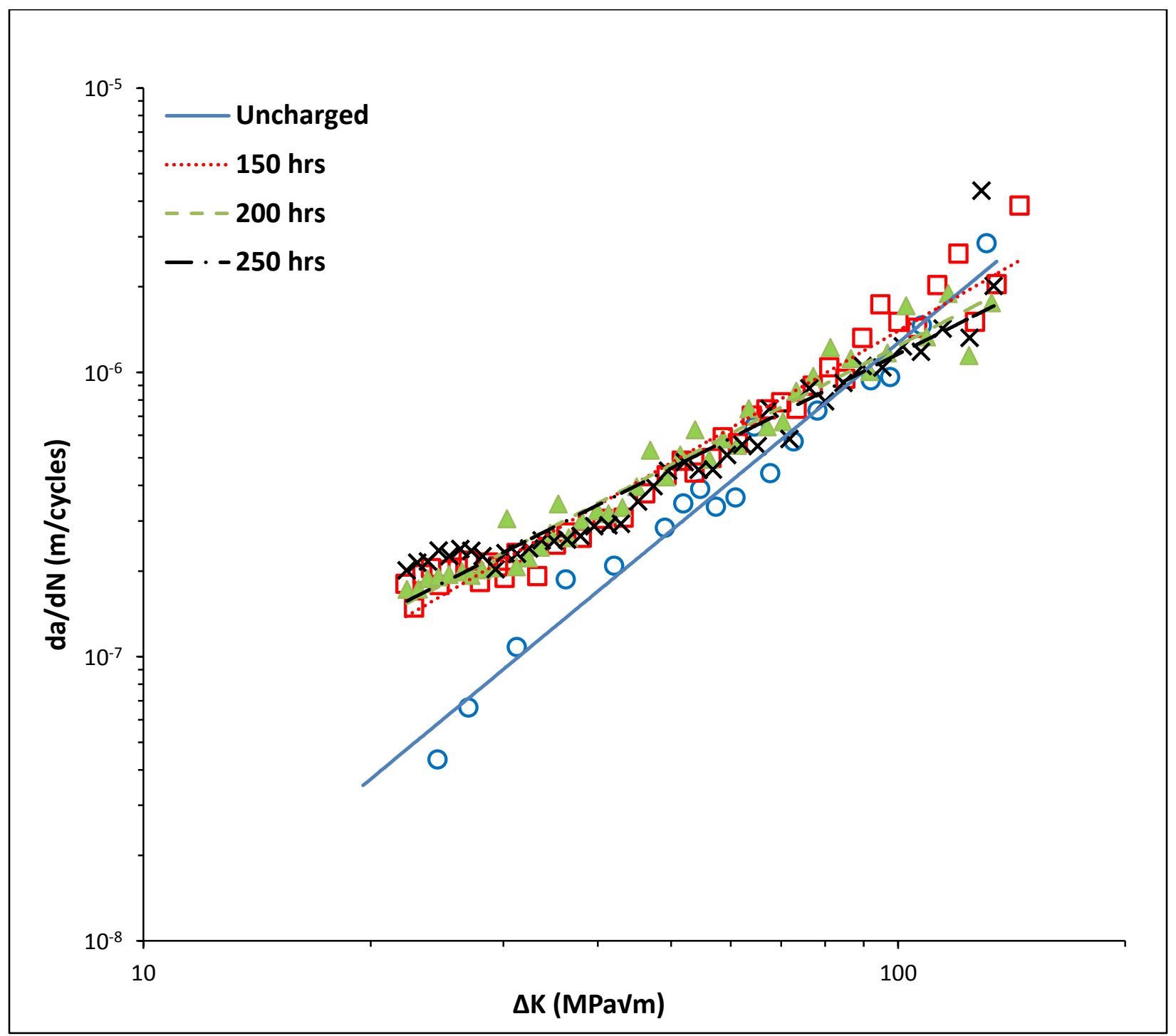

Figure 23: Comparison of fatigue crack growth rate in the linear region for $\mathrm{AB} 2$ samples 


\section{Linear Region Fractographs}

In the AB2 sample (Figure 24) with no hydrogen, the fracture surface shows typical fatigue ductile striations with a few TG facets whereas in the dissolved hydrogen samples, there is a mixed mode fracture surface consisting of TG features, extensive IG facets with extensive crack branching. The degree of IG facets increases in the order of $150 \mathrm{hrs}$ and $200 \mathrm{hrs}$, but then switches over to a mixed mode type of failure at $250 \mathrm{hrs}$. This might be the reason why the crack growth rate reduces in the $\Delta \mathrm{K}=60-70 \mathrm{MPa} \sqrt{\mathrm{m}}$ region to less than the crack growth rate of 150 hrs charged specimen. 


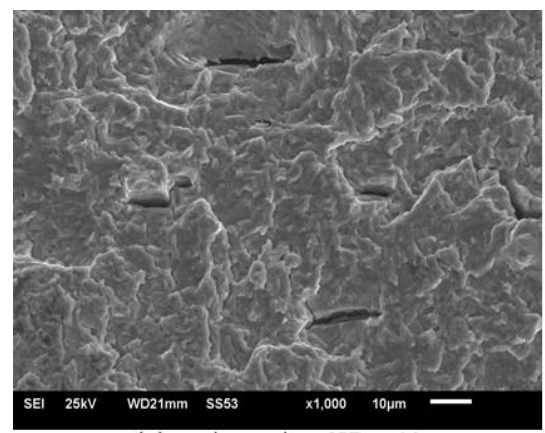

(a) uncharged at SIF 46

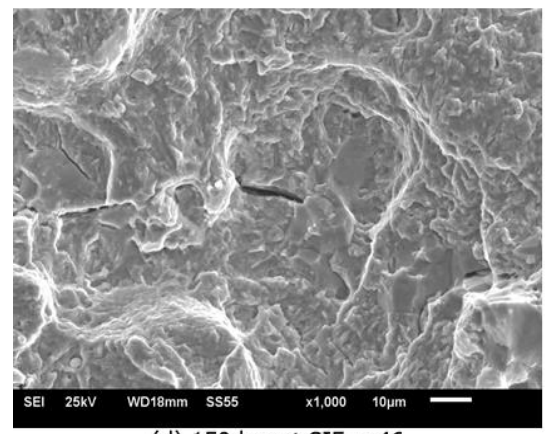

(d) $150 \mathrm{hrs}$ at SIF 46

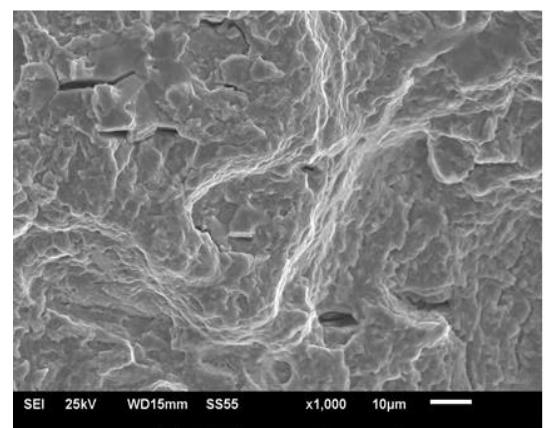

(g) $200 \mathrm{hrs}$ at SIF $\sim 46$

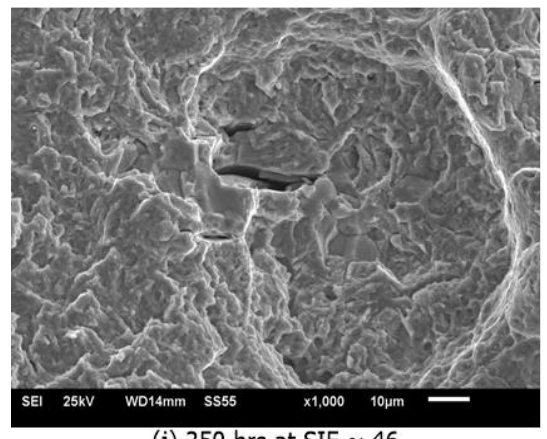

(j) 250 hrs at SIF 46

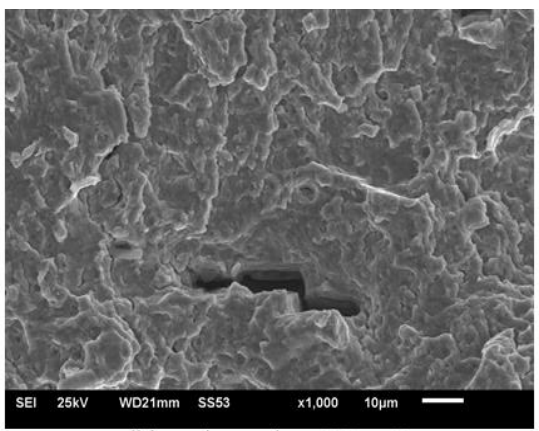

(b) uncharged at SIF 60

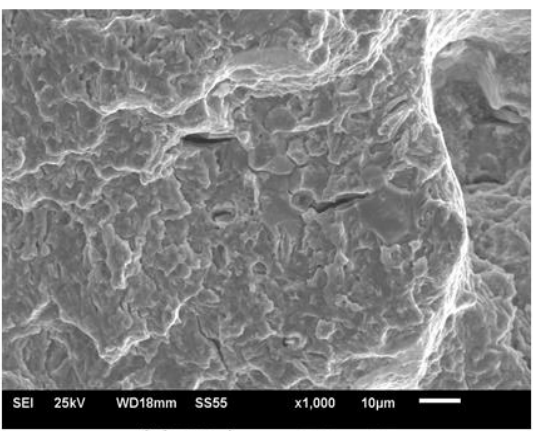

(e) 150 hrs at SIF 60

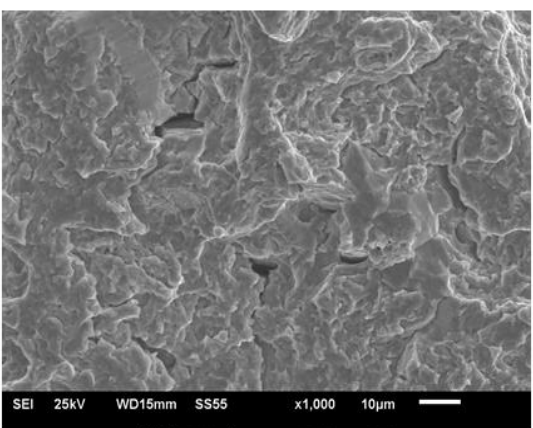

(h) 200 hrs at SIF $~ 60$

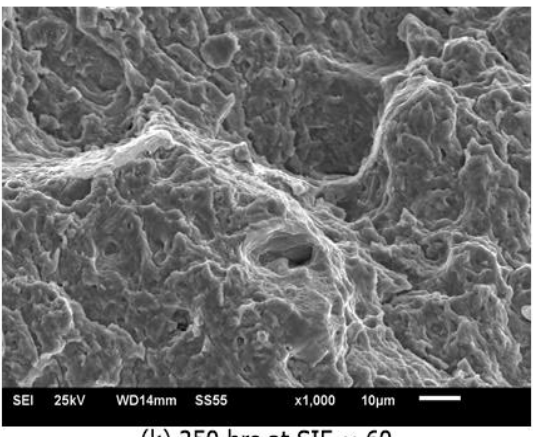

(k) 250 hrs at SIF 60

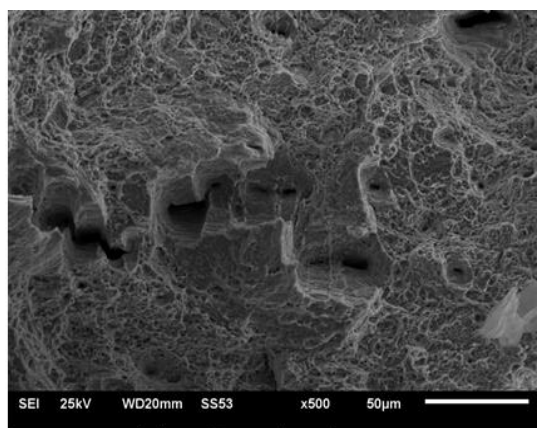

(c) uncharged at fracture

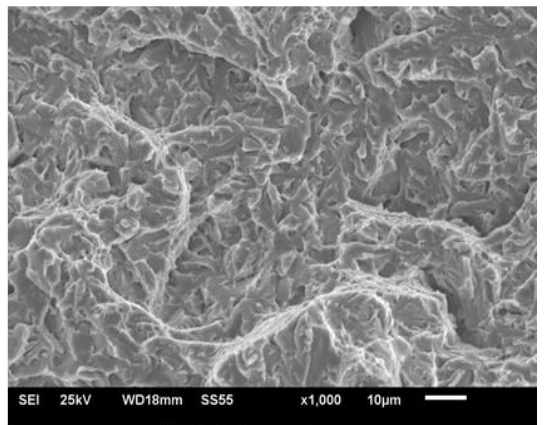

(f) $150 \mathrm{hrs}$ at fracture

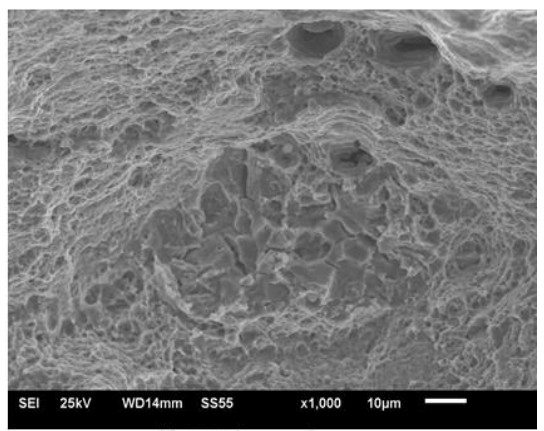

(i) $200 \mathrm{hrs}$ at fracture

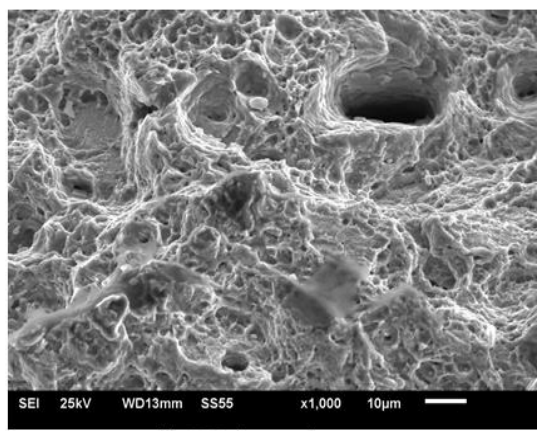

(I) $250 \mathrm{hrs}$ at fracture

Figure 24: Fatigue surface images of $\mathrm{AB} 2$ material in linear region ( $\Delta \mathrm{K}(\mathrm{SIF})$ are in

$\mathrm{MPa} \sqrt{ } \mathrm{m})$ [Note: crack propagation from right to left in all images; Magnification: 1000X] 


\section{Threshold region}

Figure 25 shows the near threshold FCP behaviour in the austempered (Batch 2) - AB2 samples. This batch had the highest concentration of hydrogen among all the three batches for the same treatment times. The fatigue thresholds are greatly affected as the hydrogen concentration increases. Similar to the AB1 samples, it is seen that the near threshold region $\left(\mathrm{da} / \mathrm{dN}>10^{-9}-\right.$ $10^{-11} \mathrm{~m} /$ cycle) is greatly affected. However, at higher FCGRs (da/dN $\left.>10^{-9} \mathrm{~m} / \mathrm{cycle}\right)$, it is interesting to note that they are not affected significantly upon increasing the dissolved hydrogen concentration almost like the previous batch of austempered samples. Unlike the AB1 samples, there is a clear cut distinction between the dissolved hydrogen curves and that with no precharging at all FCGRs fully well into the linear region. This suggests that the dissolved hydrogen in this material (AB2) is causing sufficient lattice strains to raise the local SIFs during each fatigue cycling to cause crack propagation at a lower applied stress thus degrading the fatigue life of this material (AB2). On the other hand, the likelihood of presence of more TM to $\mathrm{B}$ ratio than the $\mathrm{AB} 1$ material yielding the highest hydrogen concentration, due to the enhanced dislocation density, did not cause suppression of $\Delta \mathrm{K}_{\mathrm{th}}$ to such a large extent as it did in the other two batches. Inspite of a threefold jump in dissolved hydrogen in the AB2 material at 250 hrs, the $\Delta \mathrm{K}_{\text {th }}$ obtained was much higher than the $\mathrm{AB} 1$ material with no cathodic precharging and very close to that of uncharged annealed material. It could be said that the presence of a higher TM volume fraction in this material was responsible for such a behaviour and that a higher TM presence in B matrix along with the RA yielded one of the most resistant material to hydrogen induced cracking among the three tested batch of samples. Though the near threshold FCGRs of $\mathrm{AB} 2$ are in between that of annealed and the $\mathrm{AB} 1$ material, it requires a higher threshold to 
initiate fatigue crack propagation with a preexisting flaw under the influence of dissolved hydrogen, taking into account the high concentration of dissolved hydrogen in the material.

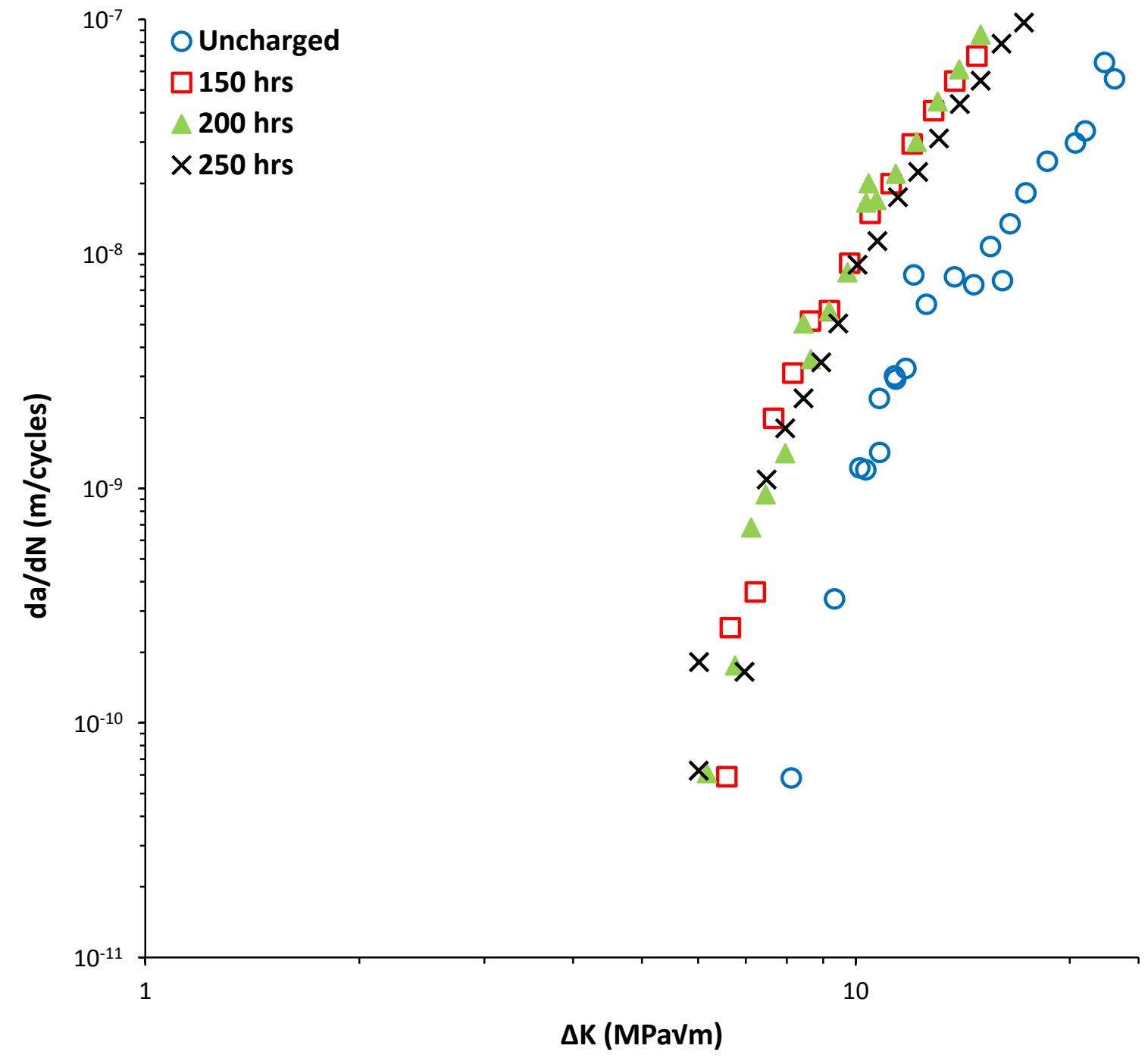

Figure 25: Comparison of fatigue crack growth rate in the near threshold region for AB2 samples 


\section{Threshold region fractographs}

Figure 26 shows the fracture surface imaging of the AB2 samples. The uncharged AB2 sample shows crystallographic type ductile mode fracture surface with some TG features in the middle while the hydrogen charged specimens shows increasing presence of IG facets, some transgranular features along with crack branching at $150 \mathrm{hrs}$ and $200 \mathrm{hrs}$ charging time. However, the $250 \mathrm{hrs}$ specimen show a brittle flat like fracture surface with IG and TG facets. 


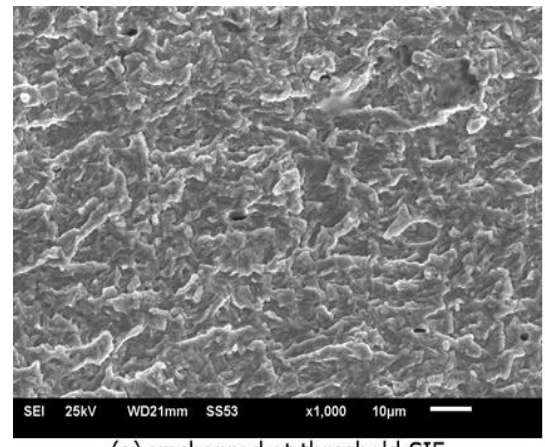

(a) uncharged at threshold SIF

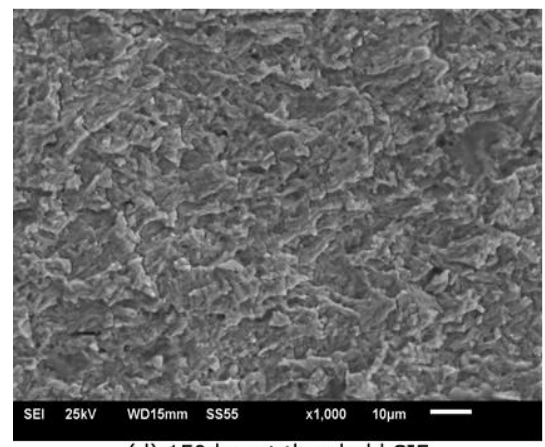

(d) $150 \mathrm{hrs}$ at threshold SIF

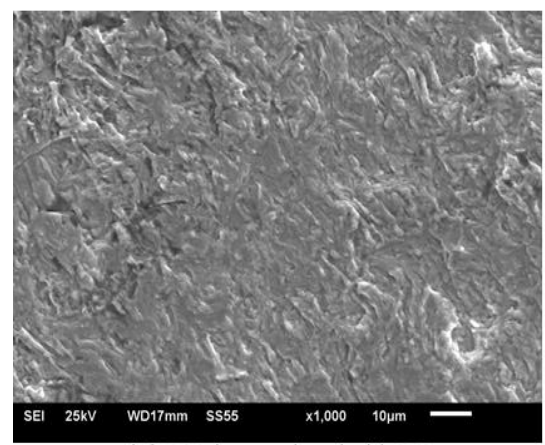

(g) $200 \mathrm{hrs}$ at threshold SIF

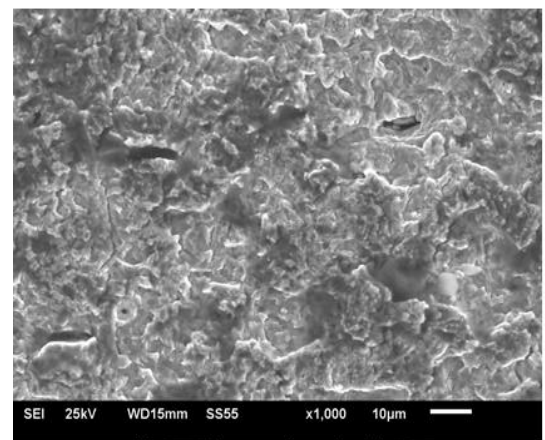

(j) 250 hrs at threshold SIF

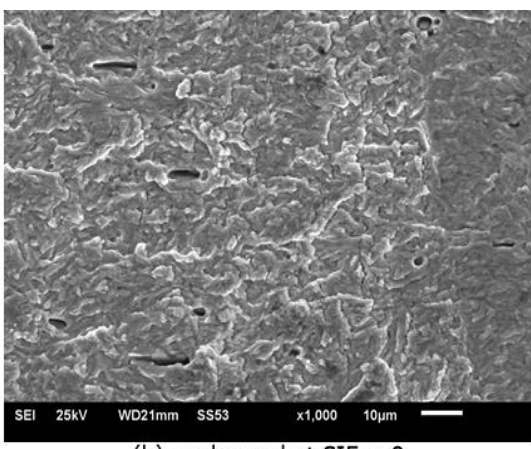

(b) uncharged at SIF 9

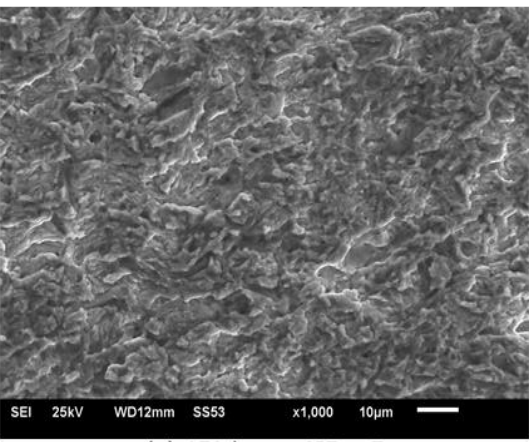

(e) 150 hrs at SIF 7

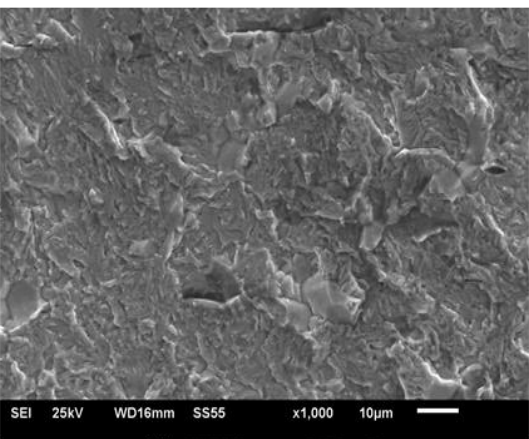

(h) 200 hrs at SIF 7

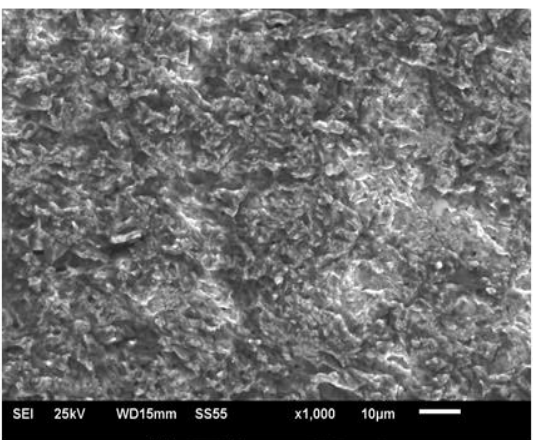

(k) 250 hrs at SIF 8

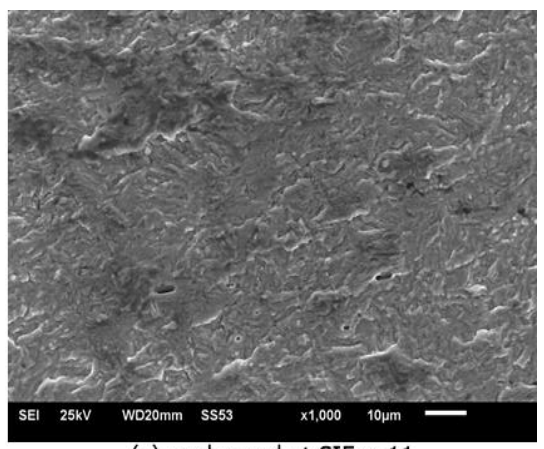

(c) uncharged at SIF 11

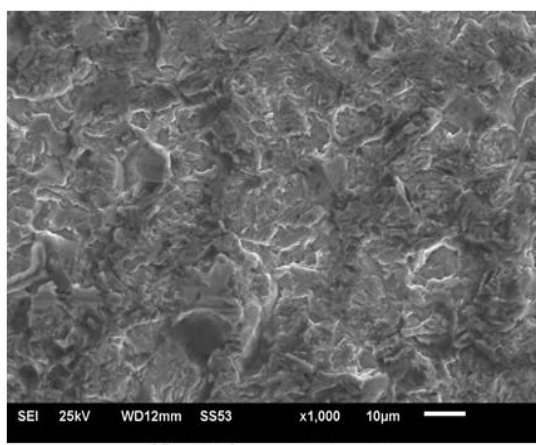

(f) 150 hrs at SIF 13

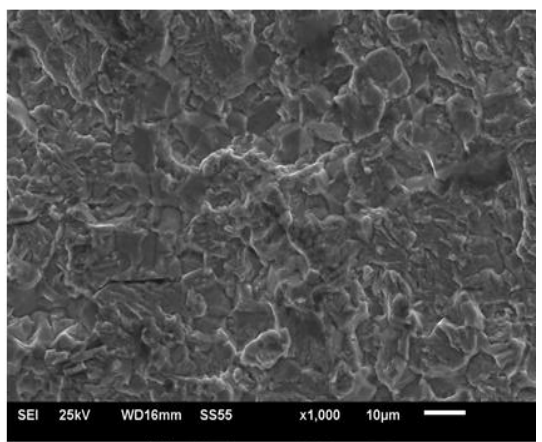

(i) 200 hrs at SIF $~ 13$

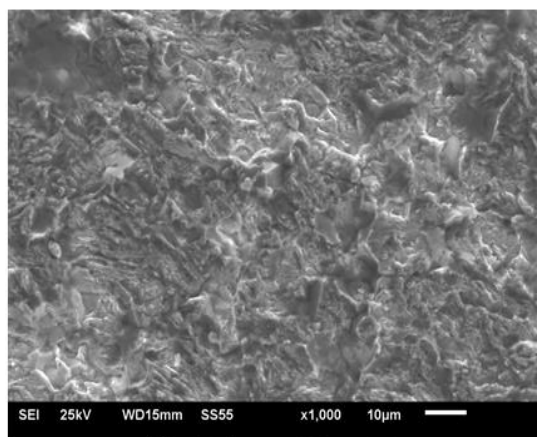

(I) 250 hrs at SIF $~ 13$

Figure 26: Fatigue surface images of $\mathrm{AB} 2$ material ( $\Delta \mathrm{K}$ (SIF) are in $\mathrm{MPa} \backslash \mathrm{m})$

[Note: crack propagation from right to left in all images; Magnification: 1000X] 


\section{Summary of observations for Austempered Batch 2 (AB2) material:}

1. The linear region FCGRs are affected by the influence of dissolved hydrogen. As the dissolved hydrogen concentration increases, the FCGRs also increases. However, the linear FCGRs converge to a single point unlike the annealed and AB1 material showing minimal influence of hydrogen as the SIF increases. The fractographs indicate an increasing degree of IG facets with increased charging time except for the $250 \mathrm{hrs}$ which changes to mixed mode type of failure.

2. The near threshold FCGRs are much faster with the dissolved hydrogen content than the uncharged specimens. However, the change in FCGRs upon increasing the hydrogen concentration is not very prominent except for suppression of fatigue thresholds. The fracture surface shows severe embrittlement in the hydrogen charged specimens The $250 \mathrm{hrs}$ specimens had a flat brittle like appearance with IG and TG facets.

3. The AB2 material had the highest fatigue threshold with dissolved hydrogen in the matrix among the three batches of specimens tested. It was much higher than the fatigue threshold of uncharged annealed and AB1 materials. 


\section{Comparison of Fatigue Crack Growth Behaviour among different heat treatment conditions}

\section{Near Threshold Fatigue Crack Growth Behavior}

Figure 27 compares the fatigue crack growth behavior of the annealed (as received) and heat treated (austempered - AB1 and AB2) samples in the threshold region without any dissolved hydrogen. The near threshold crack growth rate of $\mathrm{AB} 1$ samples are higher and the fatigue threshold $\left(\Delta \mathrm{K}_{\mathrm{th}}\right)$ was lower than the annealed and the $\mathrm{AB} 2$ samples. Table 8 reports the fatigue threshold values of all the specimens without any dissolved hydrogen. The austempered samples (AB1) had higher hardness and strength as seen in Table 2. This higher strength may have resulted making the material more susceptible for accelerated crack growth [75, 78, 83-85]. Consequently, the crack growth rate in the austempered samples (AB1) were higher than the annealed. The FCGRs of AB1 in the threshold region was higher at all SIFs.

In contrast, the austempered specimen (AB2) which had the highest hardness among all the three batches of specimens tested and strength showed a reversing trend. It is seen from Figure 27 and Table 8, that the AB2 had the highest threshold and the lowest fatigue crack growth rate among all three tested specimens with no precharging (dissolved hydrogen). Upon initial observation, this may seem to contradict the earlier discussion that higher strength material should have lower fatigue threshold and higher fatigue crack growth rates in the threshold regime.

In the microstructural analysis, it was discussed that the AB2 samples would possess a relatively higher fraction of Tempered Martensite (TM) to Bainite ratio than the AB1 samples due to the relative closeness of austempering temperature in $A B 2$ to the $M_{s}$ temperature. This may be the reason for the AB2 sample to have a higher $\Delta \mathrm{K}_{\mathrm{th}}$ and lower FCGR than the other two samples. 
This also proves that a direct relation between $\Delta \mathrm{K}_{\mathrm{th}}$ and the strength or hardness of this alloy cannot be made. This is seen to be true, in the current investigation, dealing with different microstructures (F-P and TM-B) or within the same microstructure (TM-B) having a minor variation in their relative volume fraction. Upon closer examination, this trend is particularly true in the case of TM structures. In a similar variety of low alloy steel (AISI 4130) [86], the $\Delta \mathrm{K}_{\mathrm{th}}$ has little or no influence on the strength level in tempered martensitic structures. More generally, many workers [87-90] have also observed very little influence of strength level on $\Delta \mathrm{K}_{\text {th }}$ especially in low alloy steels. Prior investigation by $\mathrm{Yu}$ [91] have shown that there is no one to one relation of strength to $\Delta \mathrm{K}_{\mathrm{th}}$ in TM structures while F-P structures [92] show an inverse relation between strength and fatigue thresholds. The fatigue thresholds obtained in this investigation for the three different heat treatment conditions validate all these observations in the case of AISI 4140. When the fatigue threshold of lower strength annealed specimen is compared with high strength austempered (AB1) specimen, the inverse relation between strength and $\Delta \mathrm{K}_{\mathrm{th}}$ holds. However, the same conclusion cannot be drawn by comparing either Batch 1 and Batch 2 austempered samples or the annealed specimen with the Batch 2 austempered samples. A similar argument can also be made on the threshold FCGRs of these three samples as seen in Figure 27. 


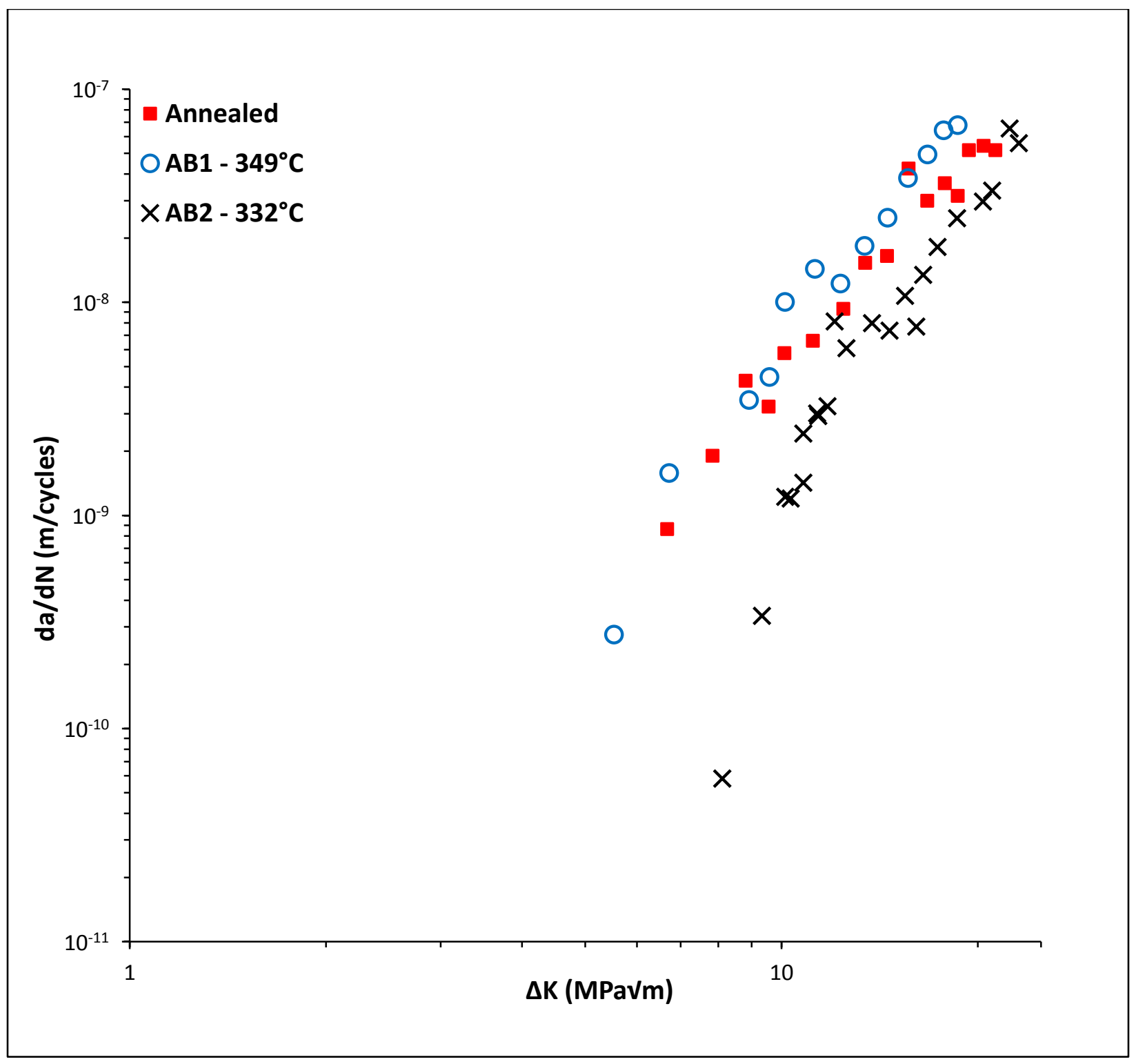

Figure 27: Near threshold fatigue crack growth behavior of the material with no exposure to hydrogen charging 
Table 8: $\Delta \mathbf{K}_{\text {th }}$ for annealed and heat treated samples without any dissolved hydrogen

\begin{tabular}{|c|c|}
\hline Material Condition & $\Delta K_{t h}\left(M P a \sqrt{ }{ }_{m}\right)$ \\
\hline Austempered (Batch 1 - 349 ${ }^{\circ} \mathrm{C}$ ) - AB1 & 5.54 \\
\hline Annealed & 6.68 \\
\hline Austempered (Batch $2-332^{\circ} \mathrm{C}$ ) $-\mathrm{AB} 2$ & 8.12 \\
\hline
\end{tabular}

In Figures 28, 29 and 30, the threshold fatigue crack growth behaviour of annealed and austempered (AB1 and $\mathrm{AB} 2)$ samples with different hydrogen concentrations are compared. It is evident that at all exposure time periods, the fatigue crack growth rate of AB1 samples are higher than the annealed and the AB2 samples. Even though both the annealed and AB1 samples had similar level of hydrogen concentration, the crack growth rates in the heat treated samples were significantly higher than the annealed samples. Moreover this difference in crack growth rates of these two sets of samples increases with increased dissolved hydrogen content. This might be a preliminary indication that the heat treated samples (AB1) having higher hardness and strength are more susceptible to hydrogen induced cracking than the annealed samples. A similar conclusion cannot be reached with respect to the AB2 samples. This batch had the lowest FCGRs and highest thresholds of all the three batches in specimens without any dissolved hydrogen. However, upon increasing the charging time and thereby the hydrogen concentration, the fatigue thresholds are considerably reduced and the FCGRs though slower in the near threshold region $\left(\mathrm{da} / \mathrm{dN}-10^{-11}-10^{-9} \mathrm{~m} /\right.$ cycle), is considerably higher than the annealed samples in the transition region ( $\mathrm{da} / \mathrm{dN}-10^{-7}-10^{-9} \mathrm{~m} /$ cycle). It is evident from this behaviour that the alloy in $\mathrm{AB} 2$ condition, though embrittled by hydrogen through the reduction in $\Delta \mathrm{Kth}$, needs sufficient crack 
driving force (or crack length) to cause further cracking even with the higher concentration of hydrogen in the material. In other words, the AB2 material needs sufficient SIF (or stress gradient) of about 8-8.5 MPa $\sqrt{\mathrm{m}}$ (at all hydrogen concentration to reduce the chemical potential of hydrogen near the crack tip so that the dissolved hydrogen in the bulk of the specimen can move to the crack tip to cause decohesion. This initial hypothesis stems from the fact that AB2 sample has a higher fraction of $\mathrm{TM}$ to $\mathrm{B}$ ratio than the $\mathrm{AB} 1$. This $\mathrm{TM}$ in $\mathrm{AB} 2$ sample has a higher dislocation density, hence a greater amount of dissolved hydrogen is present at these dislocations and grain boundaries as reversibly trapped hydrogen $[42,92]$ having the binding energies of $20-50 \mathrm{~kJ} / \mathrm{mol}$. These trapped hydrogen needs sufficient driving force or chemical potential in the form of stress gradient (or SIF) to diffuse to the crack tip to cause further cracking and accelerate crack propagation. It seems that this is a very valid assumption for the AB2 specimen because the same trend is observed at all dissolved hydrogen concentration.

It might be questionable as to why the AB1 sample had the lowest threshold and highest FCGRs among all the three batches with dissolved hydrogen despite not having the highest strength and higher concentration of hydrogen than the AB2. One possible explanation is the AB1 sample had a higher B to TM fraction where bainite has been attributed to cracking along the inter-lath carbide particles. The morphology of bainite composed of ferrite and carbides is known to reduce the susceptibility of steel to hydrogen assisted cracking than tempered martensite [93]. It must also be pointed out the Thomson and others [94] work on 4140 showed a remarkable decrease in load needed for crack initiation in hydrogen charged bend samples in quenched and tempered martensite structure as opposed to bainitic structure. The austempered samples utilized in this study has a predominantly bainitic structure with varying tempered martensite formed during the shear transformation of bainite formation. So, the trend observed is quite convincing 
and agrees with this study. On the contrary, another researcher [95] pointed out that the F-P microstructure in the 4140 steel was the most severely embrittled and showed loss in strength and \% elongation. However, in this research, it was clear that the F-P structure did not show such characteristics in terms of fatigue threshold nor in terms near threshold FCGRs. In fact, it was also seen that the annealed (F-P) microstructure did not exhibit many intergranular (IG) facets in the fractographs explained later. The only difference in the material used between these two studies were that our material was annealed and having a coarse F-P microstructure while that used by the other researchers were normalized at $750^{\circ} \mathrm{C}$ for $1 \mathrm{hr}$ and then air cooled. No information was provided regarding the hardness value after normalizing.

At this point, it could be safely told that not only subtle variations in the microstructure, as in this case, make a huge variation in the fatigue properties ( $\Delta \mathrm{K}_{\mathrm{th}}$ and FCGRs) and other mechanical properties in presence of dissolved hydrogen especially in the near threshold regime, but also the heat treatment methods involved to get that particular microstructure may be involved. It should also not be ignored that some of these effects such as yield strength, microstructure and type of heat treatment, hardness and various other metallurgical factors become coupled that one parameter cannot be taken as the sole contributor to fatigue crack growth behaviour. However from the results obtained, decreasing the austempering temperature in the 4140 alloy increases the fatigue threshold and lowers near threshold FCGRs with or without the dissolved hydrogen. 


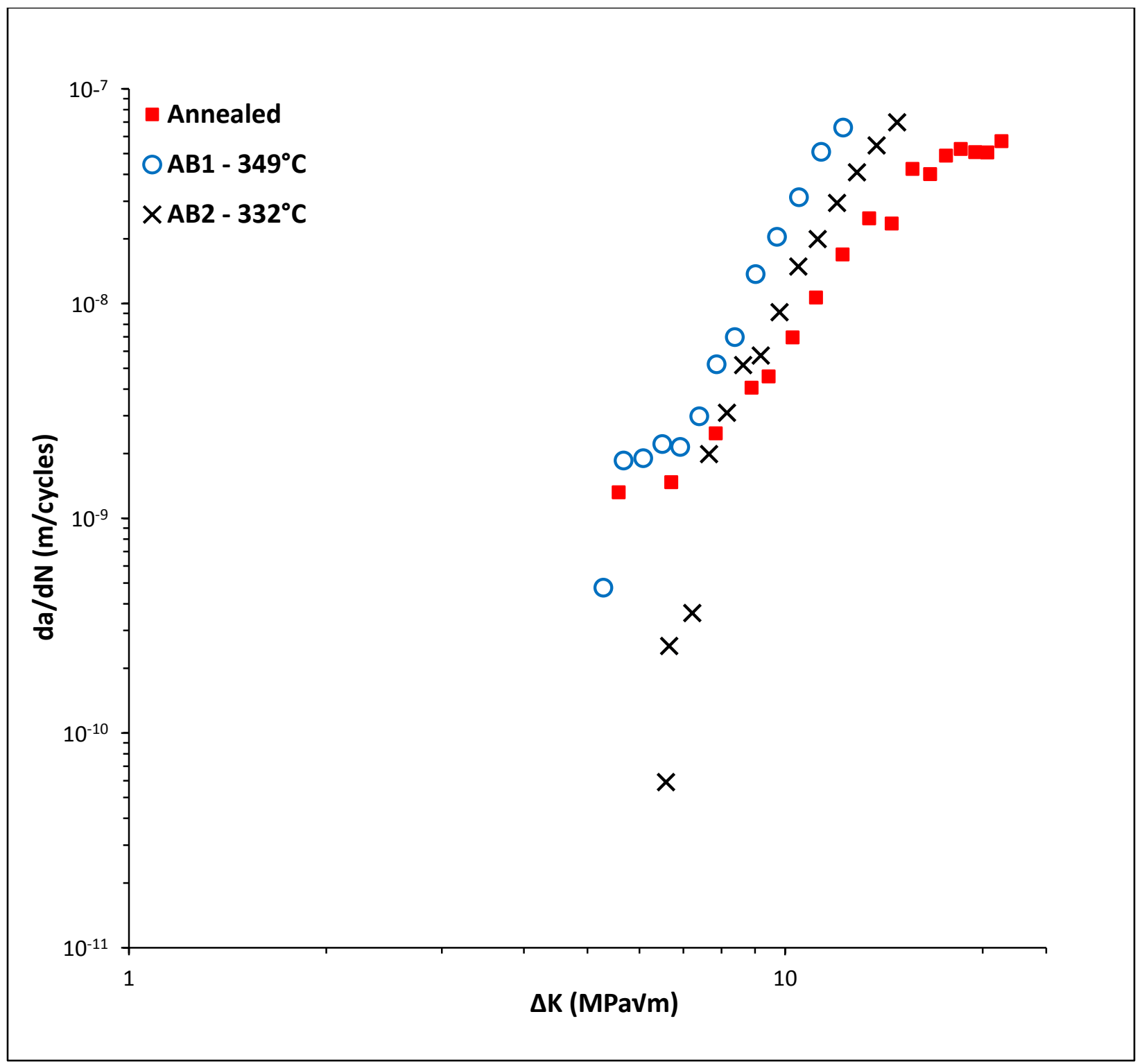

Figure 28: Near threshold fatigue crack growth behavior of the material with $150 \mathrm{hrs}$ of exposure to hydrogen 


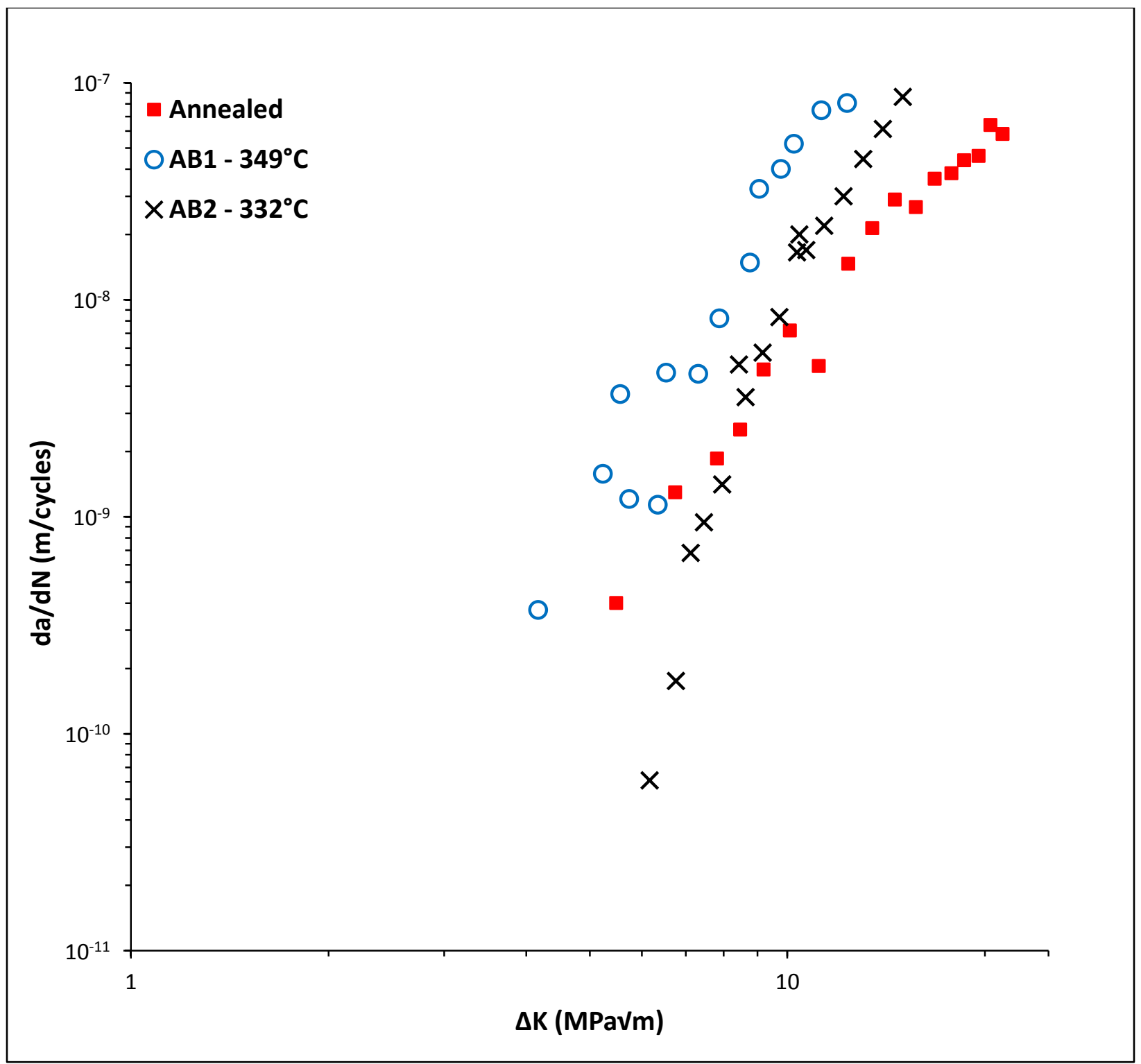

Figure 29: Near threshold fatigue crack growth behavior of the material with 200 hrs exposure to hydrogen 


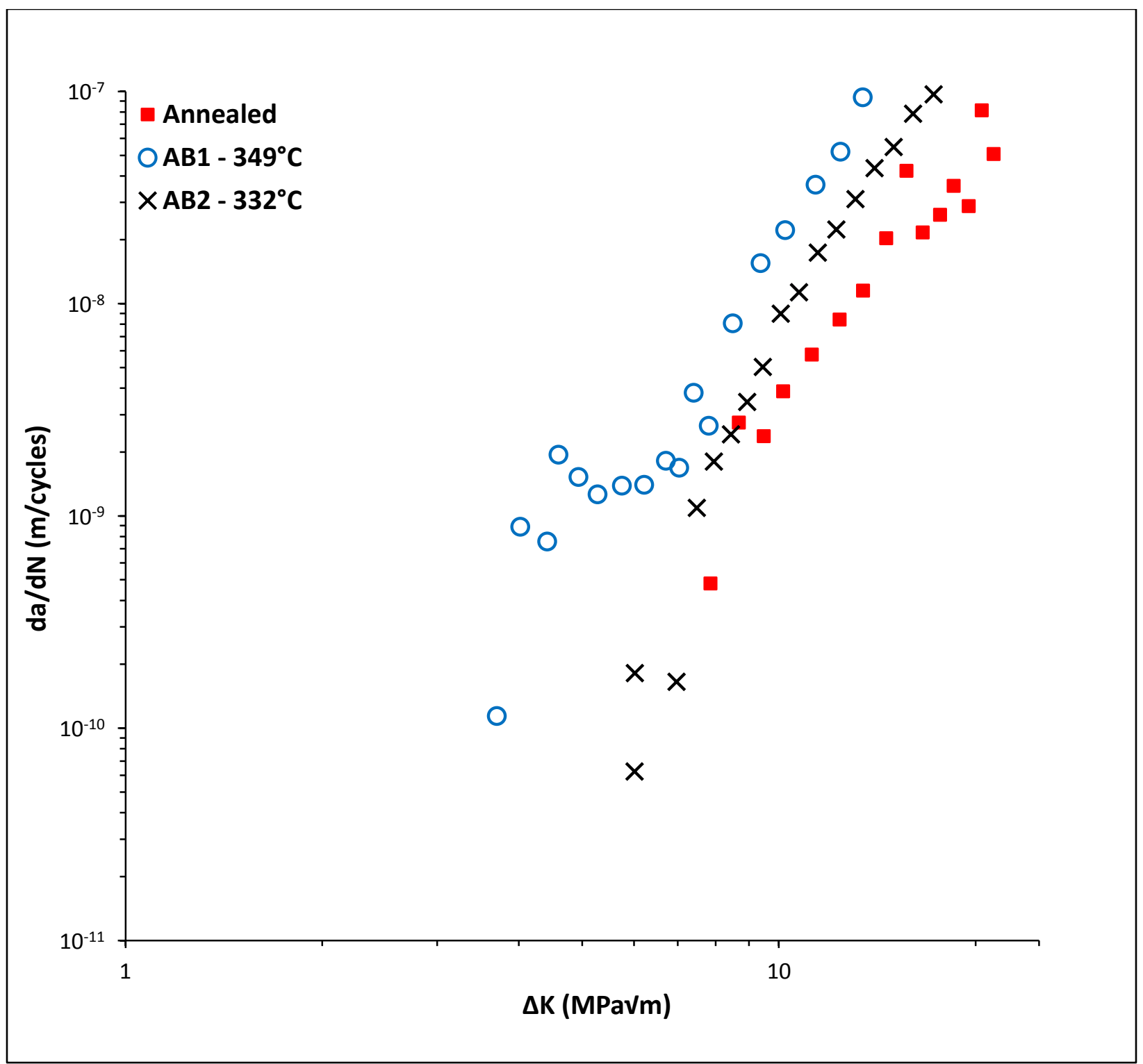

Figure 30: Near threshold fatigue crack growth behavior of the material with 250 hrs exposure to hydrogen 
Table 9: AKth for annealed and heat treated samples for different hydrogen exposure times

\begin{tabular}{|c|c|c|}
\hline Material Condition & Charging time (hrs) & $\Delta \mathbf{K}_{\text {th }}(\mathbf{M P a} \sqrt{ } \mathbf{m})$ \\
\hline \multirow[t]{3}{*}{ Annealed } & 150 & 5.58 \\
\hline & 200 & 5.49 \\
\hline & 250 & 7.85 \\
\hline \multirow{3}{*}{$\begin{array}{c}\text { Austempered } \\
\left(\text { Batch } 1-\text { 349 }^{\circ} \mathrm{C}\right)-\mathrm{AB1}\end{array}$} & 150 & 5.29 \\
\hline & 200 & 4.17 \\
\hline & 250 & 3.70 \\
\hline \multirow{3}{*}{$\begin{array}{c}\text { Austempered } \\
\left(\text { Batch } 2-\text { 332 }^{\circ} \mathrm{C}\right)-\mathrm{AB2}\end{array}$} & 150 & 6.59 \\
\hline & 200 & 6.17 \\
\hline & 250 & 6.01 \\
\hline
\end{tabular}

\section{Fatigue Crack Growth Behavior in the Linear Region}

Figure 31 reports the fatigue crack growth behaviour of annealed and austempered (AB1 and AB2) specimens in the linear region at $\mathrm{da} / \mathrm{dN}>10^{-7} \mathrm{~m} /$ cycle. It is evident from the plot that the austempered (Batch 1) - AB1 specimens has higher crack growth rate than the annealed specimen. This higher crack propagation behaviour in austempered AB1 specimens could be attributed to higher strength and hardness. In comparison, the austempered (Batch 2) - AB2 specimens had the lowest FCGRs among the three batches despite the higher hardness and strength. This behaviour is similar to what is seen in the threshold region and can be attributed to the strength independence of FCGRs in B and TM type microstructures. It is worthwhile to take note that the lower austempering temperature of $332^{\circ} \mathrm{C}(\mathrm{AB} 2$ samples) gives better fatigue crack 
growth (FCG) resistance in the linear region just as observed in the threshold region. In fact, it gives the best crack growth resistance even when compared with the low strength annealed material with a good combination of strength and hardness. Hence, upon comparing the FCGRs and $\Delta \mathrm{K}_{\mathrm{th}}$ in the linear region as well as the threshold region, it is now known that lower the austempering temperature better the FCG resistance in the 4140 alloy with no precharged hydrogen. It is good to point out that Kondo and others [61] showed a similar trend in quenched and tempered SCM440H. The lower the tempering temperature yielded low FCGR with the only difference being the microstructure was completely tempered martensite (TM). Table 10 shows the Paris constants for austempered (Batch 1 and 2) and annealed specimens. Austempered specimens (AB1) had lowest $\mathrm{C}$ and highest $\mathrm{m}$ values. 


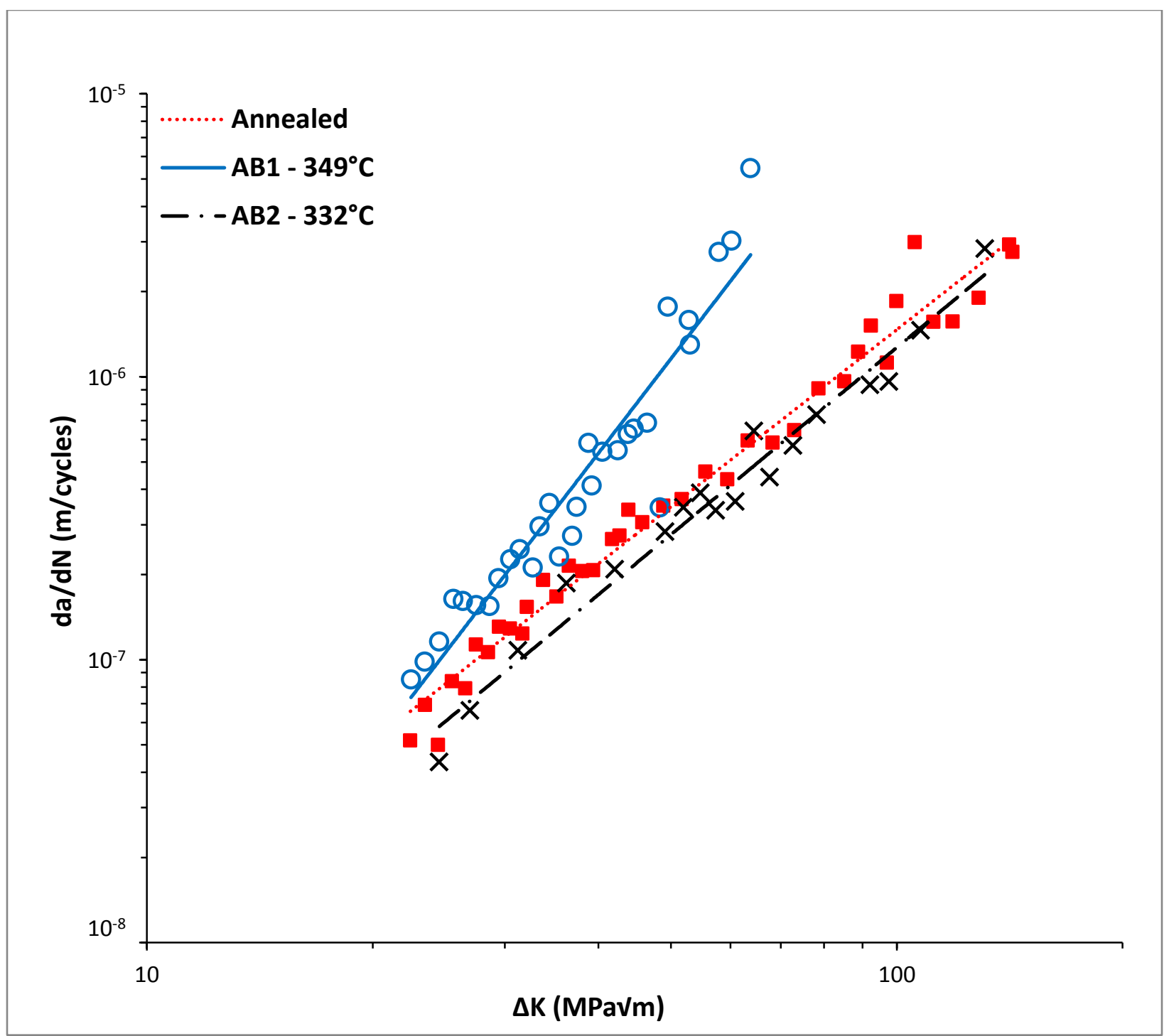

Figure 31: Comparison of the fatigue crack growth behavior of the annealed and austempered samples with no exposure to hydrogen charging 
Table 10: Comparison of Paris Constants for annealed and austempered samples

\begin{tabular}{|c|c|c|}
\hline Material Condition & $\overline{\mathbf{C}}$ & $\mathbf{m}$ \\
\hline Annealed & $1 * 10^{-10}$ & 2.08 \\
\hline Austempered (Batch $1-349^{\circ} \mathrm{C}$ ) - AB1 & $2 * 10^{-12}$ & 3.45 \\
\hline Austempered (Batch $\left.2-332^{\circ} \mathrm{C}\right)-\mathrm{AB} 2$ & $5 * 10^{-11}$ & 2.14 \\
\hline
\end{tabular}

Figures 32, 33 and 34 show the crack growth behaviour of annealed and austempered (AB1 and AB2) samples for 150,200 and $250 \mathrm{hrs}$ of exposure to hydrogen charging respectively. The austempered samples (AB1) have higher crack growth rates at all levels of dissolved hydrogen on comparison with the annealed specimens. Moreover, it is observed that the effect of hydrogen on the fatigue crack growth increases with increased hydrogen concentration in the alloy in both the specimens. The dissolved hydrogen affects the fatigue behaviour of the alloy in the linear region significantly in both the annealed and austempered (AB1) specimens. This is apparent in the figures 30 through 31 . As the hydrogen concentration increases the slope of the curves becomes steeper and also in the AB1 specimens the shift in the crack growth curves is much more pronounced than the annealed specimens. Both of these patterns indicate a drastic reduction in the fatigue resistance in the $\mathrm{AB} 1$ specimens compared to the annealed specimens due to dissolved hydrogen even in the linear region. On the other hand, the AB2 specimens are only marginally affected in the linear region. The linear FCGRs in AB2 are higher than the AB1 samples in the $\Delta \mathrm{K}$ region of $20-30 \mathrm{MPa} \sqrt{\mathrm{m}}$ but then at higher $\Delta \mathrm{K}=30-55 \mathrm{MPa} \sqrt{\mathrm{m}}$, the FCGRs decrease to less than that observed in $\mathrm{AB} 1$ samples. At the corresponding crack growth rates $\left(\mathrm{da} / \mathrm{dN} \approx 1-3^{*} 10^{-7} \mathrm{~m} / \mathrm{cycle}\right)$, these are seen as a sudden rise in crack growth rates before falling 
off shortly after $\left(\mathrm{da} / \mathrm{dN} \approx 3 * 10^{-7} \mathrm{~m} /\right.$ cycle $)$. For the $150 \mathrm{hrs}$ and $250 \mathrm{hrs}$, the point of inflection from the sudden rise to a straight line curve occurs at the same point (da/dN $\approx 2 * 10^{-7} \mathrm{~m} /$ cycle), but for the $250 \mathrm{hrs}$ specimen this occurs at marginally higher $\left(\mathrm{da} / \mathrm{dN} \approx 3 * 10^{-7} \mathrm{~m} /\right.$ cycle) crack growth rate. These changes in cracking behaviour or bursts of cracking is not seen in the untreated AB2 sample. This might be due to the embrittling nature of hydrogen and hence it is seen to marginally increase in the $250 \mathrm{hrs} \mathrm{AB2} \mathrm{sample.} \mathrm{Ritchie} \mathrm{[96]} \mathrm{has} \mathrm{also} \mathrm{reported} \mathrm{this} \mathrm{nature}$ for another low alloy steel. Also, at all concentrations of dissolved hydrogen, the FCGRs of austempered (Batch 2) samples merge the FCGRs of annealed samples at a $\Delta \mathrm{K}>55 \mathrm{MPa} \sqrt{\mathrm{m}}$. 


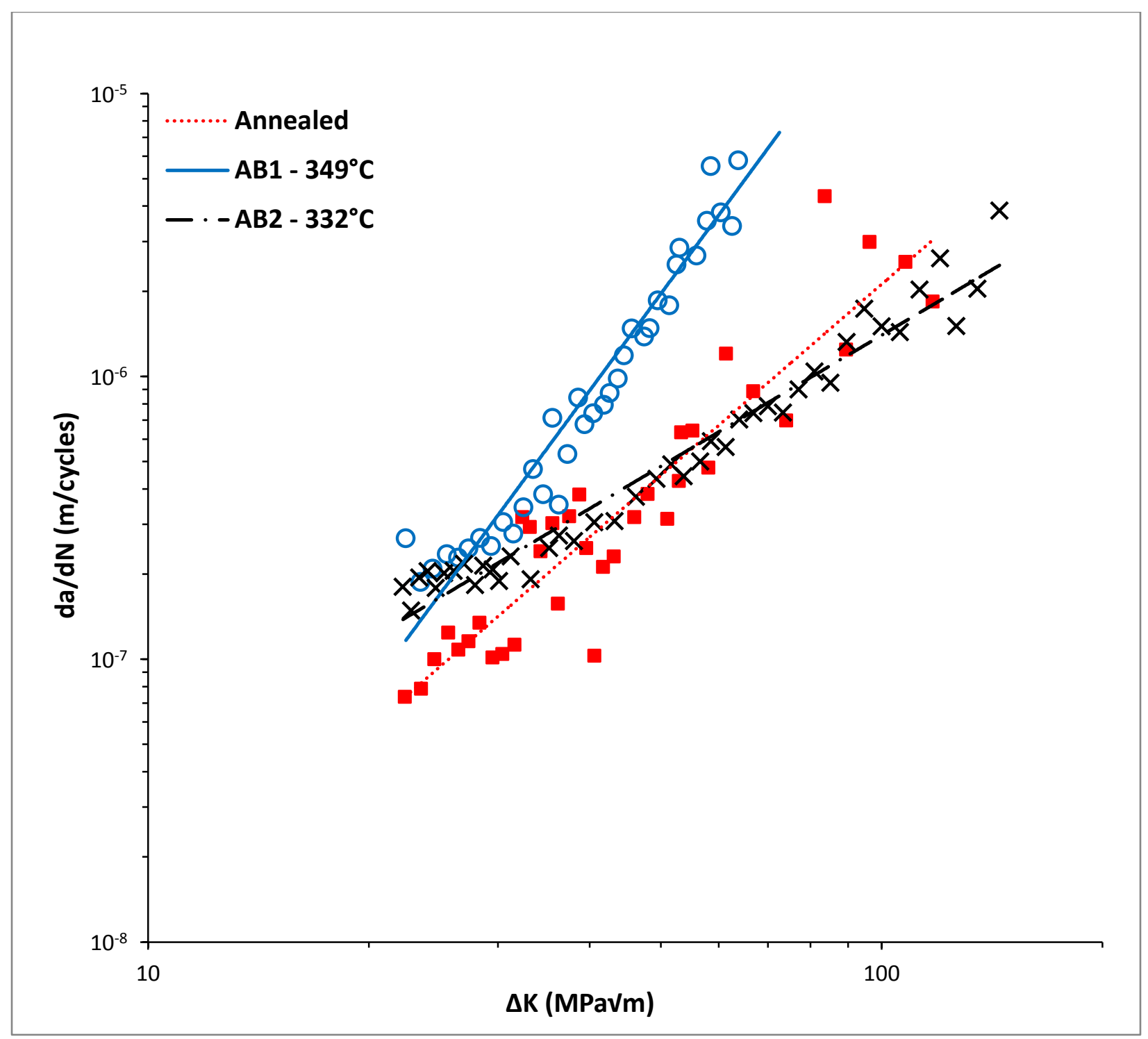

Figure 32: Comparison of the fatigue crack growth behavior of the annealed and austempered samples with $150 \mathrm{hrs}$ of exposure to hydrogen 


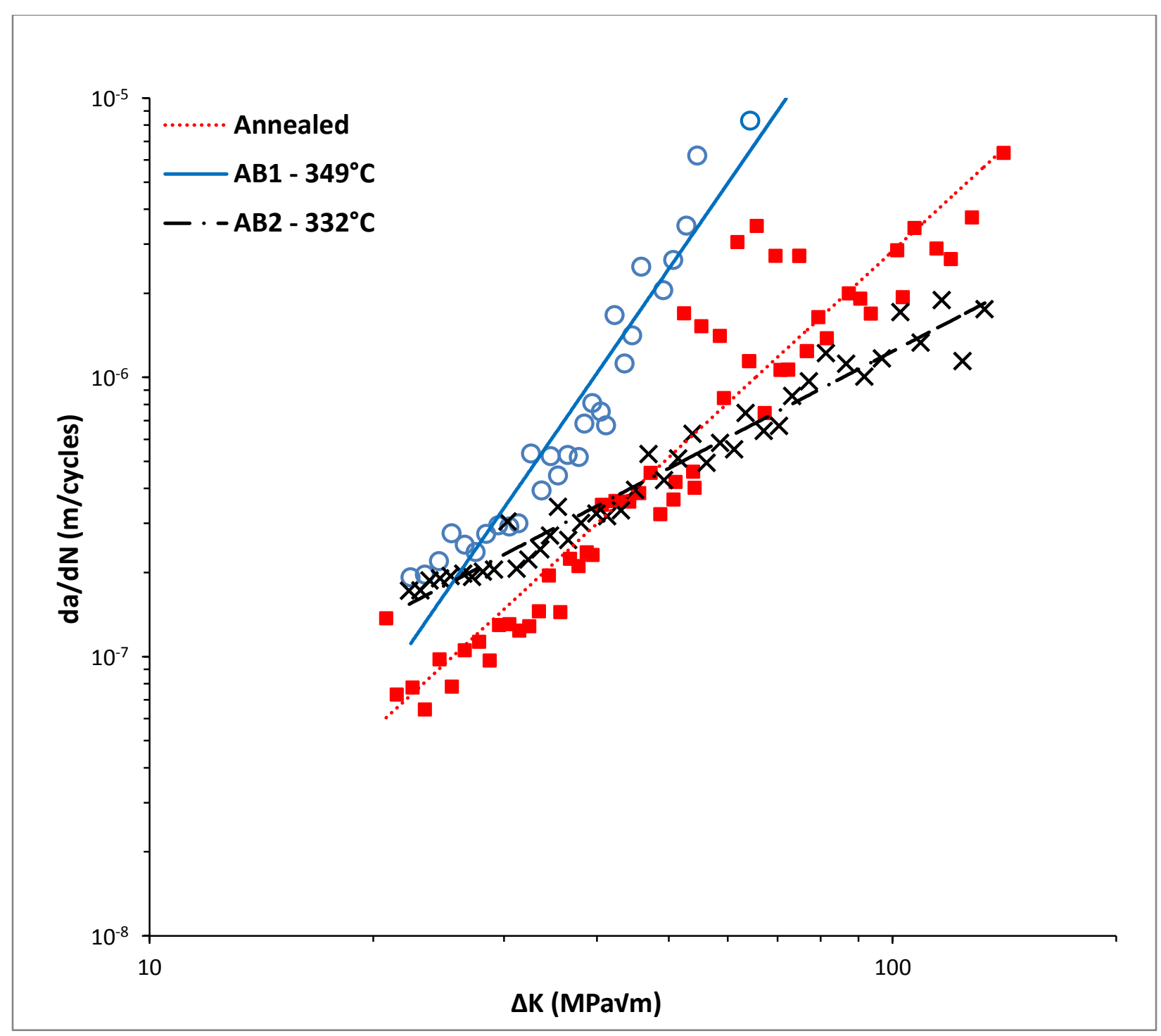

Figure 33: Comparison of the fatigue crack growth behavior of the annealed and austempered samples with 200 hrs of exposure to hydrogen 


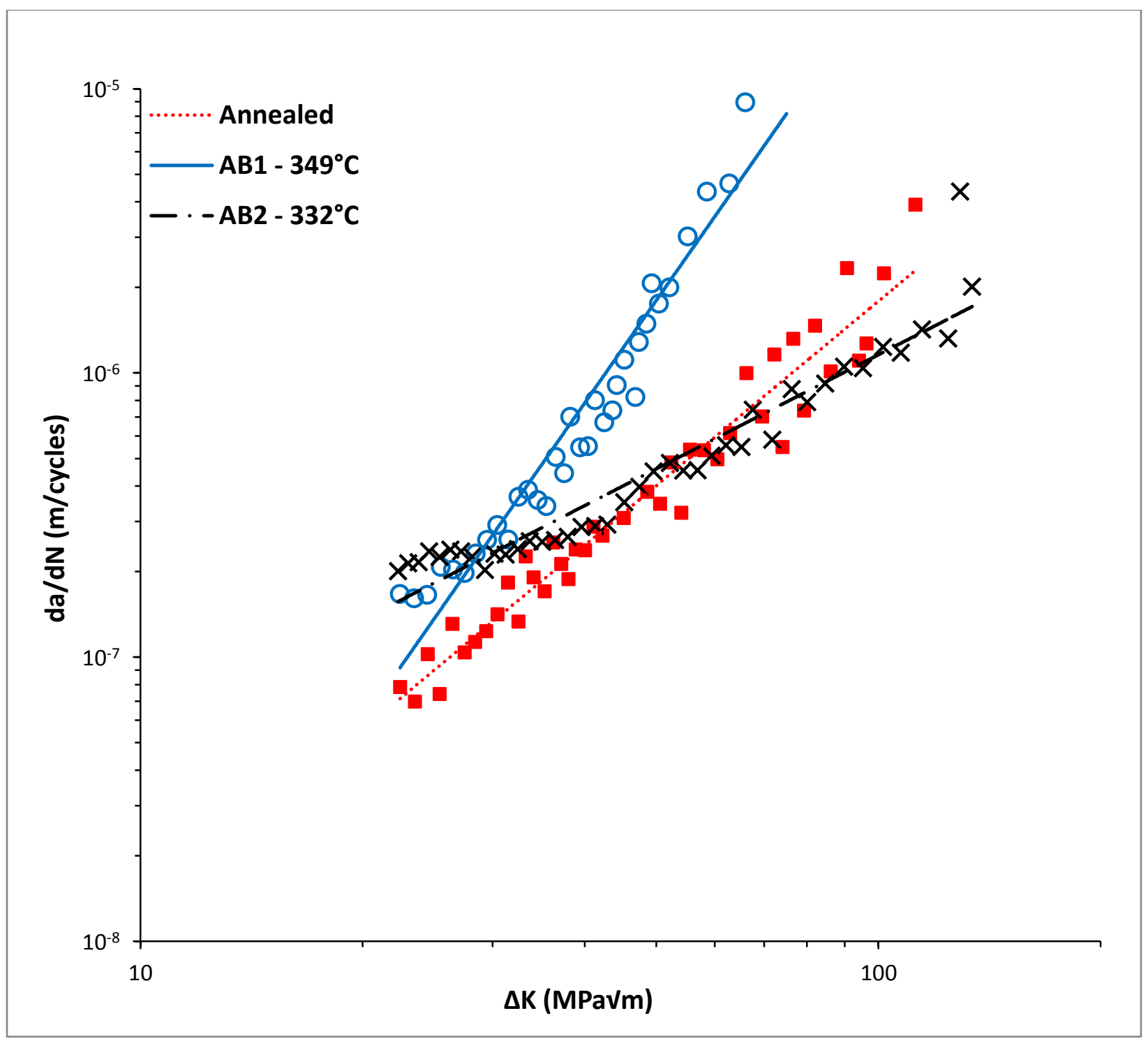

Figure 34: Comparison of the fatigue crack growth behavior of the annealed and austempered samples with $250 \mathrm{hrs}$ of exposure to hydrogen

Table 11 reports the $\mathrm{C}$ and $\mathrm{m}$ constants for the austempered (AB1 and $\mathrm{AB} 2$ ) and annealed specimens at different dissolved hydrogen concentration. In the annealed as well as austempered (AB1) specimens, as the hydrogen concentration increases, the value of $\mathrm{m}$ increases and the value of $\mathrm{C}$ decreases in both of the specimens indicating the degradation effects of hydrogen through end of the threshold region and well into the start of the linear regime (at da/dN rates 
more than $10^{-7} \mathrm{~m} /$ cycle). As the hydrogen concentration increases, the $\mathrm{C}$ and $\mathrm{m}$ values increases significantly in the austempered specimens (AB1) specimens. However in the annealed specimens, $\mathrm{C}$ and $\mathrm{m}$ are not significantly affected with increased dissolved hydrogen concentration. While the annealed and as well as the AB1 specimen are affected in the linear region, the same cannot told about the AB2 specimen. As the hydrogen concentration increases, their $\mathrm{C}$ value increases in the $\mathrm{AB} 2$ specimen, but their $\mathrm{m}$ value gradually decreases. This shows that the $\mathrm{AB} 2$ specimen is not significantly affected in the linear region as the other two conditions. The degradation effects though slightly present at low $\Delta \mathrm{K}$ diminishes after $\Delta \mathrm{K}>55$ $\mathrm{MPa} \sqrt{ } \mathrm{m}$.

Table 11: Paris constants for different hydrogen exposure time

\begin{tabular}{|c|c|c|c|}
\hline Material Condition & $\begin{array}{c}\text { Charging time } \\
\text { (hrs) }\end{array}$ & $\mathbf{C}$ & $\mathbf{m}$ \\
\hline \multirow{3}{*}{ Annealed } & 150 & $1 * 10^{-11}$ & 2.25 \\
\hline & 200 & $4 * 10^{-11}$ & 2.45 \\
\hline & 250 & $9 * 10^{-11}$ & 2.16 \\
\hline \multirow{3}{*}{$\begin{array}{c}\left.\text { Austempered (Batch } 1-349^{\circ} \mathrm{C}\right)- \\
\text { AB1 }\end{array}$} & 150 & $2 * 10^{-12}$ & 3.53 \\
\hline & 200 & $7 * 10^{-13}$ & 3.86 \\
\hline & 250 & $9 * 10^{-13}$ & 3.72 \\
\hline \multirow{3}{*}{$\begin{array}{c}\left.\text { Austempered (Batch } 2-3^{\circ}{ }^{\circ} \mathrm{C}\right)- \\
\text { AB2 }\end{array}$} & 150 & $1 * 10^{-09}$ & 1.54 \\
\hline & 200 & $2 * 10^{-09}$ & 1.39 \\
\hline & 250 & $2 * 10^{-09}$ & 1.33 \\
\hline
\end{tabular}




\section{Stress Corrosion Cracking}

\section{Annealed Material}

The stress corrosion cracking (SCC) behaviour of annealed material are shown in figure 35 . From the figure 35 , it is clear that the $\mathrm{K}_{\mathrm{ISCC}}$ value and the stress corrosion CGRs do not show any particular trend. It is evident that the material is undergoing stress corrosion cracking from the nature of the graph. However, the concentration of dissolved hydrogen did not have any significant effect on the $\mathrm{K}_{\mathrm{ISCC}}$ values. Numerous tests were conducted with different stress intensity in the range of $\mathrm{K} \approx 30-45 \mathrm{MPa} \sqrt{ } \mathrm{m}$. No crack propagation was observed at these SIFs even after 200 hrs at constant load. Therefore the SIF was increased and the curves reported in figure 35 were observed. Due to the dynamic nature of the experiment via ex situ hydrogen charging, the dissolved hydrogen might have degassed from the material during the constant load tests that not enough concentration of hydrogen is present at the crack tip to cause delayed cracking in this material. This might be the case in the specimen charged with hydrogen for 200 hrs (red curve in figure 35) where the crack growth rate increases more than the specimen charged for $150 \mathrm{hrs}$ above the $\mathrm{K} \approx 52 \mathrm{MPa} \sqrt{\mathrm{m}}$. But, below this $\mathrm{K}$ value, the CGRs are less than the specimen charged for $150 \mathrm{hrs}$. This might suggest that only above $\mathrm{K} \approx 52 \mathrm{MPa} \sqrt{\mathrm{m}}$ there is sufficient driving force to cause hydrogen induced cracking at the crack tip. In other words, until this particular $\mathrm{K}$ value is attained, there is not enough driving force for hydrogen to diffuse from the bulk the material to the crack tip to increase the crack growth rate. Table 12 lists the $\mathrm{K}_{\mathrm{ISCC}}$ values for the annealed material. Due to nature of the results obtained, it was thought that the corrosion fatigue behaviour might be more useful than the static SCC where the cyclic loads severely reduce the fatigue life of the alloy. Hence, more emphasis was given towards corrosion fatigue behaviour of the alloy. 


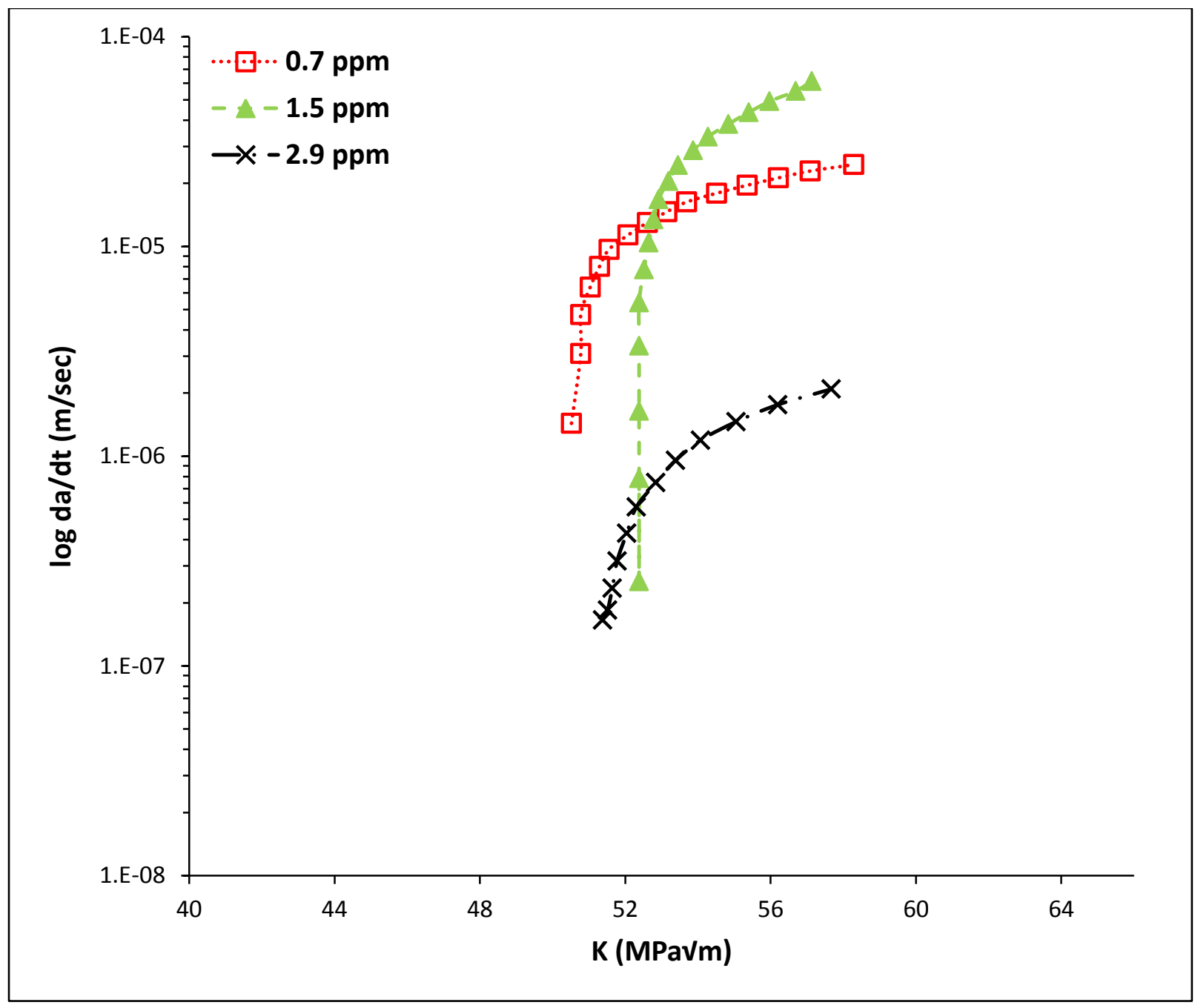

Figure 35: SCC behaviour of annealed material at different charging times of dissolved hydrogen (150 hrs - red; 200 hrs - green; 250 hrs - black) 


\section{Austempered Batch -1 (AB1) material}

A similar behaviour as observed in the annealed material was seen in the austempered batch 1 (AB1) material as shown in the figure 36. Although the specimen treated for $200 \mathrm{hrs}$ had higher CGRs at all K level, it had a higher KISCC than the sample charged for 150 hrs. Table 12 lists the $\mathrm{K}_{\mathrm{ISCC}}$ values for the $\mathrm{AB} 1$ material as a function of charging time.

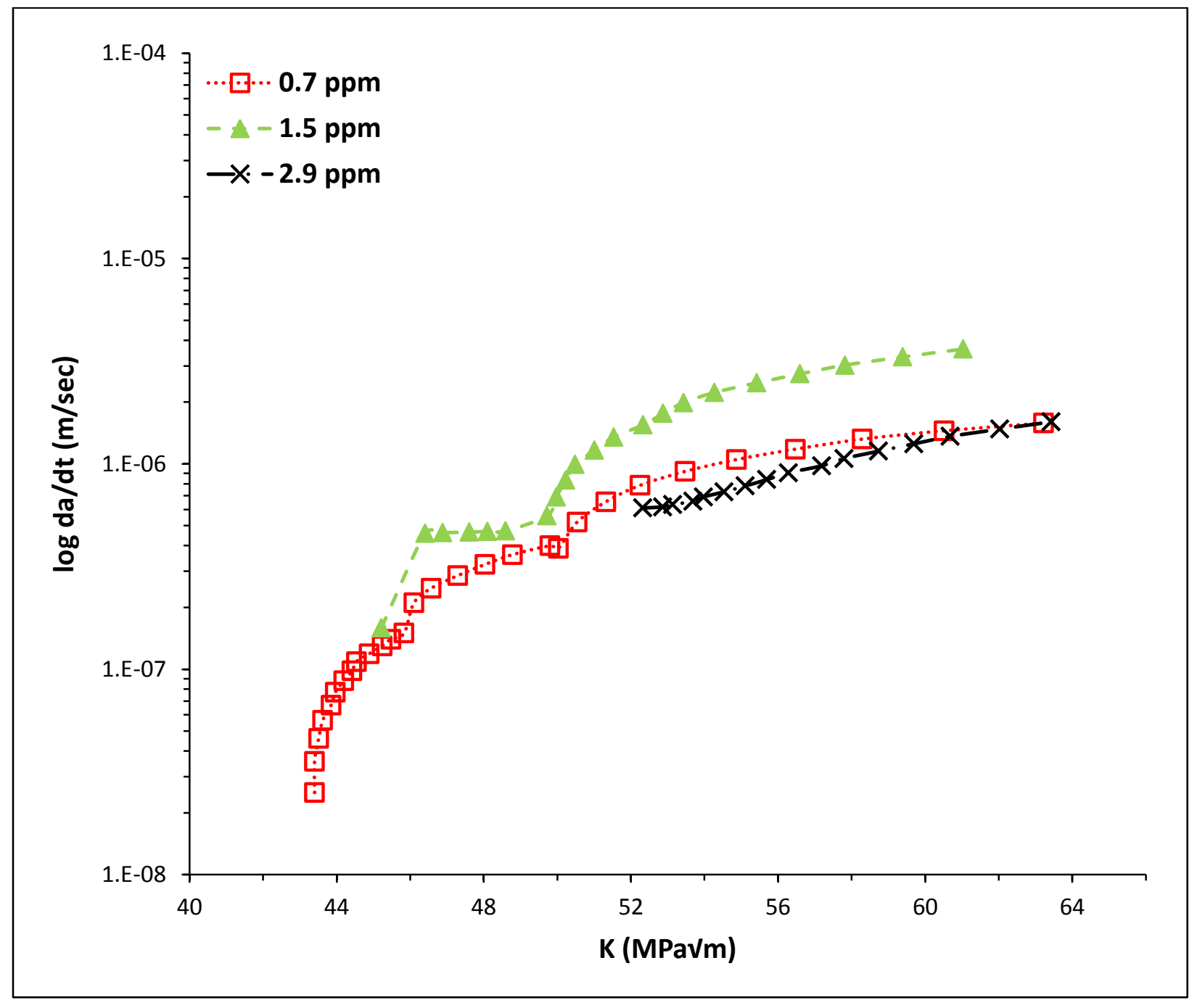

Figure 36: SCC behaviour of AB1 material at different charging times of dissolved hydrogen (150 hrs - red; 200 hrs - green; 250 hrs - black) 
When the $\mathrm{K}_{\mathrm{ISCC}}$ value of the annealed and AB1 samples were compared, it is evident that the annealed material had higher $\mathrm{K}_{\mathrm{ISCC}}$ value at lower hydrogen concentration. On the other hand, interestingly at very high hydrogen concentration, austempered (AB1) samples had higher $\mathrm{K}_{\mathrm{ISCC}}$. Generally $\mathrm{K}_{\mathrm{ISCC}}$ decreases with increase in yield strength. But here the AB1 samples have high yield strength and high $\mathrm{K}_{\mathrm{ISCC}}$. This indicates austempering may be a better heat treatment process than conventional quench and tempering. Therefore, the Bainitic - Tempered Martensitic mixed microstructure instead of pure martensitic or tempered martensitic structure will have better $\mathrm{K}_{\mathrm{ISCC}}$ value.

Table 12: KISCC parameter of the annealed material for different hydrogen charging time

\begin{tabular}{|c|c|c|c||}
\hline Material & Charging time (hrs) & $\begin{array}{c}\text { Dissolved } \\
\text { Hydrogen } \\
\text { Condition }\end{array}$ & $\begin{array}{c}\mathbf{K}_{\text {ISCC }}(\mathbf{M P a} \sqrt{\mathbf{m}}) \\
\text { Concentration } \\
\left(\mathbf{C}_{\mathbf{H}}\right)(\mathbf{p p m})\end{array}$ \\
\hline \multirow{2}{*}{$\begin{array}{c}\text { Austempered } \\
\text { (Batch 1 - 349 }\end{array}$} & & 0.7 & \\
\cline { 2 - 4 } - AB1 & 150 & 1.5 & 43.4 \\
\cline { 2 - 4 } & 200 & 2.9 & 45.2 \\
\hline \multirow{2}{*}{ Annealed } & 250 & 0.7 & 52.3 \\
& 150 & 1.5 & 50.5 \\
\cline { 2 - 4 } & 200 & 2.9 & 51.4 \\
\cline { 2 - 4 } & 250 & & \\
\hline
\end{tabular}


Influence of Hydrogen Concentration on Incubation period at different stress intensity levels

The variation of incubation period with dissolved hydrogen concentration at different SIF for the AB1 material are shown in Figure 37. Incubation period $\left(T_{i n c}\right)$ for the crack growth was found to decrease with the increase in stress intensities $(\mathrm{K})$ and also with increase in Hydrogen concentration for the Heat Treated samples. $\mathrm{T}_{\mathrm{inc}}$ was found to decrease exponentially as the $\mathrm{K}$ increased.

The corresponding equations for the variation of incubation period due to increase in hydrogen concentration as a result of increase in charging time are as follows:

For 150 hrs: $\mathrm{T}_{\text {inc }}=1 \times 10^{11} \mathrm{e}^{-0.461(\mathrm{~K})} \quad-(6)$

For 200 hrs: $\mathrm{T}_{\text {inc }}=1 \times 10^{13} \mathrm{e}^{-0.604(\mathrm{~K})} \quad-(7)$ 


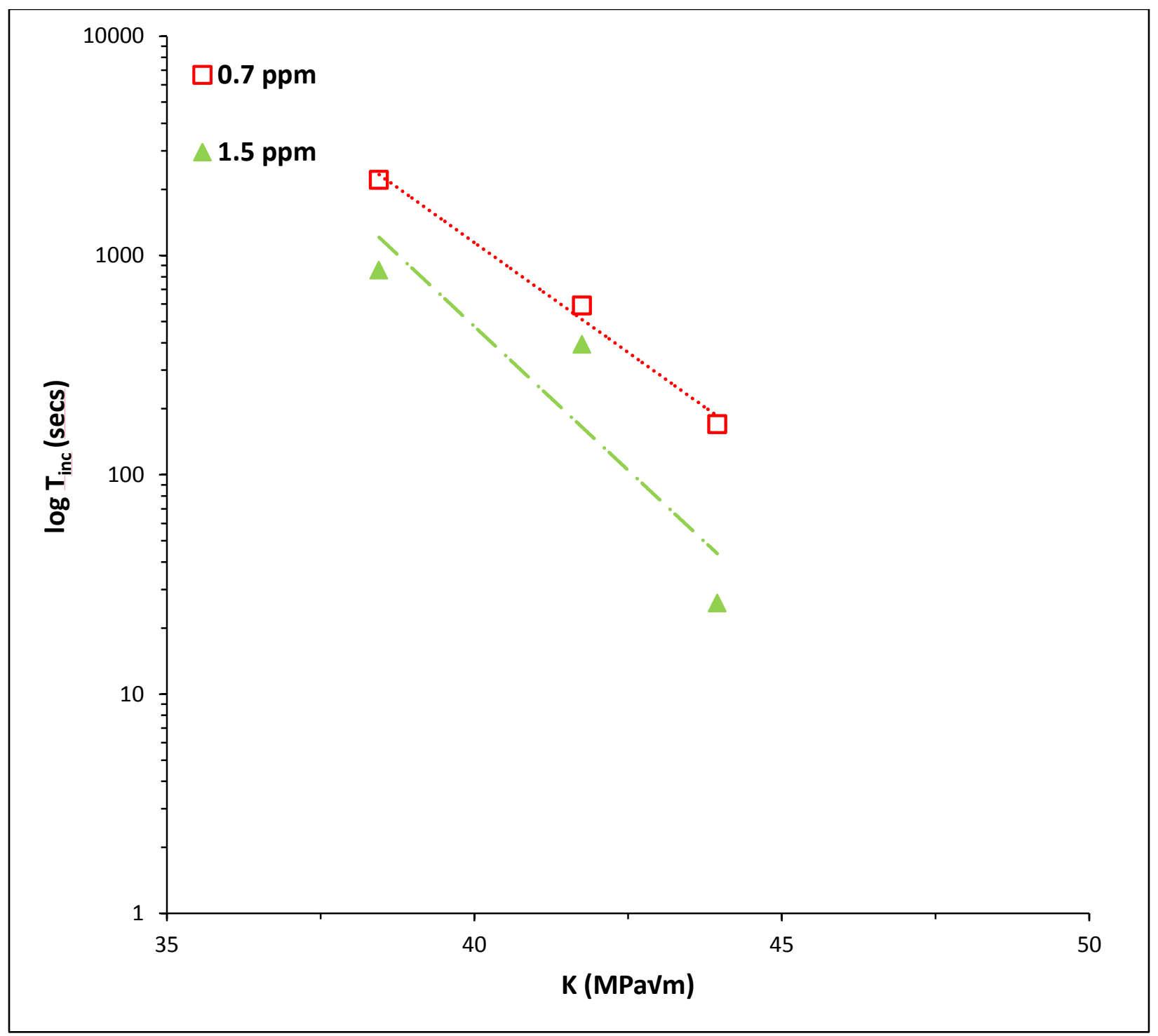

Figure 37: Influence of Hydrogen Concentration on Incubation period at different stress intensity levels in AB1 material 
Influence of Hydrogen Concentration $\left(C_{H}\right)$ on $K_{\text {Isce }}$ and crack growth rate in region 2 $(d a / d t)_{\text {II }}$

The influence of hydrogen concentration on $\mathrm{K}_{\mathrm{ISCC}}$ and the region 2 CGRs are shown in figures 38 and 39. $\mathrm{K}_{\mathrm{ISCC}}$ was found to vary with $\mathrm{C}_{\mathrm{H}}$ in the following manner (figure 38 ):

For the annealed material: $\mathrm{K}_{\mathrm{ISCC}}=51.051 \times\left(\mathrm{C}_{\mathrm{H}}\right)^{-0.3129}$

For the AB1 material: $\mathrm{K}_{\mathrm{ISCC}}=46.372 \times\left(\mathrm{C}_{\mathrm{H}}\right)^{-0.4733}$

Crack growth rate (da/dt) was found to increase with increase in stress intensity level. Also, the crack growth rate increased as the hydrogen concentration $\left(\mathrm{C}_{\mathrm{H}}\right)$ increased up to a certain level (1.5 ppm) and after that was found to have less influence (figure 39). The same phenomenon was observed in both $A B 1$ as well as annealed steel samples. Crack growth rate varies with $C_{H}$ in the following manner (figure 39):

For the annealed material: $\left(\frac{d a}{d t}\right)_{I I}=2 \times 10^{-6}\left(C_{H}\right)^{-6 \times 10^{-8}} \quad$ - (10)

For the AB1 material: $\left(\frac{d a}{d t}\right)_{I I}=2 \times 10^{-7}\left(C_{H}\right)^{1 \times 10^{-7}}$ 


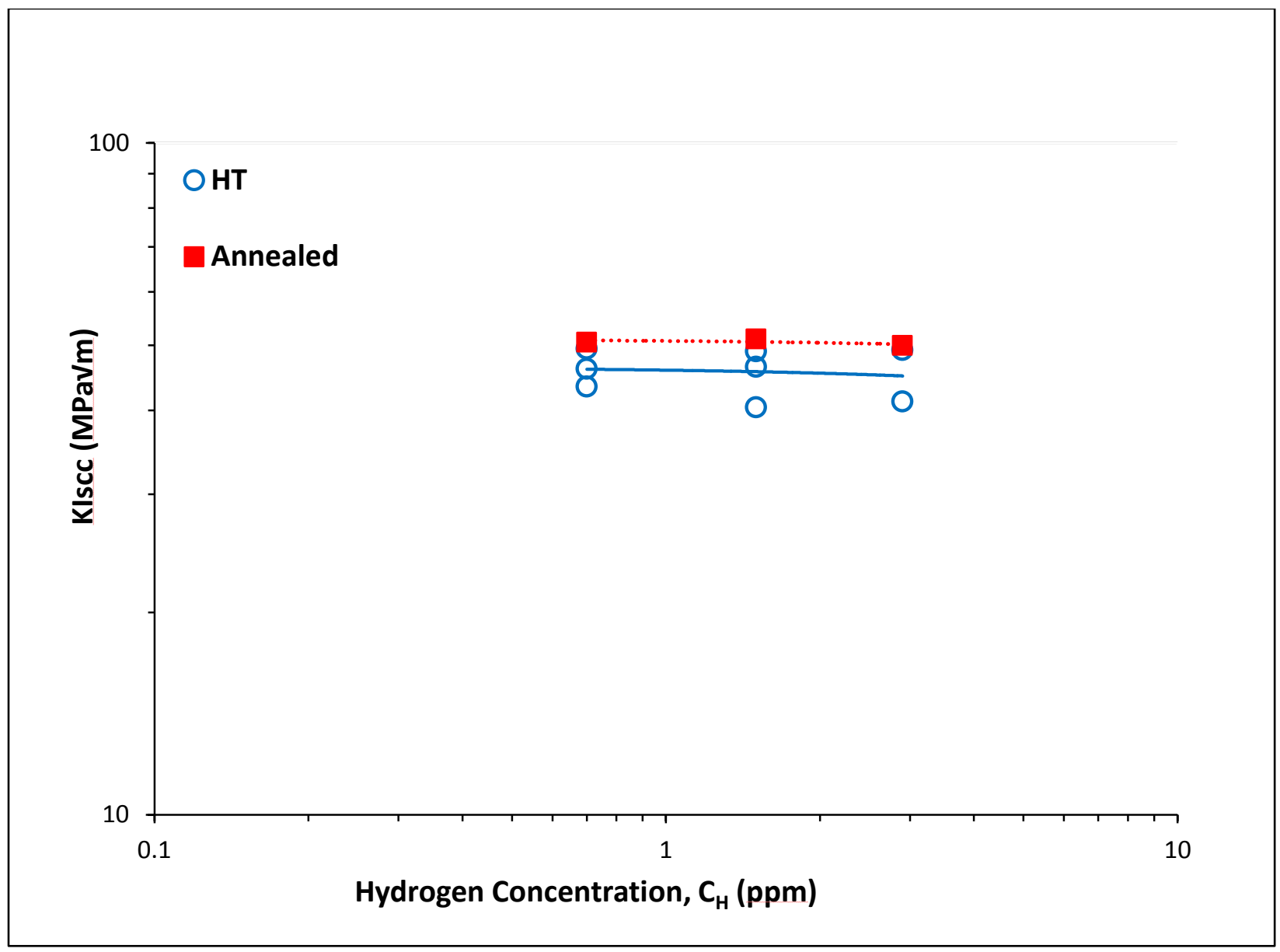

Figure 38: Influence of hydrogen concentration (Co) on KISCC (blue - AB1 material (heat treated - HT; red - annealed) 


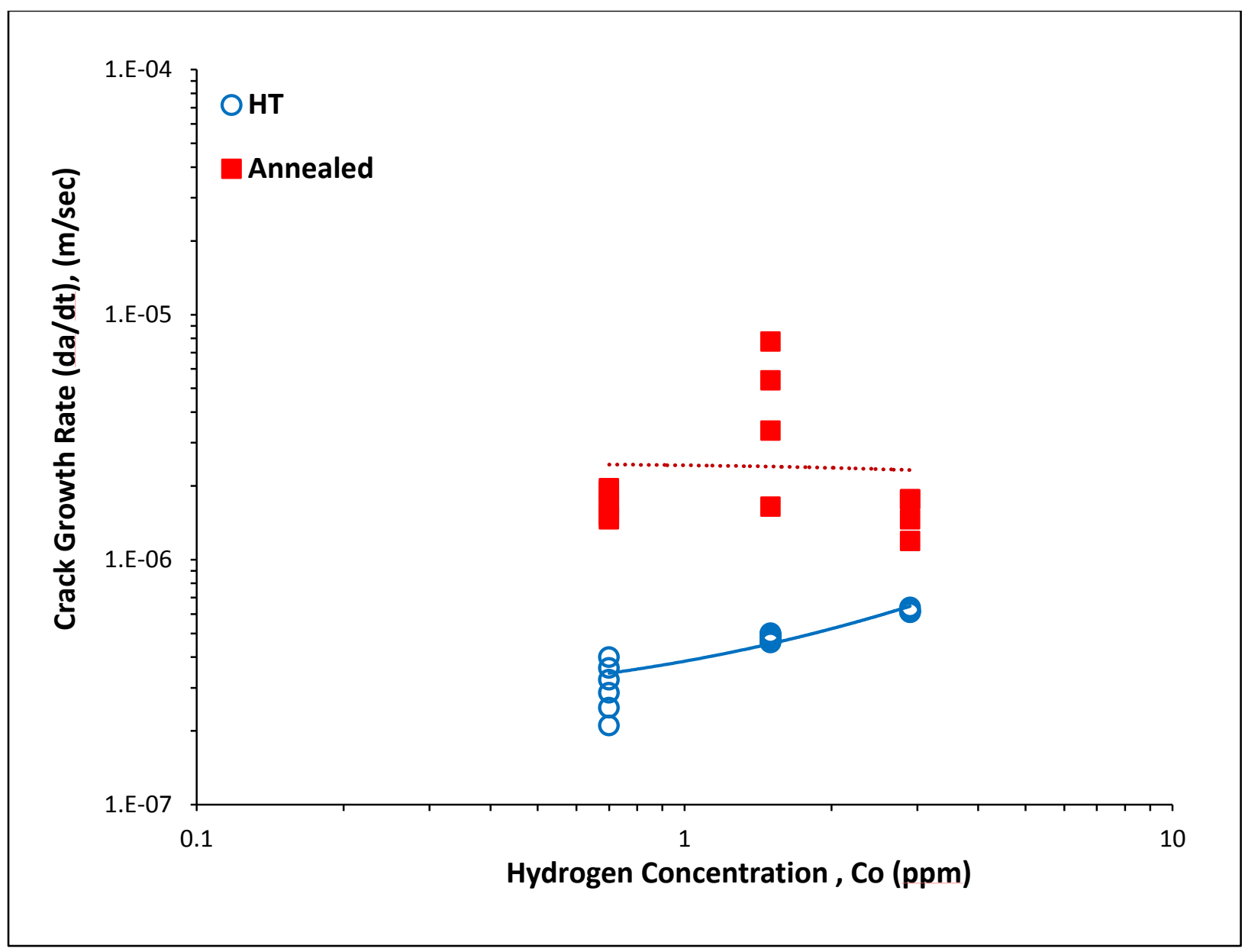

Figure 39: Influence of hydrogen concentration (Co) on da/dt in Region 2 (blue - AB1 material (heat treated - HT); red - annealed)

We wanted to investigate whether SCC behaviour can be predicted from the corrosion fatigue crack growth rate data. This is explained in the following section. 


\section{Qualitative mechanism to explain the FCGRs in the Intermediate growth rate} $\left(10^{-8} \sim 10^{-7} \mathrm{~m} /\right.$ cycle $)$ region

\section{Existence of a plateau region and its relation to SCC}

The fatigue crack growth rate behaviour (FCGRs) in the intermediate growth rate region i.e., between $\left(10^{-8} \sim 10^{-7} \mathrm{~m} / \mathrm{cycle}\right)$ has been characterized by McEvily and Wei [97] into three different classes: (a) Type A - true corrosion fatigue, (b) Type B - stress corrosion fatigue and (c) Type $\mathrm{C}-$ mixed corrosion fatigue. These are illustrated in the following figure 40 . The $\mathrm{da} / \mathrm{dN}$ regimes of interest are circled in green in figure 40.

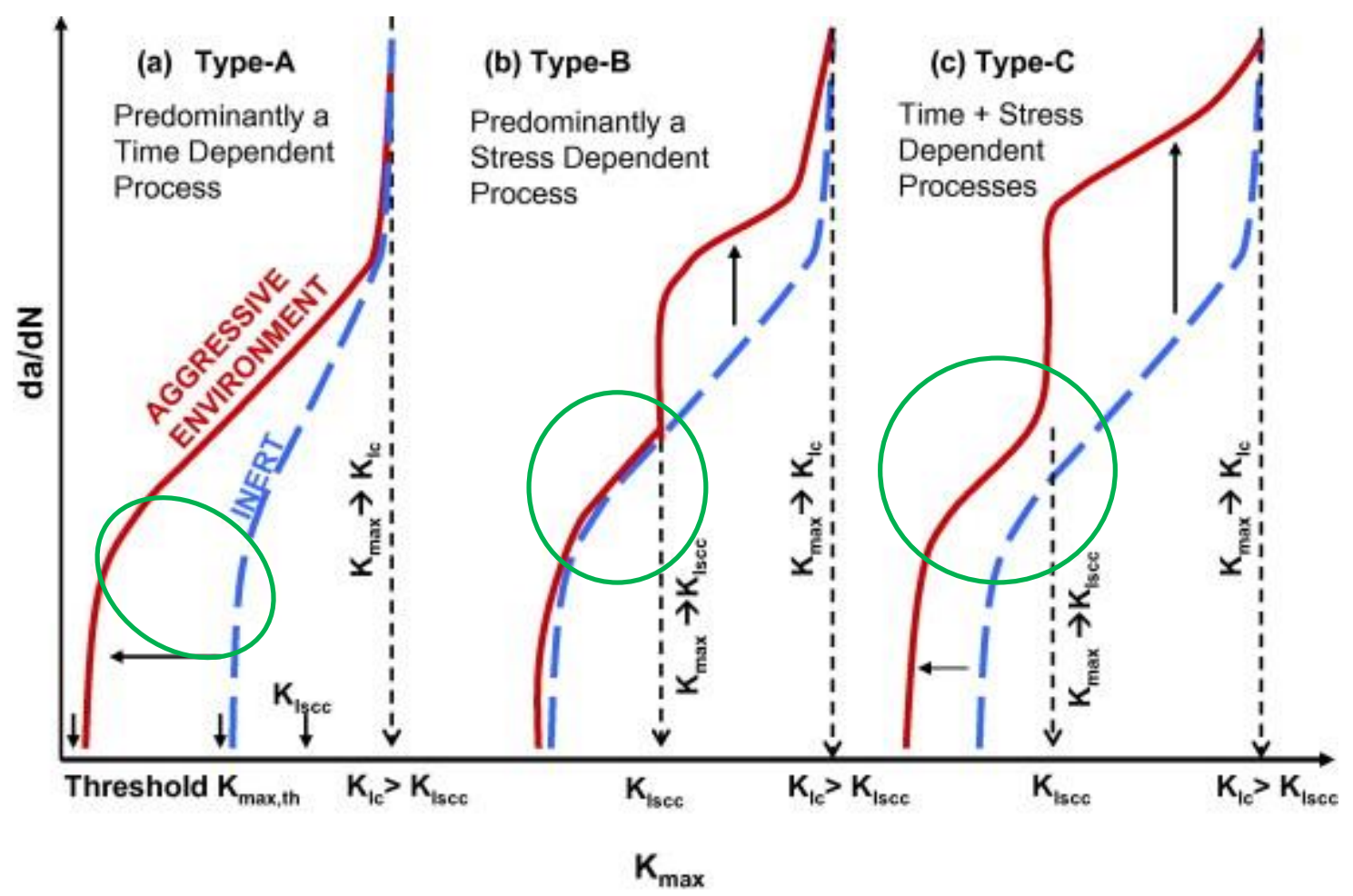

Figure 40: Classification of plateau region by McEvily and Wei $[97,98]$

The type A behaviour is characterized by the significant influence by the environment at low FCGRs followed by the gradual merging of the environmental curve with the inert curve at high 
FCGRs with minimal influence from the environment or shows a strong dependence on time or frequency. Type A behaviour is termed as True Corrosion Fatigue. In the type B behaviour, the material shows little influence due to environment until a characteristic " $\mathrm{K}_{\mathrm{ISCC}}$ " stress intensity factor is attained and then shows a marked influence on FCGRs after a SIF greater than the

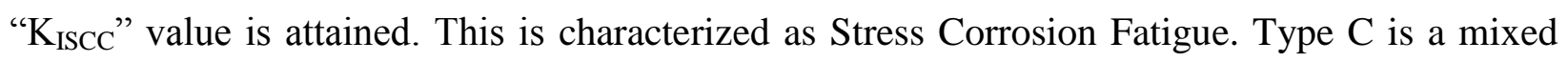
mode behaviour where the material is influenced by both time dependent (fatigue) and stress corrosion dependent (SCC) processes.

In the current investigation, it is necessary to mechanistically relate the obtained FCGRs via one of the three above mentioned mechanisms since the study was also based on SCC of 4140 alloy. This characterization mainly based on the existence of $K_{\max }^{T}$ or $\mathrm{K}_{\max }$, a characteristic SIF based on the particular material - environment system which manifests as an inflexion point on the da/dN vs $\Delta \mathrm{K}$ curve in the intermediate region very close to the start of Region 2 in fatigue (Paris regime). This mechanistic process is explained in regards to each of the three batches of material utilized in this study by means of obtained FCG curves correlated by a detailed fractographic analysis which could be linked possibly to the limited SCC curves obtained.

\section{Annealed}

The annealed 4140 material has a ferritic - pearlitic microstructure and is the only low strength $\left(\sigma_{y s}=757 \mathrm{MPa}\right)$ material used in this study. In the figure 41, the intermediate FCGRs are plotted against $\Delta \mathrm{K}$ for the annealed material at four different hydrogen charging times starting with no charging until $250 \mathrm{hrs}$. It is evident from the figure that hydrogen has very little or minimal influence on the crack growth rates at all SIF ranging from $10-90 \mathrm{MPa} \sqrt{\mathrm{m}}$. The only plateau

observed in this material exist between $\mathrm{da} / \mathrm{dN} \approx 4-5 \times 10^{-8} \mathrm{~m} /$ cycle $(\Delta \mathrm{K} \approx 17-20 \mathrm{MPa} \sqrt{\mathrm{m}})$ for 
the 150 hrs hydrogen charged condition. This is also seen in the figure 40 (e) and 40 (f) taken around the same SIF with the fracture morphology changing from transgranular to transgranular plus quasi cleavage like features. However, the inflection point is not distinct after about $\Delta \mathrm{K} \approx$ $20 \mathrm{MPa} \sqrt{ } \mathrm{m}$. Upon increasing the charging time to $200 \mathrm{hrs}$, there is minimal fatigue damage to the material at $\Delta \mathrm{K} \approx 20 \mathrm{MPa} \sqrt{\mathrm{m}}$ as shown in the figure 42 (i) and (j) and at higher SIFs, the damage is only due to cyclic loading as in figure $42(\mathrm{k})$ and (l) and almost resembles the material in uncharged condition (figure 42 (c) and (d)). 


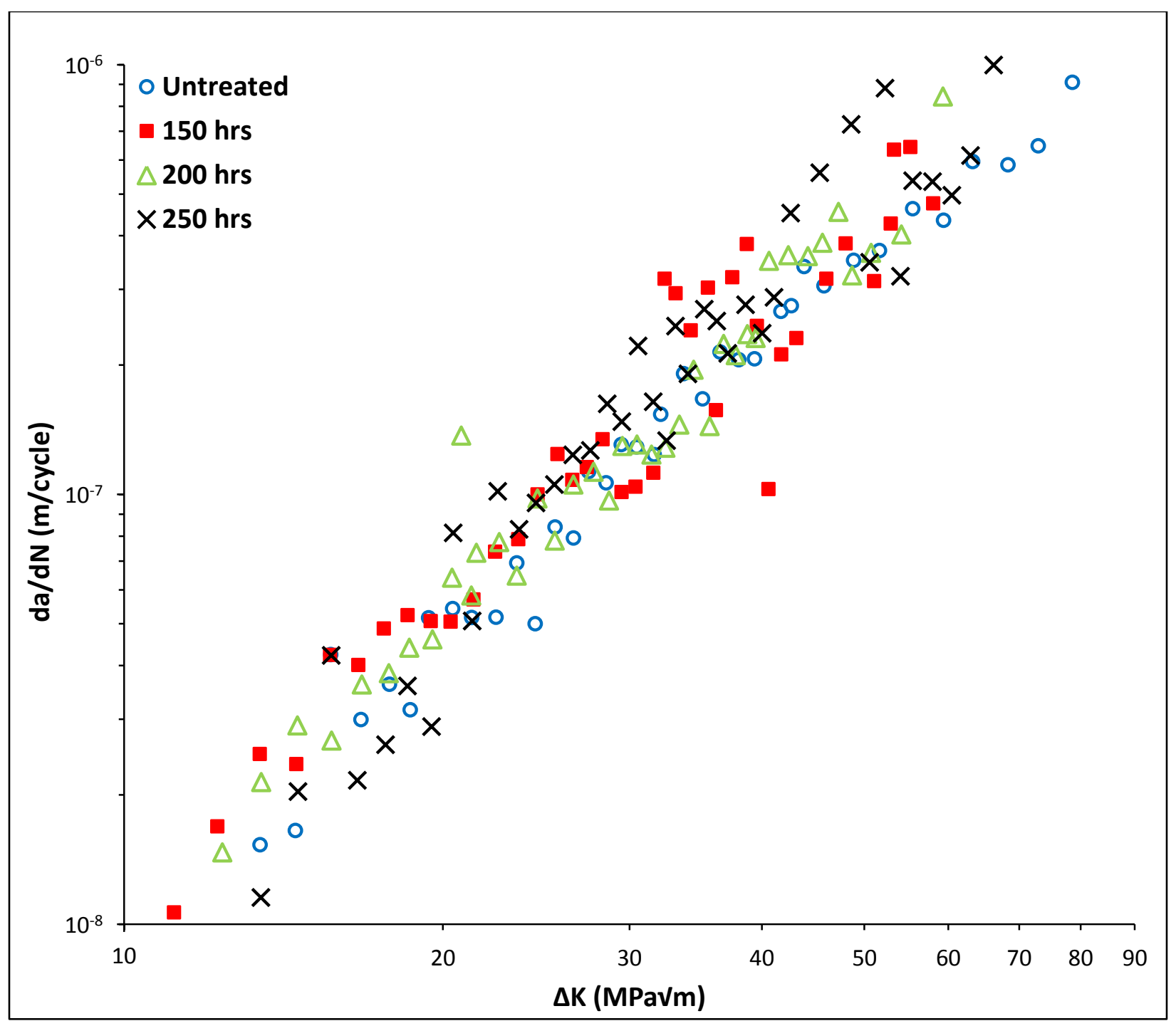

Figure 41: Comparison of FCGRs in Annealed material in Intermediate region

$$
(10-8 \sim 10-7 \mathrm{~m} / \text { cycle })
$$



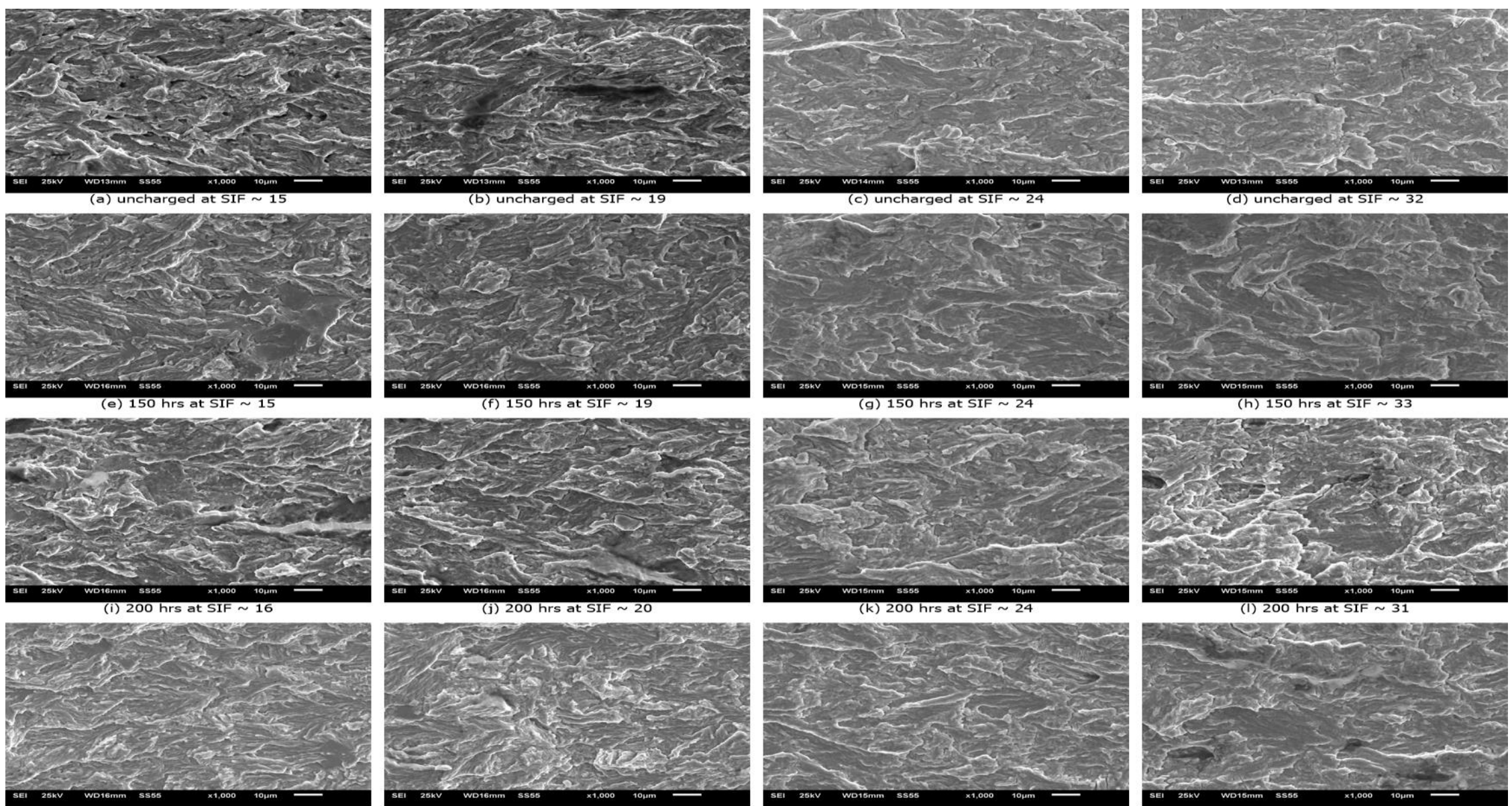

(m) 250 hrs at SIF 15

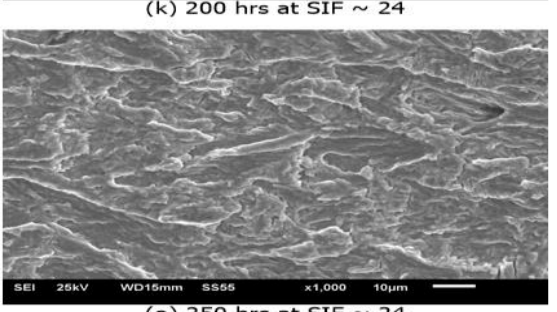

(o) $250 \mathrm{hrs}$ at SIF $\sim 24$

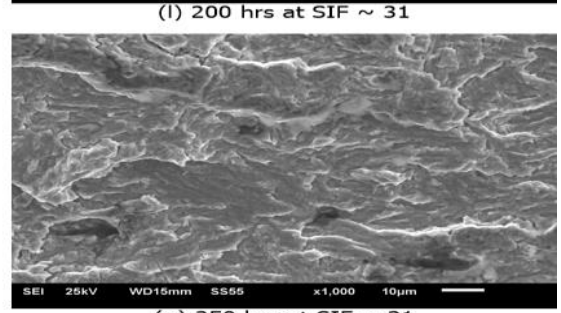

(P) 250 hrs at SIF $~ 31$

Figure 42: Fatigue surface images of annealed material ( $\Delta K$ (SIF) are in MPa $\sqrt{ }$ ) [Note: Crack propagation from right to left in all images; Magnification: 1000X] 
It is interesting however, that the material charged at $250 \mathrm{hrs}$ exhibits minor retardation in the FCGRs compared to the uncharged specimen until da/dN $\approx 5 \times 10^{-8} \mathrm{~m} /$ cycle $(\Delta \mathrm{K} \approx 20 \mathrm{MPa} \sqrt{\mathrm{m}})$ and then continue to grow at about the same rate or more than the uncharged specimen. This is again supported by the fractographs (figure 42(m) and (n)) resembling the uncharged specimen (figure 42(a) and (b)) and only at exhibiting cleavage features at $\Delta \mathrm{K} \approx 24 \mathrm{MPa} \sqrt{\mathrm{m}}_{\text {(figure } 42(\mathrm{o}) \text { ) }}$ then finally microplastic tearing at higher $\Delta \mathrm{K}$. It has been shown by Suresh and Ritchie [99], that the lower strength steels show $\mathrm{K}_{\max }<\mathrm{K}_{\mathrm{ISCC}}$ due to the strain rate sensitivity which is not encountered in high strength materials and $\mathrm{K}_{\max }$ can be markedly reduced in presence of cyclic loading. The current study shows that the annealed material could be categorized as type B behaviour, that of "stress corrosion fatigue" just by the closeness of the hydrogen charged curve to the uncharged curve (although the uncharged curve cannot be purely regarded as "inert curve"), but the absence of a clear inflection point in the FCG curves indicating the $\mathrm{K}_{\max }$ value either at, above or below the $\mathrm{K}_{\mathrm{ISCC}}$ value corroborated by the absence of predominantly IG facets at any high $\Delta \mathrm{K}$ in the figure 3 shows that it is case of type $\mathrm{A}$ behaviour. It was also these absence of any predominant brittle like features - either TG, IG or cleavage in the fracture images (figure 42), that this material yielded very little or no data in delayed brittle cracking (SCC) tests. In other words, the amount of dissolved hydrogen in this material at all charging times, either in static or cyclic loading, did not reach the critical concentration needed at or ahead of the crack tip to cause HIC and increase the CGRs significantly. Though it was considered that lower strength steels exhibit very high $\mathrm{K}_{\mathrm{ISCC}}$ comparable to high strength steels in presence of gaseous hydrogen due to static loading and that the FCGRs are markedly increased much below the $\mathrm{K}_{\mathrm{ISCC}}$ due to synergistic action cyclic load and hydrogen at the crack tip [99], it has not been observed in this material in either scenario (static or dynamic loading). 


\section{Austempered (Batch 1) - AB1}

The AB1 material had a predominantly $\alpha$ phase with almost no $\gamma$ phase after austenitizing and austempering at $349^{\circ} \mathrm{C}$. The austempered materials had a duplex - bainite + tempered martensite microstructure varying only in the relative volume fraction amounts. The AB1 material had a very high strength $\left(\sigma_{\mathrm{ys}} \approx 1370 \mathrm{MPa}\right)$ and displayed significant differences in the FCGRs compared to the uncharged material (Figure 43) in the intermediate region well into the onset of the Paris region. 


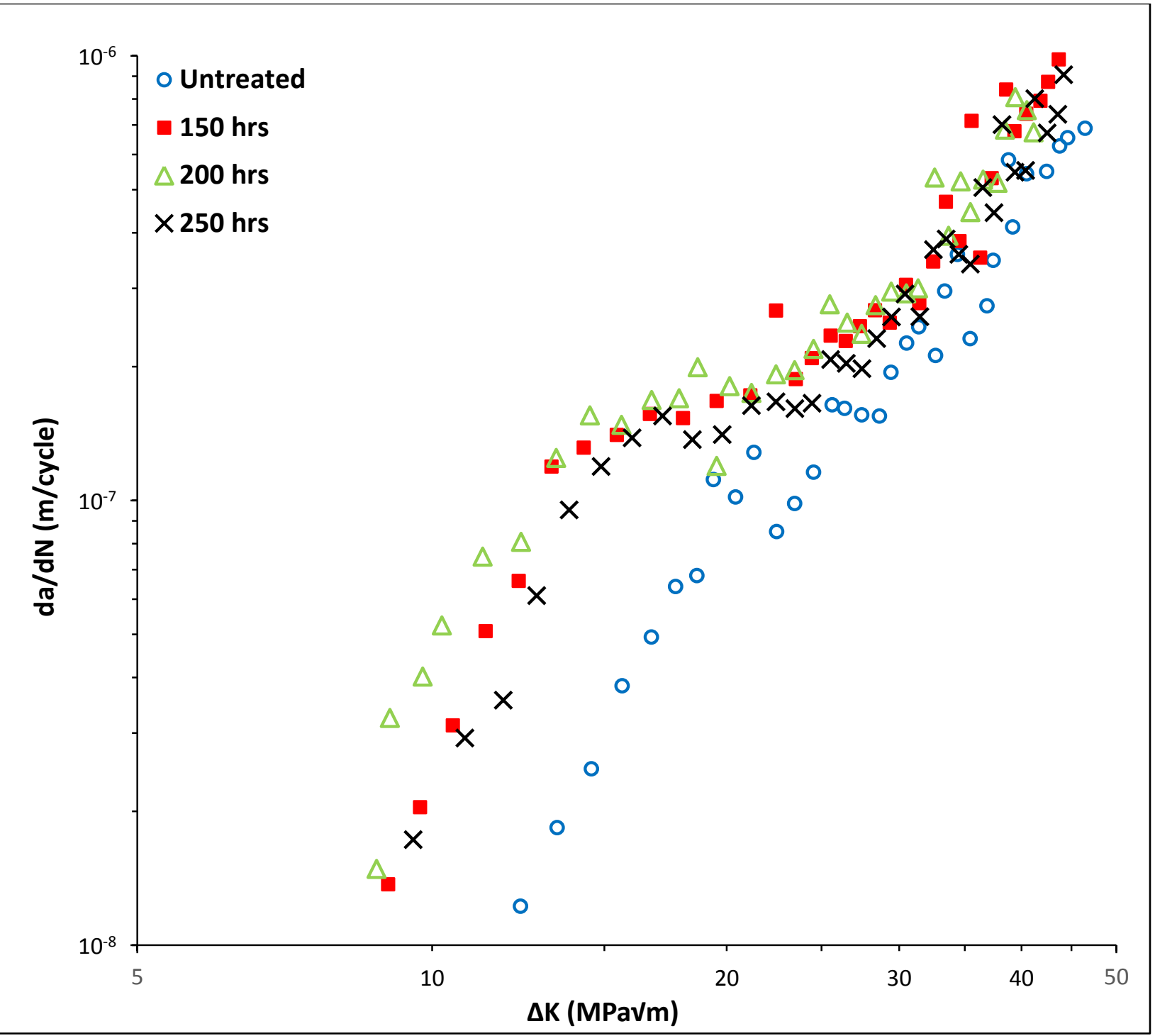

Figure 43: Comparison of FCGRs in AB1 material in Intermediate region $(10-8 \sim 10-7 \mathrm{~m} /$ cycle $)$

This behaviour could be typified as type A - "pure corrosion fatigue" from the apparent differences in the FCGRs at low $\triangle \mathrm{K}$ approaching the fatigue threshold and merging to the uncharged curve at high $\Delta \mathrm{K}$ approaching failure. The CGRs increase steadily with the increase in hydrogen charging times until $200 \mathrm{hrs}$ with the $250 \mathrm{hrs}$ charged specimen exhibiting marginally lower CGRs than the other two. The onset of the plateau region occurs at $\mathrm{da} / \mathrm{dN} \approx 1 \times 10^{-7}$ 
$\mathrm{m} /$ cycle $(\Delta \mathrm{K} \approx 17 \mathrm{MPa} \sqrt{\mathrm{m}})$ in all the three charging conditions until a $\Delta \mathrm{K} \approx 25-27 \mathrm{MPa} \sqrt{\mathrm{m}}$. The fracture images taken at different $\Delta \mathrm{K}$ shown in figure 42 qualify this behaviour. In the material charged at $150 \mathrm{hrs}$ and $200 \mathrm{hrs}$, the fracture behaviour changes from predominantly IG plus some TG facets to TG cleavage to quasi cleavage at SIFs 22, 24, $31 \mathrm{MPa} \sqrt{\mathrm{m}}$ respectively moving from left to right in the figure 44 (d) - 44 (i). However, there is a decrease in number of IG facets at $250 \mathrm{hrs}$ starting at $22 \mathrm{MPa} \sqrt{\mathrm{m}}$ which is mainly $\mathrm{TG}$ plus cleavage. The same is manifested in the figure 44 for the $250 \mathrm{hrs}$ charged material. Noting the inflection point from the same figure 43 for all three hydrogen charged condition is around $\Delta \mathrm{K} \approx 27 \mathrm{MPa} \sqrt{\mathrm{m}}\left(\mathrm{K}_{\max }=30\right.$ $\mathrm{MPa} \sqrt{\mathrm{m}}$ ) and by comparing with the $\mathrm{K}_{\mathrm{ISCC}}$ of the same material at 150 hrs hydrogen charged condition to be $43 \mathrm{MPa} \sqrt{ }$, it seems that $\mathrm{Kmax}<\mathrm{K}_{\mathrm{ISCC}}$ which is quite unlikely for $\mathrm{AB} 1$ material for two reasons [100]: one that the material has high strength and two that the material has a martensitic structure. The widely accepted idea that hydrogen concentrates at dislocations near the prior austenitic grain boundaries and/or due to concentration of hydrogen around inclusions such as MnS which was shown to be present during the microstructural analysis in this material and cause extensive IG cracking along these prior austenitic grain boundaries by decohesion at the grain interface. Though this statement is found partially true in this case due to observance of IG facets at $\Delta \mathrm{K} \approx 20 \mathrm{MPa} \sqrt{\mathrm{m}}$, it is not effective at high SIFs around the $\mathrm{K}_{\mathrm{ISCC}}$ value in this material.

For the dissolved hydrogen present in the material at each hydrogen charged condition during cyclic loading to migrate to the stressed centers such as the crack tip represents a definite time lag for diffusion from within the matrix. The cyclic loading conditions at high $\Delta \mathrm{K}$ might not give enough time for hydrogen ion migration to cause brittle cracking as observed in SCC testing at higher $\Delta \mathrm{K}$ levels. This rate limiting step of hydrogen diffusion causes less HIC damage at high 
cyclic $\Delta \mathrm{K}$, but lower than the observed $\mathrm{K}_{\mathrm{ISCC}}$ value. In addition to it, the material has a duplex microstructure of bainite and tempered martensite instead of a single microstructure quite normally observed in the case of high strength steels. This also has an additional influence on the absence of a stress corrosion type behaviour (type B) and subsequently on the superposition of corrosion fatigue behaviour on the SCC behaviour encountered in this steel. 


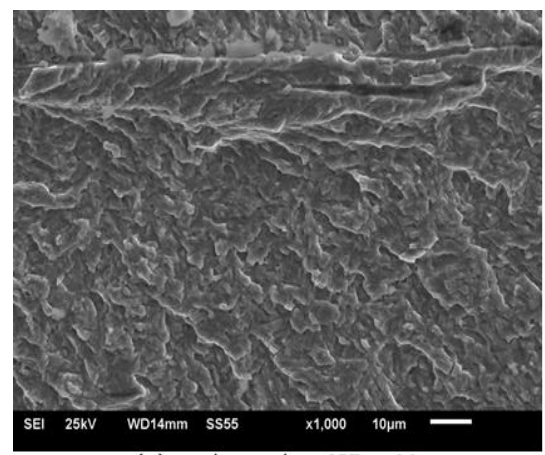

(a) uncharged at SIF 22

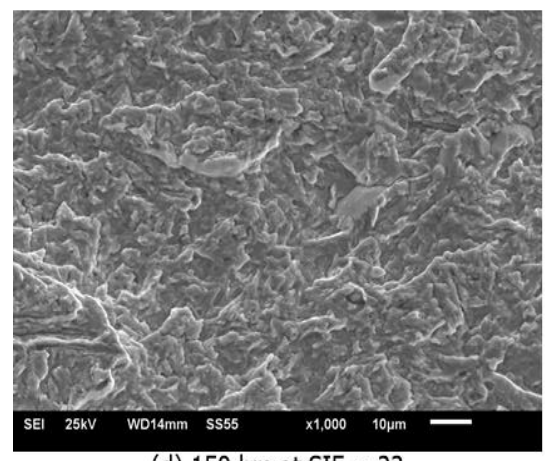

(d) 150 hrs at SIF 22

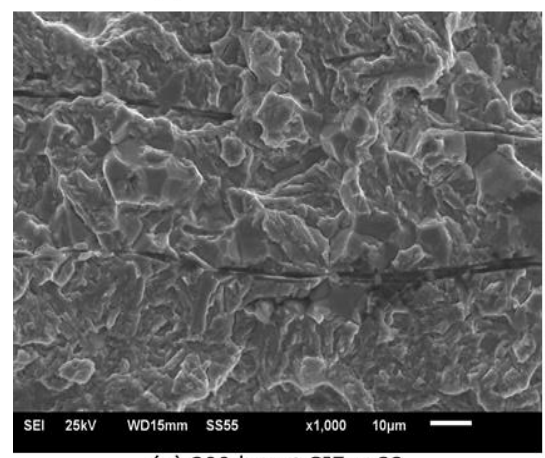

(g) 200 hrs at SIF $~ 22$

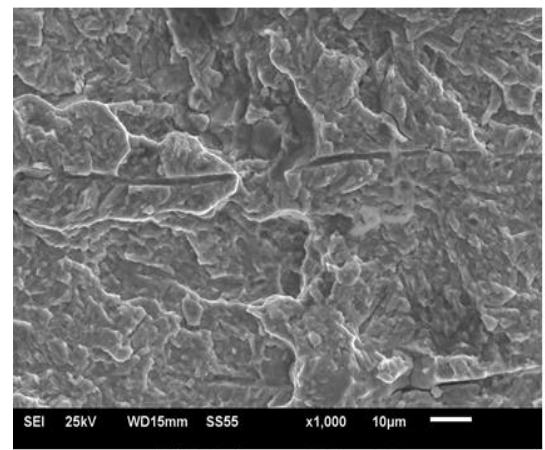

(j) 250 hrs at SIF 22

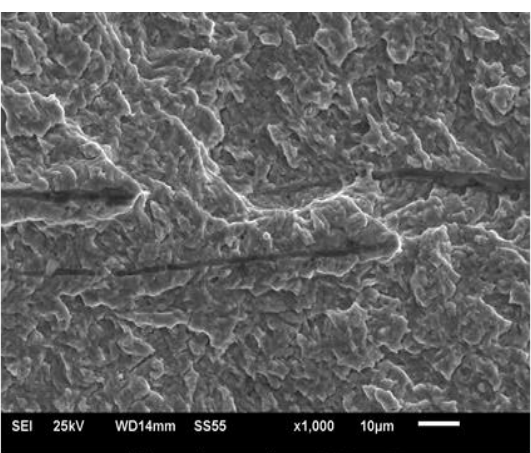

(b) uncharged at SIF 24

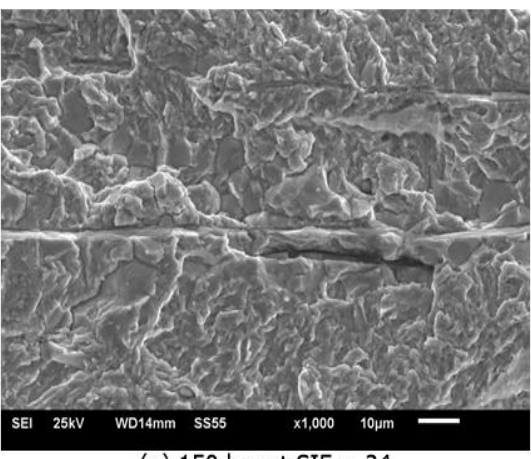

(e) 150 hrs at SIF 24

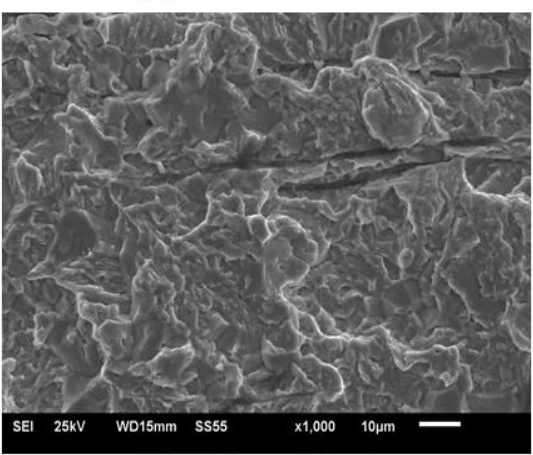

(h) 200 hrs at SIF $\sim 24$

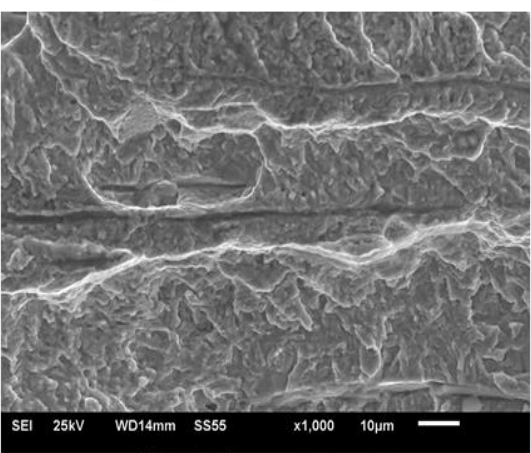

(k) 250 hrs at SIF 24

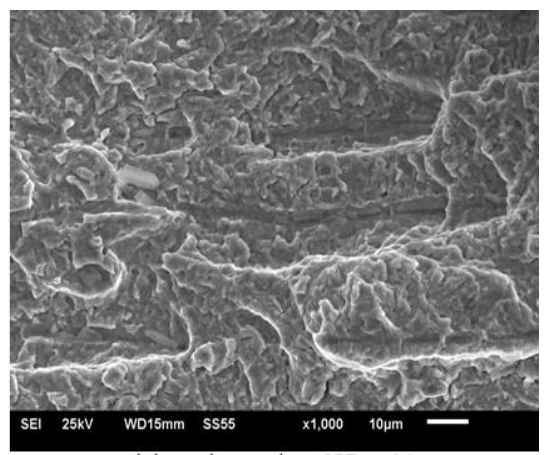

(c) uncharged at SIF 31

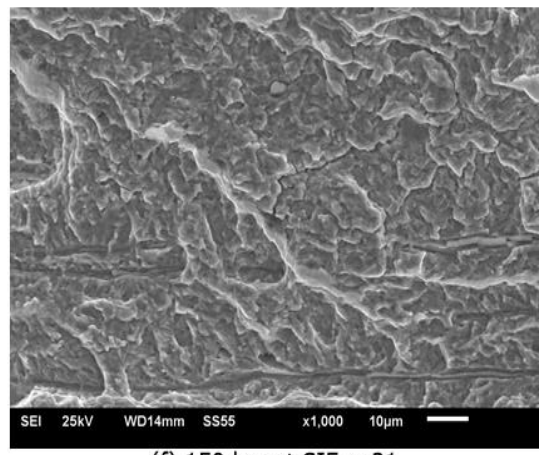

(f) $150 \mathrm{hrs}$ at SIF 31

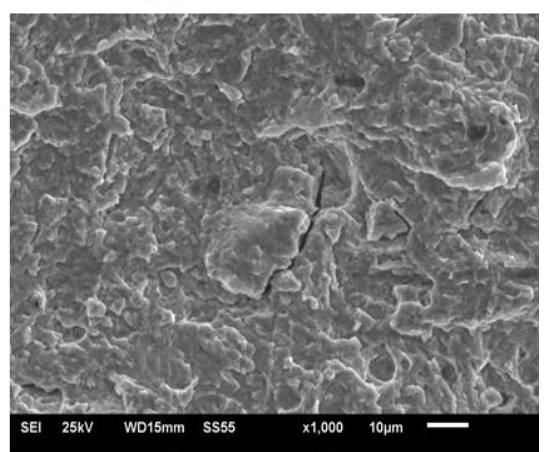

(i) $200 \mathrm{hrs}$ at SIF 31

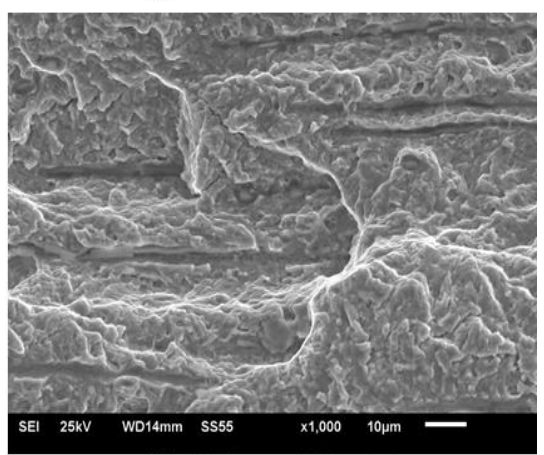

(I) 250 hrs at SIF 31

Figure 44: Fatigue surface images of $\mathrm{AB} 1$ material ( $\Delta K$ (SIF) are in $M P a \sqrt{ }$ )

[Note: Crack propagation from right to left in all images; Magnification: 1000X] 


\section{Austempered (Batch 2) - AB2}

The AB2 material austempered at $630^{\circ} \mathrm{F}$ exhibits a similar behaviour as the $\mathrm{AB} 1$ material. Owing to the lower austempering temperature, this material has a higher strength $\left(\sigma_{\mathrm{ys}} \approx 1481\right.$ MPa). The FCGRs of this material is shown in Figure 45. Even in this material, type A behaviour is observed, although the differences in the CGRs occur at a higher $\Delta \mathrm{K} \approx 10 \mathrm{MPa} \sqrt{\mathrm{m}}$ at the lower end of the crack growth curve. The extent of difference in the CGRs is more pronounced in the $\mathrm{da} / \mathrm{dN}$ range $\approx 1 \times 10^{-8}-1 \times 10^{-7} \mathrm{~m} /$ cycle than the $\mathrm{AB} 1$ material. Significant changes corresponding to the increased CGRs are seen in the fractographs shown in Figure 46. At all three charging conditions, the fracture surfaces show increasingly brittle failures mode starting with IG, mixed mode (TG plus IG) and finally TG with cleavage at $\Delta \mathrm{K} \approx 22,24,31 \mathrm{MPa} \sqrt{\mathrm{m}}$ respectively. The plateau region occurs at SIFs 17 - $31 \mathrm{MPa} \sqrt{ }$. In addition to this, there is significant variation in the FCGRs even at very high $\Delta \mathrm{K}$ of $60 \mathrm{MPa} \sqrt{\mathrm{m}}$ which is not evident in the other two batches of the 4140 alloy. It must be pointed out that the brittle nature of fracture surface explains the sudden surge in the FCGRs in the intermediate region when compared with the other two batches of specimens used in this study in the linear region fatigue crack growth behaviour. 


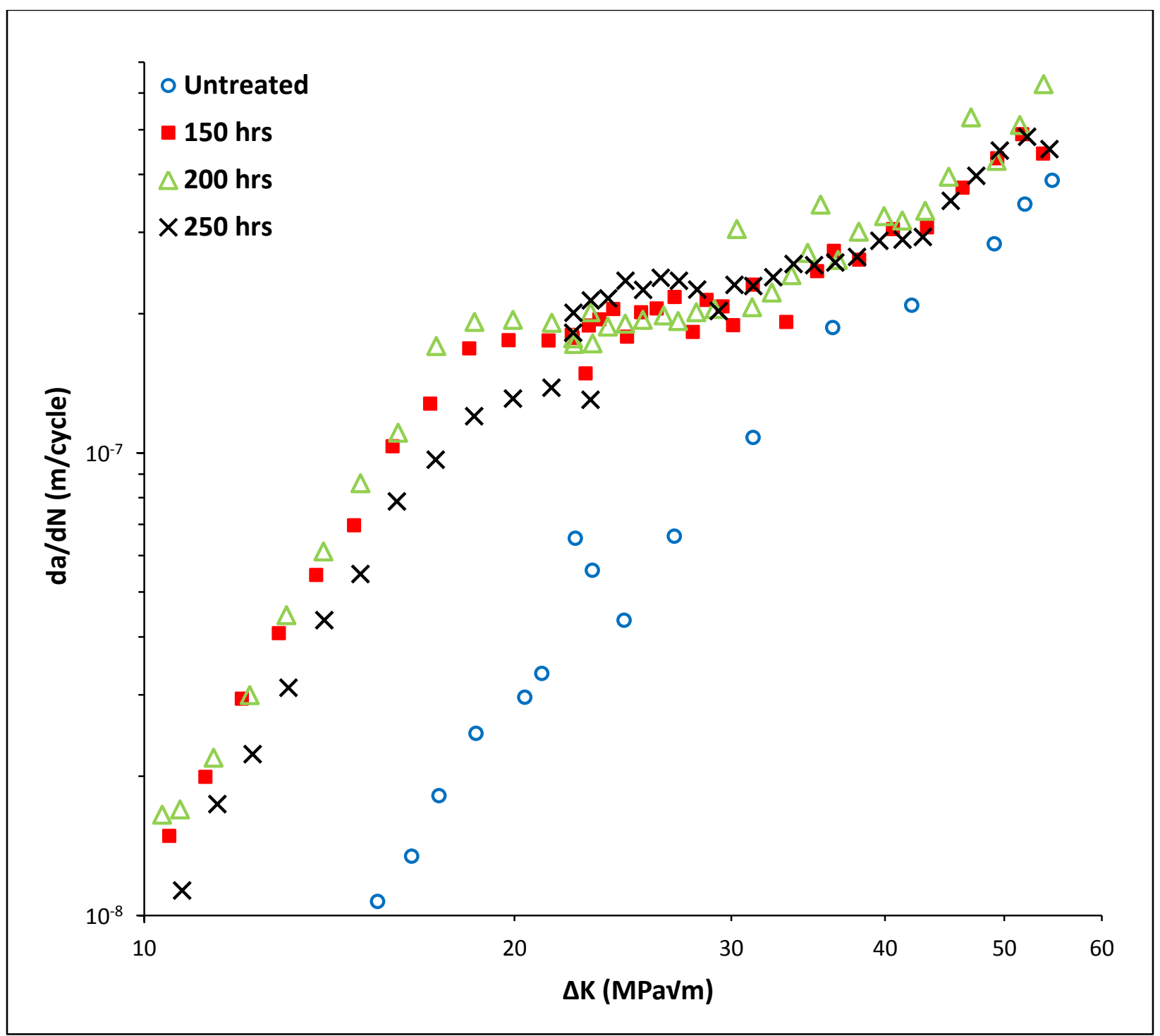

Figure 45: Comparison of FCGRs in AB2 material in Intermediate region (10-8 10-7 m/cycle) 


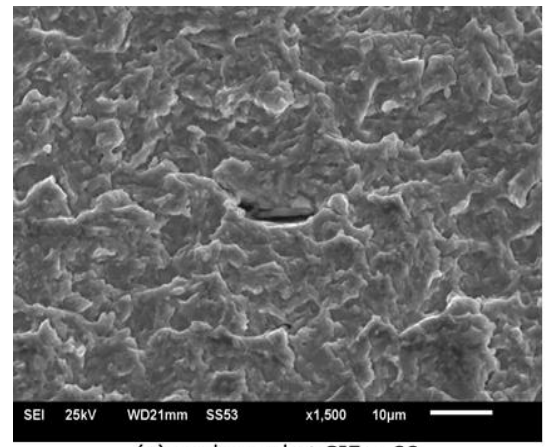

(a) uncharged at SIF 22

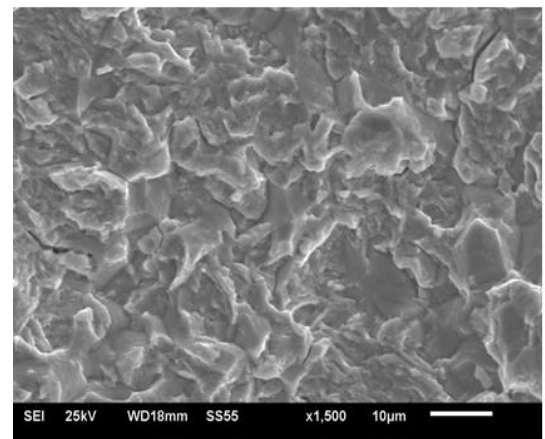

(d) 150 hrs at SIF 22

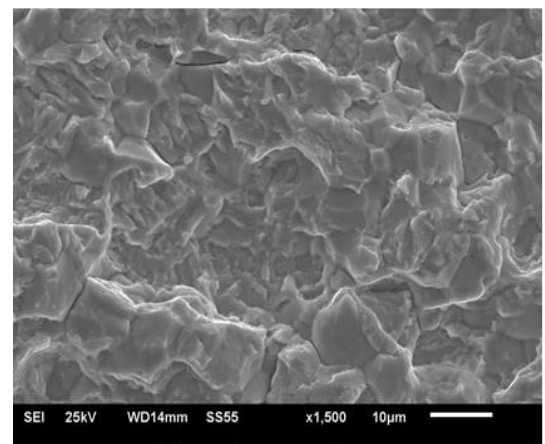

(g) 200 hrs at SIF 22

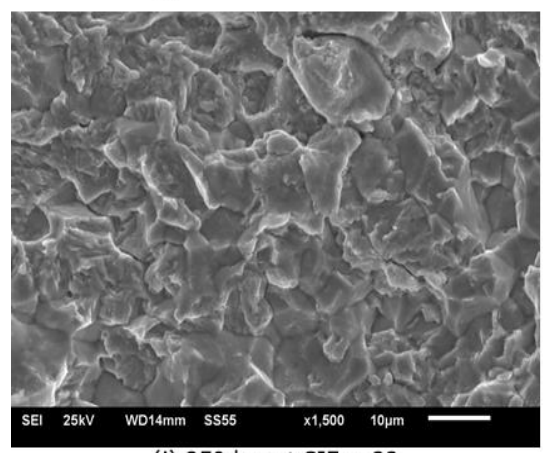

(j) 250 hrs at SIF 22

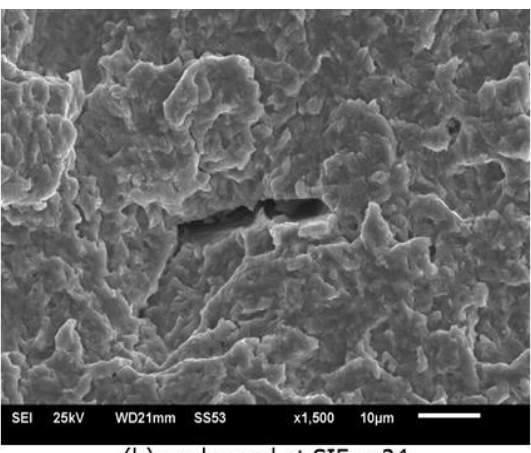

(b) uncharged at SIF 24

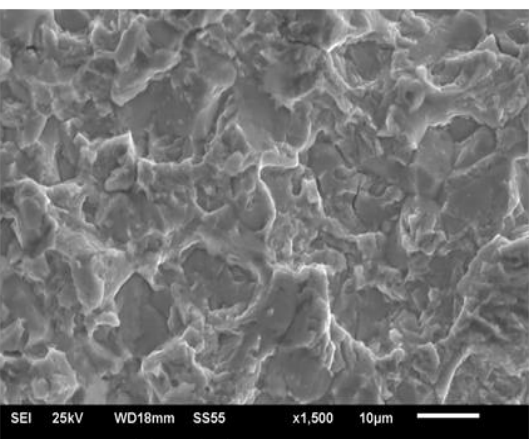

(e) 150 hrs at SIF 24

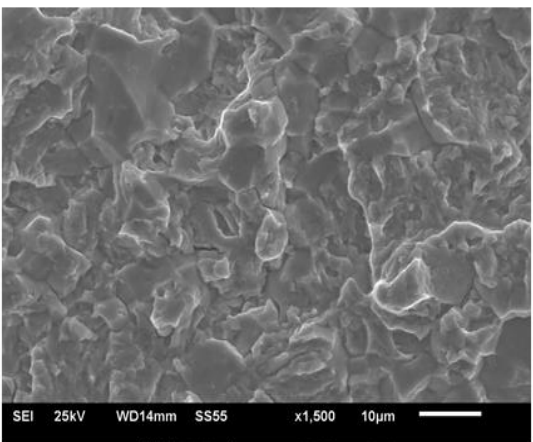

(h) 200 hrs at SIF 24

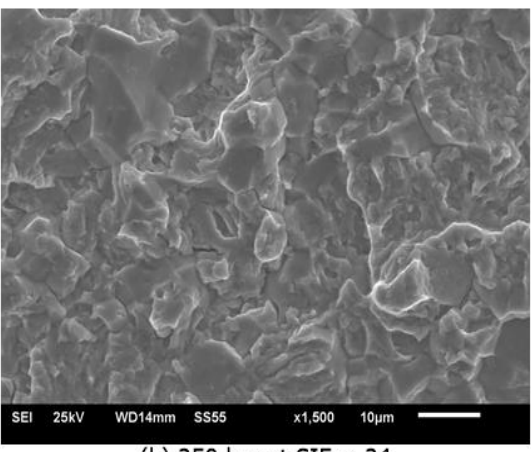

(k) 250 hrs at SIF 24

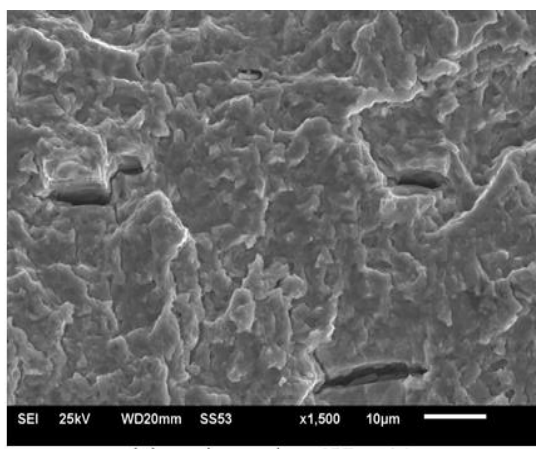

(c) uncharged at SIF 31

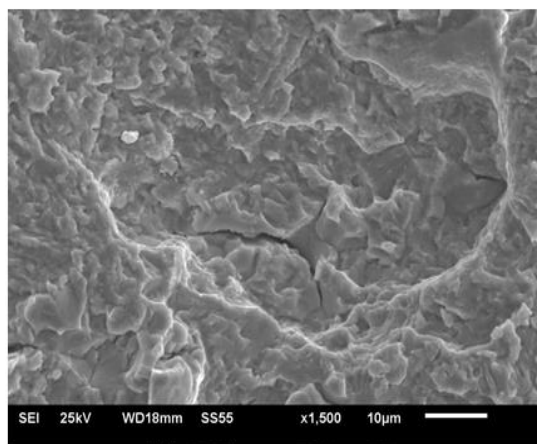

(f) 150 hrs at SIF 31

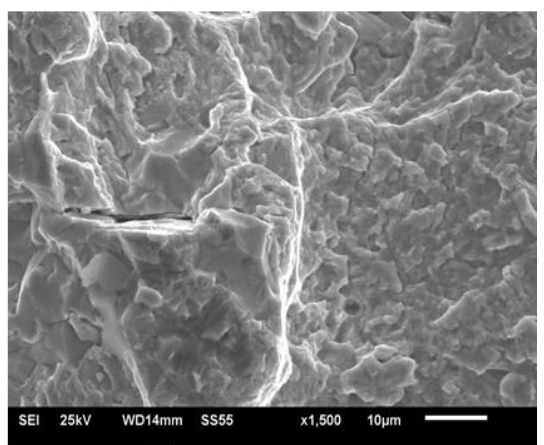

(i) 200 hrs at SIF 31

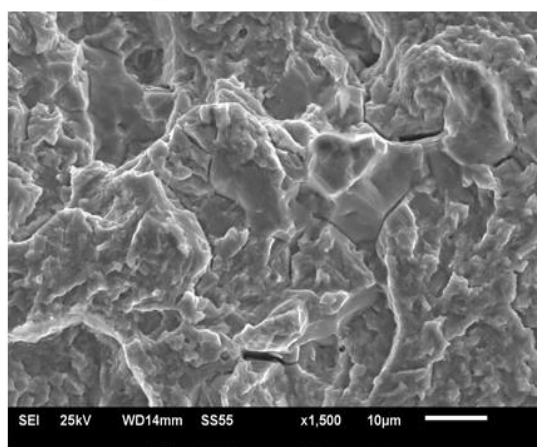

(I) 250 hrs at SIF 31

Figure 46: Fatigue surface images of AB2 material ( $\triangle \mathrm{K}$ (SIF) are in MPa $\sqrt{\mathrm{m}}$ ) [Note: Crack propagation from right to left in all images; Magnification: 1500X] 


\section{Mechanistic explanation of Fatigue Threshold Stress Intensity Factor $\left(\Delta K_{t h}\right)$ and Near Threshold Fatigue Crack Growth Rates}

\section{Annealed}

The explanation of fatigue threshold and near threshold fatigue crack growth rate in the annealed material were based on the observed FCGRs curves and the corresponding fracture surface images taken at each specified $\Delta \mathrm{K}$ as shown in the figure 47 . The overall fracture behaviour in the annealed material seems to be of transgranular nature in specimens with or without dissolved hydrogen as seen from the fractographs in figure 47. However, there was a difference observed in the nature of crack propagation within the grain structure. In the annealed material with no dissolved hydrogen, as the fatigue threshold is approached, the fracture surface transitions from a ductile like transgranular feature to more flat like appearance from $\Delta \mathrm{K} \approx 9-10 \mathrm{MPa} \vee \mathrm{m}$. The typical crystallographic fracture features were less evident as the fatigue threshold was reached. As expected, there was no presence of IG facets at any $\Delta \mathrm{K}$ due to the absence of dissolved hydrogen in the matrix. However, at a $\Delta \mathrm{K} \approx 9-10 \mathrm{MPa} \sqrt{\mathrm{m}}$, a prominent transgranular feature was observed as seen in figure 47(b) (center of the picture). This feature was from the matrix of the material as confirmed by Energy Dispersive Spectroscopy (EDS) and not due to crack propagation through or via grain pullout from an inclusion $(\mathrm{MnS})$. Upon increasing the concentration of dissolved hydrogen, more brittle like transgranular features were observed until a $\Delta \mathrm{K} \approx 9-10 \mathrm{MPa} \sqrt{\mathrm{m}}$ at all dissolved hydrogen concentrations. Unlike the specimen with no dissolved hydrogen, the mode of crack propagation thru the matrix appears to be quasi cleavage in the specimens with dissolved hydrogen. The degree of quasi cleavage features increased upon increasing the dissolved hydrogen concentration until about $1.5 \mathrm{ppm}$ (200 hrs of external hydrogen charging) until a SIF of about $9-10 \mathrm{MPa} \vee_{\mathrm{m}}$ and thereafter decreased as the $\Delta \mathrm{K}_{\mathrm{th}}$ was 
approached (Figures 47(d) - (i)). Though some quasi cleavage features was evident at $2.9 \mathrm{ppm}$ (250 hrs of external hydrogen charging) at higher SIF of $12-13 \mathrm{MPa} \sqrt{\mathrm{m}}_{\mathrm{m}}$, but it was greatly reduced at lower SIF of $9-10 \mathrm{MPa} \sqrt{\mathrm{m}}$ with some features observed at the $\Delta \mathrm{K}_{\text {th }}$. This may partially explain as to why this specimen had a lower crack growth rate and a higher $\Delta \mathrm{K}_{\text {th }}$ than the specimen without any external hydrogen charging. From the figures $47(\mathrm{a}),(\mathrm{d})$, (g) and (j) at the $\Delta \mathrm{K}_{\mathrm{th}}$, a flat featureless surface was observed in specimens with or without hydrogen. 


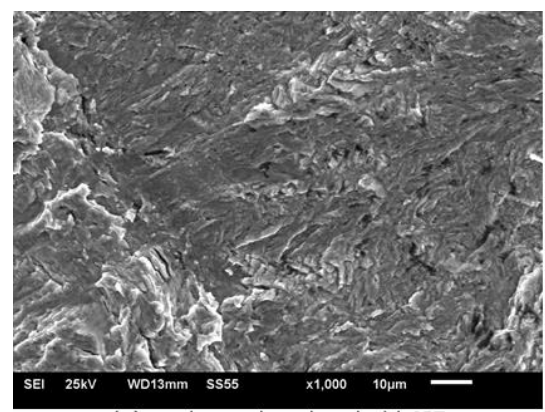

(a) uncharged at threshold SIF

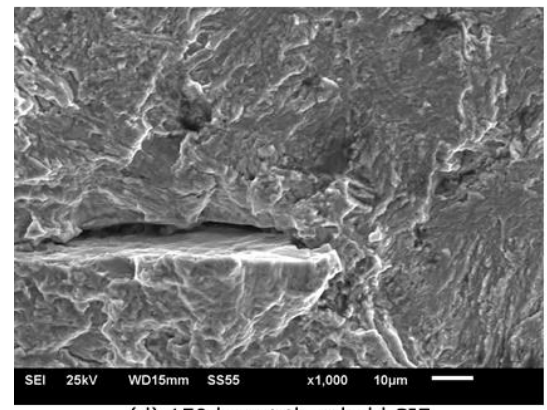

(d) $150 \mathrm{hrs}$ at threshold SIF

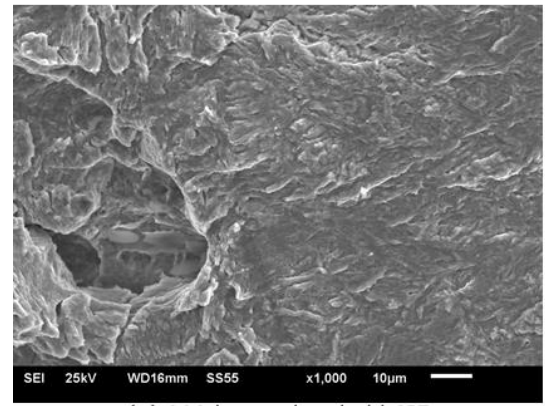

(g) $200 \mathrm{hrs}$ at threshold SIF

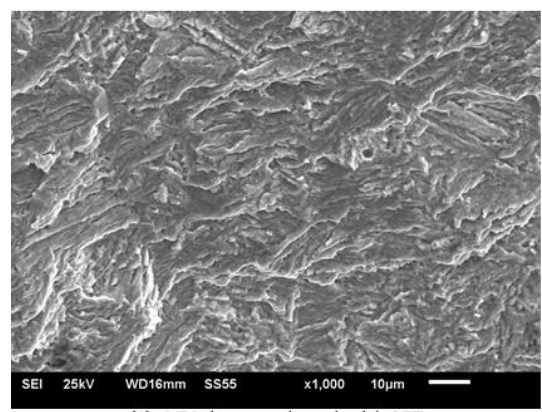

(j) $250 \mathrm{hrs}$ at threshold SIF

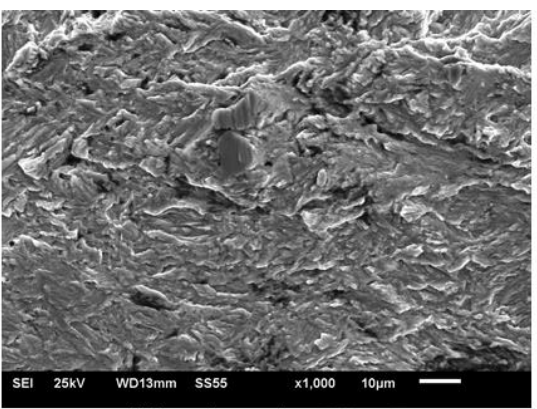

(b) uncharged at SIF 9

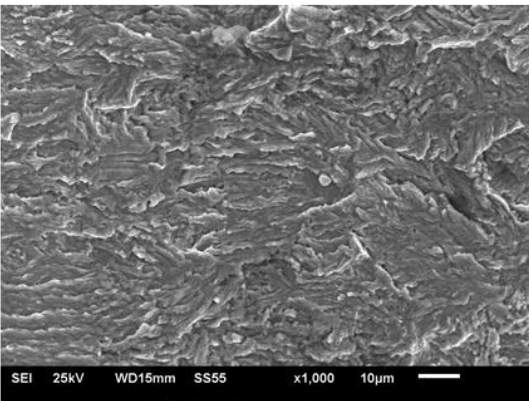

(e) 150 hrs at SIF 9

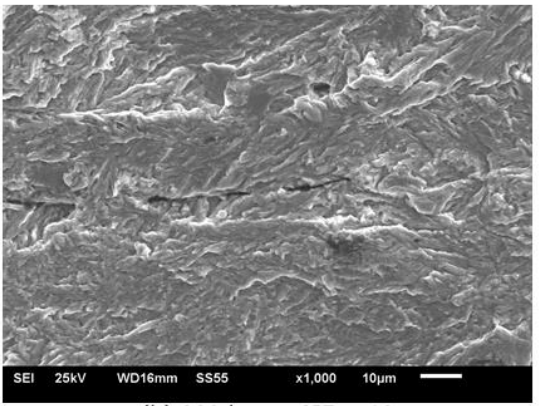

(h) $200 \mathrm{hrs}$ at SIF $~ 10$

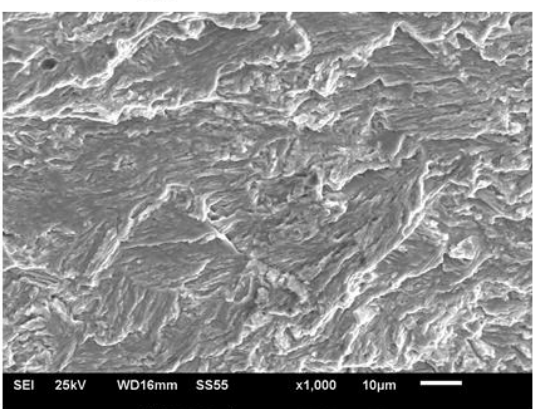

(k) 250 hrs at SIF 12

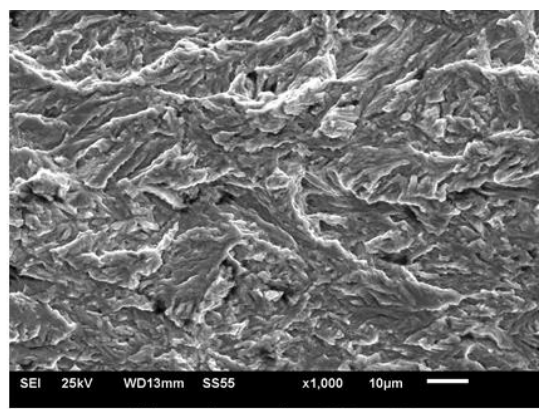

(c) uncharged at SIF 12

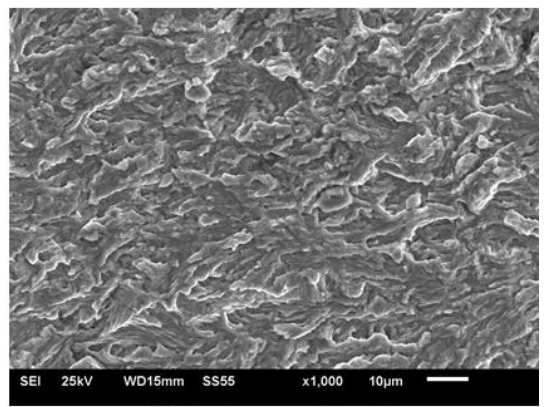

(f) $150 \mathrm{hrs}$ at SIF 12

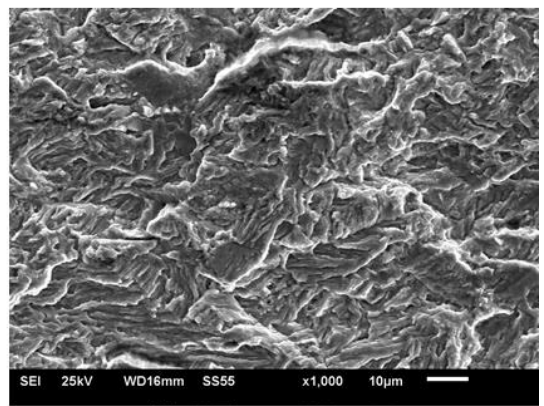

(i) $200 \mathrm{hrs}$ at SIF 13

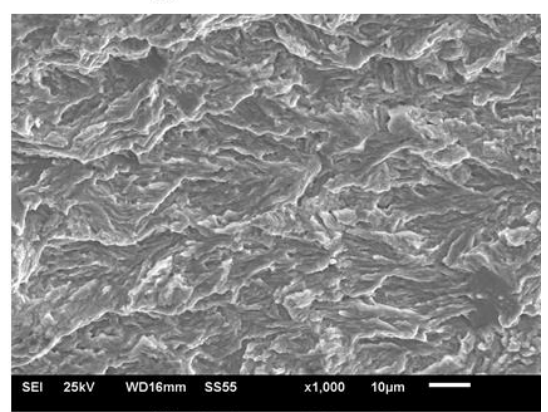

(I) $250 \mathrm{hrs}$ at SIF 15

Figure 47: Fatigue surface images of annealed material in threshold region ( $\Delta K$ (SIF) are

in MPa $\sqrt{ }$ m) [Note: Crack propagation from right to left in all images; Magnification:

$1000 \mathrm{X}]$ 
The monotonic and cyclic plastic zone size were calculated from Rice's formula [101] as given below:

Monotonic plastic zone size $=\frac{\pi}{8}\left(\frac{K_{\max }}{\sigma_{y s}}\right)^{2}$

Cyclic plastic zone size $=\frac{\pi}{32}\left(\frac{\Delta K}{\sigma_{y s}}\right)^{2}$

The monotonic and cyclic plastic zone size were computed based on the SIFs where maximum number of IG facets were found or where maximum amount of transgranular (TG) features (either ductile or brittle features) were observed from the fractographs. Table 13 lists the computed values of monotonic as well as cyclic plastic zone size along with the corresponding SIFs ( $\Delta \mathrm{K}$ and $\mathrm{K}_{\max }$ ) at which maximum TG features (either ductile or brittle features) were seen in the fractographs in figure 47. The grain size distribution in the annealed material is also listed in table 13 for comparison with the monotonic and cyclic plastic zone sizes in the near threshold region. It is evident from table 13 that the maximum amount of brittle features peaks at $\Delta \mathrm{K}$ where the cyclic plastic zone size almost equals the grain size of the matrix. A similar trend can be attributed to the specimen with no dissolved hydrogen in terms of ductile TG features. However, the monotonic plastic zone size is found to be much larger than the grain size of the matrix. This suggests that the fatigue crack propagation where the maximum TG morphology was observed with or without dissolved hydrogen is controlled by $\Delta \mathrm{K}$ rather than $\mathrm{K}_{\max }$. In other words, the damage caused by dissolved hydrogen which manifests in the form of cleavage type TG features affects the fatigue crack propagation (FCP) until the plastic zone size is almost equal to the grain size in the annealed material. This behaviour is seen in the specimens externally charged with hydrogen for 150 hrs and 200 hrs. In the specimen charged with hydrogen for 250 
hrs, the plastic zone size is comparatively larger than the grain size of the matrix and also the largest among all the annealed specimen. It may be for this reason that the some cleavage features were observed in this specimen at the fatigue threshold. This specimen also had comparatively lower FCGRs and highest threshold among all the specimens in the annealed material. The lack of significant difference in the fatigue crack growth morphology from the fractographs, in terms of lack of IG facets in specimens with dissolved hydrogen, could be used to explain the relative closeness of the near threshold FCGRs in specimens with and without dissolved hydrogen in the annealed material. Though the fractographic evidence cannot be linked directly to the observed near threshold FCGRs [81], a qualitative mechanistic explanation using the cyclic plastic zone size effects calculated based on the fractographic observations can yield much information about the crack tip triaxiality encountered at near threshold CGRs with or without the influence of dissolved hydrogen. Noting the values of the cyclic plastic zone with or without dissolved hydrogen, it is clear that the dissolved hydrogen has not caused significant reduction of the cyclic plastic zone size which in turn is responsible for 1) the fatigue crack to propagate further on the cleavage fracture plane and 2) to setup a steep stress gradient to diffuse hydrogen from the matrix to the freshly created crack tip to continue this repetitive cyclic damage process. This could be the reason, in addition to the fracture morphology, why the CGRs are not greatly affected in the presence of dissolved hydrogen in the material. Though the change in fracture morphology appears to be $\Delta \mathrm{K}$ controlled, it does not throw light on the how the fatigue threshold is reached. A two part fracture process[102]: one leading to formation of facets (IG or TG) which is $\Delta \mathrm{K}$ controlled and the second leading to the connection of these facets for crack advance by tensile tearing which is $\mathrm{K}_{\max }$ controlled could be used to describe the approaching of the fatigue threshold. Upon reaching the point of maximum transgranularity at 
the $\Delta \mathrm{K} \approx 9-10 \mathrm{MPa} \sqrt{\mathrm{m}}$, the influence of $\Delta \mathrm{K}$ on facet formation is reduced and is reflected in the fracture images (Figure 47). After this point, the $\mathrm{K}_{\max }$ component becomes more prominent in maintaining the crack front until the $\Delta \mathrm{K}_{\text {th }}$ is approached. This is due to the fact that the crack closure may or may not be operative at such low growth rates that the $K_{\min }$ value might be different than expected and hence affect the $\Delta \mathrm{K}$ experienced at the crack tip. When the fatigue threshold value was being approached, the effects of dissolved hydrogen were greatly reduced as characterized by a rather featureless smooth fracture surface which is similar to the uncharged sample. At this point, it is still unclear why such a phenomenon occurs and it remains to be seen why this kind of behaviour occurs. 
Table 13: Values of Monotonic and Cyclic Plastic Zone Size at corresponding SIFs where Maximum Transgranular (TG) features (brittle or ductile) takes place with or without dissolved hydrogen in Annealed Material at Near Threshold FCGRs

\begin{tabular}{|c|c|c|c|c|c|c|c|c|}
\hline $\begin{array}{c}\text { Hydrogen } \\
\text { Charging } \\
\text { Time } \\
\text { (hrs) }\end{array}$ & $\begin{array}{c}\text { Crack } \\
\text { length } \\
(\mathrm{mm})\end{array}$ & $\begin{array}{c}\Delta K \\
(\mathbf{M P a} \sqrt{ } \mathbf{m})\end{array}$ & $\begin{array}{c}\mathbf{K}_{\max } \\
(\mathbf{M P a} \sqrt{ } \mathbf{m})\end{array}$ & $\begin{array}{c}\text { Yield } \\
\text { Strength, } \\
\sigma_{\mathrm{ys}} \\
(\mathrm{MPa})^{1^{*}}\end{array}$ & $\begin{array}{c}\text { Monotonic } \\
\text { Plastic } \\
\text { Zone Size } \\
\quad(\mu \mathrm{m})\end{array}$ & $\begin{array}{c}\text { Cyclic } \\
\text { Plastic } \\
\text { Zone } \\
\text { Size } \\
(\mu \mathrm{m})\end{array}$ & $\begin{array}{c}\text { Grain } \\
\text { Size } \\
(\mu \mathrm{m})^{2^{*}}\end{array}$ & $\begin{array}{c}\text { Fatigue } \\
\text { Threshold, } \\
\qquad \mathbf{K}_{\mathrm{th}} \\
(\mathrm{MPa} \sqrt{\mathrm{m}})\end{array}$ \\
\hline $\begin{array}{c}\text { No } \\
\text { hydrogen }\end{array}$ & 10.16 & 9.03 & 10.03 & 757 & 69 & 14 & $8-22$ & 6.68 \\
\hline $150 \mathrm{hrs}$ & 9.525 & 8.99 & 9.99 & 757 & 68 & 14 & $8-22$ & 5.58 \\
\hline $200 \mathrm{hrs}$ & 10.033 & 10.06 & 11.18 & 757 & 86 & 17 & $8-22$ & 5.49 \\
\hline $250 \mathrm{hrs}$ & 8.0645 & 12.43 & 13.81 & 757 & 131 & 26 & $8-22$ & 7.85 \\
\hline
\end{tabular}

$1^{*}$ - Yield strength based on tensile tests conducted in uncharged condition; $2^{*}$ - grain size calculation was done from the fractographs based on the approximate size of the transgranular (TG) facets observed

Some macro photographs were taken in the threshold region and EDS analysis was performed close to the fatigue threshold (crack arrest) region in order to check for the possibility of crack closure effects. Since the fatigue test was conducted in the ambient atmosphere, the oxide induced (corrosion deposit) type crack closure was thought to have the most influence on the near threshold FCGRs and the resulting fatigue threshold. This was hypothesized due to influence of environmental moisture surrounding the fatigue specimen which might have resulted in oxide products by the reaction of freshly exposed crack surface and moisture which 
might get wedged at the crack tip during the closing cycle of the fatigue test reducing the effective SIF experienced at the crack tip. In addition, some oxide debris might have also formed by plasticity induced crack closure due to fretting action between the crack tip surfaces owing to the low strength material $\left(\sigma_{\mathrm{ys}}=757 \mathrm{MPa}\right.$ for this material) as reported elsewhere [81]. The macro photos are shown in Figure 48. No evidence of any oxides formed during the near threshold crack propagation was observed from the figure 48 in any samples in the annealed material. Some fatigue striations due to the load decreasing procedure performed during the fatigue test was observed in the sample with no hydrogen, but these were less prominent in the samples with dissolved hydrogen. EDS analysis yielded similar results showing no corrosion deposits (oxides) wedging between the crack tip very close to the fatigue threshold (at very low growth rate region). This was an interesting finding contrasting the results found by Ritchie and others [81, 103-105] when these oxides formed by corrosion or fretting action were readily observed in low strength steels $\left(\sigma_{\mathrm{ys}} \approx 600 \mathrm{MPa}\right)$ in air and hydrogen gas environments especially in the near threshold region at low $\mathrm{R}$ ratios. To add to this, the damage due to hydrogen environment was also minimal in the lower strength materials. In fact, these oxides were used as evidence to explain the larger fatigue threshold $\left(\Delta \mathrm{K}_{\mathrm{th}}\right)$ value observed in air than in dry hydrogen or argon environments [103-105]. Though all the samples (with or without hydrogen) were tested in exsitu condition, none of the samples were affected at very low FCGRs and very low $\Delta$ Ks due to the ambient moisture present. The absence of any corrosion debris proved that the crack tip reaction between steel and water (in moisture) was minimal or not very significant to produce more atomic hydrogen in addition to that present in the dissolved form in the matrix of the material. As a consequence, the crack closure effect, though not measured experimentally using force - displacement compliance technique, appears to have less influence on the near threshold 
FCGRs and also on the $\Delta \mathrm{K}_{\text {th }}$ value. Hence, the fatigue crack propagation in the near threshold region is believed to occur mainly through the cyclic crack tip plasticity mechanism in the sample with no hydrogen charging and through the influence of hydrogen assisted cracking by cleavage through the grain thereby reducing the crack tip plasticity in the samples with dissolved hydrogen. Due to the low strength of the annealed material, the effect of dissolved hydrogen on the crack propagation is diminished and the CGRs are almost comparable to the sample with no hydrogen. 


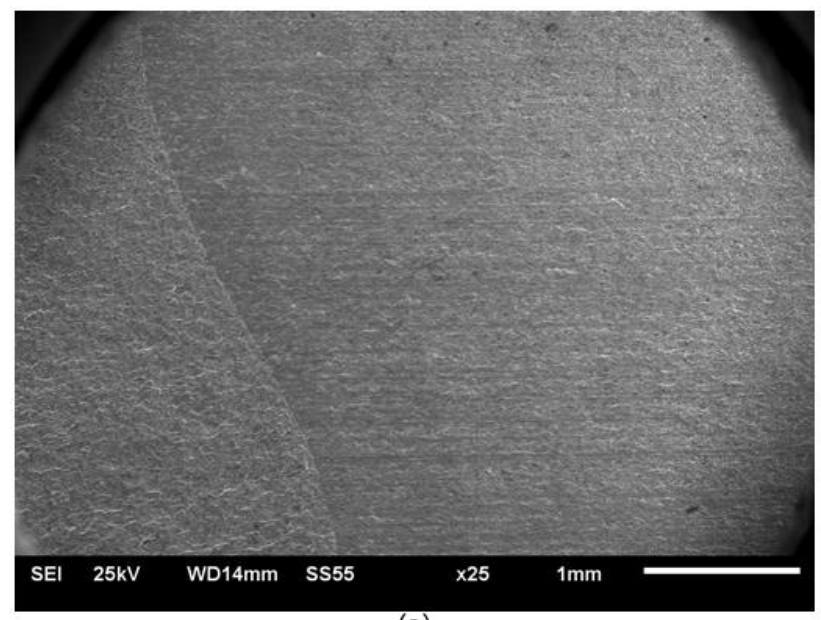

(a)

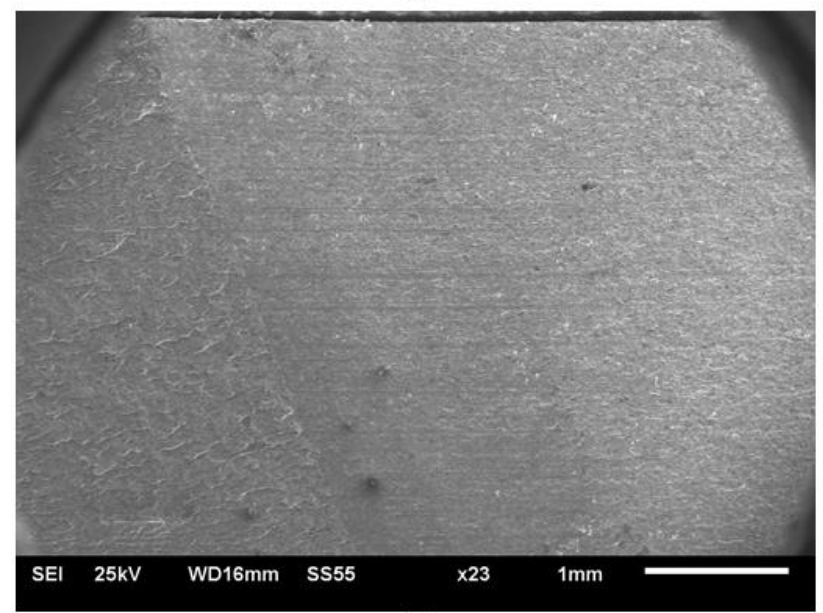

(c)

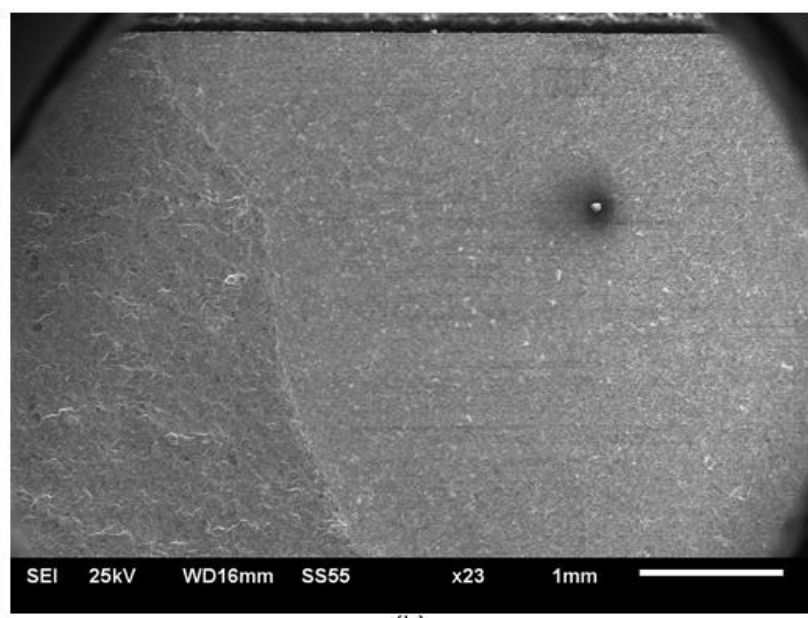

(b)

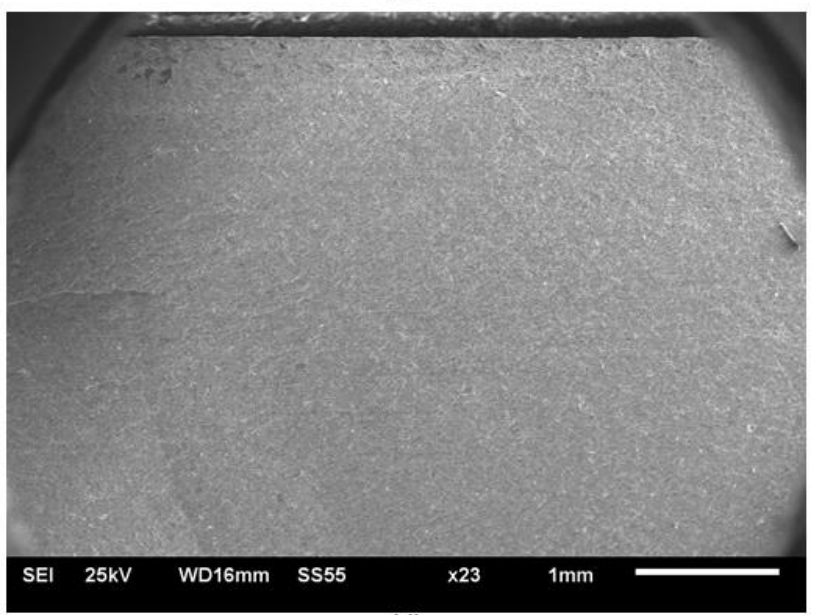

(d)

Figure 48: Macro photograph of the near threshold region to check for oxide products in annealed material; (a) No hydrogen, (b) 150 hrs, (c) 200 hrs and (d) 250 hrs [Note: Crack propagation from right to left in all images; Magnifications: (a) 25X, (b) - (d) 23X]

\section{Austempered Batch - 1 (AB1) material}

The Austempered Batch 1 (AB-1) material had a higher strength and toughness compared to the annealed material. The AB1 material was severely embrittled during the near threshold fatigue test. Figure 49 shows the effect of dissolved hydrogen on the fracture behaviour captured at each specified $\Delta \mathrm{K}$. After a careful examination of the fracture images, a lot can be said about the influence of hydrogen on near threshold fatigue behaviour in the AB1 material and how this can 
be linked to the observed near threshold FCGRs and fatigue threshold. In the specimen with no dissolved hydrogen of the $\mathrm{AB} 1$ material, the overall fatigue failure is mainly of transgranular nature with no IG facets present at the low $\Delta \mathrm{K}$ region. The maximum crystallographic type transgranular features were seen at a SIF of about $12 \mathrm{MPa} \vee \mathrm{m}$. After this $\Delta \mathrm{K}$, these transgranular were reduced as the crack propagated into the near threshold region which is shown in Figure 49(b). Some banding which was seen in the microstructure contributed to cracking along these bands (figure 49(b)) which may be responsible for faster FCGRs in the AB1 material in the uncharged condition compared to the annealed material. This cracking along the banded structure occurred even at very low SIF close to the fatigue threshold. At the fatigue threshold, a TG facet was seen in figure 49(a) in the uncharged sample on a background of the fracture surface with less features similar to the annealed material. Now, this TG facet may indicate cyclic plastic damage occurring in the $\mathrm{AB} 1$ uncharged sample at the proximity just before the crack approaches the fatigue threshold. A possible explanation could be that the crack tip experiences sufficient stress gradient due to the higher strength of $A B 1$ material, even at such low loads at the vicinity of the fatigue threshold, to cause the crack to propagate through the grain. Now that, transgranular cracking requires sufficient energy to occur in general, the smaller plastic zone size of this material (due to high strength) may be responsible to provide the driving force for the crack to advance through the grain to reach the low $\Delta \mathrm{K}_{\text {th }}$ value. In contrast with the 4140 annealed material, the AB1 samples with dissolved hydrogen was affected to a large extent by the nature and high degree of IG fracture seen readily in the low CGR region in Figure 49. The number of IG facets reaches a maximum at a SIF of about $12 \mathrm{MPa} \sqrt{\mathrm{m}}$ in all of the samples with dissolved hydrogen increasing in number with the increase in the concentration of dissolved hydrogen as shown in the figures 49(f), (i) and (1). A clear cut distinction was seen among these 
images as a function of increasing external hydrogen charging time (or concentration of dissolved hydrogen). This showed the effect of hydrogen on the fatigue behaviour at low $\Delta \mathrm{K}$ region in the $\mathrm{AB} 1$ material. As described earlier, though the degree of IG facets cannot be taken as a direct link to the CGRs [102], the fracture morphology sheds light on the effects of external factors such as dissolved hydrogen (in this case), ambient environment on the fatigue behaviour in the near threshold region at each particular $\Delta \mathrm{K}$. Intergranular fracture has been considered as the microstructurally sensitive crack path and also $\Delta \mathrm{K}$ dependent in other studies [81]. This aspect could be exploited in understanding the role how hydrogen affects the crack growth rate and also what SIF by this mechanism. By referring to the obtained fatigue fracture images in figure 49(f), (i) and (1), the crack growth occurs under $\Delta \mathrm{K}$ control until about $12 \mathrm{MPa} \vee \mathrm{m}$ causing intergranular fracture at the crack tip due to the presence of hydrogen. The acceleration of CGRs are faster in this $\mathrm{AB} 1$ material as crack growth rate takes takes place in a banded micro structure as explained in the microstructure section for this material. A metallograph of the AB1 material is shown in Figure 50 with the banded structure visible along with the $\mathrm{MnS}$ inclusion visible as a bright white feature in the lower left part of the picture. An EDS map in Figure 51 confirms the presence of $\mathrm{MnS}$ on the banded feature present on the fracture surface similar to the one visible in figure 49(i). In figure 49(i), the crack propagation occurs along this banded structure in a transgranular fashion with the crack branching off on either side of the 


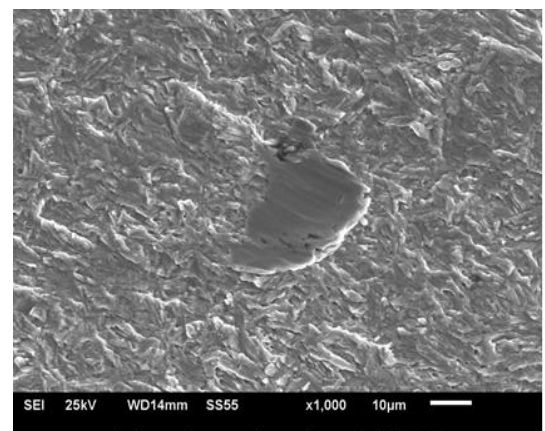

(a) uncharged at threshold SIF

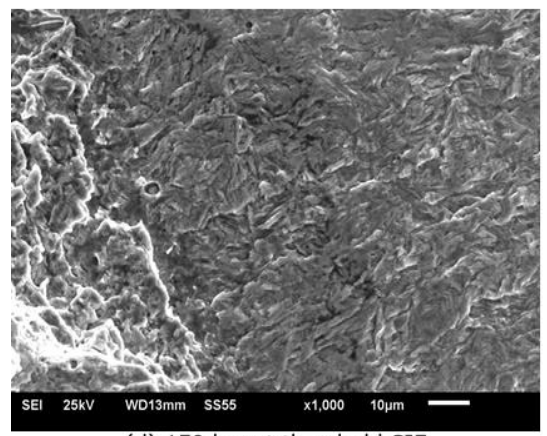

(d) $150 \mathrm{hrs}$ at threshold SIF

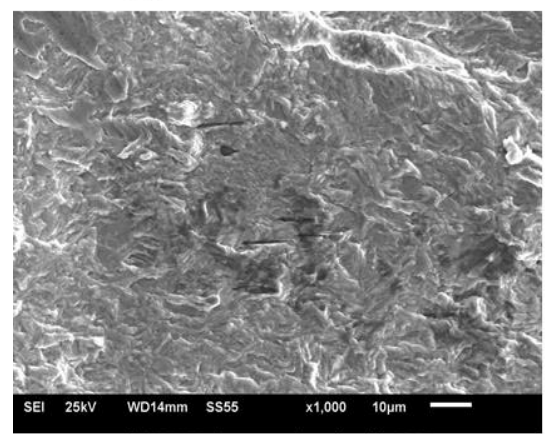

(g) 200 hrs at threshold SIF

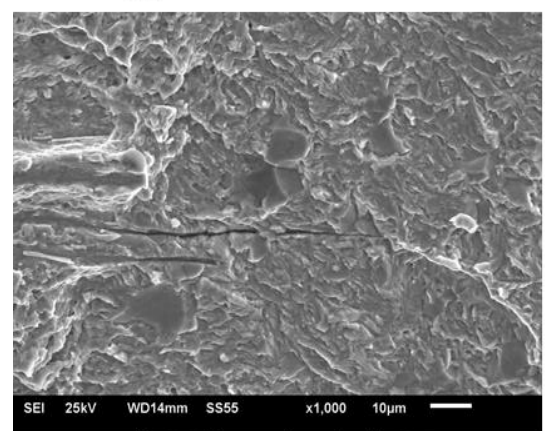

(j) 250 hrs at threshold SIF

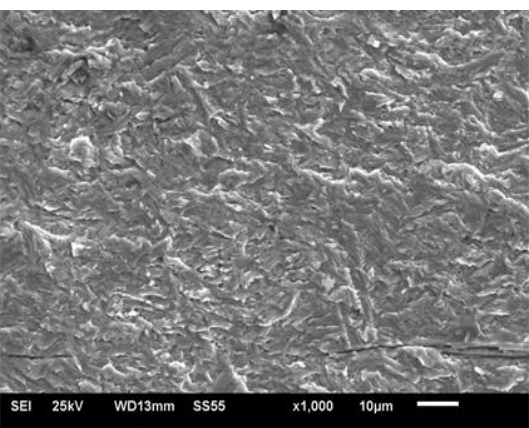

(b) uncharged at SIF 9

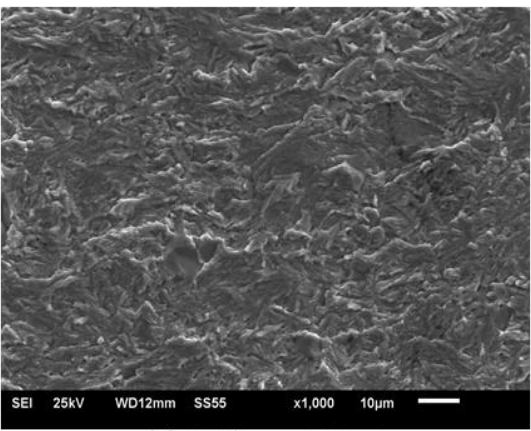

(e) 150 hrs at SIF 9

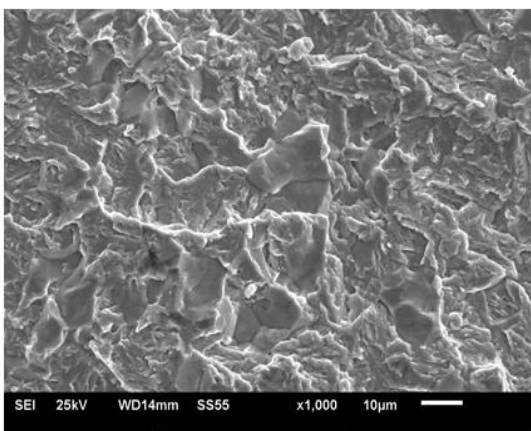

(h) 200 hrs at SIF 9

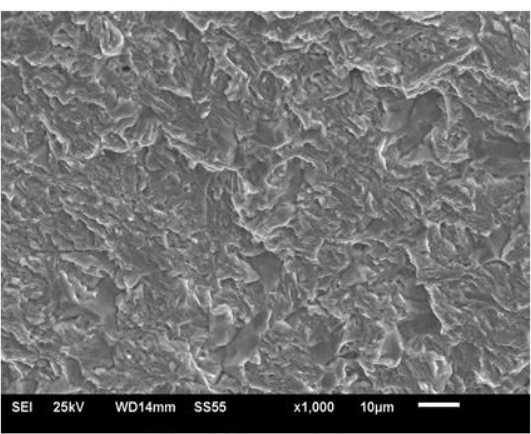

(k) 250 hrs at SIF 9

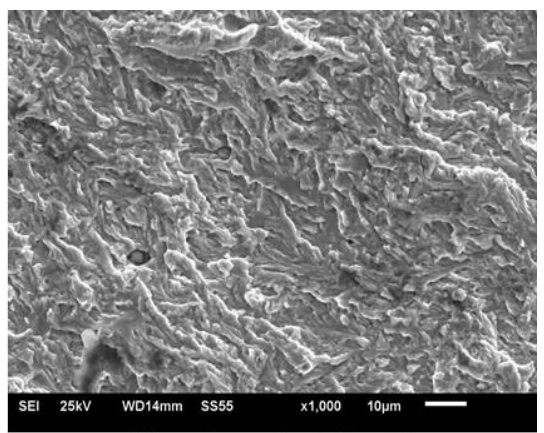

(c) uncharged at SIF 12

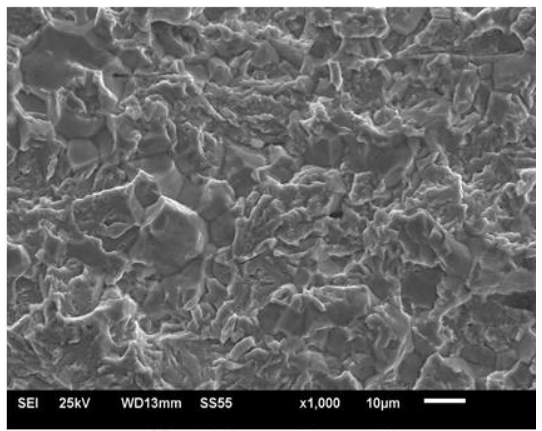

(f) $150 \mathrm{hrs}$ at SIF 13

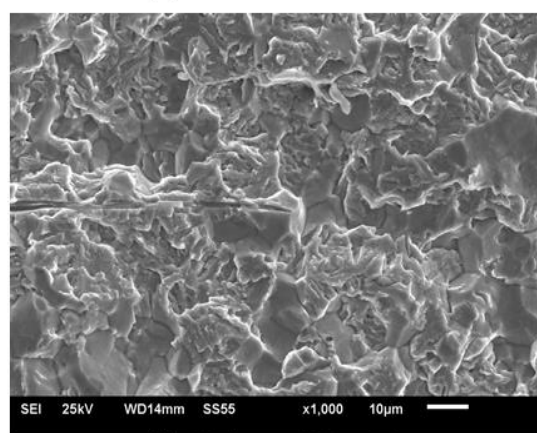

(i) 200 hrs at SIF $~ 12$

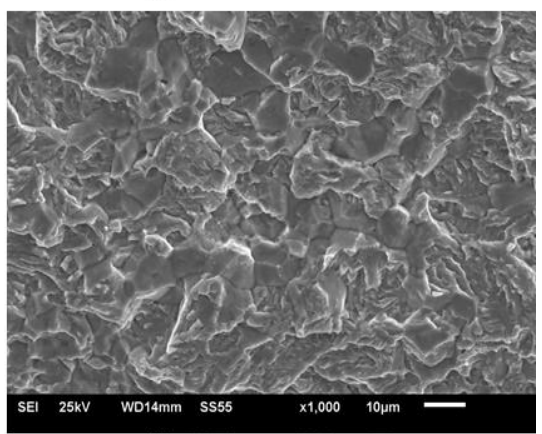

(I) 250 hrs at SIF 12

Figure 49: Fatigue surface images of AB1 material in threshold region ( $\Delta K$ (SIF) are in $\operatorname{MPa} \sqrt{ } \mathbf{m}$ [Note: Crack propagation from right to left in all images; Magnification: 1000X] 


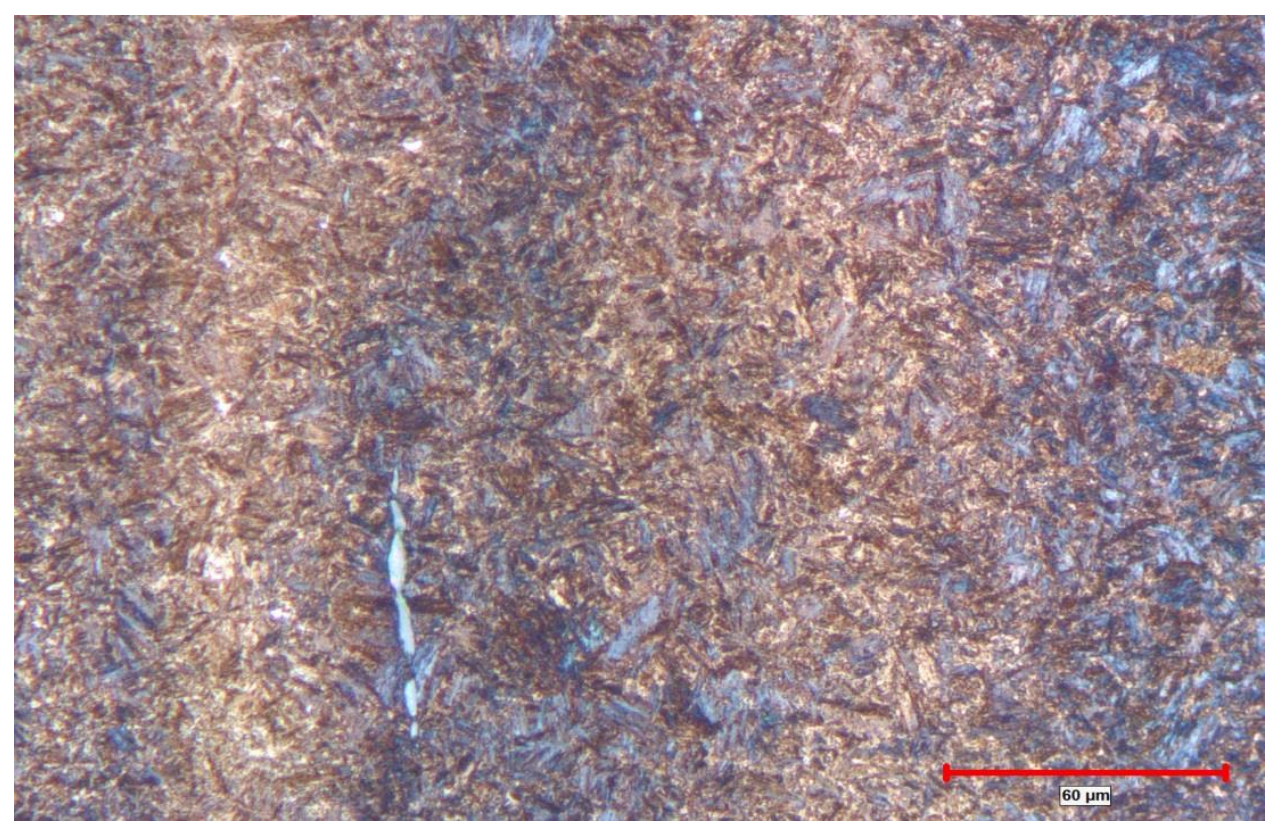

Figure 50: Banded microstructure of the AB1 material with MnS inclusion (bright white elongated feature at lower left section; Magnification: 500X)

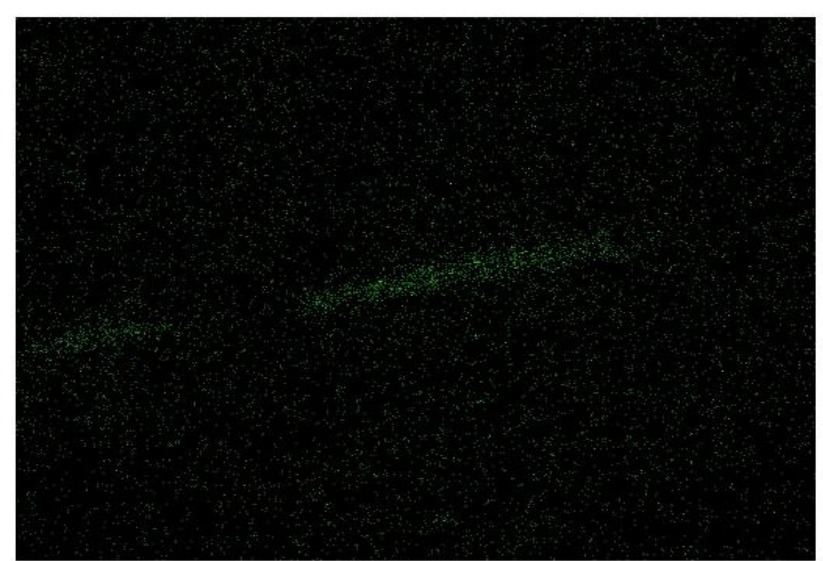

(a) MnK line

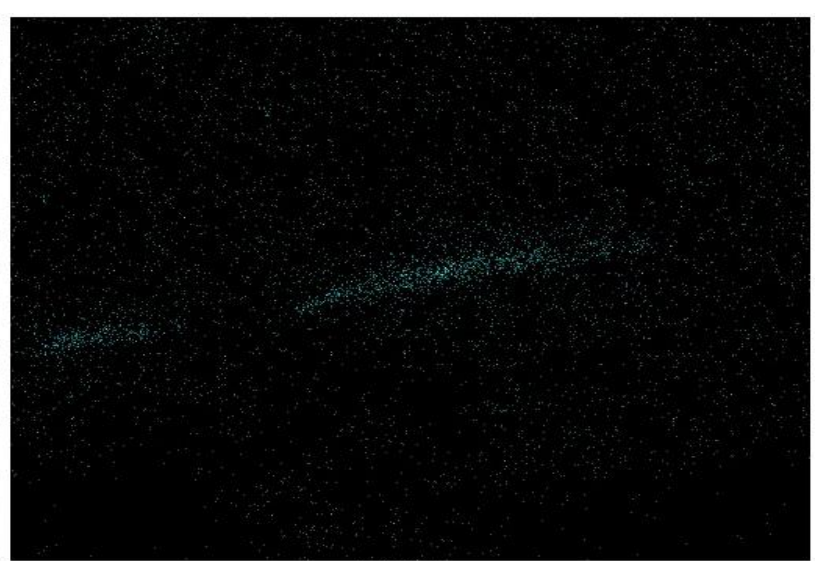

(b) SK line

Figure 51: EDS map of the banded feature from the fracture surface showing MnS inclusions in AB1 material 
of the banded structure providing an easy path for crack propagation even at low SIF particularly in the samples with dissolved hydrogen. To understand the peak in IG facets at this SIF $(\approx 12$ $\mathrm{MPa} \sqrt{\mathrm{m}}$ ), a plastic zone size estimation was performed similar to the 4140 alloy in annealed condition. These are listed in Table 14. Two important observations arise from the table 2: (a) the yield strength effect resulting in a very small plastic zone size near the minimum grain size even at a higher $\mathrm{SIF}(\approx 12 \mathrm{MPa} \sqrt{\mathrm{m}})$ in the $\mathrm{AB} 1$ material compared to the annealed material $(\approx 9-10$ $\mathrm{MPa} \sqrt{\mathrm{m}}$ ), (b) the plastic zone size becomes equal to the minimum grain size of the material with a minimal reduction in $\Delta \mathrm{K}$, except in the sample charged for $150 \mathrm{hrs}$, all other variables being constant.

Table 14: Values of Monotonic and Cyclic Plastic Zone Size at corresponding SIFs where Maximum Intergranular or Transgranular features (brittle or ductile) takes place with or without dissolved hydrogen in AB1 Material at Near Threshold FCGRs

\begin{tabular}{|c|c|c|c|c|c|c|c|c|}
\hline $\begin{array}{c}\text { Hydrogen } \\
\text { Charging } \\
\text { Time } \\
\text { (hrs) }\end{array}$ & $\begin{array}{l}\text { Crack } \\
\text { length } \\
(\mathrm{mm})\end{array}$ & $\begin{array}{c}\Delta K \\
(\mathrm{MPa} \sqrt{ })\end{array}$ & $\begin{array}{c}\mathbf{K}_{\max } \\
\left(\mathbf{M P a} \sqrt{ }{ }^{\prime}\right)\end{array}$ & $\begin{array}{c}\text { Yield } \\
\text { Strength, } \\
\sigma_{\mathrm{ys}} \\
(\mathrm{MPa})^{1^{*}}\end{array}$ & $\begin{array}{l}\text { Monotonic } \\
\text { Plastic } \\
\text { Zone Size } \\
\qquad(\mu \mathrm{m})\end{array}$ & $\begin{array}{c}\text { Cyclic } \\
\text { Plastic } \\
\text { Zone } \\
\text { Size } \\
(\mu \mathrm{m})\end{array}$ & $\begin{array}{c}\text { Grain } \\
\text { Size } \\
(\mu \mathrm{m})^{2^{*}}\end{array}$ & $\begin{array}{c}\text { Fatigue } \\
\text { Threshold, } \\
\qquad \mathbf{K}_{\text {th }} \\
\left(\mathbf{M P a} \sqrt{m}_{\mathbf{m})}\right.\end{array}$ \\
\hline $\begin{array}{c}\text { No } \\
\text { hydrogen }\end{array}$ & 7.45 & 12.56 & 13.96 & 1369 & 41 & 8 & $8-22$ & 5.54 \\
\hline $150 \mathrm{hrs}$ & 6.1 & 13.28 & 14.76 & 1369 & 46 & 9 & $8-22$ & 5.29 \\
\hline $200 \mathrm{hrs}$ & 7.47 & 12.34 & 13.71 & 1369 & 39 & 8 & $8-22$ & 4.17 \\
\hline $250 \mathrm{hrs}$ & 7.45 & 12.31 & 13.68 & 1369 & 39 & 8 & $8-22$ & 3.70 \\
\hline
\end{tabular}


$1^{*}$ - Yield strength based on tensile tests conducted in uncharged condition; $2^{*}$ - grain size calculation was done from the fractographs based on the approximate size of the intergranular (IG) facets observed

This is a strong indication of the effects of dissolved hydrogen in the material which upon increasing the concentration in the $\mathrm{AB} 1$ material diffuses under a stress gradient at a faster rate due to increased volume fraction of bainite in this material, accumulates at the grain boundary, causes FCP to proceed via IG mode (microstructurally sensitive crack path) and thereby increases the FCGRs at comparatively lower SIFs than the uncharged sample. The banded microstructure also contributes to provide a less resistant path for crack propagation by confining the crack plane almost along this band to a greater extent in the samples with dissolved hydrogen at near threshold FCG region. The greatest difference in the CGRs between the charged and uncharged samples occur also at the same $\Delta \mathrm{K} \approx 12 \mathrm{MPa} \sqrt{\mathrm{m}}$ and there after continues to decrease marginally but is significant when the $\Delta \mathrm{K}_{\mathrm{th}}$ is reached. The two part fracture process [102], explained earlier in the discussion on the near threshold FCGRs in the annealed material, with $\Delta \mathrm{K}$ and $\mathrm{K}_{\max }$ control parameters was also applicable to this material. The $\Delta \mathrm{K}$ control responsible for formation of facets operated until about a SIF of $12 \mathrm{MPa} \sqrt{\mathrm{m}}$ and thereafter had less influence on the FCP process, though some effects were seen even at the fatigue threshold in the sample charged for 250 hours in the form of IG facets and also CGRs along the banded structure which may have had MnS inclusions. The two implications of this behaviour were that: (a) it was significantly different from the annealed material which was characterized by a rather smooth featureless fracture surface at the fatigue threshold, and (b) there was a combined influence of both $\Delta \mathrm{K}$ (to a much less degree) and $\mathrm{K}_{\max }$ at the $\Delta \mathrm{K}_{\mathrm{th}}$. The influence of $\mathrm{K}_{\max }$ after $\Delta \mathrm{K} \approx 12$ $\mathrm{MPa} \sqrt{\mathrm{m}}$ were evident in the figure 49(b), (e), (h) and (k) characterized by the typical transgranular morphology though the $\Delta \mathrm{K}$ effects were experienced to a less degree by the sample charged for $250 \mathrm{hrs}$ in figure $49(\mathrm{k})$. The reduced but prevalent influence of $\Delta \mathrm{K}$ effects almost 
until the fatigue threshold might be construed as a reason why crack closure effects in the $\mathrm{AB} 1$ material could be expected to be minimal or negligible. It is seen that this is true in the $\mathrm{AB} 1$ material as documented in the figure 6. No corrosion products or oxides resulting from steel environment interactions were observed in any of the samples in AB1 material. It was therefore concluded that the effect of crack closure on the effective SIF $\left(\Delta \mathrm{K}_{\mathrm{eff}}=\mathrm{K}_{\max }-\mathrm{K}_{\mathrm{cl}}\right)$ was almost equal to the $\Delta \mathrm{K}$ utilized in the testing. The experimental FCGRs showed a trend that followed this complete mechanistic behaviour as explained above and the corresponding evidence in the manner of fractographs and plastic zone size effects supported this argument. However, at the fatigue threshold, the fracture behaviour was not one of the featureless transgranular type observed in the annealed material. At the fatigue threshold SIFs obtained, a simple calculation of monotonic plastic zone size yields a value much less than the grain size of the AB1 material in the sample precharged for 200 and 250 hours. Though the maximum SIF $\left(\mathrm{K}_{\max }\right)$ is thought to be responsible at $\Delta \mathrm{K}<12 \mathrm{MPa} \sqrt{\mathrm{m}}$ in facilitating the crack front to propagate by connection of facets via tensile tearing which is evident at $\Delta \mathrm{K} \approx 9 \mathrm{MPa} \sqrt{\mathrm{m}}$ in Figure 49 , the same cannot be said when the fatigue threshold is approached. In this $A B 1$ material, the $\Delta K$ is thought to influence the facet formation at the threshold which appears in the Figure 49(j) in some unspecified manner. To better understand this phenomenon, experiments involving mean stress effects which is thought to affect adversely the fatigue behaviour in the near-threshold region $[81,102,106]$ might shed some new light on this behaviour. 


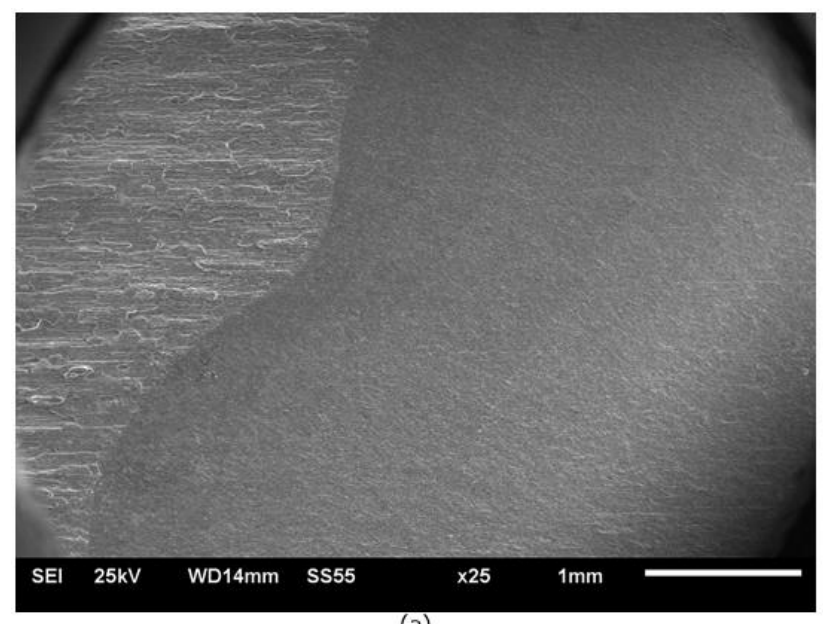

(a)

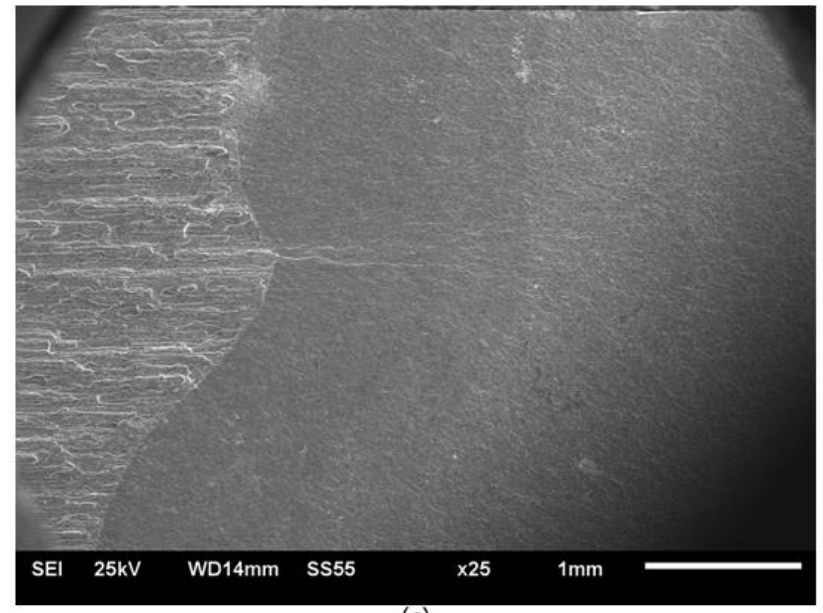

(c)

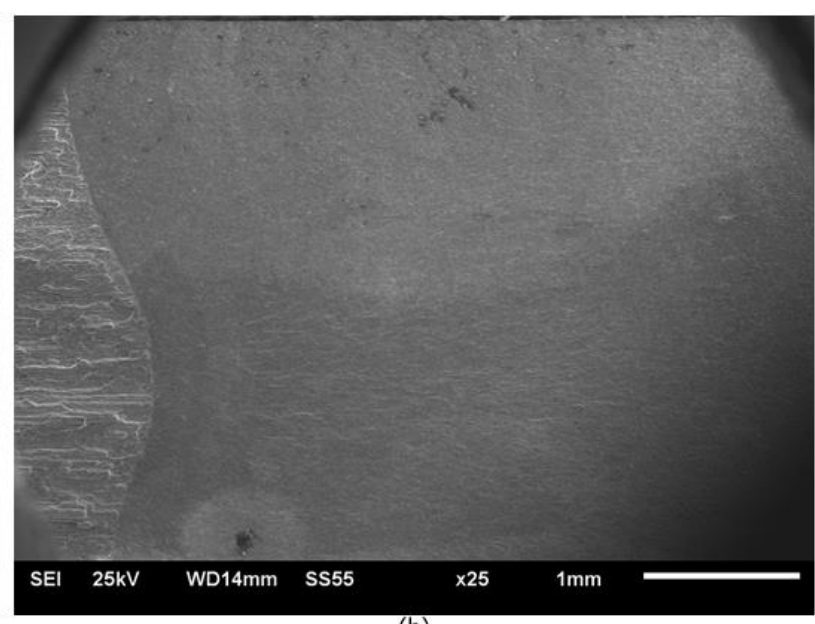

(b)

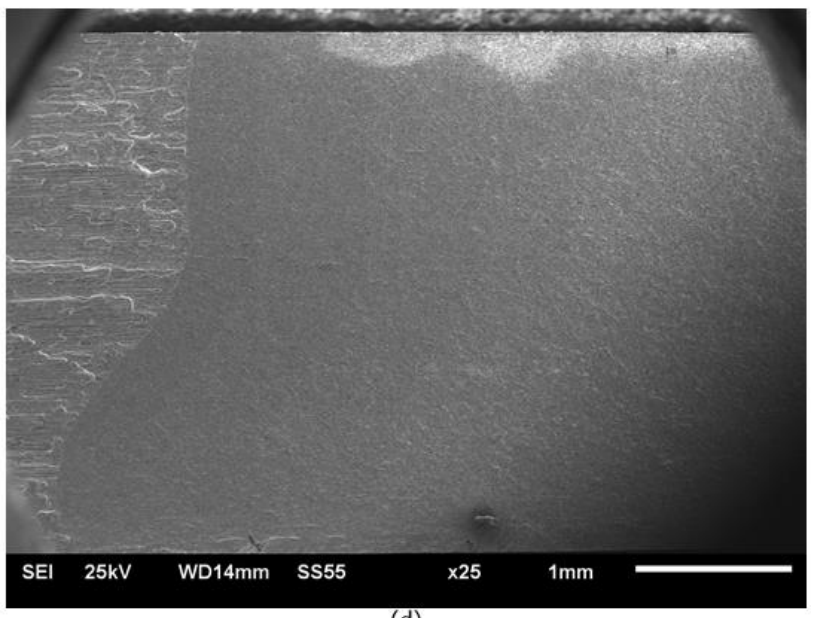

(d)

Figure 52: Macro photograph of the near threshold region to check for oxide products in

AB1 material; (a) No hydrogen, (b) 150 hrs, (c) 200 hrs and (d) 250 hrs [Note: Crack propagation from right to left in all images; Magnification: 25X]

\section{Austempered Batch - 2 (AB2) material}

The AB2 material shows a very different and distinct near threshold fatigue crack growth behaviour than the annealed and AB1 material. At the start of the threshold region $\left(\mathrm{da} / \mathrm{dN} \approx 10^{-8}\right.$ $\mathrm{m} /$ cycle), the FCGRs are greater than in the annealed material in the samples with dissolved hydrogen but lesser than in the AB2 material. However at the near threshold region $\left(\mathrm{da} / \mathrm{dN} \approx 10^{-9}\right.$ $\mathrm{m} /$ cycle), a transition occurs in the FCGRs in the AB2 material showing diminished influence 
compared to the annealed material in the samples with dissolved hydrogen. Though this material had the highest yield strength and was expected to be greatly affected in presence of dissolved hydrogen especially in the low $\Delta \mathrm{K}$ region, such typical behaviour was not seen in this material. In the discussion on the fatigue behaviour at intermediate rates $\left(\mathrm{da} / \mathrm{dN} \approx 10^{-8} \sim 10^{-7} \mathrm{~m} / \mathrm{cycle}\right)$, it was seen that significant differences exist in the FCGRs of the annealed material and the AB2 material in samples with dissolved hydrogen until the crossover occurs at a $\Delta \mathrm{K} \approx 7-8 \mathrm{MPa} \sqrt{\mathrm{m}}$ after which the fatigue crack in AB2 material propagates at much less velocity than the annealed material regardless of the concentration of dissolved hydrogen present in the material. This behaviour can be explained based on the observed fracture imaging work at the end of the intermediate region and well until the fatigue threshold is reached. At the end of the intermediate region, just before the low growth rate region $\left(\mathrm{da} / \mathrm{dN} \approx 10^{-8} \mathrm{~m} /\right.$ cycle $)$ starts, a peak in $\mathrm{IG}$ facets is observed in the AB2 samples with dissolved hydrogen. This occurs at a comparatively high stress intensity factor $(\Delta \mathrm{K} \approx 19 \mathrm{MPa} \sqrt{\mathrm{m}})$ than in the annealed and as well as the AB1 material. Figure 53 shows the extent of IG damage caused by dissolved hydrogen at increasing charging duration (or increasing hydrogen concentration). The most damage in terms of IG cracking occurs in the specimen charged with hydrogen for 200 hours and after that reduces marginally in the specimen charged for 250 hours. This type of cracking behaviour accelerates the crack growth rate whereby hydrogen present in the material concentrates at the crack tip due to intense cyclic loading stress gradients and causes decohesion along the grain boundaries leading to crack propagation with this dissolved hydrogen migrating again to the crack tip setting up the repetitive damage cycle. In the threshold region FCGRs of $\mathrm{AB} 2$ material at about da/dN $\approx 10^{-8} \mathrm{~m} / \mathrm{cycle}$, the above mentioned trend was noted. Increasing the dissolved hydrogen concentration up until a charging time of $200 \mathrm{hrs}$ increased the near threshold FCGRs, but at a charging time of $250 \mathrm{hrs}$ 
the FCGRs had a slight reduction at comparable stress intensities. The fractographic evidence supports this finding with a marginally reduction in brittle crack morphology in terms of IG facets as seen in the figure 53(c).
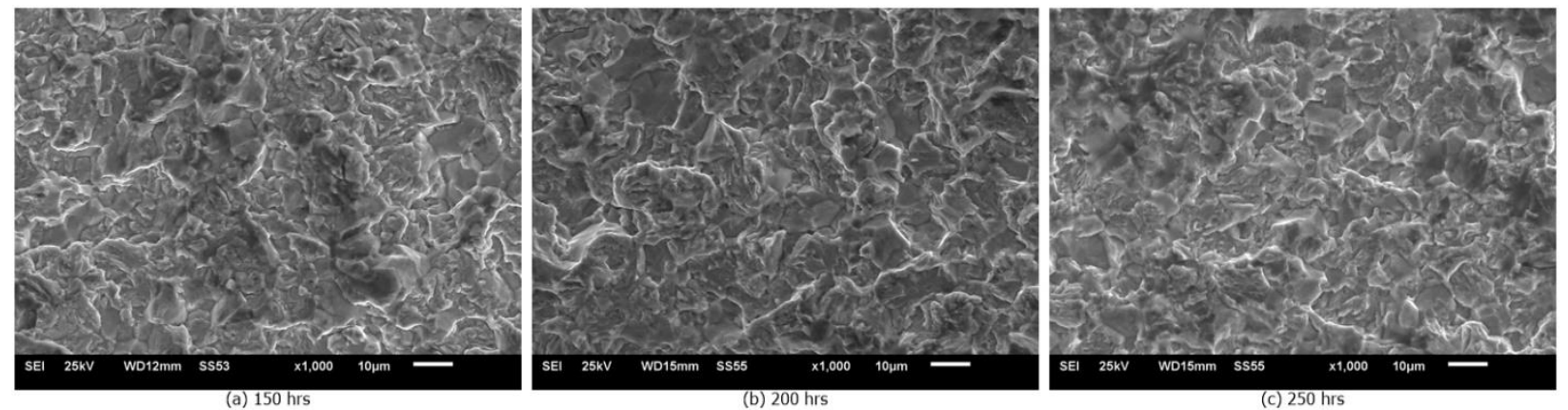

Figure 53: Fractographs of AB1 material showing the peak in IG facets at the start of the near threshold region; $\Delta \mathrm{K} \approx 19 \mathrm{MPa} \vee \mathrm{m}$ [Note: Crack propagation from right to left in all images; Magnification: $1000 \mathrm{X}]$

In addition to this, the FCP behaviour in the threshold region is believed to occur in plane strain conditions regardless of the specimen thickness as long as the linear elastic conditions exist at the crack tip [106]. A lack of the appearance of shear lips at the end of the specimen thickness is a manifestation of plane strain conditions and therefore indicates the FCP in the low growth rate region (or threshold region). On the other hand, the longer the length of the shear lip appearing on the low magnification fracture images the later will be the commencement of the threshold region (or the faster will be the CGRs) or the end of the fast CGR intermediate - linear behaviour. A low magnification image showing crack propagation plane at the start of the threshold region fatigue test of the sample charged for $200 \mathrm{hrs}$ is shown in Figure 54 illustrating the appearance of shear lips starting from the crack notch. This observation was taken as 
evidence to show the higher CGRs in the AB2 material in all the samples containing dissolved hydrogen in the mid growth rate region (transition region $-\mathrm{da} / \mathrm{dN} \approx 10^{-8} \sim 10^{-7} \mathrm{~m} /$ cycle) until the start of threshold region. In addition, the length of the shear lip were noted in all of the precharged samples in an effort to correlate to the observed CGRs. These are recorded in Table 15.

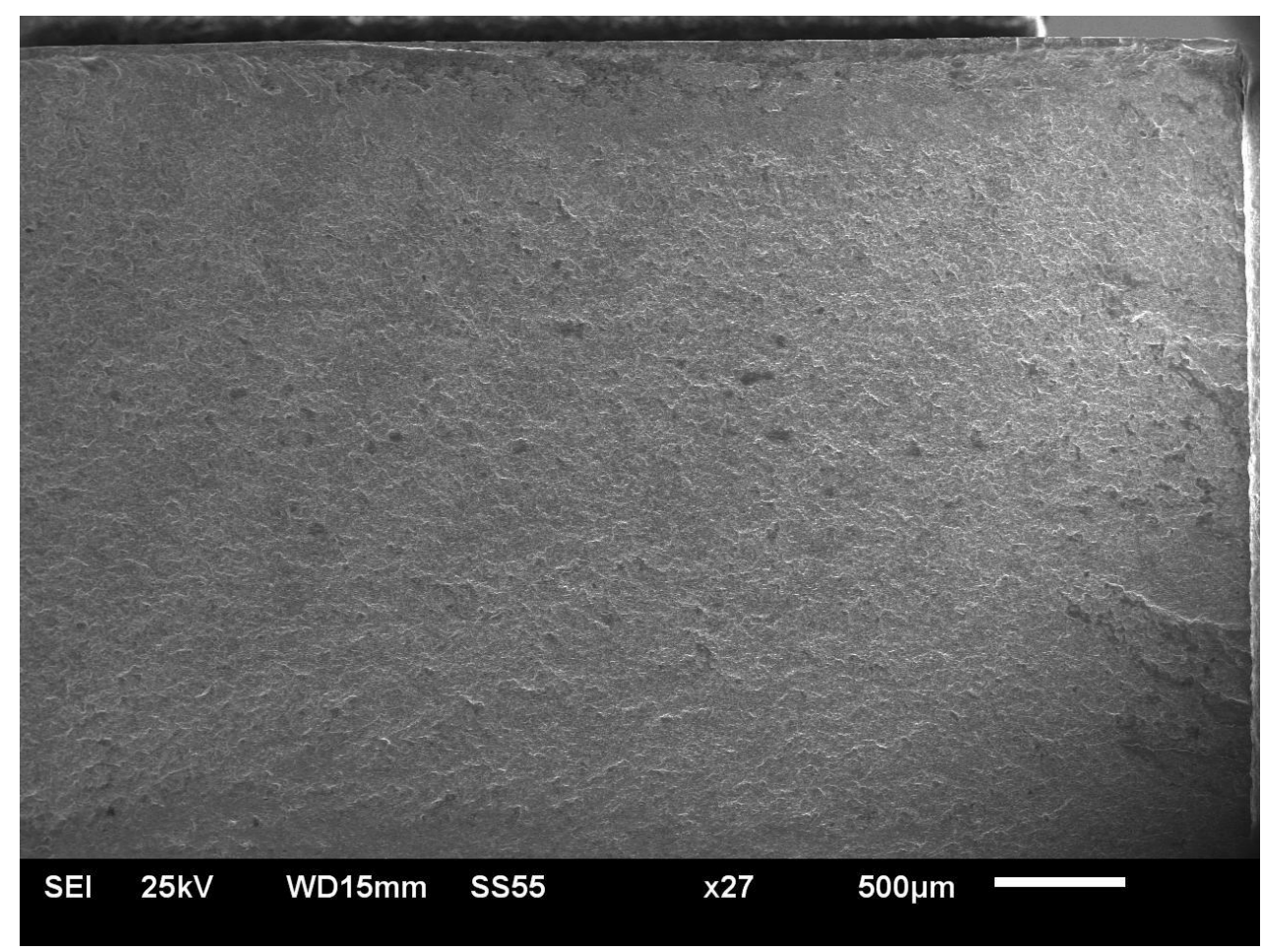

Figure 54: Crack propagation plane in AB2 material of the sample charged with hydrogen for 200 hrs showing the appearance of shear lips near the crack starter notch (Magnification: 27X)

The effect of increasing dissolved hydrogen concentration was seen to increase the intermediate FCGRs until a certain limit (200 hrs of precharging time - $3.6 \mathrm{ppm}$ ) and after that limit the fatigue damage effects were less pronounced from the shear lip data (table 15). The same behaviour was explained earlier in the fractographs taken at the SIF where the peak in IG facets 
takes place which was also reflected in the threshold FCGRs of the AB2 material. In addition, the appearance of shear lip at the beginning of the threshold region in the AB2 samples, which was not readily observed in the other two batches namely annealed and AB1 samples, shows why the FCGRs are higher in AB2 until the transition region than the annealed samples. In a similar fashion, the peak in IG facets at the higher $\Delta \mathrm{K}$ elaborates how faster FCGRs are encountered in the $\mathrm{AB} 2$ material at mid crack growth rates and thereafter decreases quite significantly than the annealed material due to crack propagation via microstructure sensitive crack path.

Table 15: Length of shear lip observed in the transition region (end of intermediate - start of threshold region) in the $\mathrm{AB} 2$ material

\begin{tabular}{|c|c|c|c|}
\hline $\begin{array}{c}\text { Hydrogen } \\
\text { Charging } \\
\text { Time } \\
\text { (hrs) }\end{array}$ & $\begin{array}{l}\text { Observed } \\
\text { length of } \\
\text { shear lip } \\
(\mathrm{mm})\end{array}$ & $\begin{array}{l}\text { Approximate } \\
\Delta K \text { at the end } \\
\text { of the shear } \\
\text { lip }(M P a \sqrt{ } \text { m) }\end{array}$ & $\begin{array}{l}\text { Approximate } \\
\text { da/dN at the } \\
\text { end of the shear } \\
\text { lip (m/cycle) }\end{array}$ \\
\hline $150 \mathrm{hrs}$ & 4.26 & $18.5-19.0$ & $1.1-1.3 \times 10^{-7}$ \\
\hline $200 \mathrm{hrs}$ & 6.536 & 15.5 & $8.3-8.5 \times 10^{-8}$ \\
\hline $250 \mathrm{hrs}$ & 4.288 & $18.5-19.0$ & $1.0-1.1 \times 10^{-7}$ \\
\hline
\end{tabular}

At a $\Delta \mathrm{K}<19 \mathrm{MPa} \sqrt{\mathrm{m}}$, the degree of IG facets decreases in the samples charged with dissolved hydrogen the crack propagates into the threshold region and so does the influence of dissolved hydrogen. At very low SIFs (9-7 MPa $\sqrt{\mathrm{m}}$ ), the fracture images show a rather different morphology than the other two batches of steel specimens (figure 55(c), (f), (i) and (1)). The 
uncharged specimen shows a featureless surface as seen in the annealed material whereas the samples precharged with hydrogen show minimal TG or IG features, unlike the AB1 material, except in the case of sample charged for $200 \mathrm{hrs}$ in which some intergranularity was visible (figure 55(i)). For this sample, at $\Delta \mathrm{K} \approx 9-7 \mathrm{MPa} \sqrt{\mathrm{m}}$ was the region where marginally high near threshold FCGRs were observed and thereafter was reduced by a small extent. As the SIF was stepped down to about $6 \mathrm{MPa} \sqrt{\mathrm{m}}$, some transgranularity was evident in all the specimens of $\mathrm{AB} 2$ material (figure $55(\mathrm{~b}),(\mathrm{e}),(\mathrm{h})$ and (k)). The uncharged specimen switched from a featureless to more crystallographic failure type having some ductile features with some cracking along MnS stringers while the precharged specimens transitioned from a ductile - brittle fracture surface to a flat fracture surface with brittle features with $\mathrm{MnS}$ stringers and finally to one resembling the uncharged specimen but with some oxide like spots as the dissolved hydrogen concentration was increased. An EDS spectrum on a similar feature in the 250 hours charged specimen revealed the presence of iron oxide as is shown in figure 56. Though some oxides were found close at the threshold region, these oxides were only observed in very few random locations to be of concern to cause any significant contribution to the effective SIF experienced at the crack tip even at the low $\Delta \mathrm{K}$ values. There was good reasoning to believe this claim because the AB2 material had a very high strength among all the three batches of steel specimens tested which means that it had the smallest cyclic plastic zone size at comparable near threshold stress intensities. To add to this effect, the AB2 material approached the fatigue threshold at moderately higher SIFs $(6-7$ $\mathrm{MPa} \sqrt{\mathrm{m}}$ ) than the other two batches of steel samples. Therefore, a greater load was felt between the crack tip surfaces in which case oxide wedging does not appear to be a major factor in the diminishing the effect of the applied SIF. Vasudeven et. al [107] have also commented, in the review on crack closure and fatigue threshold, that the crack closure contribution arising from 
oxide formation via fretting action and these oxide asperities wedging at the crack tip are random processes whose influence is very less on the effective SIFs at the crack tip. A plastic zone size analysis was also carried out like in the other two batches of samples to see how the high yield strength played a role in the crack propagation in the very low da/dN region especially in presence of dissolved hydrogen which is listed in Table 16. 


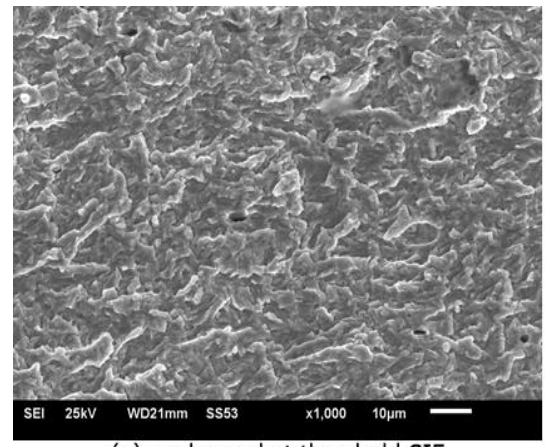

(a) uncharged at threshold SIF

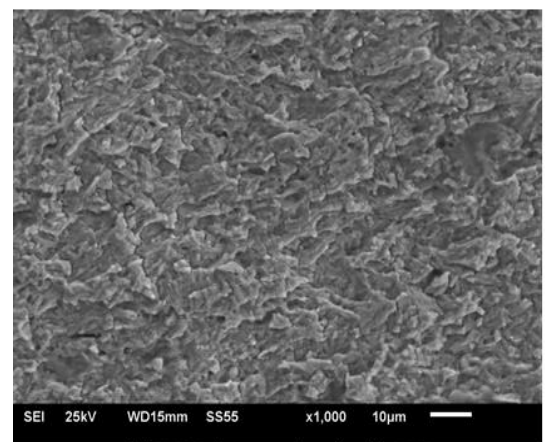

(d) $150 \mathrm{hrs}$ at threshold SIF

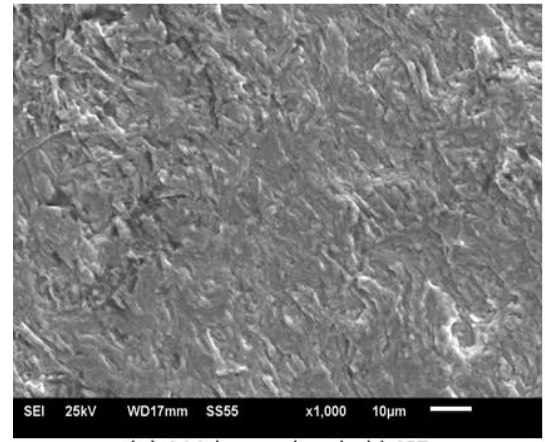

(g) 200 hrs at threshold SIF

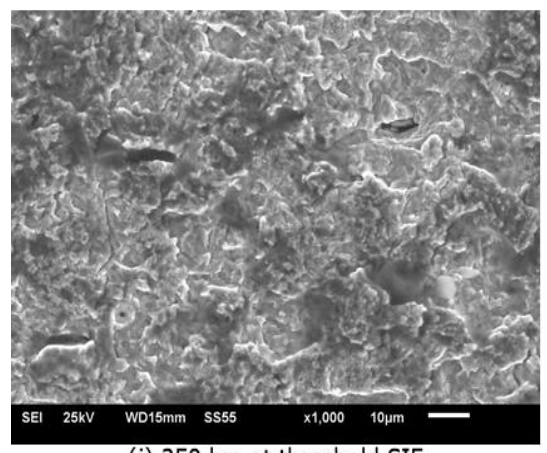

(j) $250 \mathrm{hrs}$ at threshold SIF

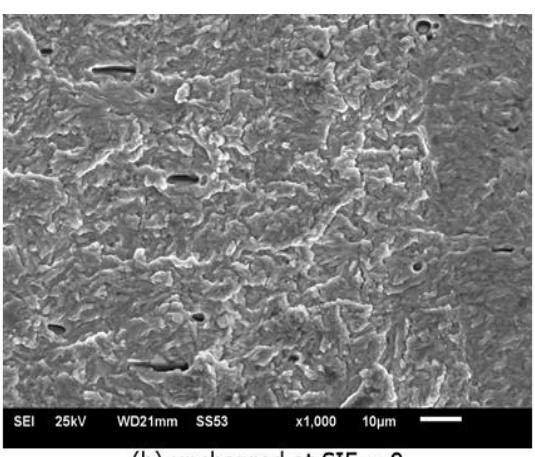

(b) uncharged at SIF 9

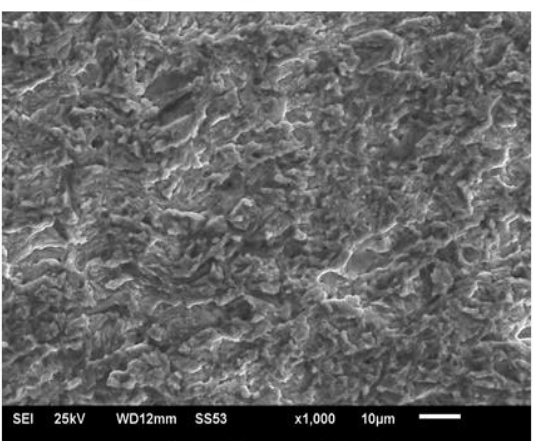

(e) 150 hrs at SIF 7

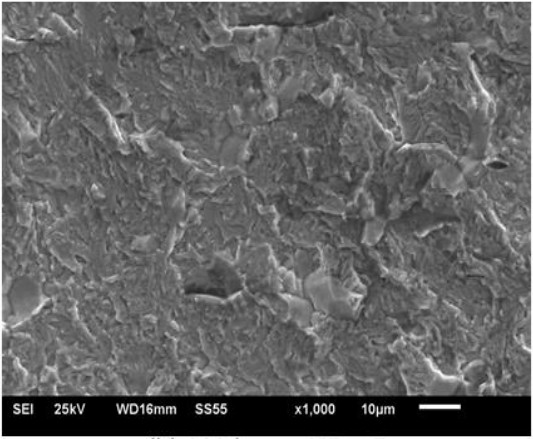

(h) 200 hrs at SIF $~ 7$

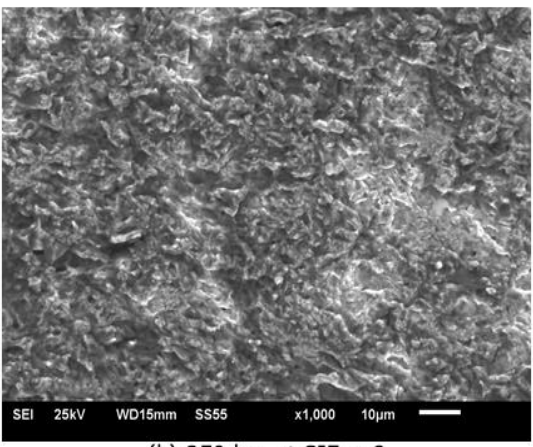

(k) 250 hrs at SIF 8

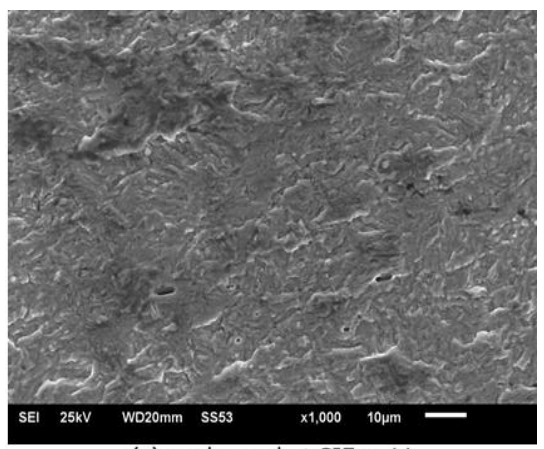

(c) uncharged at SIF 11

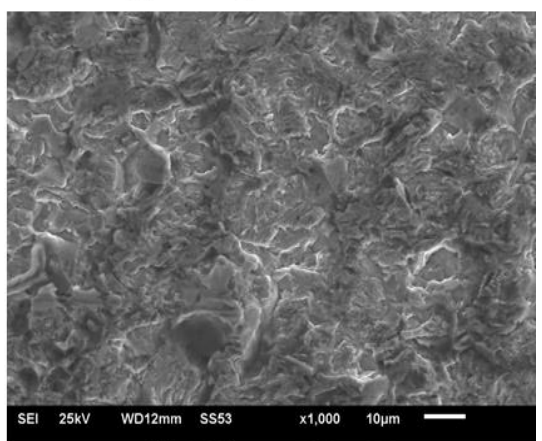

(f) 150 hrs at SIF 13

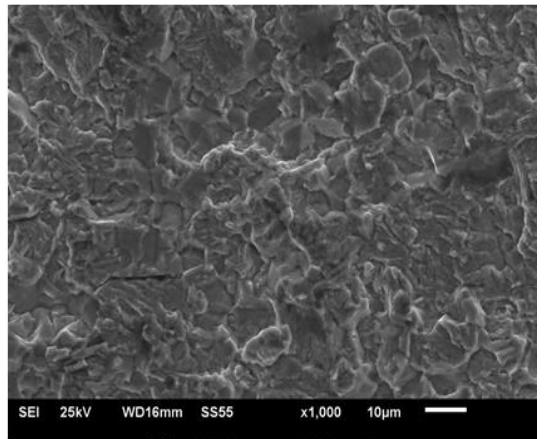

(i) 200 hrs at SIF $~ 13$

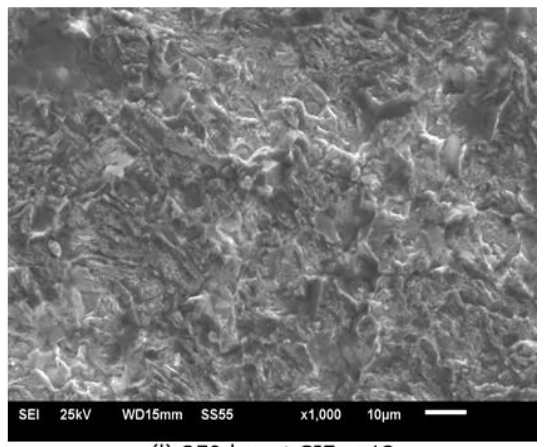

(I) 250 hrs at SIF 13

Figure 55: Fatigue surface images of $\mathrm{AB2}$ material ( $\Delta K$ (SIF) are in $\mathrm{MPa} \sqrt{\mathrm{m}}$ )

[Note: Crack propagation from right to left in all images; Magnification: 1000X] 

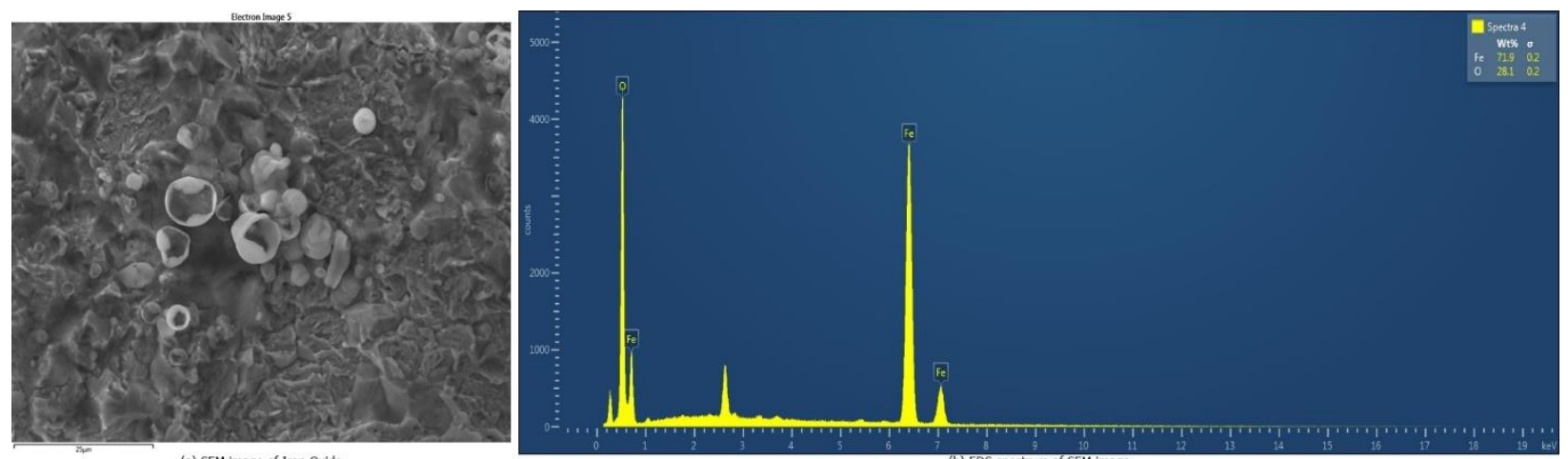

Figure 56: SEM image (Magnification: 1500X) and EDS spectrum of Iron Oxide found in the threshold region of the AB2 sample charged with hydrogen for $250 \mathrm{hrs}$

Table 16: Values of Monotonic and Cyclic Plastic Zone Size at corresponding SIFs where

Maximum Intergranular or Transgranular features (brittle or ductile) takes place with or without dissolved hydrogen in AB2 Material at Near Threshold FCGRs

\begin{tabular}{|c|c|c|c|c|c|c|c|c|}
\hline $\begin{array}{l}\text { Hydrogen } \\
\text { Charging } \\
\text { Time } \\
\text { (hrs) }\end{array}$ & $\begin{array}{l}\text { Crack } \\
\text { length } \\
(\mathrm{mm})\end{array}$ & $\begin{array}{l}\Delta \mathrm{K} \\
(\mathrm{MPa} \sqrt{ } \mathrm{m})\end{array}$ & $\begin{array}{l}\mathbf{K}_{\max } \\
(\mathrm{MPa} \sqrt{ })\end{array}$ & $\begin{array}{l}\text { Yield } \\
\text { Strength, } \\
\sigma_{\text {ys }} \text { (Mpa) }\end{array}$ & $\begin{array}{l}\text { Monotonic } \\
\text { Plastic } \\
\text { Zone Size } \\
(\mu \mathrm{m})\end{array}$ & $\begin{array}{l}\text { Cyclic } \\
\text { Plastic } \\
\text { Zone } \\
\text { Size } \\
(\mu \mathrm{m})\end{array}$ & $\begin{array}{l}\text { Grain } \\
\text { Size } \\
(\mu \mathrm{m})\end{array}$ & $\begin{array}{l}\text { Fatigue } \\
\text { Threshold, } \\
\Delta \mathbf{K}_{\text {th }} \\
\left(\mathrm{MPa} \sqrt{m}_{\mathrm{m}}\right)\end{array}$ \\
\hline $\begin{array}{c}\text { No } \\
\text { hydrogen }\end{array}$ & - & - & - & - & - & - & - & 8.12 \\
\hline 150 & 3.937 & 19.94 & 22.16 & 1481 & 88 & 18 & $8-22$ & 6.59 \\
\hline 200 & $\mathbf{3 . 9 3 7}$ & 19.96 & 22.18 & 1481 & 88 & 18 & $8-22$ & 6.17 \\
\hline 250 & $\mathbf{3 . 9 3 7}$ & 19.93 & 22.14 & 1481 & 88 & 18 & 8- 22 & 6.01 \\
\hline
\end{tabular}


The AB2 material had the largest plastic zone size inspite of its very high strength based on the SIF where maximum IG features were observed or until the point where the degradation due to dissolved hydrogen on the FCP was the greatest. The occurrence of IG maxima at high SIF can be attributed to this behaviour. The change in plastic zone size with increase in dissolved hydrogen concentration was not seen in the AB2 material unlike the other two batches. After the point of IG maxima, the reduced influence of dissolved hydrogen was reflected in the observed FCGRs as well as the fatigue crack growth morphologies (figure 55). The lack of yield strength effect resulting in smaller cyclic plastic zone size leading to faster FCGRs in the AB2 material is quite interesting. The AB2 material had a higher volume fraction of martensite from the volume fraction analysis explained earlier and also much less banded structure than the AB1 material as shown in the figure 10. The relative diffusion coefficient of hydrogen in martensite was lesser than the bainite phase [76]. At sufficiently high $\mathrm{SIF}(>=19 \mathrm{MPa} \sqrt{\mathrm{m}})$, there is enough stress gradient to provide the crack driving force for crack propagation. When hydrogen is present, the high stress gradient provides the necessary concentration gradient through minor differences in diffusivities in each phase to maintain FCP by crack advance through prior austenite grain boundaries. As the crack propagates into lower SIF region ( $<=19 \mathrm{MPa} \sqrt{\mathrm{m}})$, the stress gradient is not strong enough to provide the concentration gradient to diffuse hydrogen fast enough ahead of the crack tip to cause grain boundary cracking. Hence, the CGR reduce quite fast after a SIF of about $19 \mathrm{MPa} \sqrt{ }$. More volume fraction of martensite cause irreversible hydrogen trapping which have high binding energy to remove hydrogen from one trap and move ahead to next trap in the vicinity of the crack tip. A possible location would be an inclusion such as MnS. Very large number of repetitive loading cycles (a characteristic of near threshold region) is needed to cause crack propagation via an inclusion pullout in the wake of reduced influence of hydrogen, 
even when present in higher concentration in the AB2 material. Hence, the relatively higher fatigue threshold and lower CGRs are seen in the AB2 material.

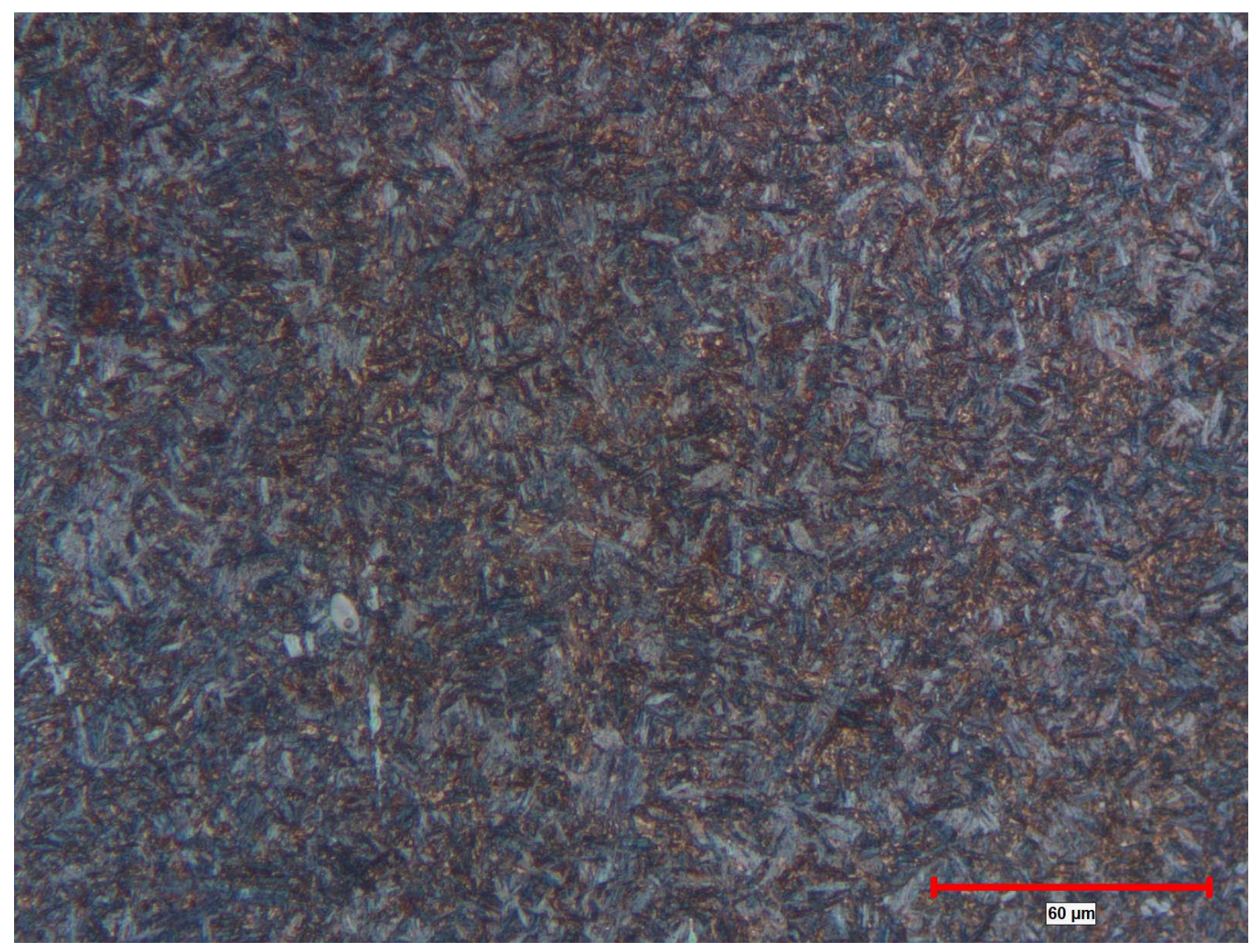

Figure 57: Microstructure of the AB2 material showing uniformly dispersed martensite and bainite phases with MnS stringers (white streak); Magnification: 500X 


\section{Mechanistic explanation of Linear Region Fatigue Crack Growth Rates}

\section{Annealed material}

In the annealed material, the high $\Delta \mathrm{K}$ linear region shows a very different fracture morphology than the threshold region in both the charged and uncharged specimens (Figure 57). In the uncharged specimen, the fatigue surface was characterized by a rough ductile surface with some cellular fracture at a $\Delta \mathrm{K} \approx 47 \mathrm{MPa} \sqrt{\mathrm{m}}$ (figure $57 \mathrm{a}$ ). As the $\mathrm{SIF}$ increased, the fracture behaviour changed to ductile tearing with pit like crack initiation sites, possibly due to inclusions as seen in the Figure 57b. The morphology became rougher due to crack propagation through multiple adjacent crystallographic planes in the annealed material resulting in crack branching at some localized regions (Figure 57b). No striations like growth patterns could be distinctly characterized to link the fracture behaviour to the observed CGRs. At the failure region in figure $57 \mathrm{c}$, the failure occurred via a predominantly ductile mode characterized by dimples and some TG like facets. Upon charging with dissolved hydrogen, the crack propagation in the fast crack propagation region changed to a more flat like appearance dotted with brittle like features. On increasing the hydrogen charging time, the crack plane is confined to a single plane to a greater extent until 200 hours (Figure 57d, g) and thereafter at 250 hours has a mixed mode behaviour with a fragmented surface (Figure 57j) mimicking that of the uncharged specimen but also with some brittle feature like the sample charged for 150 hours. This indicates the decrease in the influence of dissolved hydrogen after reaching a certain concentration of about 1.5 ppm (at 200 hours) in this case. This behaviour is clearly reflected in the linear region FCGRs in the annealed material for $250 \mathrm{hrs}$. At a point close to $\Delta \mathrm{K} \approx 45 \mathrm{MPa} \sqrt{\mathrm{m}}$ in the sample precharged for 250 hours, there is shift in the FCGRs line to lower crack growth rates than the other two samples. Even after this point, some damage due to dissolved hydrogen was evident at a high $\Delta \mathrm{K}$ of about 
$65 \mathrm{MPa} \sqrt{ } \mathrm{m}$ in figure $11 \mathrm{k}$ in the form of transgranular features. It was explained earlier that the hydrogen effect at a high $\Delta \mathrm{K}$ region is not so significant compared to the mechanical damage due to cyclic plasticity [2] at the vicinity of the crack tip which seems to be the case until this point $(\Delta \mathrm{K} \approx 65 \mathrm{MPa} \sqrt{ } \mathrm{m})$. However, this fracture behavior of shearing through some of the grains in the steel matrix at this high CGR region shows some influence of dissolved hydrogen in the annealed material. Some microstructural influence was believed to cause such a behavior. From prior investigations [108-109], the permeability of hydrogen was higher in pearlite compared to bainitic structures which was found in the other two austempered steels (with varying volume fraction of tempered martensite) used in this investigation. Hence, at this higher concentration of 2.9 ppm (charging time of 250 hours) in the annealed material, the migration of dissolved hydrogen was fast enough to keep pace with the fast moving crack front (the high stress intensity might have also played a role in increased stress assisted diffusion of hydrogen from the surrounding matrix to the crack tip). When this fast crack front with the ability to concentrate hydrogen at fast rates due to the microstructure met a grain boundary, the very high load experienced at the crack tip was sufficient enough to plastically tear through the grain in a localized fashion with the hydrogen playing its role to aid in the cleaving process. This might have given rise to the localized TG facets observed at these crack growth rates. As a consequence of this process, though the linear CGRs in the 250 hours charged specimen dips to a value less than the other two charging conditions (150 and 200 hours) at $\Delta \mathrm{K} \approx 45 \mathrm{MPa} \sqrt{\mathrm{m}}$, the CGRs are high enough at high SIFs than the uncharged specimen until the point of fracture. This is reflected in table 17 in the comparison of $\mathrm{C}$ and $\mathrm{m}$ values of the Paris constants. 


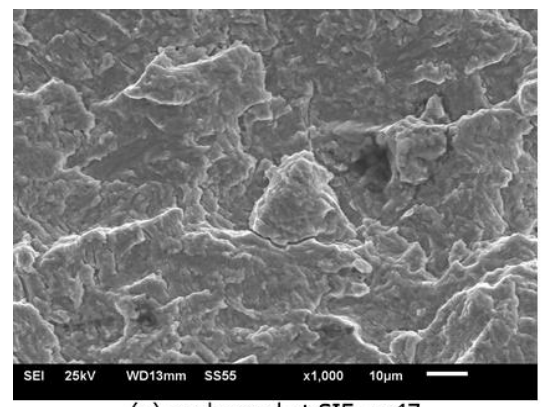

(a) uncharged at SIF $\sim 47$

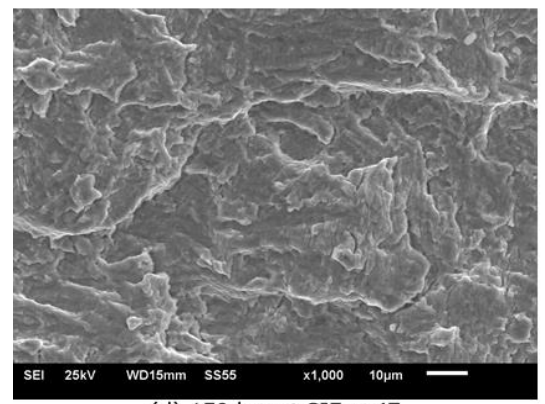

(d) $150 \mathrm{hrs}$ at SIF 47

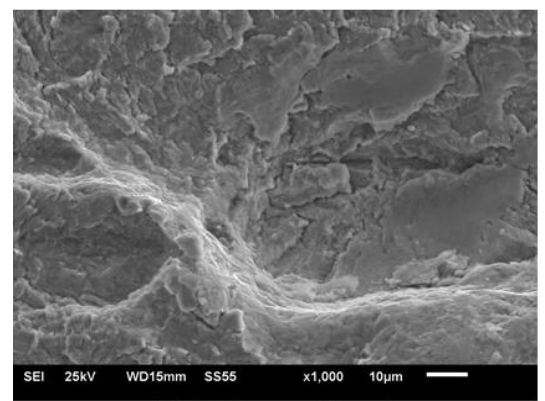

(g) 200 hrs at SIF 45

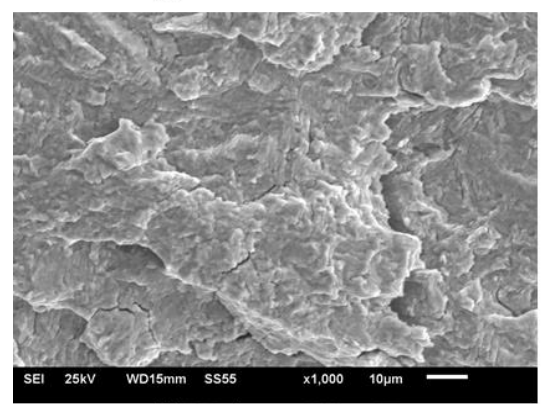

(j) 250 hrs at SIF 45

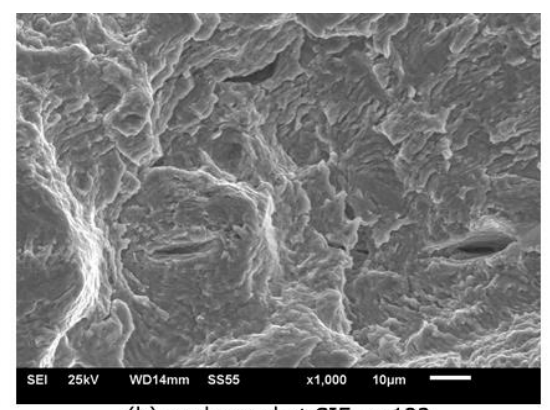

(b) uncharged at SIF $\sim 123$

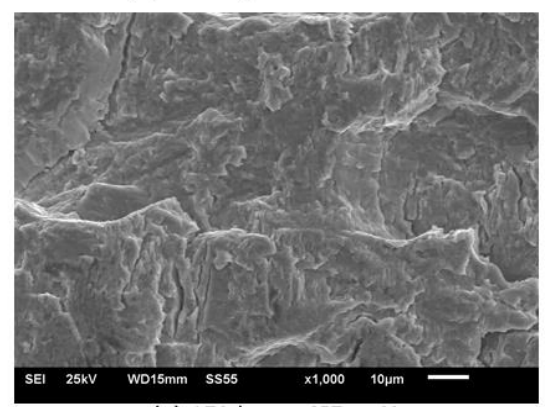

(e) 150 hrs at SIF 62

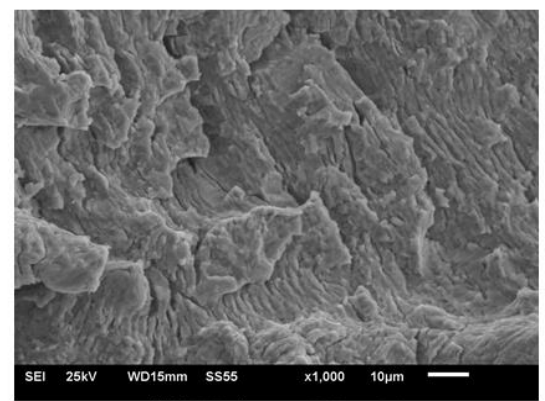

(h) 200 hrs at SIF 64

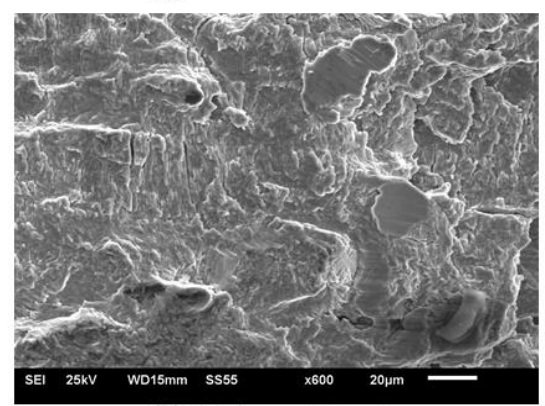

(k) 250 hrs at SIF $~ 60$

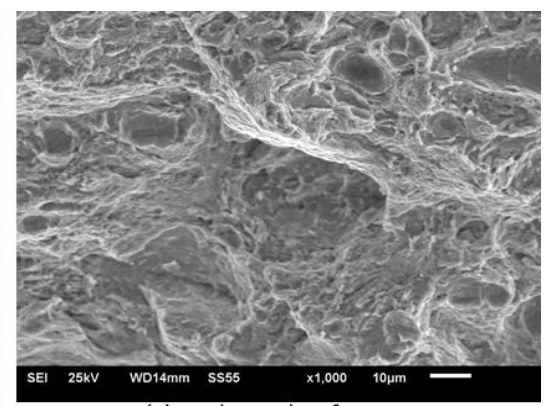

(c) uncharged at fracture

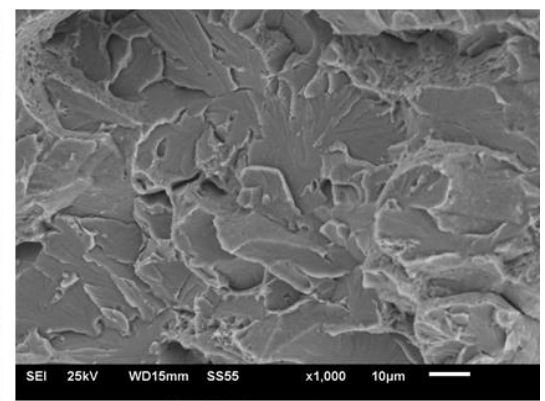

(f) $150 \mathrm{hrs}$ at fracture

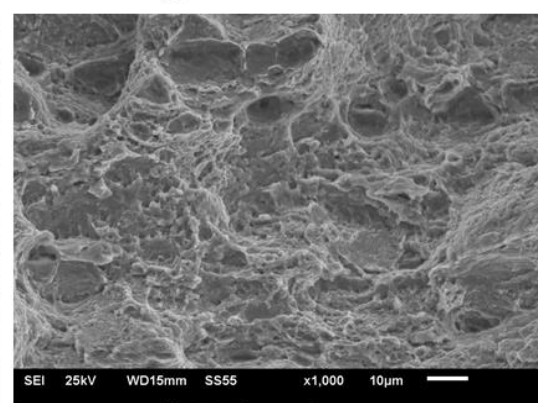

(i) $200 \mathrm{hrs}$ at fracture

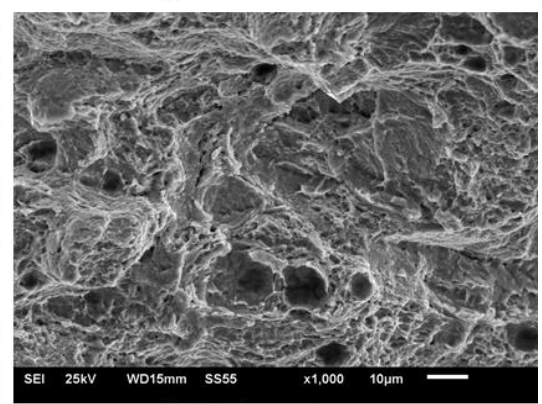

(i) $250 \mathrm{hrs}$ at fracture

Figure 57: Fatigue surface images of annealed material in linear region ( $\Delta K$ (SIF) are in MPa $\sqrt{ }$ m) [Note: Crack propagation from right to left in all images; Magnification: 600X:

(k) and $1000 \mathrm{X}$ : rest of the images] 
Table 17: Paris constants ( $\mathrm{C}$ and $\mathrm{m}$ ) in the annealed material at different hydrogen charging conditions

\begin{tabular}{|c|c|c||}
\hline $\begin{array}{c}\text { Charging time } \\
\text { (hrs) }\end{array}$ & $\mathbf{C}$ & $\mathbf{m}$ \\
\hline No hydrogen & $1 * 10^{-10}$ & 2.08 \\
\hline 150 & $1 * 10^{-11}$ & 2.25 \\
\hline 200 & $4 * 10^{-11}$ & 2.45 \\
\hline 250 & $9 * 10^{-11}$ & 2.16 \\
\hline
\end{tabular}

\section{Austempered Batch - 1 (AB1) material}

The $\mathrm{AB}-1$ material with its banded structure had a higher rate of crack propagation at all charging conditions as was seen in the linear region results earlier. The fractographic evidence gathered was able to elucidate this behavior as shown in Figure 58. The uncharged specimen shows a ductile type fracture surface populated with micro void coalescence (MVC) on a heavily fragmented background at a SIF of $46 \mathrm{MPa} \sqrt{\mathrm{m}}$ (Figure $58 \mathrm{a}$ ). The linear region fatigue crack propagation in $\mathrm{AB} 1$ material was mediated by cracking along the banded structure with some matrix separation occurring from the MnS inclusions lying along the banding lines. However, from the metallographic studies conducted, it was unclear whether these features i.e., the peak and the valley in the band belonged to a purely bainitic or purely martensitic phase or a combination of the two. On the other hand, since the relative amount of each of this phase in the material was known, some useful observations can be drawn correlating the FCGRs to the fracture images. As the SIF increased in the uncharged specimen to $60 \mathrm{MPa} \sqrt{\mathrm{m}}$, the fracture 
behavior showed reduction in micro voids and the crack propagation across multiple planes leading to plastic tearing as seen in the middle of figure $58 \mathrm{~b}$. The crack front progressed to failure with extensive plastic tearing across adjacent bands dotted with micro voids with a flatter ductile background (figure 58c). Evidence pointing to crack propagation across multiple planes at all SIFs, which was not seen in the uncharged annealed material, in the high $\Delta \mathrm{K}$ region suggested that the crack propagation rate increased as the cyclic crack front proceeded to failure. The higher yield strength lead to greater cyclic plasticity experienced at the crack tip for fast crack propagation. As the dissolved hydrogen concentration was increased, a mixed mode characterized by flat featureless surface with ductile + brittle like features scattered through the fracture surface with a few TG facets (even at this high $\Delta \mathrm{K}$ region) at 150 hours charging time, a predominantly brittle surface at $200 \mathrm{hrs}$ and showing diminished influence at $250 \mathrm{hrs}$ at SIF of 46 $\mathrm{MPa} \sqrt{\mathrm{m}}$. Upon further crack progression, at $60 \mathrm{MPa} \vee \mathrm{m}$, the CGRs were faster due to increased brittle failure modes at 150 hours and 200 hours which showed some TG facets and transgranular cleavage. In contrast, the 250 hours charged specimen showed less influence due to the increased hydrogen concentration with the fracture morphology lying in between the mostly ductile uncharged specimen and having some brittle morphology like the sample charged for 200 hours. The micro voids reappeared at certain regions within the 250 hours charges specimen which were not present, for most part, in the 200 hours charged specimen with flat surface showing the brittle nature, occurring as the crack progressed, as was noted earlier in the latter specimen. In short, the effect of causing brittle fatigue failure from dissolved hydrogen while still in effect, was lessened to a certain degree than the specimen with lower concentration of dissolved hydrogen. As a consequence, this also suggested that there may be a threshold concentration of dissolved hydrogen in the steel matrix over which the embrittlement effects were minimal or 
caused no addition acceleration of CGRs. The common denominator in the charged specimens were that the crack propagated across multiple planes with crack branching and/or having multiple crack origins but all leading to the fracture at inclusion sites. The cyclic plasticity effects in causing FCP were superimposed with that of the underlying banding structure and the inclusion sites (possibly elongated along these banding lines) either leading to grain pullouts from within multiple planes of the steel matrix or separation of the two mating crack planes around the inclusion boundaries. The resultant of these superimposed effects were the micro voids, usually left in the wake of the crack tip, indicating where the crack would propagate without a banded structure and inclusions sites by ductile failure mode and the flat surface (or the brittle features), lying at the point (or slightly ahead) of the crack tip, showing the brittle characteristics due to presence of inclusions. Aiding in the grain pullout or decohesion across the inclusion boundary or at certain areas at the grain boundary was the dissolved hydrogen present in the matrix. This hydrogen atom trapped irreversibly at the inclusion or void sites [40 - 44] and does not readily diffuse under cyclic stress fields because of high binding energies in releasing the atom from the trapped site. The inherent microstructure of bainite (higher volume fraction in $\mathrm{AB} 1$ material) and tempered martensite (lower volume fraction in the AB1 material) plays a key role in the diffusion process. The higher volume fraction bainite aids in faster diffusion of dissolved hydrogen (diffusible or reversibly) trapped, accentuated more by very steep stress gradients in the high $\Delta \mathrm{K}$ region, in the neighboring tempered martensite which has good trapping efficiency due to its large dislocation density [42]. In general, though the diffusion rates are not able to keep up with the fast CGRs in the linear region $[79,80]$ showing less damage to the steel matrix, when the crack front approaches an inclusion site in its crack path or in the vicinity (several adjacent planes parallel to the crack path) the high load in the linear region causes 
plastic damage by tearing at an inclusion site. The reason being the difference in strength of the steel matrix and the inclusion itself which provides a path of least resistance for crack rupture. The localized hydrogen trapped at these sites get released by the grain pullout or inclusion separation from the matrix and thereby ease the crack propagation further by causing localized transgranular (TG) or cleavage thru the adjacent grains leading to brittle mode failure. Since the bainite phase has a higher volume fraction in the material, the probability of bainitic phase boundary occurring adjacent to the inclusion site is quite high. That being the case, the diffusion effects of bainitic phase was believed to transport hydrogen from the adjacent matrix locally to crack tip vicinity: firstly due to localized concentration differences via diffusion and secondly promoting the diffusion to increased rates due to stress assisted effects. This leads to fast crack propagation via brittle mode fracture ahead of the inclusion area. This mechanism is seen to be valid from the fractographs in figure 58. Hence, the $m$ values were seen to increase with respect to increase in the charging time in the AB1 material as displayed in Table 18.

Table 18: Paris constants ( $\mathrm{C}$ and $\mathrm{m}$ ) in the $\mathrm{AB} 1$ material at different hydrogen charging conditions

\begin{tabular}{|c|c|c||}
\hline $\begin{array}{c}\text { Charging time } \\
\text { (hrs) }\end{array}$ & $\mathbf{C}$ & $\mathbf{m}$ \\
\hline No hydrogen & $5 * 10^{-11}$ & 3.45 \\
\hline 150 & $2 * 10^{-12}$ & 3.53 \\
\hline 200 & $7 * 10^{-13}$ & 3.86 \\
\hline 250 & $9 * 10^{-13}$ & 3.72 \\
\hline
\end{tabular}




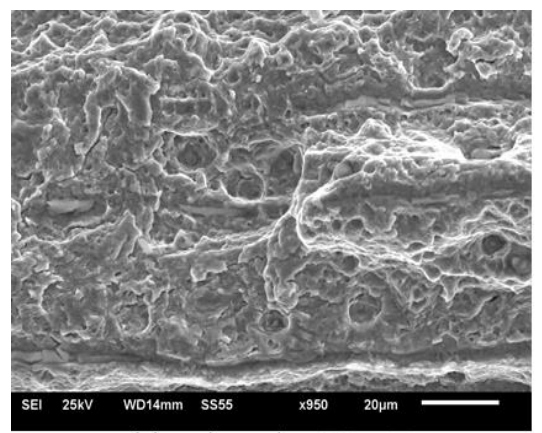

(a) uncharged at SIF 46

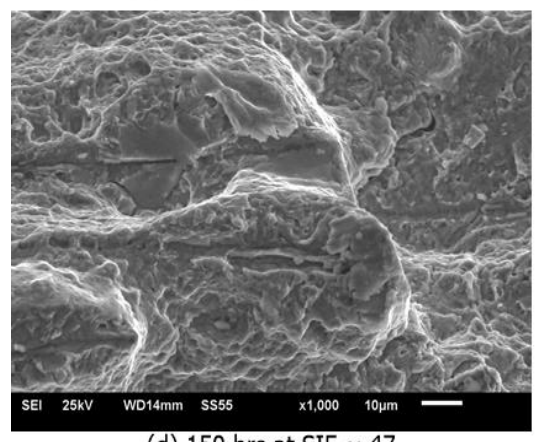

(d) 150 hrs at SIF 47

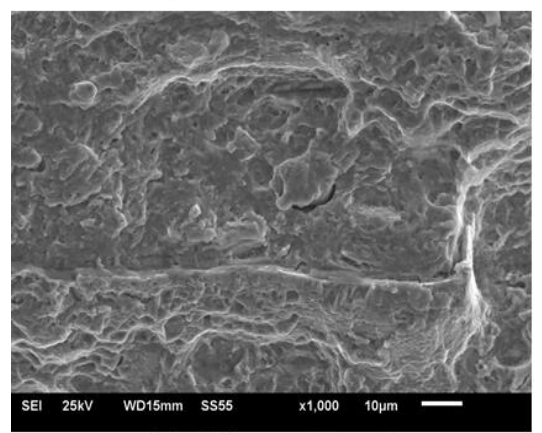

(g) $200 \mathrm{hrs}$ at SIF 48

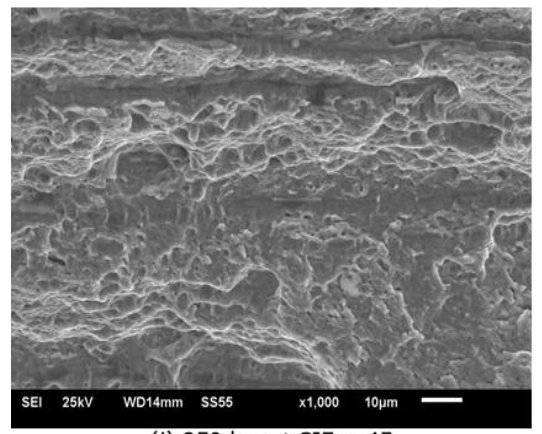

(j) 250 hrs at SIF 45

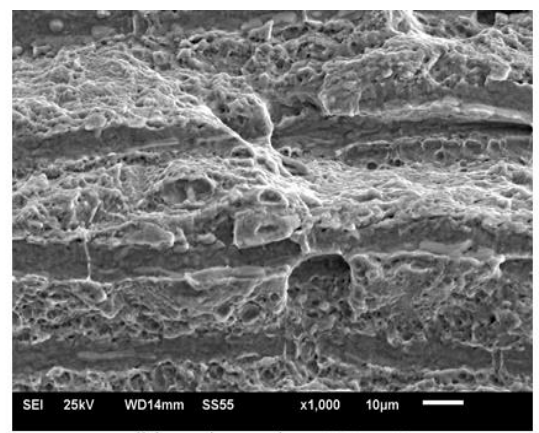

(b) uncharged at SIF 60

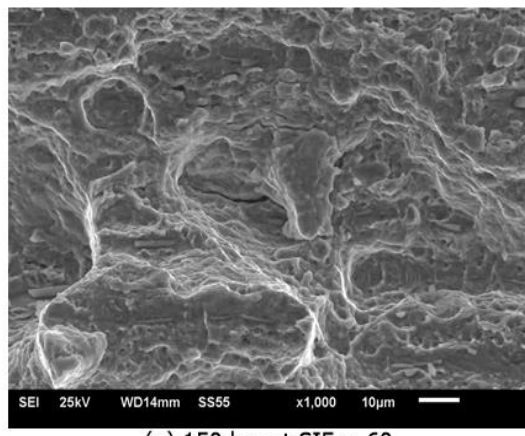

(e) 150 hrs at SIF 60

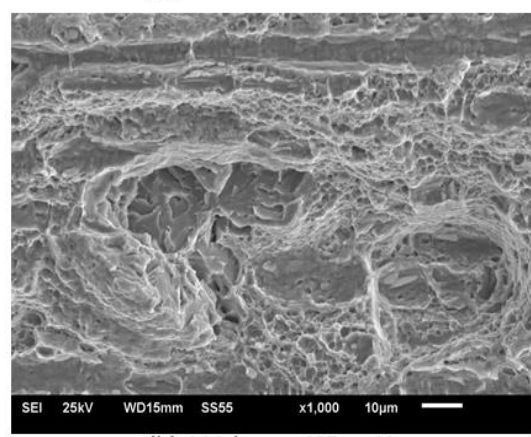

(h) 200 hrs at SIF 60

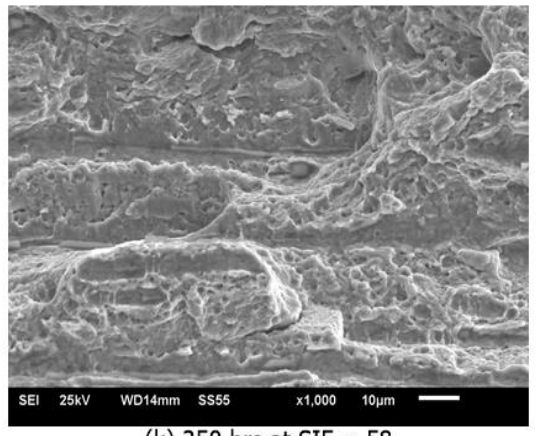

(k) 250 hrs at SIF 58

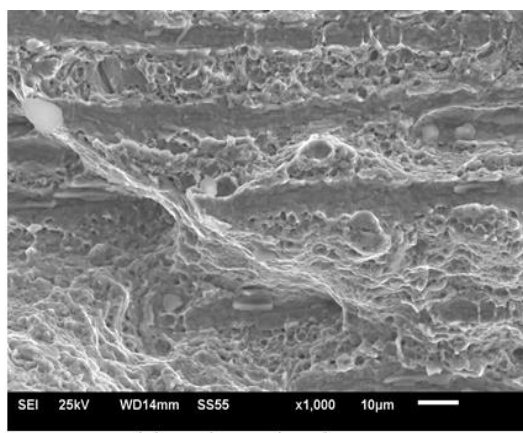

(c) uncharged at fracture

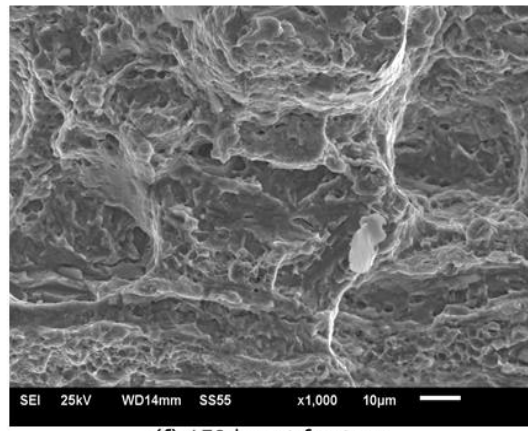

(f) $150 \mathrm{hrs}$ at fracture

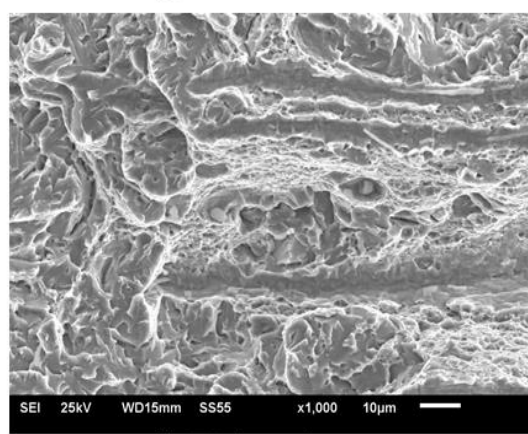

(i) $200 \mathrm{hrs}$ at fracture

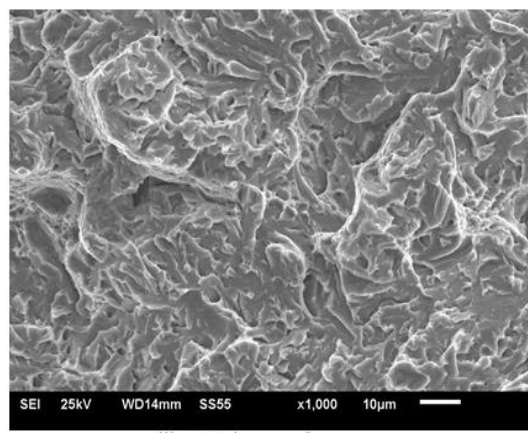

(I) $250 \mathrm{hrs}$ at fracture

Figure 58: Fatigue surface images of $\mathrm{AB} 1$ material in linear region ( $\Delta K$ (SIF) are in $\mathrm{MPa} \sqrt{ } \mathrm{m})$ [Note: Crack propagation from right to left in all images; Magnification: 1000X] 


\section{Austempered Batch - 2 (AB2) material}

The AB2 material had a distinct behaviour in regard to the effect of dissolved hydrogen especially in the linear fast crack growth region. The microstructure was similar to be AB1 material varying only in the relative volume fraction of tempered martensite and bainite. Due to the lower austempering temperature, a higher fraction of tempered martensite to bainite ratio exists in this steel. The fracture morphology of the AB2 material at charged and uncharged conditions have been outlined in the figure 59. The uncharged specimen at SIF of $46 \mathrm{MPa} \sqrt{\mathrm{m}}$ shows a fragmented fracture surface (figure 59a), with much flat background than the AB1 material, with grain pullouts from inclusion spots. The fragmentation of the fracture surface appears to show a much brittle nature of the alloy in the AB2 condition. However, if the brittle surface is to be an artifact of the higher strength in this alloy which might point towards faster FCGRs in the linear region than the AB1 material, we would expect this material to show more brittle like features in the fracture images as the crack advances ahead raising the crack tip SIF. On the contrary, upon comparing the fracture images in figure 59a and 59b, we see that this is not the case. Even a high SIF of $60 \mathrm{MPa} \sqrt{\mathrm{m}}$ in figure $59 \mathrm{~b}$, it shows a similarity to the behaviour at $46 \mathrm{MPa} \sqrt{\mathrm{m}}$. This suggests that the crack growth rate doesn't increase drastically or change significantly with drastic increase in the SIF as was observed in the other two steels particularly in the high $\Delta \mathrm{K}$ region. This might be an indication that there is cyclic stability taking place [16], to some degree, in the AB2 material. Though some degree of cyclic plastic deformation takes place as the crack advances under the influence of high SIF in the linear region, it was observed that the crack growth was slowed to some extent as the crack progressed to failure. In the samples charged with hydrogen, the fracture behaviour showed some damage in the form of brittle features which were not seen in the uncharged specimens. As the SIF increased from 46 to 
$60 \mathrm{MPa} \sqrt{\mathrm{m}}$, at all the three charging conditions, there were brittle features observed in the specimens (figures 59 (d), (e), (g), (h), (j) and (k)) with no significant changes with the increase in SIF. Significant damage from crack nucleation from inclusions were observed extensively in all of these specimens. A similar mechanism as explained for the AB1 material was thought to be valid for the AB2 material. Some isolated intergranular (IG) facets were seen in all the charged specimens at 45 and $60 \mathrm{MPa} \sqrt{ } \mathrm{m}$ but for the one charged for 250 hours at $60 \mathrm{MPa} \sqrt{\mathrm{m}}$ (figure 59(k)). It was believed that the higher concentration of dissolved hydrogen, for the same charging time in comparison with the other two batches of steel, due to higher volume fraction of tempered martensite and the influence of inclusions (explained in the AB1 material) were responsible for the appearance of isolated IG facets in this material. The high dislocation density of tempered martensite with its relatively higher hardness might have caused this localized failure. On the brighter side, the appearance of IG facets only at locations where the crack front encountered inclusions suggested that the fatigue crack growth resistance of this AB2 material can be improvised just by reducing the inclusion volume fraction in the matrix. It is still fully unclear as to why the $\mathrm{m}$ values reduce in the samples charged with dissolved hydrogen as listed in Table 19. 
Table 19: Paris constants ( $\mathrm{C}$ and $\mathrm{m}$ ) in the AB2 material at different hydrogen charging conditions

\begin{tabular}{|c|c|c|}
\hline $\begin{array}{c}\text { Charging time } \\
\text { (hrs) }\end{array}$ & $\mathbf{C}$ & $\mathbf{m}$ \\
\hline No hydrogen & $5 * 10^{-11}$ & 2.14 \\
\hline 150 & $1 * 10^{-09}$ & 1.54 \\
\hline 200 & $2 * 10^{-09}$ & 1.39 \\
\hline 250 & $2 * 10^{-09}$ & 1.33 \\
\hline
\end{tabular}




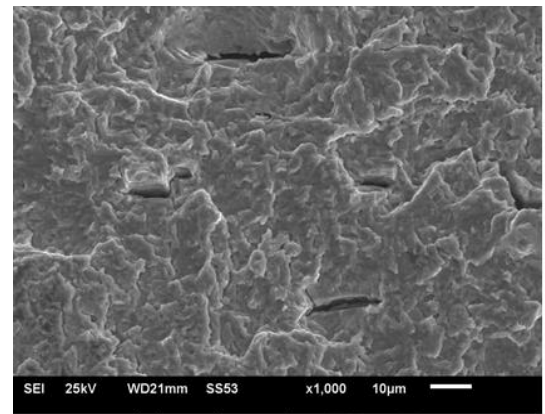

(a) uncharged at SIF 46

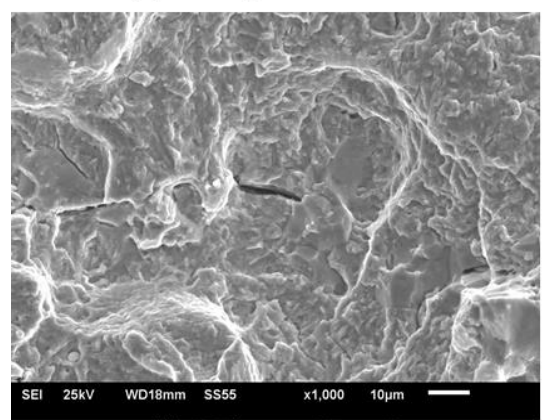

(d) 150 hrs at SIF 46

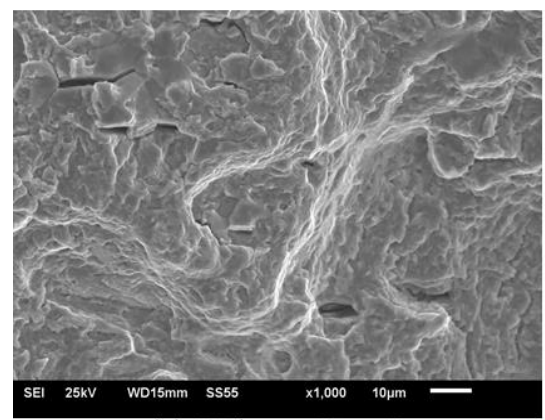

(g) 200 hrs at SIF 46

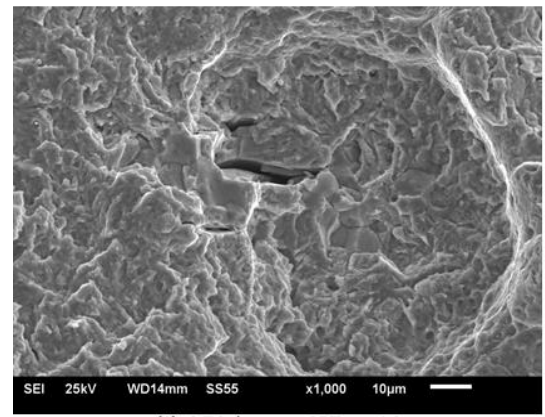

(j) 250 hrs at SIF 46

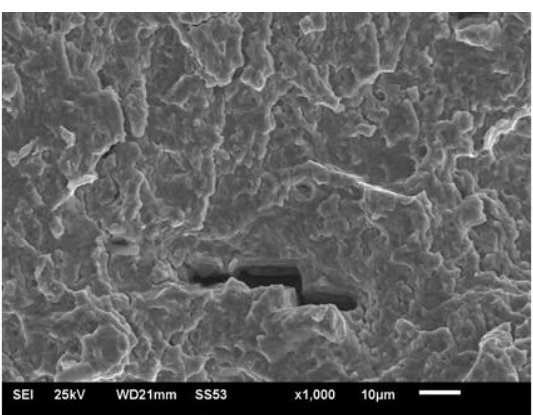

(b) uncharged at SIF 60

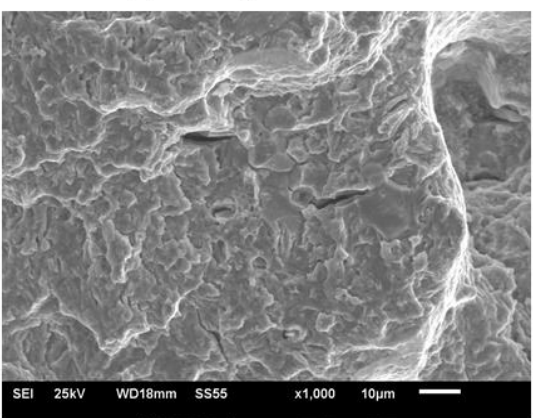

(e) 150 hrs at SIF 60

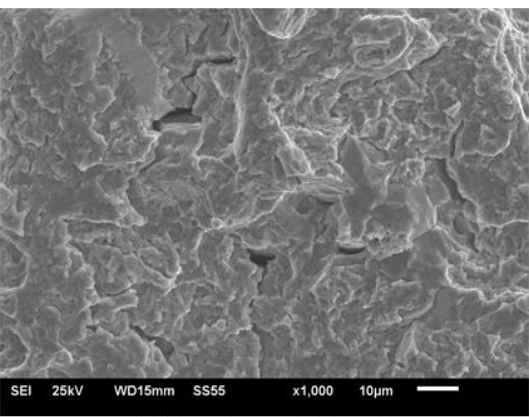

(h) 200 hrs at SIF $~ 60$

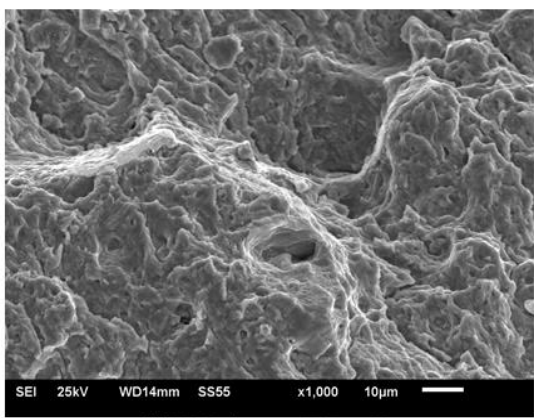

(k) 250 hrs at SIF 60

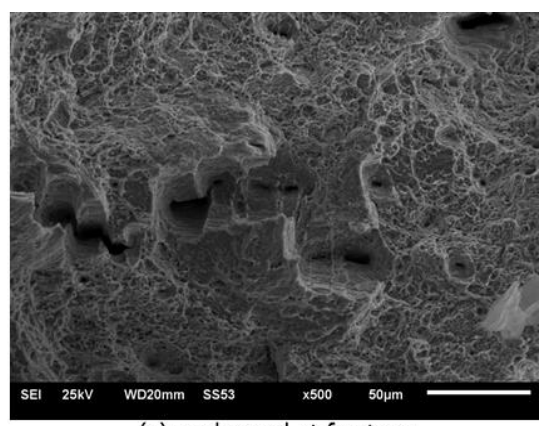

(c) uncharged at fracture

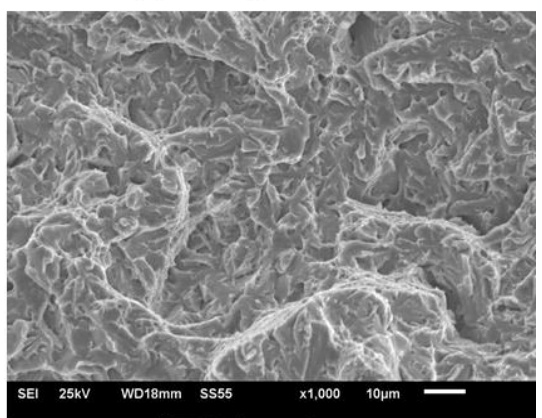

(f) $150 \mathrm{hrs}$ at fracture

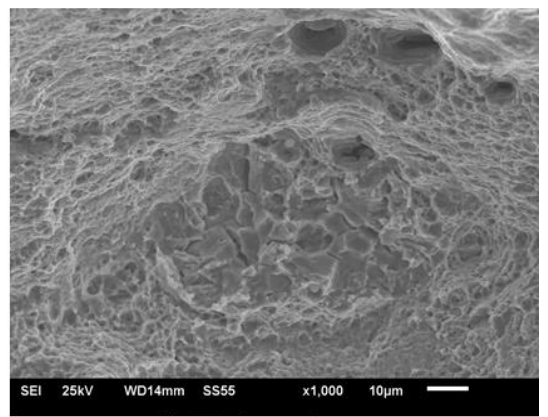

(i) $200 \mathrm{hrs}$ at fracture

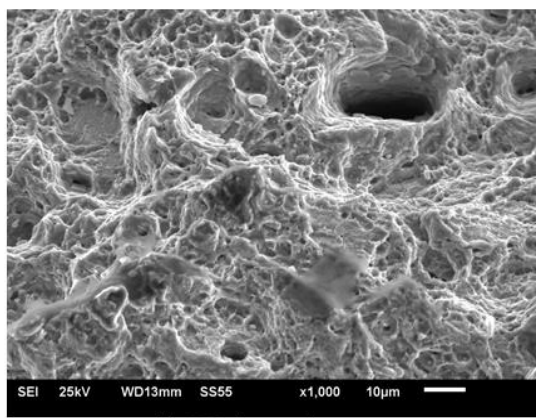

(I) 250 hrs at fracture

Figure 59: Fatigue surface images of $\mathrm{AB2}$ material in linear region ( $\Delta \mathrm{K}$ (SIF) are in MPa $\sqrt{ }$ m) [Note: Crack propagation from right to left in all images; Magnification: (c) $500 \mathrm{X}$, all other images $-1000 \mathrm{X}]$ 


\section{CHAPTER 6 - CONCLUSIONS}

1. The test results show that the dissolved hydrogen content increases with the exposure time in both annealed and austempered materials, but to a greater extent in the austempered (AB2) samples which may be due to marginally higher volume fraction of tempered martensite to bainite ratio.

\section{In the annealed material:}

a. The linear region FCGRs are accelerated in presence of hydrogen compared to the specimens with no hydrogen precharging. The linear region FCGRs are increased with increasing hydrogen concentration until about $1.5 \mathrm{ppm}$ concentration above which there is little effect of hydrogen. The fractographs show increasing brittle features with crack branching with the increase in hydrogen concentration.

b. The near threshold FCGRs are also accelerated and the fatigue thresholds decrease with increasing hydrogen concentration upto $200 \mathrm{hrs}$ of charging time. This again indicates that above $1.5 \mathrm{ppm}$ of hydrogen in the material it may be beneficial in the material. The fractographs show signs of quasi cleavage fracture on increasing the dissolved hydrogen concentration.

c. An interesting phenomenon was observed in the case of annealed specimens charged with hydrogen for $250 \mathrm{hrs}$. The fatigue threshold stress intensity $\left(\Delta \mathrm{K}_{\mathrm{th}}\right)$ was found to be higher in the $250 \mathrm{hrs}$ charged specimens than the uncharged specimens. There appears to be a threshold value of hydrogen concentration of $1.5 \mathrm{ppm}$ in the annealed material above which the degradation effects of hydrogen diminishes and is found to be beneficial in the material. Further investigation is necessary to resolve this issue. 


\section{In the austempered (AB1) material:}

a. On increasing the dissolved hydrogen concentration in the $\mathrm{AB} 1$ material, the linear FCGRs are greatly affected and increases with the hydrogen charging time. The $250 \mathrm{hrs}$ charged specimen had a lower FCGR than the 200 hrs charged specimen. However, the charged FCGRs at all times were significantly higher than the uncharged specimen. The fractographs showed signs of embrittlement with brittle like features on the fracture surface.

b. The near threshold FCGRs are increased and the fatigue thresholds are decreased in the AB1 material upon increasing the dissolved hydrogen concentration and to a greater extent than the annealed material. The $\Delta \mathrm{K}_{\mathrm{th}}$ at all charged conditions is lower than the uncharged condition. The higher strength might be responsible for this behaviour. The embrittlement effects are much severe in the threshold condition as indicated by the highly faceted fracture surface.

\section{In the austempered (AB2) material:}

a. The linear region FCGRs are affected by the influence of dissolved hydrogen. Faster the FCGRs on increasing the dissolved hydrogen concentration. However, the linear FCGRs converge to a single point unlike the annealed and $\mathrm{AB} 1$ material showing minimal influence of hydrogen as the SIF increases. The fractographs indicate an increasing degree of IG facets with increased charging time except for the $250 \mathrm{hrs}$ which changes to mixed mode type of failure.

b. The near threshold FCGRs are much faster with the dissolved hydrogen specimens than the uncharged specimens. However, the change in FCGRs upon increasing the hydrogen concentration is not very prominent except for suppression of fatigue thresholds. The 
fracture surface shows severe embrittlement in the hydrogen charged specimens The 250 hrs specimens had a flat brittle like appearance with IG and TG facets.

c. The AB2 material had the highest fatigue threshold with dissolved hydrogen at $250 \mathrm{hrs}$ charging time in the matrix among the three batches of specimens tested. It was much higher than the fatigue threshold of uncharged annealed and AB1 materials.

d. The near threshold fatigue crack growth rate of austempered (AB1) specimens is significantly higher in presence of dissolved hydrogen than the annealed specimens and the fatigue threshold stress intensity ( $\Delta \mathrm{K}$ th) decreases with increased dissolved hydrogen content. However, the near threshold FCGRs of AB2 are less than the annealed samples and is only higher in the transition region (da/dN between 10-9 to $10-7 \mathrm{~m} /$ cycle).

e. The fatigue crack growth rate in the linear region is also found to accelerate as a function of increasing dissolved hydrogen concentration for annealed as well as austempered $\mathrm{AB} 1$ materials whereas it has a diminished effect on the austempered AB2 samples.

f. Higher the austempering temperature lower is the effect of hydrogen on the fatigue crack growth behaviour and fatigue threshold. Hence, the austempered (AB2) samples are found to possess the best strength and fatigue resistance to hydrogen even with very high concentration of dissolved hydrogen in the material.

This is a promising initial finding that AISI 4140 austempered at $332^{\circ} \mathrm{C}$ could be explored as a good candidate for hydrogen bearing environments to serve possibly in wide variety of applications for the upcoming Hydrogen Economy. 


\section{CHAPTER 7 - FUTURE WORK}

Some of the aspects that could be explored further based on the current work are to check the influence of dissolved hydrogen on the tensile and fracture toughness properties in the annealed and austempered conditions. In order to gain a better insight on the near threshold fatigue crack growth behaviour in presence of dissolved hydrogen, it is also important to check the effect of load ratio and cycling frequency in annealed as well as austempered conditions. Austempering at various other temperatures than the ones used in this study would be very helpful to understand the influence of austempering temperature on the fatigue behaviour of 4140. It was our initial understanding that a small variation in the volume fraction of inclusions in the steel could lead to drastic changes in the fatigue behaviour of the alloy as observed in the austempered batch -1 material. Hence, a study needs to be conducted to know the effect of impurity levels of the steel on the fatigue behaviour possibly at the same austempering temperatures utilized in this work. A statistical analysis could be worked to check the number of samples required to obtain a reasonable estimate of the fatigue threshold and the paris law constants and also to know the tolerance levels of the variation in fatigue threshold and the paris law constants. An in-situ study mimicking this work would be beneficial to assess how the austempered materials perform under continuous exposure to hydrogen environments. As a final note, some theoretical considerations should be looked into to develop equation based models to correlate the experimental fatigue behaviour which may help refine the fatigue behaviour, especially of austempered materials, in presence of hydrogen bearing environments. 


\section{REFERENCES}

1. P.C. Paris, F. Erdogan, A critical analysis of crack propagation laws, Journal of Basic Engineering, Volume 85, pp 528-534, (1963).

2. P. Fassina, F. Brunella, L. Lazzari, G. Re, L. Vergani, A. Sciuccati, Fatigue Behavior Of Pipeline Steel Under Hydrogen Environment And Low Temperature, Procedia Engineering, Volume 10, pp 3345-3352, (2011).

3. K. Banerjee, U.K. Chatterjee, Effect of microstructure on hydrogen embrittlement of weldsimulated HSLA-80 and HSLA-100 steels, Metallurgical and Materials Transactions A, Volume 34A, pp 1297-1309, (2003).

4. S.K. Putatunda, V. Venugopal, Influence of Overload Plastic Zone Size on Stress Corrosion Crack Growth Behaviour of a Low Alloy Steel in 3.0\% NaCl Solution, Journal of Testing and Evaluation, Volume 18 (3), pp 182-190, (1990).

5. S. Suresh, Fatigue of Materials, $2^{\text {nd }}$ Edition, University Press, Cambridge, (1998).

6. A.R. Troiano, The role of hydrogen and other interstitials in the mechanical behaviour of metals, Transactions of ASM, Volume 52, pp 54-80, (1960).

7. J.G. Morlet, H.A. Johnson and A.R. Troiano, A new concept of hydrogen embrittlement in steel, Journal of Iron and Steel Institute, Volume 189, p 37, (1958).

8. W. Beck, E.J. Jankowsky, and P. Fisher, Hydrogen Stress Cracking of High Strength Steels, NADC-MA-7140, Naval Air Development Center, Pennsylvania, (1971).

9. G. Sandoz, Stress Corrosion Cracking of high Strength Steels, NRL, Washington, D.C., (1972)

10. O.E. Wheller, Spectrum Loading and Crack Growth, journal of Basic Engineering, ASME, Volume 94 (1972), pp. 181-186. 
11. S.E. Gurevich : Proceedings of 3rd International Conference on Mechanical Behavior of Materials , Cambridge, England , (August 20-24, 1979), p.457

12. D.A. Jones, Principles and prevention of corrosion., Macmillan, New York (1992) (p. 234$89 ; 333-55)$.

13. S.P. Lynch, Failures of structures and components by environmentally assisted cracking. Eng. Failure Analysis Volume 1(2), pp. 77-90, (1994).

14. C.L. Briant and S.K. Banerji, Intergranular failure in steel: the role of grain-boundary composition. International Materials Reviews, Volume 23(4), pp. 164-199, (1978).

15. C.L. Briant and S.K. Banerji, Intergranular fracture in ferrous alloys in nonaggressive environments. In: C.L. Briant and S.K. Banerji, Editors, Treatise on materials science and technology, vol. 25, Academic Press, New York (1983), pp. 21-58.

16. Hertzberg RW. Deformation and fracture mechanics of engineering materials. 4th ed. New York: John Wiley \& Sons, 1996. p. 460-4; 485-520.

17. H.G. Nelson, Hydrogen Embrittlement, Treatise on Materials Science and Technology, Embrittlement of Engineering Alloys, Volume 25, pp 275-359, (Editors: C.L. Briant, S.K. Banerji), Academic Press, New York, (1983).

18. J.K. Tien, A.W. Thompson, I.M. Bernstein and R.J. Richards, Hydrogen transport by dislocations, Metallurgical Transactions A, Volume 7A(6), pp. 821-829, (1976).

19. A.N. Stroh, A theory of the fracture of metals. Adv. Phys. 6(24), pp. 418-465, (1957).

20. H.H. Johnson and P.C. Paris: Journal of Engineering Fracture Mechanics., Volume 1, (1968) p.3

21. W.J. Mills and R.W.Hertzberg: Engineering Fracture Mechanics., 7, (1975) p.705

22. H.R. Smith, B.E. Piper and F.K. Downey: Engineering Fracture Mechanics 1,( 1968) p.123 
23. C.D. Beachem, A new model for hydrogen assisted cracking (Hydrogen "Embrittlement"), Metallurugical Transactions, Volume 3, pp 437-451, (1972).

24. D.S. Shih, I.M. Robertson and H.K. Birnbaum, Hydrogen embrittlement of alpha titanium: in situ TEM studies. Acta Metallurgica Volume 36(1), pp. 111-124, (1988).

25. H.K. Birnbaum, Mechanisms of hydrogen related fracture of metals. In: N.R. Moody and A.W. Thompson, Editors, Proceedings of the Fourth International Conference on the Effect of Hydrogen on the Behavior of Materials, Warrendale: TMS, Wyoming, 1990 (1989), pp. 639-660.

26. M. Beghini, G. Benamati and L. Bertini, Hydrogen embrittlement characterization by disk pressure tests: test analysis and application to high chromium martensitic steels. J. Eng. Mater. Technol. 1182 (1996), pp. 179-185.

27. P. Jung, Compositional variation of hydrogen permeability in ferritic alloys and steels. $J$. Nucl. Mater. 238 2-3 (1996), pp. 189-197.

28. R. Padmanabham and W.E. Wood, Corrosion NACE 41, (1985), p.12.

29. H.H. Johnson, Hydrogen gas embrittlement, Hydrogen in Metals, ASM International, Metals Park, OH, pp 35-49, (1974).

30. A.W. Thomson, I.M. Bernstein, Microstructure and hydrogen embrittlement, Hydrogen effects in metals, Metallurgical Society of AIME, New York, pp 291-308, (1981).

31. I.M. Bernstein, A. W. Thomson, Effect of metallurgical variables on environmental fracture of steels, International Materials Reviews, Volume 21, pp 269-287, (1976).

32. P. Sofronis, Mechanics of hydrogen embrittlement, Ph.D. Thesis, Univeristy of Illinois Urbana-Champaign, (1987), http://www.osti.gov/energycitations/product.biblio.jsp?osti_id=6408952. 
33. H. C. Rogers, Hydrogen Embrittlement of Metals, Science, Volume 159 (3819), pp10571064, (1968).

34. R.K. Dayal, N. Parvathavarthini, Hydrogen embrittlement in power plant steels, Sadhana, Volume 28, Parts 3 \& 4, pp 431-451, (2003).

35. H.K. Birmbaum, Mechanisms of hydrogen related fracture of metals, Technical Report, Office of Naval Research, Contract No. USN - $00014-83$ - K - 0468, (1989), http://www.dtic.mil/dtic/tr/fulltext/u2/a208210.pdf

36. R.A. Oriani, Hydrogen embrittlement of steels, Annual Reviews of Materials Science, Volume 8, pp 327-357, (1978).

37. C.A. Zapffe, C.E. Sims, Hydrogen embrittlement, internal stress and defects in steels, Transactions of Metal Society of AIME, Volume 145, pp 225-261, (1941).

38. N.J. Petch, The lowering of fracture-stress due to surface adsorption, Philosophical Magazine, Volume 1, pp 331-337, (1956).

39. N.J. Petch, P. Stables, Delayed fracture of metals under static load, Nature, Volume 169, pp 842-843, (1952).

40. A.H.M. Krom, A. Bakker, Hydrogen trapping models in steel, Metallurgical and Materials Transactions B, Volume 31(6), pp 1475-1482, (2000).

41. T. Michler, J. Naumann, Microstructural aspects upon hydrogen environment embrittlement of various bcc steels, International Journal of Hydrogen Energy, Volume 35 (2), pp 821832, (2010).

42. N. Parvathavarthini, S. Saroja, R.K. Dayal, H.S. Khatak, Studies on hydrogen permeability of $2.25 \% \mathrm{Cr}-1 \%$ Mo ferritic steel: correlation with microstructure, Journal of Nuclear Materials, Volume 288, Issues 2-3, pp 187-196, (2001). 
43. A.W. DeVillier, Microstructural Effects on the Hydrogen Embrittlement of High Strength Steels, M.S. Thesis, (2010), http://idea.library.drexel.edu/handle/1860/3405? mode=full.

44. M. Nagumo, H. Shimura, T. Chaya, H. Hayashi, I. Ochiai, Fatigue damage and its interaction with hydrogen in martensitic steels, Materials Science and Engineering: A, Volume 348, Issues 1-2, pp 192-200, (2003).

45. P. Harvey, Material Data Sheet for 4140; 4140H, Engineering Properties of Steel, pp 113116, (1982).

46. H. Lee, H. Uhlig, Corrosion fatigue of type 4140 high strength steel, Metallurgical and Materials Transactions B, Volume3(11), pp 2949-2957, (1972).

47. Y. Kondo, M. Kubota, K. Shimada, Hydrogen enhanced crack propagation of SCM440H low-alloy steel under long tern varying load, Engineering Fracture Mechanics, Volume 77, pp 1963-1974, (2010).

48. J. L. Evins, Dependence of Strength on Corrosion-Fatigue Resistance of AISI 4130 Steel, Thesis, (2004), http://smartech.gatech.edu/handle/1853/5265?show=full.

49. J. Lukács, Fatigue Crack Propagation Limit Curves for Different Metallic and Non-Metallic Materials, Materials Science Forum, Volume 31, pp 414-415, (2003).

50. S.K. Putatunda, Effect of overload on corrosion fatigue crack growth behavior of a low alloy steel, Journal of Materials Engineering, Volume 13, pp 229-236, (1991).

51. S.K. Putatunda, Corrosion fatigue crack growth behavior of a low alloy steel in threshold region, Transactions of Indian Institute of Metals, Volume 42, pp 207-211, (1989).

52. R.A. Karim, Cathodic hydrogen charging of high strength low alloy 4140 steel, Materials Performance, Volume 45 (8), pp 58-63, (2006). 
53. K. Genel, M. Demirkol, T. Gulmez, Corrosion fatigue behaviour of ion nitrided AISI 4140 steel, Materials Science and Engineering A, Volume 288, pp 91-100, (2000).

54. F. Sarioglu, The effect of tempering on susceptibility to stress corrosion cracking of AISI 4140 steel in $33 \%$ sodium hydroxide at $80^{\circ} \mathrm{C}$, Materials Science and Engineering A, Volume 315, pp 98-102, (2001).

55. J.H. Chuang, L.W. Tsay, C. Chen, Crack growth behaviour of heat-treated 4140 steel in air and gaseous hydrogen, International Journal of Fatigue, Volume 20(7), pp 531-536, (1998).

56. A. Çelik, A.F. Yetim, A. Alsaran, M. Karakan, Effect of magnetic treatment on fatigue life of AISI 4140 steel, Materials \& Design, Volume 26(8), pp 700-704, (2005).

57. K. Genel, M. Demirkol, M. Çapa, Effect of ion nitriding on fatigue behaviour of AISI 4140 steel, Materials Science and Engineering: A, Volume 279(1-2), pp 207-216, (2000).

58. S. K. Putatunda, A.V. Singar, R. Tackett, G. Lawes, Development of a high strength high toughness ausferritic steel, Materials Science and Engineering: A, Volume 513-514, pp 329-339, (2009).

59. S. K. Putatunda, C. Martis, J. Boileau, Influence of austempering temperature on the mechanical properties of a low carbon low alloy steel, Materials Science and Engineering: A, Volume 528, Issue 15, pp 5053-5059, (2011).

60. J.M. Tartaglia, K.L. Hayrynen, A Comparison of Fatigue Properties of Austempered Versus Quenched and Tempered 4340 Steel, Journal of Materials Engineering and Performance, Volume 21(6), pp 1008-1024, (2012).

61. J.M. Tartaglia, K.A. Lazzari, G.P. Hui, K.L. Hayrynen, A Comparison of Mechanical Properties and Hydrogen Embrittlement Resistance of Austempered vs Quenched and 
Tempered 4340 Steel, Metallurgical and Materials Transactions A, Volume 39(3), pp 559576, (2008).

62. N.E. Nanninga, Effect of Microstructure and Alloying Elements on the Resistance of Fastener Grade Steels to Hydrogen Assisted Cracking, Thesis, (2005), http://services.lib.mtu.edu/etd/THESIS/2005/MaterialsSci\%26Eng/nanninga/thesis.pdf

63. Y. Tomita, K. Okabayashi, Improvement in lower temperature mechanical properties of 0.40 pct C-Ni-Cr-Mo ultrahigh strength steel with the second phase lower bainite, Metallurgical Transactions A, Volume 14(2), pp 485-492, (1983).

64. Y. Tomita, K. Okabayashi, Mechanical properties of 0.40 pct C-Ni-Cr-Mo high strength steel having a mixed structure of martensite and bainite, Metallurgical Transactions A, Volume 16(1), pp 73-82, (1985).

65. Y. Tomita, Improved lower temperature fracture toughness of ultrahigh strength 4340 steel through modified heat treatment, Metallurgical Transactions A, Volume 18(8), pp 14951501, (1987).

66. ASTM Standard E-647-08, (2010), "Standard Test Method for Measurement of Fatigue Crack Growth Rates", ASTM International, West Conshohocken, PA, www.astm.org.

67. ASTM Standard E-399, (2011), "Standard Test Methods for Tension Testing of Metallic Materials", ASTM International, West Conshohocken, PA, www.astm.org.

68. ASTM Standard E-8/E-8M-11, (2011), "Standard Test Methods for Tension Testing of Metallic Materials", ASTM International, West Conshohocken, PA, www.astm.org.

69. H.K.D.H. Bhadeshia, Bainite in steels: transformations, microstructure and properties, (2001), IOM Communications, London 
70. E.W. Institute, Get TTT and CCT Diagram with Steel Composition. Available from: http://calculations.ewi.org/vjp/secure/TTTCCTPlots.asp.

71. K.W. Andrews, Empirical formulas for the calculation of some transformation temperatures. Journal of Iron and Steel Institute, Volume 203, pp 721-727, (1965).

72. Heat Treating Data Sheet for 4140; 4140H, in Heat Treater's Guide: Practices and Procedures for Irons and Steels, 2nd Edition. 1995, ASM International. p. 319-325.

73. D.A. Porter, K.E. Easterling, Phase transformations in metals and alloys. (1981), Chapman and Hall, London.

74. B.D. Cullity, Elements of X-ray diffraction. (1956), Addison-Wesley Publication Co, Reading, MA.

75. N. Eliaz, A. Shachar, B. Tal, D. Eliezer, Characteristics of hydrogen embrittlement, stress corrosion cracking and tempered martensite embrittlement in high-strength steels, Engineering Failure Analysis, Volume 9, Issue 2, pp 167-184, (2002).

76. C.D. Kim, A. W. Longinow, Techniques for investigating Hydrogen - Induced Cracking of steels with high yield strength, Corrosion, Volume 24, No. 10, pp 313-318, (1968).

77. C.F. Dong, X.G. Li, Z. Y. Liu, Y. R. Zhang, Hydrogen - induced cracking and healing behaviour of X70 steel, Journal of Alloys and Compounds, Volume 484, pp 966-972, (2009).

78. L.S. Darken, R.P. Smith, Behaviour of Hydrogen in Steel during and after immersion in acid, Corrosion, Volume 5, pp 1-16, (1949).

79. K.A. Esaklul, W.W. Gerberich., Influence of internal hydrogen on fatigue thresholds of HSLA steel, Scripta Metallurgica, Volume 17, pp 1079-1082, (1983). 
80. H. Nykyforchyn, Effect of hydrogen on the kinetics and mechanism of fatigue crack growth in structural steels, Materials Science, Volume 33(4), pp 504-515, (1997).

81. P. K. Liaw, S. J. Hudak JR., J. K. Donald, Influence of gaseous environments on rates of near-threshold fatigue crack propagation in nicrmov steel, Metallurgical Transactions A: Physical Metallurgy and Materials Science, Volume 13A(9), pp 1633-1645, (1982).

82. M. Imade, S. Fukuyama, L. Zhang, M. Wen, K. Yokogawa, Hydrogen environment embrittlement of SCM440 steel in high pressure hydrogen at room temperature, Journal of Japan Institute of Metals, Volume 69(2), pp 190-193, (2005).

83. J. Ćwiek, Hydrogen degradation of high-strength steels, Journal of Achievements in Materials and Manufacturing Engineering, Volume 37(2), pp 193-212, (2009).

84. L.W. Tsay, C.C. Liu, Y.H. Chao, Y.H. Shieh, Fatigue crack propagation in 2.25Cr - 1.0Mo steel weldments in air and hydrogen, Materials Science and Engineering A, Volume 299, pp 16-26, (2001).

85. S. Homrossukon, S. Mostovoy, J.A. Todd, Investigation of Hydrogen Assisted Cracking in High and Low Strength Steels, Journal of Pressure Vessel Technology, Volume 131, pp 041405-1 - 041405-11, (2009).

86. J. Ćwiek, Prevention methods against hydrogen degradation of steel, Journal of Achievements in Materials and Manufacturing Engineering, Volume 43(1), pp 214-221, (2010).

87. S.K. Putatunda, Influence of material strength level on fatigue crack closure, Engineering Fracture Mechanics, Volume 30, No 5, pp 627-639, (1988). 
88. L. Nian, D. Bai-ping, Z. Hui-jiu, On the relationship between fatigue limit, threshold and microstructure of a low-carbon Cr-Ni steel, International Journal of Fatigue, Volume 6(2), pp 89-94, (1984).

89. F. Heubaum, M.E. Eine, Short fatigue crack growth behavior in a high strength low alloy steel, Scripta Metallurgica, Volume 18(11), pp 1235-1240, (1984).

90. L. Guerra-Rosa, C. Moura Branco, J.C. Radon, Monotonic and cyclic crack tip plasticity, International Journal of Fatigue, Volume 6(1), pp 17-24, (1984).

91. M.T. Yu, T.H. Topper, The Effects of Material Strength, Stress Ratio, and Compressive Overload on the Threshold Behavior of a SAE1045 Steel, Journal of Engineering Materials and Technology, Volume 107(1), pp19-25, (1985).

92. J.I. Dickson, Mou-Chih Lu, J.P. Bailon, The influence of strain aging on the fatigue crack propagation threshold, Scripta Metallurgica, Volume 17(1), pp 49-52, (1983).

93. Y. Li, Z. Yang, S. Li, et al, Effect of Hydrogen on fatigue strength of high strength steels in the VHCF regime, Advanced Engineering Materials, Volume 11(7), pp 561-567, (2009).

94. A.W. Thomson, I.M. Bernstein, Microstructure and Hydrogen Embrittlement, Hydrogen Effects in Metals, AIME, pp 291-308, (1981).

95. R.A. Karim, Cathodic Hydrogen Charging of High Strength Low Alloyed AISI 4140 steel, Materials Performance, pp 58-63, (2006).

96. R.O. Ritchie, J.F. Knott, Mechanisms of fatigue crack growth in low alloy steels, Acta Metallurgica, Volume 21, pp 639-648, (1973).

97. R.P. Wei, A.J. McEvily, Fracture Mechanics and Corrosion Fatigue. in Proceedings of NACE conference on "Corrosion fatigue, chemistry, mechanics and microstructure", pp 381-395, (1972). 
98. A.K. Vasudevan, K. Sadananda, Classification of environmentally assisted fatigue crack growth behavior. International Journal of Fatigue, Volume 31(11-12), pp 1696-1708, (2009).

99. S. Suresh, R.O. Ritchie, Mechanistic dissimilarities between environmentally-influenced fatigue-crack propagation at near-threshold and higher growth rates in lower-strength steels. Metal Science, Volume 16, pp 529-538, (1981).

100. S.A. Shipilov, Mechanisms for corrosion fatigue crack propagation. Fatigue \& Fracture of Engineering Materials \& Structures, Volume 25(3), pp 243-259, (2002).

101. J.R. Rice, in Fatigue Crack Propagation, ASTM STP 415, p. 247, (1967).

102. R.J. Cooke, P.E. Irving, G.S. Booth and C.J. Beevers, The slow fatigue crack growth and threshold behaviour of a medium carbon alloy steel in air and vacuum, Engineering Fracture Mechanics, Volume 7, pp 69-77, (1975).

103. R.O. Ritchie, S. Suresh, and J. Toplosky: MIT Fatigue and Plasticity Laboratory, Report No. FPL/R/80/1030, Cambridge, MA, (1980).

104. R.O. Ritchie, Proceedings of the International Conference on Analytical and Experimental Fracture Mechanics, Rome, June 1980, G.C. Sih, ed., Sijthoff and Noordhoff, the Netherlands, p 81 .

105. R.O. Ritchie, C.M. Moss, and S. Suresh: MIT Fatigue and Plasticity Laboratory, Report No. FPL/R/79/1025, Cambridge, MA, (1979).

106. R.O. Ritchie, Near-threshold fatigue propagation in steels, International Metal Reviews, Review 245, Nos. 5 and 6, pp 205-230, (1979). 
107. A.K. Vasudeven, K. Sadananda, N. Louat, A review of crack closure, fatigue crack threshold and related phenomena, Materials Science and Engineering A, Volume 188, pp 122, (1994).

108. G.T. Park, S.U. Koh, H.G. Jung, K.Y. Kim, Effect of microstructure on the hydrogen trapping efficiency and hydrogen induced cracking of linepipe steel, Corrosion Science, Volume 50 (7), pp 1865-1871, (2008).

109. N. Parvathavarthini, S. Saroja, R.K. Dayal, Influence of microstructure on the hydrogen permeability of $9 \% \mathrm{Cr}-1 \%$ Mo ferritic steel, Journal of Nuclear Materials, Volume 264 (1-2), pp 35-47, (1999). 


\begin{abstract}
INFLUENCE OF DISSOLVED HYDROGEN ON THE FATIGUE CRACK GROWTH BEHAVIOUR OF AISI 4140 STEEL
\end{abstract}

by

VARUN RAMASAGARA NAGARAJAN

May 2014

\title{
Advisor: Prof. Susil K. Putatunda
}

\section{Major: Materials Science and Engineering}

\section{Degree: Doctor of Philosophy}

Many metallic structural components come into contact with hydrogen during manufacturing processes or forming operations such as hot stamping of auto body frames and while in service. This interaction of metallic parts with hydrogen can occur due to various reasons such as water molecule dissociation during plating operations, interaction with atmospheric hydrogen due to the moisture present in air during stamping operations or due to prevailing conditions in service (e.g.: acidic or marine environments). Hydrogen, being much smaller in size compared to other metallic elements such as Iron in steels, can enter the material and become dissolved in the steel matrix. It can lodge itself in interstitials locations of the metal atoms, at vacancies or dislocations in the metallic matrix or at grain boundaries or inclusions (impurities) in the alloy. This dissolved hydrogen can affect the functional life of these structural components leading to catastrophic failures in mission critical applications resulting in loss of lives and structural component. Therefore, it is very important to understand the influence of the dissolved hydrogen on the failure of these structural materials due to cyclic loading (fatigue). For 
the next generation of hydrogen based fuel cell vehicles and energy systems, it is very crucial to develop structural materials for hydrogen storage and containment which are highly resistant to hydrogen embrittlement. These materials should also be able to provide good long term life in cyclic loading, without undergoing degradation, even when exposed to hydrogen rich environments for extended periods of time.

The primary focus of this investigation was to examine the influence of dissolved hydrogen on the fatigue crack growth behaviour of a commercially available high strength medium carbon low alloy (AISI 4140) steel, to examine the influence of microstructure on the fatigue crack growth behaviour of this material and to determine the hydrogen induced failure mechanism in this material during cyclic loading. The secondary objective of this investigation was to determine the role of inclusions and their influence in affecting the fatigue crack growth rate of this material.

The test results show that the dissolved hydrogen concentration increases with the increase in charging time in all three heat treated conditions and the hydrogen uptake shows a strong dependence on the microstructure of the alloy. It was also observed that the microstructure has a significant influence of on the fatigue crack growth behaviour of the alloy with dissolved hydrogen. As the dissolved hydrogen concentration increases, the fatigue threshold was found to decrease and the near threshold crack growth rate increases in all three heat treated conditions showing the deleterious effect of hydrogen, but to a different extent in each condition. Current test results also indicate that the fatigue crack growth rates in the linear region increases as the dissolved hydrogen content increases in all three heat treated conditions. It is also observed that increasing the austempering temperature decreases the resistance to hydrogen embrittlement. An interesting phenomenon was observed in annealed specimen 
charged with hydrogen for $250 \mathrm{~h}$ which had an unusually high fatigue threshold ( $\Delta \mathrm{K}$ th). An attempt has been satisfactorily made to explain these experimental observations and tie them mechanistically to hydrogen induced fatigue damage based on fractographic as well as metallographic evidences. 


\section{AUTOBIOGRAPHICAL STATEMENT}

Varun Ramasagara Nagarajan is a final year graduate student completing his Ph.D. in Materials Science and Engineering from Wayne State University, Detroit, MI, USA and currently working as a Materials Engineer at Altair ProductDesign (assigned to Chrysler LLC). He received his M.S. in Materials Science and Engineering from Wayne State University, Detroit, MI, USA in August 2008 and his B.E. in Chemical Engineering from Dayananda Sagar College of Engineering, Bangalore, India in August 2005.

Varun's research has been focused on improving fatigue properties in high strength steels with specific emphasis on using austempering heat treatments to minimize degradation of the alloy due to influence of dissolved hydrogen. 